Portland State University

PDXScholar

\title{
A Case Study of the Acceptance of the Tacoma- Pierce County Needle Exchange Program by Three Diverse Groups: Law Enforcement Personnel, Health Department Officials, and Program Clients (i.e., Intravenous Drug Users)
}

Lauren Sue Ibrahim

Portland State University

Follow this and additional works at: https://pdxscholar.library.pdx.edu/open_access_etds Let us know how access to this document benefits you.

\section{Recommended Citation}

Ibrahim, Lauren Sue, "A Case Study of the Acceptance of the Tacoma-Pierce County Needle Exchange Program by Three Diverse Groups: Law Enforcement Personnel, Health Department Officials, and Program Clients (i.e., Intravenous Drug Users)" (1993). Dissertations and Theses. Paper 1383.

https://doi.org/10.15760/etd.1382

This Dissertation is brought to you for free and open access. It has been accepted for inclusion in Dissertations and Theses by an authorized administrator of PDXScholar. Please contact us if we can make this document more accessible: pdxscholar@pdx.edu. 
A CASE STUDY OF THE ACCEPTANCE OF THE TACOMA-PIERCE COUNTY NEEDLE EXCHANGE PROGRAM BY THREE DIVERSE GROUPS:

LAW ENFORCEMENT PERSONNEL, HEALTH DEPARTMENT OFFICIALS, AND PROGRAM CLIENTS (I.E., INTRAVENOUS DRUG USERS)

by

LAUREN SUE IBRAHIM

A dissertation submitted in partial fulfillment

of the requirements for the degree of

DOCTOR OF PHILOSOPHY

in

PUBLIC ADMINISTRATION AND POLICY

Portland State University

01993 
TO THE OFFICE OF GRADUATE STUDIES

The members of the Committee approve the dissertation of Lauren Sue Ibrahim presented July 22, 1993.

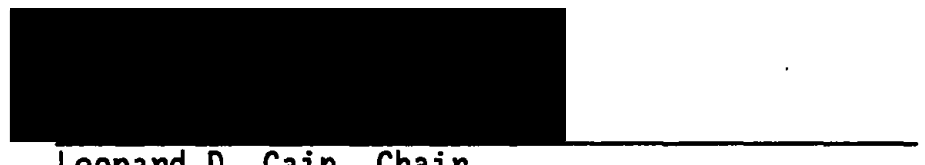

Leonard D. Cain, Chair
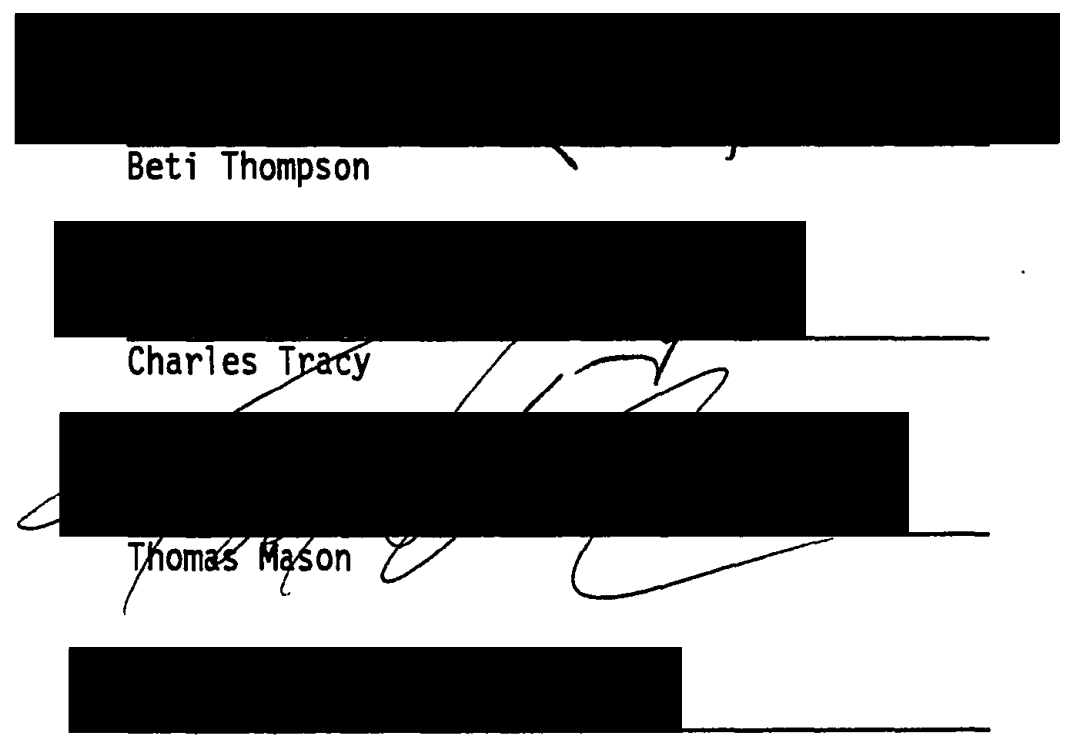

Martha Balshem
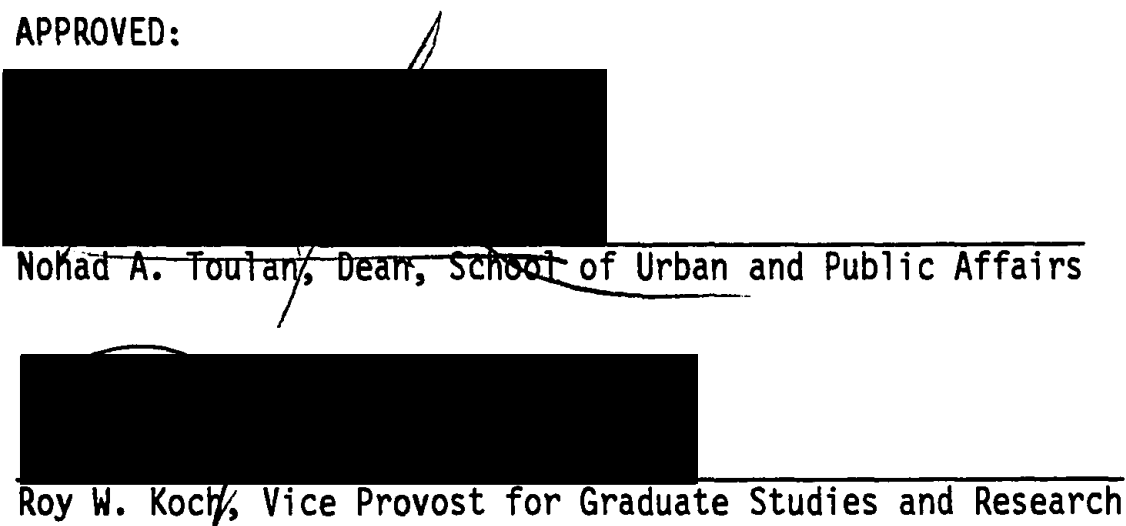
AN ABSTRACT OF THE DISSERTATION OF Lauren Sue Ibrahim for the Doctor of Philosophy in Public Administration and Policy presented July 22, 1993.

Title: A Case Study of the Acceptance of the Tacoma-Pierce County Needle Exchange Program by Three Diverse Groups: Law Enforcement Personnel, Health Department Officials, Program Clients (i.e., Intravenous Drug Users).

APPROVED BY THE MEMBERS OF THE DISSERTATION COMMITTEE:

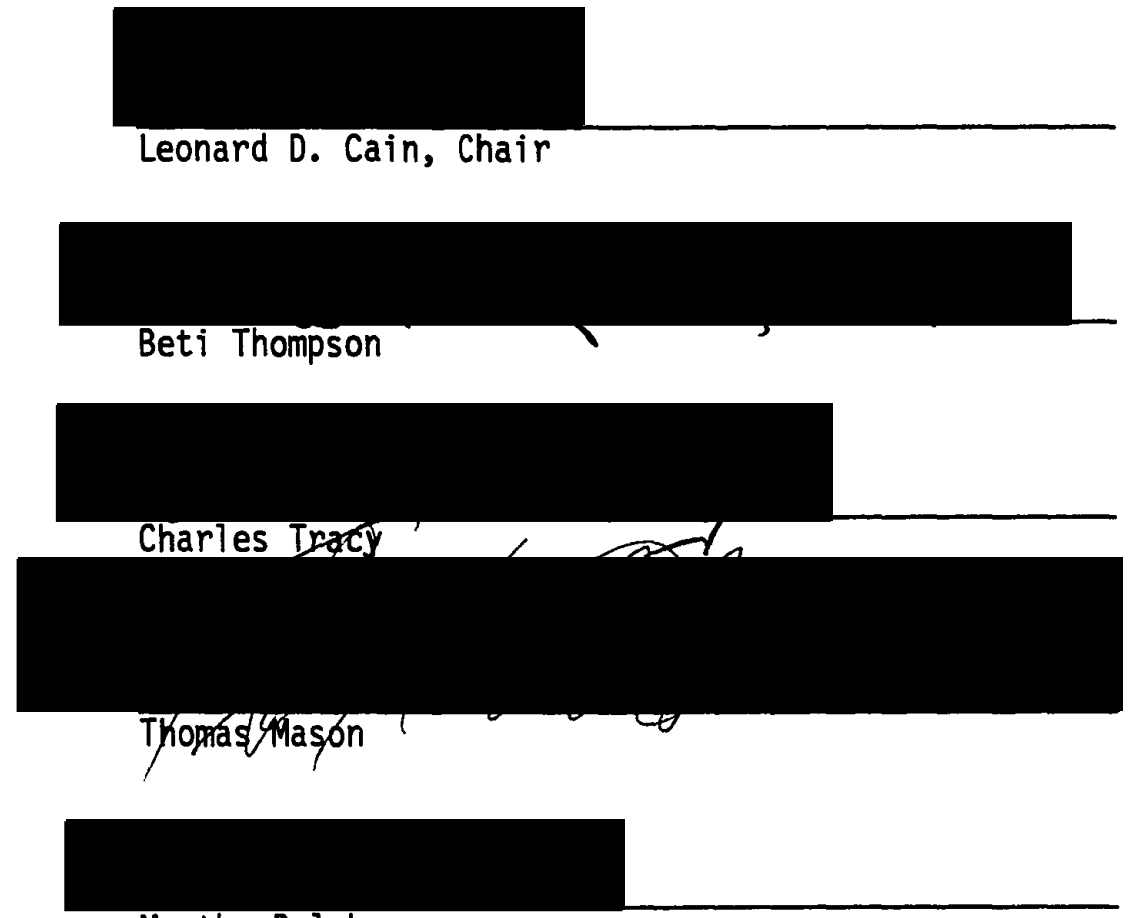

Martha Balshem

Legitimate and underground needle exchange programs, specifically targeted for intravenous drug users (IVDUs) (i.e., currently the second 
largest risk group in the AIDS epidemic), have emerged in various locales in a desperate attempt to change their drug use practices and behaviors associated with the transmission of HIV-1/AIDS. This study focuses on one such program, the Tacoma-Pierce County Needle Exchange Program, in which the pioneering efforts of a private individual are provided, the manifestations of public entrepreneurism are examined, and in which various attributes of program acceptance are identified and explored.

An introductory and exploratory case study approach is the research strategy used in this dissertation, since it is adaptive and flexible to accommodate the use of multiple data sources. Data have been collected through semi-structured interviews involving four law enforcement personnel and 21 program clients (i.e., IVDUs), which consisted of openand close-ended questions regarding program acceptance. Existing data sources, such as court documents, published interviews with key officials, journals, and various news articles provide an assessment of the events and activities that relate to the evolution and success of the Tacoma-Pierce County Needle Exchange Program.

The attributes identified and explored in this study include: settings, type of staff, method of service delivery (including spillover effects), nature of the geographic area, concern over the effects of AIDS, external environmental conduits (the informal communication network and the media), and characteristics of program clients. These attributes were found to be important to program acceptance of the Tacoma-Pierce County Needle Exchange Program; however, they should be further examined in other communities to see if they remain important. 
To this extent, the findings indicated that needle exchange programs have complex characteristics attached to them, and that they deserve to be further studied to understand those complexities.

Other benefits of the Tacoma-Pierce County Needle Exchange Program found to be important include: (1) fewer citizen complaints about the carelessly discarded, used syringes often found in gutters, parks, greenbelts, alleys, and streets; and (2) fewer reports of infections caused by accidental needle stick injuries among law enforcement personnel (which can occur when a law enforcement officer frisks a suspect), maintenance employees, and grounds-keepers. Overall, phenomenal savings can accrue from such unintentional and additional benefits of needle exchange programs. In light of this debilitating disease, and of the high cost associated with medical care, such innovative interventions are perceived worthy in the course of this deadly epidemic. 


\section{ACKNOWLEDGMENTS}

This dissertation research has been made possible through the inspiration and support of several very special people to whom I am deeply indebted.

First of all, I wish to express a multitude of thanks to my Dissertation Chairperson, Dr. Leonard D. Cain, who not only offered his intellectual expertise and worthy ideas, but also shared in my enthusiasm for this research. Dr. Cain's continual support and encouragement are tremendousiy appreciated.

Special gratitude is extended to Dr. Nohad Toulan (Dean of the School of Urban and Public Affairs) and my four other cormittee members, Dr. Beti Thompson, Dr. Charles Tracy, Dr. Tom Mason, and Dr. Martha Balshem for their kind assistance, patience, intellectual expertise, and cooperation.

Special acknowledgments and gratitude are given to two very dear friends, Dr. Beti Thompson and Dr. Doris Lyon, who were instrumental in getting me interested in the topic of needle exchange programs. Their academic expertise, support, motivation, and keen insights have made this research possible. Both friends literally went that "extra mile" to attend my colloquium and dissertation defense. I am deeply indebted to both of these friends for the rest of my life.

I wish to express my love and thanks to my mother and friend, Carrie Marcus, who extended her skills and support for my study. Love and thanks also go to my husband and friend, Sami Abdullah Ibrahim, and the 
Al-Ibrahim family for their financial generosity for which I am deeply indebted. Without their support, my education achievements might not have been attained. 
TABLE OF CONTENTS

ACKNOWLEDGMENTS ............................

LIST OF TABLES .......................... ix

LIST OF FIGURES .................. xi

CHAPTER

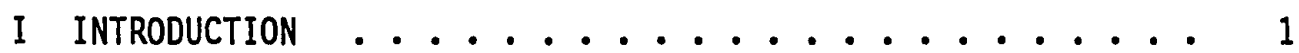

Statement of the Problem ........... 3

Focus of the Research ........... 5

Research Questions ................ 6

Purpose of the Study ............. 7

II REVIEW OF THE LITERATURE ............. 8

Part One: Overview of HIV-1/AIDS Epidemic . . . 8

The Pandemic of AIDS ........... 8

The Number of AIDS Cases ........... 9

Racial and Ethnic Statistics ......................... 10

Short Term Prognosis ............ 11

Pathogenesis ..................... 12

Transmission ........................... 13

Intimate Sexual Contact .......... 13

Parenteral Exposure to Blood/Biood Products :.:. 15

Perinatal Transmission ........... 15

Theoretical Routes of Transmission ....... 16

The Origin of the AIDS .............. 19

The Emergence of an Epidemic .......... 21

The First Wave ............. 21

The Second Wave ................ 22 
Controiling the Spread of HIV-1/AIDS ....... 27

Drug Treatment ............. 28

Education ......................... 30

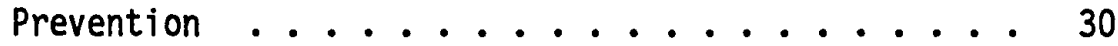

Part Two: Overview of Needle Exchange Programs . . . 31

International Needle Exchange Programs . . . . . 32

The Netherlands .......... 33

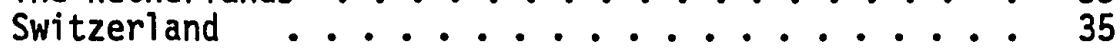

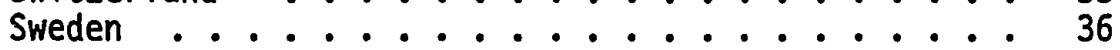

West Germany .............. 38

The United Kingdom ............ 40

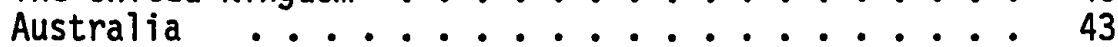

Thailand ......................... 45

Canada ................... 45

National Needle Exchange Programs ........ 47

New York City .............. 52

Boston, Massachusetts ........... 56

Boulder, Colorado ................ 58

New Haven, Connecticut .......... 59

Honolulu, Hawai ............. 61

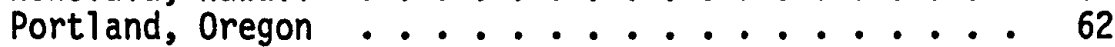

Seattle, Washington .......... 64

Tacoma, Washington ........... 65

III CONCEPTUAL FRAMEWORK ................ 72

Prevention of Disease: Reducing Risk Factors .... 73

The Health Behavior Model .......... 76

Health-Belief Theory ........... 77

Community Approaches to Health ....... 79

Surmary .................... 81

The Research Questions ......... 82

IV RESEARCH STRATEGY ................... 84

The Case Study Approach .......... 84

Data Sources ............. 87

Existing Records ............ 88

Litigation Records/Court Documents ...... 89

Semi-Structured Interviews .......... 89 
vii

Addressing the Research Questions ......... 94

Research Question \#1 .......... 94

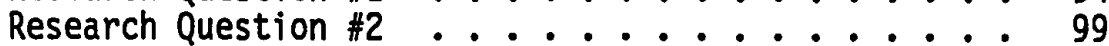

Research Question \#3 .......... 102

Analysis ....................... 103

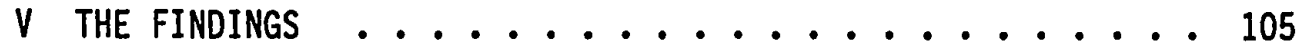

Part One: The History of the Tacoma-Pierce County

Needle Exchange Program .......... 107

The Role of Dave Purchase . . . . . . . . 108

Washington State Legislation on Needle

Exchange Programs ........... 113

The Lawsuit . . . . . . . . . . 117

Part Two: Interviewees' Perspectives on

Program Acceptance ........... 125

Research Question \#1 .......... 125

Research Question \#2 ........ 137

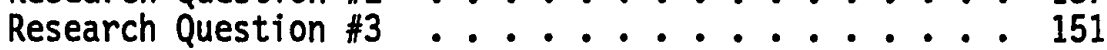

VI THE CONCLUSION: SUMMARY OF FINDINGS,

IMPLICATIONS, AND LIMITATIONS ........... 157

Summary of Findings .............. 160

Implications .............................. 164

Relationship to Public Policy ........ 165

Relationship to Urban Studies ........ 167

Health Care Costs ........... 167

Civil Disobedience ...................... 170

Limitations ............... 172

The Inability to Interview Health Department

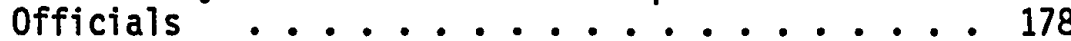

Sources of Bias ............. 178

Disadvantages of the Case Study Approach ..... 183

A Call for More Research . . . . . . . . 183

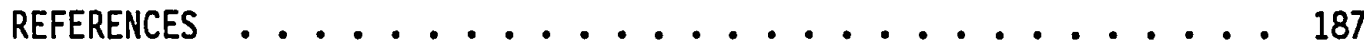


viij

APPENDICES

A INJECTION EQUIPMENT AND DRUG PARAPHERNALIA ("WORKS") OF IVDUS: THE POTENTIAL SOURCES OF CONTAMINATION . . . 204

B INTERVIEW SCHEDULES: HEALTH DEPARTMENT OFFICIALS, LAW ENFORCEMENT PERSONNEL, AND PROGRAM CLIENTS (IVDUS) • • 207

C COPIES OF LETTERS FROM VARIOUS STATE OFFICIALS, HOUSE BILL NO. 1793, AND SECTION 107 THAT WAS VETOED BY FORMER GOVERNOR BOOTH GARDNER ........... 262

D COPY OF MEMORANDUM (COVER LETTER) AND INTRA-AGENCY ROUTING SLIP SENT BY HOLLY HAGEN, TACOMA-PIERCE COUNTY HEALTH DEPARTMENT'S EPIDEMIOLOGIST IN REFERENCE TO HER INITIAL SUPPORT AND COOPERATION WITH THE RESEARCHER 


\section{LIST OF TABLES}

\section{TABLE}

I Possible Strategies for Controlling the Spread of HIV-1/AIDS Among Intravenous Drug Users (IVDUs) . . . 29

II Percentage of all Reported AIDS Cases Among Intravenous Drug Users (IVDUs) in the United

III HIV Seroprevalence Among Intravenous Drug Users (IVDUs) in the United States ........... 50

IV Outside-In Needle Exchange Program Report November 1989 to January 1990 ........... 63

$\checkmark$ Distance Traveled by Interviewed Program Clients to Receive Services of the Tacoma-Pierce County Needle Exchange Program ............ 127

VI Return Visits as an Indicator of Accessibility:

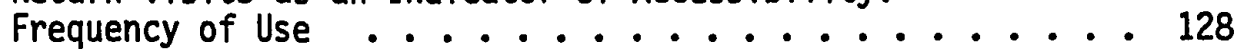

VII Interviewed Clients' Perceptions of Program Staff . . . . 130

VIII Interviewed IVDUs' Perception of the External Environment .................. 140

IX Interviewed IVDUs' Concern Over the Effects of AIDS . . 143

$X$ How Respondents (IVDUs) Heard About the Needle Exchange Program in Tacoma .......... 148

XI Characteristics of Interviewed Program Clients:

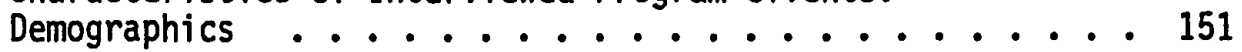

XII Characteristics of Interviewed Program Clients:

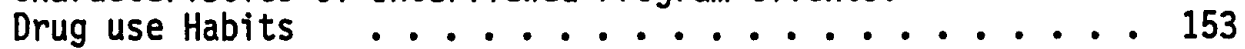

XIII Male/Female, Adult Drug Abuse Arrests by Race: Tacoma, Washington, From 1988 - 1991 . . . . . . 154

XIV Male/Female, Adult Drug Abuse Arrest Statistics by Age Groups: Tacoma, Washington, 1988 - 1991 . . . 156 


\section{FIGURE}

\section{LIST OF FIGURES}

1 Duration of Injection of Needle Exchange Clients, Tacoma, Washington, by Number of Years

(Initial Results, 1988)

2 Needle Exchange Clients, Tacoma, Washington,

by Race and Region (Tacoma Metro Population and the Community of Intravenous Drug Use Population Under Study), With General

Information on Mean Age and Percent Male/Female (Initial Results, 1988)

3 Hygiene Behavior of Needle Exchange Clients, Tacoma, Washington, Pre- and Post-Needle Exchange Behavior by Percent -- Sharing Equipment, Using Bleach, and Needle Hygiene (Initial Results, 1988) .. 


\section{CHAPTER I}

\section{INTRODUCTION}

Infectious diseases, particularly those which have reached epidemic proportion and have occupied unique roles in the course of world history, have posed serious challenges to entire societies. For example, a form of plague called the "Black Death" wiped out a quarter of the entire population of Europe during the 1300s (Allen and Betts 1967). Another disease, cholera, spread quickly and dramatically throughout Europe during the nineteenth century, killing about half of those it attacked (Rosenberg 1986). During the American Revolution, the greatest killer was smallpox, even though prevention by inoculation was known at the time (Allen and Betts 1967). Disease (e.g., yellow fever, typhus, typhoid, malaria, and dysentery) kilied approximately seven times as many American men than did military combat in the MexicanAmerican War; in fact, approximately 11,000 of the 90,000 American troops that served in Mexico died from disease, while less than 1600 were killed in combat (Allen and Betts 1967).

In the wake of responding to such challenges, however, various groups have been stigmatized or branded as the culprit responsible for an outbreak of a particular epidemic. For example, Jews were blamed for poisoning the wells during the fourteenth-century plague (Tuchman 1978). 
During the cholera and yellow fever epidemics in the United States, the poor were blamed for their lack of hygiene, and immigrants for their immorality (Rosenberg 1962). Chinese immigrants in San Francisco were considered responsible for the outbreak of smallpox during the latter part of the nineteenth century (Trauner 1978), and Norwegian immigrants were accused of being the carriers of polio as late as the 1940 s (Benison 1974).

The stigmatization, fear, and panic that accompany epidemics lead to conflicts and controversies which unequivocally result in particular political, social, and economic courses of action. Often such courses of action generate much debate and pose difficulties in establishing a local, state, or federal policy. The conflicts and controversies encompassing stigmatization, fear, and panic are especially evident in policies centering upon the world's latest life-threatening epidemic: AIDS.

Confronting the infectious disease now known as "acquired immune deficiency syndrome" (AIDS) ${ }^{1}$ has produced many challenges for

\footnotetext{
${ }^{1}$ In 1981, when AIDS first surfaced in the United States among male homosexuals, the Centers for Disease Control (CDC) adopted a strict epidemiological-surveillance definition for the disease. At that time, individuals were reported as having AIDS if they contracted a rare cancer known as Kaposi's sarcoma (KS) or pneumocytis carini $i$ pneumonia (PCP) (Redfield and Burke 1989). By 1987, the CDC (1985) expanded its AIDS surveillance definition to include other, more severe, clinical manifestations of HIV-1 infections. This expanded definition of AIDS includes those individuals who have other manifestations of HIV-1related infections and diseases. Such protozoal and fungal infections (i.e., regarded as "opportunistic infections and diseases") are specific enough to indicate whether or not an individual has AIDS. These include pneumocystis carinij pneumonia (PCP), toxoplasmosis (parasitic infections often manifested in the brain and can lead to seizures and coma), chronic crypto-sporidiosis (typically manifested in the intestinal tract causing chronic diarrhea), chronic infection with the herpes simplex virus, cytomegalovirus infection (a viral infection that is a cause of
} 
lawmakers, public health officials, health care and medical professionals, as well as citizens from many walks of life. In essence, deciding on particular courses of action in response to AIDS' treatment and prevention involves challenges to many societal sectors, including the various risk groups ${ }^{2}$ involved in the transmission of human immunodeficiency virus type one (HIV-1) ${ }^{3}$ and acquired immune deficiency syndrome (AIDS).

\section{STATEMENT OF THE PROBLEM}

The dramatic rise in the number of AIDS cases and deaths, since the identification of the AIDS virus in 1984, accentuates the need for effective interventions aimed at changing the behaviors of those population groups at risk for transmitting AIDS. Behaviors involving sexual intimacy and/or addictions (i.e., the two main behaviors which are responsible for the spread of HIV-1/AIDS) are very complex in and of

pneumonia, encephalitis, blindness and inflammation of the gastrointestinal tract) of an organ other than liver or lymph node, candida esophagitis (a fungus causing thrush), cryptococcal meningitis, histoplasmosis (which can cause chronic fevers), Kaposi's sarcoma, primary brain lymphoma, and central nervous system HIV-1 infection and AIDS dementia complex. (Castro et al. 1988; Redfield and Burke 1989; Price et al. 1988).

2Population groups often cited as being at risk for the transmission and acquisition of AIDS are: (1) homosexual/ bisexual males, (2) intravenous drug users, (3) hemophiliacs, and (4) heterosexual partners of infected persons or those at recognized risk, such as prostitutes. In the early days of the epidemic, Haitians were also among those considered to be at risk.

${ }^{3}$ Human immunodeficiency virus type one (HIV-1) is the retrovirus that causes AIDS. HIV-1 becomes AIDS when the immune system can no longer combat various opportunistic infections and/or cancers (First for Women 1992). 
themselves; changes in such behaviors are thus a difficult task. Nevertheless, given the rapid spread of AIDS and the dire consequences of the disease, it is imperative to move beyond the standard behavioral change strategies that may require several years to manifest change.

Innovative approaches can be critical to influencing changes in behavior and protecting high-risk groups from transmitting a particular disease. For AIDS prevention, one. such innovative approach has been targeted for one-high-risk population: the intravenous drug users (IVDUs). IVDUs are apparently the most critical group in the "second wave" ${ }^{14}$ transmission of AIDS. Since their risk is linked to the sharing of drug injection equipment, the availability and accessibility of sterile needles/syringes are considered, by some, critical and essential factors in controlling HIV-1/AIDS. Although it is not absolutely known that needle exchange programs reduce the spread of HIV-1/AIDS, making sterile injection equipment more accessible and available to IVDUs is an innovative approach to changing the risk behaviors and practices of IVDUs that are related to AIDS. More specifically, this study will examine in detail one such program, the Tacoma-Pierce County Needle Exchange Program in Tacoma, Washington, to the program attributes that have led to program acceptance among the groups most affected by the program: (1) law enforcement personnel, (2) health department officials, and (3) intravenous drug users (IVDUs).

${ }^{4}$ In the United States, the first signs of a strange immune suppression infection began to surface among male homosexuals which is indicative of the first wave of the AIDS epidemic. The second wave of the AIDS epidemic was set in motion by another high-risk group -intravenous drug users (IVDUs). 
The distribution of sterile injection equipment is not always problematic. Several countries (e.g., Denmark, West Germany, Norway, Austria, France, Italy) now allow pharmacies to sell needles/syringes legally without a prescription or with little restriction (e.g., Greece and Spain). Actual availability and accessibility of such products to IVDUs, however, is still limited in most'countries (Stimson 1989). For instance, the operating hours of pharmacies limit access, and the cost of needles/syringes makes it difficult for IVDUs to obtain sterile equipment. Moreover, not all pharmacies desire to sell such items as they do not wish to attract a clientele of illicit drug users (Stover 1989). Stimson (1989) points out that 50 percent of 208 pharmacists in Glasgow, Scotland, had been approached by IVDUs to purchase syringes, but only 19 percent actually sold to drug users. In response to those difficulties, some countries have instituted needle exchange programs that make sterile injection equipment more accessible and available to IVDUs.

\section{FOCUS OF THE RESEARCH}

Needle exchange programs differ around the world, and some have been more successful in attracting and maintaining clientele than others. These innovative programs can offer easier access and availability of clean injection equipment perhaps better than other means and, at the same time, provide other services (e.g., AIDS education, drug education, testing, and counseling) to their clientele. The Tacoma-Pierce County Needle Exchange Program provides an opportunity to examine the benefits of needle exchange programs and to 
systematically observe factors that affect the acceptance of this particular needle exchange program in a community with legal prohibitions against the possession of illicit drugs and related paraphernalia. Given that such programs have generated considerable controversy, the detailed examination of the implementation and acceptance of the Tacoma-Pierce County Needle Exchange Program can produce insights for other groups considering this strategy which aims at changing risk behaviors associated with the transmission of HIV-1/AIDS among IVDUs. Beyond this, a close examination of such an innovative program can add to the challenge of understanding the concerns and issues associated with the transmission of HIV-1/AIDS among this particular high-risk group of intravenous drug users (IVDUs).

\section{RESEARCH QUESTIONS}

There are three major research questions that will guide this study:

(1) "What characteristics of the Tacoma-Pierce County Needle Exchange Program are linked to program acceptance by law enforcement personnel, health department officials, and program clients (i.e., IVDUS)?"

(2) "What characteristics of the external environment are linked to program acceptance of the Tacoma-Pierce County Needle Exchange Program by law enforcement personnel, health department officials, and program clients (i.e., IVDUs)?"

(3) "What characteristics of the program clients are linked to program acceptance of the Tacoma-Pierce County Needle Exchange Program 
by law enforcement personnel, health department officials, and program clients (i.e., IVDUs)?"

\section{PURPOSE OF THE STUDY}

Insofar as the above research questions can be answered, the public health community will have an empirical base on which to further examine policies and interventions that seek to change behaviors and practices associated with the transmission of HIV-1/AIDS among IVDUs. Since the Tacoma-Pierce County Needle Exchange Program has been hailed nationally and internationally as a success (The Morning News Tribune 1992), and since it has achieved considerable longevity, it is an ideal case to study.

The following chapter provides an overview of the current literature on HIV-1/AIDS that has prompted communities such as Tacoma (in Washington State) to implement innovative public policies and public health interventions to combat the epidemic. Also reviewed are the efforts, international and national, that have led to needle exchange programs as a key force in changing injection habits associated with the transmission of HIV-1/AIDS among IVDUs. 


\section{CHAPTER II}

\section{REVIEW OF THE LITERATURE}

PART ONE: OVERVIEW OF HIV-1/AIDS EPIDEMIC

This chapter provides an overview of the emergence of HIV-1/AIDS, how the HIV-1 attacks the immune system; the modes of transmission, and why it is a serious threat to the wellness of the general public. This overview is based on the current knowledge of the disease as reported primarily in medical, science, and epidemiological journals and weekly reports.

\section{THE PANDEMIC OF AIDS}

The emergence of HIV-1/AIDS has brought forth intense challenges worldwide to the medical and public health community. In 1981, when AIDS was initially recognized in the United States, the medical and public health community was completely baffled, unaware of the full potential or threat of this debilitating disease. ${ }^{5}$ These early AIDS cases, in the United States, however, established a distorted view of the course of this deadly virus. To elaborate, the first reports of a strange immune suppression illness in the United States involved

\footnotetext{
${ }^{5}$ The initial AIDS cases in the United States were reported before a
} causative agent had been identified and isolated (Gottlieb et al. 1981). 
homosexual males; thus many thought that this disease was part of the homosexual lifestyle (Heyward and Curran 1989). ${ }^{6}$

As more AIDS cases appeared around the United States, the medical and public health community became cognizant that not only homosexual males, but also hemophiliacs, Haitians, and IVDUs were unfortunate candidates for this perplexing and fatal disease (Heyward and Curran 1989). The enormity of this public health problem, internationally and nationally, hence took on new dimensions, as the number of AIDS cases and of those infected with HIV-1 continue to rise.

\section{The Number of AIDS Cases}

Throughout the world, twelve million people are suspected to be infected with HIV-1. Of this estimated twelve million, more than half are found in Africa (particularly in Kenya, Tanzania, Sudan, Uganda, Zambia, and Zaire), where sexual intimacy among heterosexuals is the primary mode of transmission (First for Women 1992). Moreover, women account for 50 percent of the cases infected with HIV-1 worldwide (First for Women 1992). Nationally, however, AIDS has overwhelmingly stricken the population rather unevenly since HIV-1 first entered the homosexual male population.

Since 1981, the Centers for Disease Control (CDC) document that there have been more than 220,000 cases of AIDS and 140,000 deaths from

\footnotetext{
${ }^{6}$ The Gay Liberation Movement (GLM) allowed for homosexual males to "come out of the closet," by displaying to the heterosexual population a whole lifestyle of frequenting bath houses and bars to engage in sexual intimacies, promiscuous conduct, and use of inhalants during encounters. Early reports attempted to link the use of inhalants to heighten their sexual experiences with the outbreak of the strange immune suppression infection in male homosexuals (Marx 1985).
} 
this debilitating illness in the United States (First for Women 1992). To reiterate, the majority of adult AIDS cases in the United States have occurred in homosexual or bisexual males having no history of intravenous drug use $(130,000$ cases). Intravenous drug users (IVDUs) account for the next highest number of AIDS cases $(62,000)$ in the United States (First for Women 1992). To a lesser extent, other population groups contribute to the number of AIDS cases in the United States such as heterosexual males $(5,100$ cases $)$, transfusion recipients/hemophiliacs $(6,594$ cases $)$, and medical/healthcare professionals (32). The remainder of cases is said to be undetermined since risk information is incomplete (Heyward and Curran 1989; First for Women 1992).

\section{Racial and Ethnic Statistics}

Racial and ethnic characteristics of AIDS cases in the United States are as follows: 62 percent of reported adult AIDS cases and 23 percent of reported pediatric AIDS cases have occurred in whites; 25 percent of reported adult AIDS cases and 56 percent of reported pediatric AIDS cases have occurred in blacks; 13 percent of reported adult AIDS cases and 20 percent of reported pediatric AIDS cases have occurred in Hispanics (Curran et a1. 1988).

Blacks and Hispanics are disproportionately represented in the total number of AIDS cases according to their percentage of total population in the United States (blacks account for nearly 12 percent of the total population and Hispanics account for 6.5 percent) (Curran et al. 1988; Heyward and Curran 1989). The disproportionate percentage among such minorities largely reflects higher rates of AIDS due to intravenous drug use, their sexual partners, and offspring. Based on data from the CDC, 
Craven (1988a) asserts that "the cumulative incidence of AIDS among Blacks is nearly six times that of whites between the ages of 15 and 49 years, and black women have a rate 15 times that of white women" (CDC $1986 a ; 1983 a)$.

\section{Short-Term Prognosis}

Morbidity and mortality rates for HIV-1/AIDS will continue to increase in the near future; that is, the CDC estimate that two million people in the United States may be infected with HIV-1 (First for Women 1992). Researchers predict the number of deaths due to AIDS, in the United States, will reach one million by the end of the twentieth century (First for Women 1992). The AIDS virus poses a "serious threat to most sexually active adults and to infected mothers" (Anderson and May 1992).

The global prognosis is more bleak than the dismal estimates of the AIDS epidemic in the United States.' Reports indicate that by the end of the twentieth century the number of people infected with HIV-1 may reach 110 million -- three times that of earlier projections (First for Women 1992). ${ }^{8}$ According to Anderson and May (1992):

The balance of reported cases will shift rapidly from a majority in the Western world, largely the US, to a majority in the developing world. Given the long incubation period of AIDS, averaging about 10 years in adults, the currently reported incidencs of AIDS . . . probably reflects only about 10 percent of the actual number of people infected.

\footnotetext{
'Note that this prognosis is in the absence of any efficacious prevention or treatment developments.

${ }^{8}$ These estimates are provided in a study conducted by a research team headed by Jonathan Mann, M.D., of the Harvard School of Medicine.
} 


\section{PATHOGENESIS}

The disease known as AIDS is the final stage of an infection caused by HIV-1 (Fauci 1988; Gallo and Montagnier 1989; Heyward and Curran 1989; Redfield and Burke 1989).9. First identified in 1984, HIV-1 is a ribonucleic acid (RNA) containing retrovirus ${ }^{10}$ which serves as a template (i.e., pattern) to produce a complementary deoxyribonucleic acid (DNA) sequence that is assimilated into the host cell; the virus may remain latent for several years (Fauci 1988; Haseltine and WongStaal 1989; Sodroski and Haseltine 1988; Redfield and Burke 1989). The host cell that is infected is called the "T-4 lymphocyte" (i.e., a white blood cell) and is key to controlling the entire immune system. Within time, HIV-1 starts reproducing itself within the cell and the new virus escapes by way of brute force; that is, by punching holes in the cell's membrane and consequently killing the T-4 lymphocyte (Fauci 1988; Haseltine and Wong-Staal 1989; Sodroski and Haseltine 1988; Redfield and Burke 1989). This destructive process of the T-4 cells debilitates the immune system to such an extent that the person becomes vulnerable to

\footnotetext{
'Generally speaking, AIDS progresses in the following way: (1) blood tests detect HIV-1 antibody after infection between one to three months; (2) an onset of symptoms (fatigue, weight loss, fever, night sweats, diarrhea, flu-like illnesses, and/or enlarged lymph glands) may occur after the seventh year from infection resulting in full-blown AIDS (when one or more opportunistic infections occur such as cancers, pneumonia, dementia, and skin lesions); and (3) death usually results after two years diagnosed with full-blown AIDS (First for Women 1992).

${ }^{10}$ The Random House Dictionary (1987) defines retrovirus as any of a family of single-stranded RNA viruses having a spiral envelope and containing an enzyme that allows for a reversal of genetic transcription, from RNA to DNA, rather than from the normal DNA to RNA, the newly transcribed viral DNA being introduced into the host cell's DNA strand for the production of new RNA retroviruses: included in this family are AIDS virus and oncogene-carrying viruses involved in cancers.
} 
infections. and cancers that normally would never occur (Redfield and Burke 1989)'. Such infections are known as "opportunistic infections"11 as they develop under an impaired immune system.

This final stage of HIV-1, when opportunistic infections or cancers develop, is recognized as full-blown AIDS. In other words, the combination of immune dysfunction caused by the HIV-1 along with one or more opportunistic infections or cancer is what defines a person as having AIDS (Haseltine and WonguStaal 1988; Redfield and Burke 1989).

\section{TRANSMISSION}

Serological studies among population groups at risk in the United States have helped to confirm the modes of transmitting HIV-1. PrimariTy, these modes of transmission consist of intimate sexual contact, parenteral exposure to blood and blood products, and perinatally (i.e., from mother to child during the time of birth) (Heyward and Curran 1989; Curran et al. 1988). Each of these is explained below.

\section{Intimate Sexual Contact}

The AIDS virus (i.e., HIV-1) has been transmitted in the United States mainly through intimate sexual activities among male homosexuals as of 1993. Many studies (e.g., Chmiel et al. 1987; Goedert et al. 1984; Ho et al. 1984; Kingsley et al. 1987; Polk et al. 1987) indicate that the risk of infection among male homosexuals increases with the number of sexual partners and the frequency with which they are the

\footnotetext{
${ }^{11}$ Opportunistic infection is a disease or infection caused by a micro-organism that does not normally cause disease but which, under certain conditions (e.g., a weakened immune system), becomes pathologic (Slaff and Brubaker 1985).
} 
receptive ${ }^{12}$ partner in unprotected ${ }^{13}$ anal intercourse (Curran et al. 1988). Like other sexually transmitted diseases (STDs), female-tofemale transmission of HIV-1. is very low; for instance, only two cases have been reported in which the transmission seems to have occurred through this type of relationship (Curran et al. 1988). Heterosexual transmi.ssion (i.e; female-to-male and male-to-female) has been documented in a number of studies (e.g., Piot et al. 1984; Van de Perre et a1. 1984; CDC 1983b); however, researchers conclude that study populations have not been large enough to assess the relative efficiencies of transmission between the two directions (Curran et al. 1988).

Several studies (e.g., Goedert et a1. 1987; Redfield et a1. 1985) do indicate that infection is markedly higher in the female partners of infected male IVDUs than that of other population groups at risk. Such findings imply that biological factors as well as behavioral factors may assist in transmitting HIV-1; that is, some people may be more proficient transmitters of HIV-1 than others and, in addition, an individual's infectiousness may change from time to time (Heyward and Curran 1989). The presence of other sexually-transmitted diseases (STDs) such as genital ulcers, syphilis, or herpes simplex virus is also presumed to increase the rate of transmitting HIV-1 (Curran et al. 1988).

\footnotetext{
${ }^{12}$ Sexual partners are referred as being either "receptive" or "insertive."

${ }^{13}$ Unprotected refers to intercourse that occurs without the use of a condom.
} 
Parenteral Exposure to Blood/Blood Products

Another mode of transmission is parenteral exposure to blood or blood products through sharing injection equipment (see Appendix A) in the use of illicit drugs, transfusions, infected organ tissue, and in rare instances, occupational needle stick injuries (Curran et al. 1988). By and large, sharing injection equipment among IVDUs is perhaps the major source of parenteral exposure to blood which transmits HIV-1 (Heyward and Curran 1989). Literature on this mode of transmission (particularly in reference to the sharing of injection equipment among IVDUs) is addressed further in subsequent sections of this chapter.

Transfusion recipients in the United States are less likely to contract AIDS today than prior to the mid-1980s when blood screening for HIV-1 antibodies did not exist (Heyward and Curran 1989). The blood supply in the United States has become relatively safe for hemophiliacs and other potential transfusion recipients.

Parenteral exposure to blood and blood products has occurred in a few cases involving health care and medical professionals. According to the CDC, 8,000 health-care workers have been reported as having AIDS, but relatively few (32) were infected on the job (First for Women 1992). The CDC indicate only one doctor (Florida dentist David J. Acer) as being responsible for transmitting HIV-1/AIDS to five patients (including Kimberly Bergalis) (First for Women 1992).

\section{Perinatal Transmission}

Reports indicate that HIV-1 can be transmitted perinatally -- that is, from an infected mother to her newborn child (Curran et al. 1988; Heyward and Curran 1989). Even though all newborn children (i.e., who 
are born to HIV-1 infected mothers) will carry their mother's antibodies and test positive for the virus.at birth, only about one-third of these infants will become infected, remain HIV-1 positive after age one, and eventually develop full-blown AIDS: The remaining two-thirds will lose their mother's antibodies and thus test HIV-1 negative (First for Women 1992). Moreover, an HIV-1 infected mother may give birth to one baby who develops full-blown AIDS, and subsequently deliver another who does not. This phenomenon is under examination by various scientists and medical professionals (First for Women 1992).

Other reports suggest that HIV-1 can be transmitted from mother to child through breast feeding (Curran et al. 1988; Piot et al. 1988). The number of pediatric AIDS cases (i.e., children under 13 years), in the United States, is increasing rapidly (Heyward and Curran 1989). Since 1981, approximately 3,000 pediatric AIDS cases have been reported to the CDC (First for Women 1992).

\section{Theoretical Routes of Transmission}

The aforementioned modes of transmission of HIV-1 have been documented and account for most cases of infection; but there has been some concern that, in rare instances, other modes of transmission might occur. From time to time, questions surface in the literature about the possibility of whether an insect could be a vector to transmit HIV-1 through its bite. Studies indicate that HIV-1 has been found to survive evidence that indicates HIV-1 does reproduce in insects, for several hours, even days, in insects who were artificially fed blood containing high concentrations of the infectious virus or injected with contaminated blood (Curran et al. 1988). There is, however, a lack of 
evidence that indicates HIV-1 does reproduce in insects ${ }^{14}$ and research findings indicate no patterns of the virus consistent with the idea of insects as vectors for transmitting HIV-1 (Curran et al. 1988; CDC 1986b). The Office of Technology Assessment (1987) addresses this issue and tersely states:

There is no evidence that insect transmission causes HIV-1 infections in temperate zones or even in tropical climates . . . If insect transmission is occurring at al1, each case would be a rare and unusual event.

In the earlier years of the epidemic, there has been much concern and debate regarding casual contact as a possible mode of transmission. Studies in the United States have been conducted of the family members of both children and adults with HIV-1 to explore the theoretical risk of transmission through casual contact (Redfield et al. 1985; Fischl et a1. 1987; Curran et al. 1988). Findings indicate that even under extensive and long term contact with infected individuals in household settings, not one of over 400 family members had contracted HIV-1, except for sexual partners of the infected persons and perinatal transmission. Subsequently, the potential risk of transmitting HIV-1 through household contact and other social environments (e.g., offices, schools, and churches) is considered to be extremely rare, if at all possible (Curran et al. 1988).

The AIDS virus has been cultured from saliva (Ho et al. 1984; Curran et al. 1988) and isolated from tears (Salahuddin et al. 1985), resulting in concerns regarding kissing, sneezing, biting, spitting, and any other

\footnotetext{
${ }^{14}$ Reproducing or replication is a biological event which is considered important in most viral diseases transmitted by insects (Heyward and Curran 1988).
} 
activity that may involve the transmission of such body fluids. There has been only one case which suggests oral-to-oral HIV-1 transmission from husband to wife. The wife, at first, was reported to be seronegative $^{15}$ and culture-positive for HIV.-1 but subsequent tests were seronegative and additional efforts to culture virus have been unsuccessful (Salahuddin et al. 1985)

There has been one reported case in West Germany. in which it was suggested that a bite between two siblings resulted in the transmission of HIV-1. The skin, however, was not broken (Curran et a1. 1988). Other studies have been unsuccessful in documenting transmission of HIV1 through human biting (Darrow et al. 1988).

Heyward and Curran (1989) point out that in a study conducted by the CDC on 48 health care workers who were parenterally or mucous-membrane exposed to saliva, no infection occurred. Reports indicate that the virus is markediy less concentrated in saliva than in blood (Curran et al. 1988; Ho et a1. 1984; Levy et al. 1985). Currently, the likelihood that other unidentified routes of transmitting HIV-1 might exist can not be entirely ruled out; however, the possibility seems to be extremely rare and remote.

\footnotetext{
${ }^{15}$ Seronegative indicates that no significant level of serum antibodies, or other immunologic marker in the serum, that would indicate previous exposure to the infectious agent being tested (The Random House Dictionary 1987).
} 
THE ORIGIN OF. THE AIDS

Acquired immune deficiency syndrome (AIDS) has generated much speculation and controversy over its geographic origin and inception. ${ }^{16}$ Blood stored as early as 1959 in Zaire (a country in central Africa) has been noted to contain antibodies against the AIDS virus (Mann et al. 1989; Swenson 1988; First for Women 1992). Another early case involved a Norwegian seaman who traveled to Africa, contracted an AIDS-like illness in the mid-1960s, and hence died in 1976; his wife and child died shortly thereafter (First for Women 1992). Ten years later (i.e., 1986), the family's blood specimens tested HIV-1 positive (First for Women 1992). Nonetheless, there is no concrete evidence, at this time, substantiating where and when this epidemic began.

Many medical researchers (Gallo and Montagnier 1989; Swenson 1988; Essex and Kanki 1989; Mann et a1. 1989), however, allude to central Africa as a possible location of origin of HIV-1; both Gal10 17 and Montagnier ${ }^{18}$ presume that HIV-1 has existed for many years in small, isolated groups in countries of central Africa or perhaps elsewhere. In such remote groups, however, the spread of HIV-1 had been 1 imited, as

\footnotetext{
${ }^{16}$ Various theories have surfaced, from time to time, on the origin and inception of AIDS. The "African connection" theories suggest different inceptions -- one stating that sexual practices using monkey blood to heighten arousal; another indicating that an early type of polio vaccine, first tested in Africa, might have utilized contaminated monkey tissue in its formulation (First for Women 1992). As yet, there has been no evidence to support any of these claims.

${ }^{17}$ Robert C. Gallo established the cause of AIDS. He is Chief of the Laboratory of Tumor Cell Biology at the National Cancer Institute.

${ }^{18}$ Luc Montagnier established the cause of AIDS; he is a Professor of virology at the Pasteur Institute in Paris and Director of Research at the French National Center for Scientific Research (CNRS).
} 
very little contact with the outside world occurred (Gallo and Montagnier 1989; Mann et a.l. 1989). As people started to migrate to urban centers, the way of life in central Africa began to change and sexual mores began to differ from those of the small, remote village (Fineberg 1989). In short, the disruption of the traditional ways of life (in Africa) during the latter part of the twentieth century may have augmented the spread of HIV-1 in central Africa, and thus to other parts of the world via modern technology (Fineberg 1989).

One particular technology of the twentieth century often considered as playing an important role in the spread of HIV-1/AIDS to other continents is the advent of the jumbo jet (Swenson 1988). As Swenson (1988) writes:
as fourteenth-century travel had to become rapid and efficient enough to bring plague from Asia, modern jet travel had to expand to central Africa to bring HIV to the rest of world . . . the earliest sites were probably Europe and Haiti.

The AIDS epidemic in Haiti has been well documented (Pape et a1. 1983). Like the AIDS cases in central Africa, AIDS cases in Haiti are largely attributed to heterosexual transmission (Curran et al. 1988). In the eariy 1980s, Haitian immigrants in the United States were placed on a list containing high-risk categories (Ginzburg et al. 1986); however, by April, 1985, the CDC indicated that Haitian immigrants were no longer among the high-risk groups (Ginzburg et al. 1986).

Swenson speculates that the transmission path of AIDs to the United States seems to be male homosexuals who traveled to the area of Port-auPrince, Haiti, for vacation. Similarly, Shilts (1987) points out that the epidemic advanced in a particular way as a result of widespread 
travel to and from large urban centers such as San Francisco, New York, and Los Angeles. Shilts (1987) writes:

The air bridges between Los Angeles, New York, and San Francisco clearly had helped spread this virus around the country at breakneck speed.

Shilts points out that several airline employees actively played a vital link in the spread of HIV-1/AIDS in the United States. One particular flight attendant, Gaetan Dugas, is referred to as "patient zero"19 $^{19}$ in the AIDS epidemic within the United States. Dugas had numerous sexual relations with other male homosexuals in various locales, as being a flight attendant enabled him to travel extensively. He continued to remain sexually active and promiscuous despite knowledge of having contracted a deadly infection (Shilts 1987).$^{20}$ Subsequently, HIV-1/AIDS was carried to those areas having the greatest concentration of male homosexuals, such as San Francisco, Los Angeles, and New York.

\section{THE EMERGENCE OF AN EPIDEMIC}

\section{The First Wave}

By the 1970's, the first wave of the AIDS epidemic in the United States was set in motion: HIV-1 infection began spreading extensively.

\footnotetext{
${ }^{19}$ French Canadian Gaetan Dugas is the first North American diagnosed with AIDS. Of 248 American homosexuals diagnosed in 1982, 40 had been involved with Dugas. Dugas revealed that he had sex with 2,500 men during a ten-year period, spreading HIV-1 to various urban centers such as New York, Toronto, Los Angeles, and San Francisco (Shilts 1987; First for Women 1992).

${ }^{20}$ Unlike Gaeton Dugas, infected individuals who knowingly spread HIV-1/AIDS may be charged with a crime in some states today. There are also lawsuits pending in various courts asking for monetary settlements for those individuals who have contracted HIV-1/AIDS from specific people.
} 
By mid-1981, federal officials took note of a strange immune disorder that was afflicting primarily male homosexuals (Gottlieb et al. 1981); thus, the first signs of an epidemic were beginning to surface ${ }^{21}$. The AIDS virus spread rapidly among male homosexuals because of several factors: (1) anal intercourse (as previously discussed); ${ }^{22}$ (2) the relatively small, sexually-closed community, concentrated in various major urban centers having large populations of male homosexuals; and (3) the Gay Liberation Movement (GLM) that promoted sexual freedom and encouraged promiscuous behavior among male homosexuals (Turner et al. 1989). The AIDS infection among this particular high-risk group (i.e., male homosexuals) is likely to continue to some extent into the future. There is, however, another high-risk group that is currently experiencing a dramatic rise in the number of AIDS cases, namely intravenous drug users (IVDUs).

\section{The Second Wave}

This second wave of the AIDS epidemic in the United States has thus surfaced among intravenous drug users (i.e., individuals who engage in the injection of illicit drugs), ${ }^{23}$ the focus of this research. (Des

${ }^{21}$ There is a long latent period between infection of HIV-1 and full-blown AIDS. This latent period varies among cases (Peterman et al. 1985).

${ }^{22}$ Receptive anal intercourse is viewed as the most effective means of sexual transmission (Chmiel et a1. 1987; Kingsley et al. 1987; Polk et a1. 1987).

${ }^{23}$ Ginzburg (1984) defines "drug user" or "drug abuser" as "any person who uses psychoactive substances in a manner that does not constitute an approved medical intervention prescribed by a health professional. The term 'intravenous drug user' refers to a person who voluntarily injects psychoactive substances directly into his or her blood circulation." 
Jarlais 1987a; Des Jarlais et al. 1987a; Newmeyer 1988). Currently, intravenous drug users (IVDUS) comprise the largest number of heterosexuals infected with HIV-1 in the United States (Friedland and Klein 1987); moreover, they are often cited as being the main source for the transmission of HIV-1 into the non-injecting, heterosexual population.

A further concern within the field of medicine and public health is the fact that female IVDUs and sexual partners of male IVDUs are a main source for perinatal transmission of HIV-1 (CDC 1986a; Heyward and Curran 1989). By April 4, 1988, approximately 74 percent of the 919 pediatric AIDS cases in the United States were infected by a parent who was an IVDU or by a parent who had had sexual relations with an IVDU (CDC 1986a).

Intravenous drug users (IVDUS) possess specific behaviors which are considered important in understanding their role in the transmission chain of HIV-1/AIDS. Two main types of behavior are of critical

concern: (1) sharing injection equipment, and (2) frequent injection of various types of drugs (Turner et a1. 1989). These are discussed in more detail below.

Sharing Injection Equipment. Sharing injection equipment ${ }^{24}$ is a common practice among IVDUs (Black et a1. 1986; Brown et a1. 1987); that is, nearly all IVDUs have experienced sharing injection equipment at least once (Black et al. 1986). The use of contaminated injection equipment has been linked to a number of infections in IVDUs, including

\footnotetext{
${ }^{24}$ Injection equipment is also known as "works," "rigs," "instruments," and "outfits" among IVDUs. Refer to Appendix A for a more detailed description of injection equipment.
} 
hepatitis, malaria, and cellulitis (Louria et al. 1967). Just as these blood-borne infections are spread from the infected to the uninfected user, so is human immunodeficiency virus type one (HIV-1) spread. The chance of contracting HIV-1 increases with each added injector using the same equipment (Chaisson et al. 1987). Several reasons (or combinations of reasons) may account for the sharing of injection equipment: availability and accessibility, and (2) social bonding. ${ }^{25}$ These two main reasons for sharing injection equipment are addressed below.

1. Availability and accessibility. Availability and accessibility of injection equipment are serious factors in the transmission of HIV1/AIDS. Even those going through withdrawal may weaken and obtain the first available needle/syringe to satisfy their addiction to drugs, ignoring the known consequences for using unclean needles/syringes (Fineberg 1988).

Another aspect of the availability of injection equipment is that many IVDUs choose not to tote them, as in some states possession of needles/syringes for illegal drug use is a criminal offense (Friedman et al. 1986). This, in turn, leads IVDUs to "hide" their injection equipment in various places (e.g., a friend's apartment) thus ignorant of who may borrow their "works." Beyond this, in larger urban centers IVDUs opt to go to "shooting galleries/parlors" (places such as apartments or abandoned buildings) where injectors congregate. Those who operate shooting galleries will offer the use of the concealed place and will supply used injection equipment for a given fee. These sites are

\footnotetext{
${ }^{25}$ The subculture and social bonding of IVDUs are discussed in more detail in Friedman et al. (1986) and Fineberg (1988).
} 
notorious for supplying contaminated injection equipment (Des Jarlais et a). 1986a).

In Portland, Oregon, sharing injection equipment and the use of unsterile needles occur despite the legal sale of needles/syringes in pharmacies without prescriptions. According to Maynard (1988):

\begin{abstract}
strict legal accessibility is not the same as true accessibility .. . they [IVDUs] are often harassed and refused outright [by pharmacists] . . And the psychological process of denial may keep them out of stores . . many drug users maintain the personal fiction that they are not drug users ... So, in reality, many IV drug users get their'works' on the streets for a dollar apiece and no guarantee of sterility. Or, in Portland, it is common for a drug seller to inject heroin or cocaine into the buyer at the time of the sale, using the same needle and syringe over and over.
\end{abstract}

2. Social bonding. In addition to the availability and accessibility of needles/syringes, social bonding is another reason often stated as why IVDUs share injection equipment. Sharing injection equipment is often noted as being part of the drug subculture involving social psychological forces (Agar 1973; Des Jarlais et al. 1986b). To elaborate, using the same injection equipment and injecting drugs together are often compared to "sharing a bottle of wine;" it is a form of social bonding among IVDUs (Friedman et al. 1986; Booth 1988). Moreover, Des Jarlais et al. (1986b) indicate that sharing injection equipment and injecting each other seem to connote strong sexual implications.

A complex set of relationships exists between sexual behavior and illicit drug use. Illicit drug use has been associated with various sexual conducts which increase the risk of HIV-1 acquisition and 
transmission (Turner et al. 1989). For example, female IVDUs ${ }^{26}$ who are sexual partners of male IVDUs often employ sex to obtain drugs or sex becomes an element of a relationship based on illicit drug use (Worth 1988).

Another dimension of sexual conduct often associated with illicit drug use is prostitution. Prostitutes are noted to be at high-risk for the AIDS virus for several reasons: (1) they have a multitude of sexual partners; (2) they often have a greater chance of having other STDs ; ${ }^{27}$ (3) they associate with other IVDUs; and (4) their own use of illicit drugs puts them at risk (Turner et al. 1989). Reports from the CDC indicate that 30 to 50 percent of female IVDUs also engage in prostitution (CDC 1986a; CDC 1987a).

Frequent Injection of Various Types of Drugs. The frequency of injection and type of drug used are other behavioral factors associated with HIV-1 which are important in understanding the injection behavior of IVDUs. In the United States, these behaviors have varied over the years and among the different geographic areas. ${ }^{28}$ Several studies (e.g., Blattner et al. 1985; Des Jarlais 1987b; Friedland et al. 1985) indicate that the chance of contracting HIV-1/AIDS increases with the frequency of injecting illicit drugs. IVDUs who inject cocaine

\footnotetext{
${ }^{26}$ Approximately 30 percent of IVDUs are female and most of these women are in their prime child bearing years (Drucker 1986).

${ }^{27}$ STDs are often noted as being a possible cofactor in the spread of HIV-1. A cofactor, in this context, increases the probability of the development of disease in the presence of the basic etiologic agent of that disease.

${ }^{28}$ Heroin was the major drug injected several years ago, while today IVDUs are known to shoot a variety of drugs such as cocaine, a mix of heroin and cocaine, even amphetamines (Black et al. 1986).
} 
experience a shorter "high" than if they had used another type of drug such as heroin; therefore, cocaine-injecting drug users are noted as injecting more often than those who use heroin (Gold et al. 1986; Turner et al. 1989). Friedland et al. (1985), point out that sharing injection equipment is a common behavior in both frequent and less frequent injectors, but contend that there is a higher likelihood of HIV-I among frequent users because of the increased incidence of sharing that occurs.

Studies have linked cocaine to HIV-1 infection in New York City and San Francisco (Chaisson et a1. 1988; Friedman et al. 1988). In a survey of 673 IVDUs in San Francisco, Chaisson et al. (1988) reported the use of intravenous cocaine as the link which significantly increased the risk of HIV-1 infection.

Acknowledging the frequency of injection and type of drug used appears to be a critical factor in determining what treatment and prevention strategy is most feasible. Some forms of drug treatment, including methadone, are considered ineffective for cocaine dependency (Chaisson et a1. 1988). In short, such factors need to be considered in the implementation of a particular intervention such as a needle exchange program which aims at changing the drug use behaviors associated with the transmission of the AIDS virus among IVDUs.

CONTROLLING THE SPREAD OF HIV-1/AIDS

Recently, various strategies of intervention have been suggested as possible means to reduce the risk of transmitting HIV-1/AIDS, as there is no cure known to date. Table I, presented on a following page, 
reveals the possible AIDS intervention strategies. A very brief and general discussion of such strategies follows to acknowledge their existence; however, it is beyond the scope of this research to discuss them in greater detail. Again, the focus is only on one such strategy by increasing the availability and assessibility of sterile injection equipment via needle exchange programs, which aim to promote new and safer injection practices among IVDUs.

\section{Drug Treatment}

Treatment for drug abuse is obviously a vital way to control the spread of HIV-1/AIDS. Drug treatment encompasses rapid or long-term outpatient detoxification, inpatient detoxification, residential programs, or methadone maintenance programs. In addition, treatment for drug abuse varies among programs and involves numerous variables. The many issues that surround drug abuse and the various treatment programs are complex and often controversial (Craven 1988). Beyond this, there is a limited number of drug users who can be admitted to a treatment program at one particular time; some programs have decided to admit only those who al ready test positive for HIV-1 (Turner et al. 1989). Some drug treatment programs have not yet incorporated effective education about spreading HIV-1/AIDS; moreover, many are not adequately equipped to care for the social psychological needs of their clients (Craven 1988). 
TABLE I

POSSIBLE STRATEGIES FOR CONTROLLING THE SPREAD OF

HIV-1/AIDS AMONG INTRAVENOUS DRUG USERS (IVDUS)

Drug treatment.

Access to drug treatment

More customized treatment programs

Better rehabilitation after treatment

Access to HIV-1 testing and counseling

Preferential admission for HIV-1 seropositive IV drug users

Special programs for pregnant addicts and adolescents

Prevention

Access to sterile needles (needle exchange, sale of sterile needles without prescription)

Needle-syringe disinfection with bleach

Anonymous or confidential HIV-1 antibody testing and counseling

for IVDUs and their needle and sexual contacts

Access to and use of condoms

\section{Education}

Programs on IV drug use prevention and risk reduction for IVDUs, as well as the general public

Culturally appropriate prevention programs for schools and "drop outs"

Education of IV drug user prevention and risk reduction

Programs for IVDUs with their sexual partners

Community outreach and peer educational programs

\section{Legal Intervention}

Strict enforcement of drug trafficking laws

Higher penalties for possession of heroin and cocaine

Mandatory education for prisoners

Stop drug use in prisons

Mandatory education and listing of "Johns"

Change state laws regarding possession of needles

Close "shooting galleries"

Source: Craven, Donald E. "AIDS in Intravenous Drug Users." In AIDS 1988: American Association for the Advancement of Science (AAASS) Symposia Papers, ed. Ruth Kulstad Washington, D.C.: American Advancement of Science, (1988): 114. 


\section{Education}

Unlike other population groups at risk for contracting and transmitting HIV-1/AIDS (particularly male homosexuals), IVDUs do not have any active organization which mobilizes support or that renders education about sharing needles and sexual behavior. The inability to reach the majority of intravenous drug users (particularly hard-core drug users) is often cited as an obstacle to drug treatment and other social services. The inability to reach such a "hidden" population (i.e., IVDUs) is thus an issue that becomes critically important in the design and implementation of any AIDS intervention strategy.

\section{Prevention}

Although intravenous drug users (IVDUs) are a hidden population group that is considered "hard to reach" in delivering social services or in attracting them to utilize social programs, research does indicate that it is possible to educate IVDUs about the spread of HIV-1/AIDS (Des Jarlais et al. 1987b; Selwyn et a1. 1987). Recent data on IVDUs in methadone maintenance programs indicate that behavioral changes do occur among this population group when members are informed of the dangers of sharing needles, unprotected intimate sexual contact, and promiscuity. This implies that treatment centers are a logical vehicle to disseminate information about the spread of HIV-1/AIDS and to educate IVDUs of safer needle and sexual practices (Craven 1988). Other possible sites to reach IVDUs who are not in treatment programs have been suggested, such as in hospitals, clinics, jails, prisons, courts, and welfare and unemployment offices (Craven 1988). An innovative intervention such as a needle exchange program can serve as a means to disseminate informa- 
tion to such a population group as well as to make injection equipment more readily available to them. The extent to which such programs contribute to the decline in the transmission of HIV-1/AIDS remains to be determined.

In sum, there is no set strategy nor single solution to control the spread of HIV-1/AIDS among IVDUs, al though some combination of education and active intervention appears to be critical. A needle exchange program is one such strategy in which education can incorporate. Again, the examination of the evolution, implementation, and acceptance of the Tacoma-Pierce County Needle Exchange Program may provide valuable insights for other communities seeking to adopt a similar AIDS intervention for this particular high-risk group.

\section{PART TWO: OVERVIEW OF NEEDLE EXCHANGE PROGRAMS}

Any topic which involves needle exchange programs for intravenous drug users (IVDUS) is considered contemporary, as such intervention strategies were not introduced until 1984. To date, much of the literature that focuses on needle exchange programs for IVDUs tends to describe the particular services provided by given program and operating philosophies employed. In addition to those articles of a descriptive nature, there is a growing body of evaluative literature that has been made available through the Narcotic and Drug Research of New York, New York, and the now-defunct International Working Group on AIDS and Intravenous Drug Use. That group has collected information regarding AIDS from a number of conferences, workshops, and symposia, and has encouraged the sharing of information and statistics about needle 
exchange programs. Many of the descriptions provided by these two agencies are parts of ongoing. studies of needle exchange programs currently under examination. Such a network of information has been extremely valuable to the compiling of data for this study.

The National Research Council and the American Association for the Advancement of Science have also compiled a number of articles which appear in various journals or have been presented at various conferences. These efforts provide valuable information on such a contemporary topic, particularly during a time when most needle exchange programs are still in their infancy. The information from these agencies which focuses on needle exchange programs is summarized below.

\section{INTERNATIONAL NEEDLE EXCHANGE PROGRAMS}

This section provides an overview of the various needle exchange programs that have evolved (outside the United States) in order to help slow the spread of blood-borne infectious diseases, particularly HIV-1/ AIDS. The few countries that have implemented such innovative AIDS intervention strategies are considered to be the "real" pioneers in the history of needle exchange programs. An overview of these international needle exchange programs can provide insights to broaden the perspectives on formulating and implementing such programs in the United States. In addition, reviewing the experiences encountered by other countries allows for a basis to compare and contrast such efforts involved in formulating and implementing the Tacoma-Pierce County Needle Exchange Program. 
The Netherlands

The world's first needle exchange program was started in The Netherlands, in 1984, by a league of drug addicts known as "Junky Union" (Kools and Buurman 1986). This particular Dutch needle exchange program grew out of the fear of an outbreak of another serious blood-borne disease known as "hepatitis B." Although Dutch health authorities were not excited about this intervention strategy initially, they did cooperate by supplying large quantities of disposable needles to the Junky Union. From the start, an estimated 1000 needles/syringes were exchanged each day (Buning et al. 1988a).

As the number of AIDS cases among IVDUs increased, more Dutch institutions decided to participate more actively in the needle exchange program. The Amsterdam Municipal Heal th Service decided to expand the program by adding other locations to distribute clean needles/syringes as well as making them available on methadone buses (Buning et al. 1988a). The number of exchanged needles/syringes rose from 25,000 in 1984 to approximately 700,000 in 1987 (Buning et al. 1988b).

Several evaluations of the Dutch needle/syringe exchange have been conducted in the past few years to determine the effectiveness of the programs. Buning et al. (1988b) evaluated Amsterdam's needle exchange program and the findings were reported at the Fourth International Conference on AIDS which was held in Stockholm, Sweden, from June 12 to 16, 1988. Buning et al. (1988b) asked questions to 148 IVDUs about the drug situation in Amsterdam. Their findings indicate that IVDUs who exchanged needles regularly differed from the non-exchangers in terms of average age ( 31.5 versus 28.10 ) and average length of drug use ( 9 versus 
7 years). The majority of those who used the exchange program are of Dutch origin and have been in contact. with.drug aid agencies. Over 70 percent stated that they decreased injection or at least did not increase injection compared to 49 percent of those who did not use the exchange program (i.e., the latter were more likely to increase their drug use). Approximately 82 percent of those who exchange needles/ syringes reported using their injection equipment only once compared to only 28 percent of non-exchangers.

In another study, conducted by Hartgers et al. (1989), a group consisting of 145 IVDUs in Amsterdam was interviewed about injection practices and participation in the program. A follow-up survey was carried out approximately one year later. As with the study conducted by Buning et al. (1988b), findings concluded that IVDUs who used the program did not increase levels of injection nor lend needles to others. The risk level of the injection process for those who exchanged needles was much lower than that of the non-exchangers.

The Netherlands' positive experience with needle exchange programs has led other countries around the world (e.g., England, Scotland, Austria, Switzerland, Sweden, West Germany, France, Australia, Thailand, Canada, and the United States) to implement similar programs for IVDUs. Despite the same goal, to control the spread of HIV-1/AIDS, each needle exchange program has evolved uniquely and has tended to reflect its country's laws, policies, and programs that deal with AIDS, as well as with the current laws regarding illicit drug use and possession of related paraphernalia. Beyond this, social values and ethics are intertwined with such legalities. For example, Sweden is one European 
country where needles/syringes cannot be purchased in pharmacies (Des Jarlais and Woods 1988); yet, there is a needle exchange program that has been successfully operating out of a hospital in the City of Lund. Even where needle exchange programs have emerged (legally sanctioned or underground), it is worth reiterating the fact that each has unique methods of service delivery and tends to operate somewhat differently.

\section{Switzerland}

Switzerland is reported as having the highest per capita incidence of AIDS in Europe. As of March 31, 1989, 29 percent of the 809 cases reported to the central health authorities occurred among IVDUs (Schultz 1989). In addition, 80 percent of the infants known to have contracted AIDS have been traced to an addicted, or formerly-addicted, mother (Schultz 1989).

One Swiss city, Zurich, cognizant of the societal implications of such alarmingly high percentages of infection that are manifested by this high-risk group, had, until recently, turned a "blind eye" toward illicit drug use in hopes of isolating the threat of AIDS from the remaining non-injecting, heterosexual population (Safer 1990). The television program 60 Minutes had presented Zurich's "Needle in the Park Campaign" to highlight the tragic life and bleak prognosis for IVDUs. The report focused on the City of Zurich which is trying to prevent IVDUs from sharing needles by isolating them in the city's downtown park, "The Platzspitz" -- or what has come to be known as "Needle Park." 
According to Morley. Safer's report, approximately $7,000^{29}$ dirty needles were returned each day.

For the most part, the illicit activities that have occurred in Needle Park have been tolerated by the general public and Zurich police for nearly three years. Moreover, the program was a success in reducing the incidence of new AIDS cases from 50 percent to five percent. ${ }^{30}$ Despite such success, Zurich officials decided to close Needle Park due to an increase in crime and numbers of professional drug dealers (i.e., particularly Lebanese, Yugoslav, and Turkish gangs) that were drawn to the area (Time 1992). Most of the drug users went underground in Switzerland, while others went in search of methadone. Beyond that, controlling the spread of HIV-1/AIDS will probably become more difficult in Zurich.

\section{Sweden}

Sweden's pattern of drug use is somewhat different from other countries in terms of the type of drugs injected; ${ }^{31}$ yet, as in other countries, higher incidences of infection appear to occur in the larger urban centers. Overall, infection rates are higher in the capital city, Stockholm, where drug abuse is also considered to be greater, while

\footnotetext{
${ }^{29}$ The population of Zurich, Switzerland, is approximately 250,000 (Safer 1990).

${ }^{30}$ Overall, 20 percent of Zurich's drug addicts have tested positive for HIV-1 (Time 1992).

${ }^{31}$ The majority of the estimated 10,000 IVDUs mainly inject amphetamines, while less than 15 percent use heroin as their principal drug (Lundborg 1988). As of 1987, approximately 63 percent of the heroin-injecting drug users are HIV-1 infected (Des Jarlais and Woods 1988).
} 
lower rates of infection exist in southern Sweden where IVDUs cross the border to Denmark to purchase sterile needles/syringes in pharmacies (Tunving et al. 1989). The purchasing of injection equipment across the border, and fearing the AIDS epidemic, the Clinic for Infectious Diseases along with the Drug Dependence Unit in Sweden organized a needle exchange program in the City of Lund.

Lund's needle exchange program commenced in 1986 at the $\mathrm{Clinic}$ for Treatment of Infectious Diseases at the General Hospital. The program is operated by physicians and nurses and is open to all IVDUs.

Information on risk-reduction behavior, HIV-1 testing, free condoms, and education on safer injection practices are other services provided at the program site (Tunving et a1. 1989).

From November 1986 until May 1989, 900 people have used the program in Lund, during which time 20 percent of them have frequented the program more than ten times (Tunving et a1. 1989). Program clients have been profiled as follows: (1) the average age is 30; (2) the majority have a family and children; (3) most maintain a social life; and (4) they are often only weekend drug users (Des Jarlais and Woods 1988). The Lund program appears to be working as an AIDS intervention program for IVDUs, as only 17 cases have been reported in the area (Andersson et al. 1988; Des Jarlais and Woods 1988). Of these seventeen cases, however, most migrated from Stockholm (where no needle exchange program exists) and were more likely infected a priori (Andersson et al. 1988; Des Jarlais and Woods 1988).

Intravenous drug users (IVDUs) in Stockholm purchase their injection equipment on the "black market," as there is no needle exchange program 
or pharmacy which sells such paraphernalia: The National Social Welfare Board in Sweden opposes needle exchange programs, and much political opposition exists among the conservatives and social democrats who will not tolerate the possibility of IVDUs remaining anonymous (Tunving et al. 1989). Moreover, many officials and politicians perceive that "all drug addicts shall get into treatment and stop using drugs . . the best way to avoid AIDS" (Tunving et al. 1989).

The situation is not favorable for maintaining such a naive view; the spread of HIV-1 is extensive in the capital city. In 1985, nearly 50 percent of all heroin addicts that attended a detoxification clinic in Stockholm had been infected by HIV-1 (Tunving et al. 1989). In the past few years, the Swedish Medical Association (comprised of all doctors in Sweden) has forcefully and officially spoken in favor of implementing more needle exchange programs, but politicians remain adamant against this type of intervention (Tunving et al. 1989).

\section{West Germany}

The AIDS virus among IVDUs has been on the rise since 1982 in west Germany. As of March 31, 1989, approximately 11 percent of the 3086 AIDS cases stemmed from intravenous drug use, and nearly one percent of the total cases were traced to both intravenous drug use and homosexual activity (Stover 1989). Compared with 31 other European countries, West Germany is below the average in its AIDS' statistics. To illustrate, approximately 24 percent of the total European AIDS cases $(16,247$ as of September 30,1989$)$ stem from intravenous drug use, and about 27 percent indicate intravenous drug use as well as homosexual relations (Stover 1989). Although data indicate that West Germany is below the European 
level, the problem should not be minimized. Stover (1989) confidently points out that HIV-1 prevalence among IVDUs is approximated at 30 percent, and that there are vast regional differences that exist which can distort the picture of national statistics.

The reluctance of public health officials to implement a needle exchange program raised the concerns of a self-help group in West Germany. In 1984, this group ("Kormunale Drogenpolitik/Verein fur Akzeptierende Drogenarbeit") ${ }^{32}$ dispensed free needles/syringes in Bremen, ${ }^{33}$ West Germany, as a one time event in protest of officials' inaction, and to demonstrate the need to take an active role in promoting safer injection practices among this population group (Stover 1989). Still, health officials did not adopt any new measures for this burgeoning condition.

In 1986, the self-help group started a street-based exchange program in Bremen, which only dispensed needles on Sundays and holidays (presuming IVDUs were unable to buy needles/syringes in pharmacies on these days). In time, the self-help group recognized that these hours of operation were insufficient to meet the demands of the targeted population. In 1987, two converted cigarette vending machines were installed near the site where IVDUs congregated in order to offer an inexpensive, anonymous means to purchase needles/syringes on a 24-hour basis (Stover 1989). Such a scheme has been in operation in Copenhagen, Denmark, and appears successful even though their pharmacies are noted

\footnotetext{
${ }^{32}$ English translation: "Local Drug Policy/Association for Accepting Drug Social Work."

${ }^{33}$ Bremen is a port city with a population of about 600,000 and approximately 700 intravenous drug users (Stover 1989).
} 
for being open on a 24-hour basis (Stover 1989). Each month approximately 5,000 package-units (i.e., two syringes and two needles) are purchased through these automats (vending machines) for the price of about fifty cents each (Stover 1989).

\section{The United Kingdom}

Unlike the reticence of officials of both Sweden and West Germany to adopt and sponsor a needle exchange program, authorities of the United Kingdom (England, Northern Ireland, Scotland and Wales) have launched a number of AIDS intervention strategies for IVDUs. As recentiy as 1986, government officials opposed any intervention that allowed for the open availability of needles/syringes (Short 1986). The change in government's response was fueled by reports which indicated alarmingly high levels of HIV-1 among IVDUs (Stimson 1988). The highest rates of seropositive HIV-1 have been reported in Edinburgh, Scotland, where between 1983 and 1985 half of the 164 heroin injectors tested positive (Robertson et al. 1986). As in West Germany, there are regional differences in the number of HIV-1 infection rates among IVDUs.

The Scottish Home and Health Department (SHHD) appointed a comittee to help determine what gave rise to the HIV-1 infection rate in Edinburgh during 1984 and 1985 . The committee attributed the rapid rise in such rates to two significant factors. In September 1986, the committee addressed these factors in the McClelland Report: (1) police activity which discouraged the sale of needles appears to have contributed to extensive sharing of injection equipment; and (2) minimal availability of treatment services which may have sustained illicit drug use (SHHD 1986). These two main factors of concern increased the 
awareness of the spread of HIV-1 and, as a result, officials in both the Scottish Home and Health Department and the Department of Health and Social Security (DHSS) ${ }^{34}$ acted to curb the spread of the AIDS virus. The Secretary of State for Social Services announced the provision of funds to enable drug agencies to expand their counseling services on AIDS and illicit drug use and to establish a number of needle exchange programs (DHSS 1986). The DHSS allowed existing drug agencies to establish pilot needle exchange programs for one year and the SHHD allowed health boards to set up needle exchange programs in Scotland (Stimson 1988). Fifteen agencies in England and Scotland have been drafted to operate these needle exchange programs. According to the Monitoring Research Group, ${ }^{35}$ program clients (i.e., those individuais using the officially sanctioned exchange program) are described as follows: (1) ages range from 17 to 52, with an average of about 27; (2) having a long-elapsed drug use, with the average time since the first injection experience as eight years; (3) 78 percent are male; and (4) most clients are opiate users, with 57 percent on heroin, 13 percent on methadone, and 17 percent on amphetamines. The Monitoring Research Group has further found that client drop-out rate is high, that women and younger users are less likely to frequent the exchange, and that most clients lack primary medical and social care. This perhaps is characteristic of the IVDUs as being a hidden population group.

\footnotetext{
${ }^{34}$ The Department of Health and Social Security (DHSS) is responsible for health care in England and Wales.

${ }^{35}$ The Monitoring Research Group is located at Goldsmith's College in London, England.
} 
Separate from the officially sanctioned programs which commenced in April 1987, two other unofficial programs have been underway in the cities of Liverpool ${ }^{36}$ and Peterborough. ${ }^{37}$ The Liverpool program was launched by a local drug training and information service in October 1986, while the one in Peterborough was initiated by the District Health Authority in February 1987 and operates out of the local general hospital (Stimson 1988).

During a 16-week period (from December 5, 1986 to March 27, 1987), 318 clients, mostly heroin injectors, had used the Liverpool program, totalling 1,111 visits (Stimson 1988). Approximately 10,000 needles had been dispensed during this same time period, with the same number being returned (Newcombe 1987). In the first ten months of operation, 774 clients made a total of 3,177 visits to the program: Approximately 52,451 needles were dispensed and 44,987 were returned (Carr and Dalton 1988).

Program clients of the Liverpool program have been profiled as follows: (1) about 85 percent of the 774 clients that visited the program during October 1986 and the end of 1987 were male; (2) age range was from 15 to 50 , with the average being 25; and (3) 42 percent were not in a treatment program (Carr and Dalton 1988). There are 1,500 potential clients to reach in Liverpool (Stimson 1988). Carr and Dalton (1988) state that clients of the Liverpool exchange program are

\footnotetext{
${ }^{36}$ Liverpool is a large city in England with a declining economic base, high unemployment, and much drug-related crime. High levels of heroin use are evident (Parker et a1. 1987).

${ }^{37}$ Peterborough is located in a rural part of central England with an expanding economic base. The chief drugs injected are heroin and amphetamines (Stimson 1988).
} 
reluctant to utilize established health and social services for fear of punishment.

\section{Australia}

Australia has the fourth highest per capita incidence of AIDS among the countries of the Western world, reporting 1,079 cases as of November 1988 (Swensen 1988). Most of these reported cases have occurred in New South Wales, ${ }^{38}$ and have largely stemmed from homosexual/bisexual activities (Dolan 1989). ${ }^{39}$

The number of IVDUs in Australia is estimated between 50,000 and 110,000 (The Commonwealth Department of Community Services and Health), ${ }^{40}$ and in New South Wales there are about 30,000 to 40,000

IVDUs (Eaton et al. 1988). ${ }^{41}$ Research conducted by Dolan (1989) identifies six studies that find increasing levels of HIV-1 among

\footnotetext{
${ }^{38} \mathrm{New}$ South Wales is one of the eight states and territories of Australia, with a population of about six million (Eaton et al. 1988).

${ }^{39}$ In the study conducted by Dolan (1989), 88 percent of the reported cases in New South Wales were male homosexuals/bisexuals. Homosexual/bisexual IVDUs accounted for two and a half percent, and less than one percent were attributed to heterosexuals who used illicit drugs. Heterosexual transmission accounted for only a little more than one percent of all reported cases.

${ }^{40}$ There have been different estimates as to the number of IVDUs in Australia, due to definition (e.g., habitual, recreational, or occasional user).

${ }^{41}$ There are discrepancies in the estimated number of IVDUs in New South Wales. For instance, The Drug and Alcohol Authority of New South Wales estimates that there are between 10,000 and 14,000 IVDUs (Sandland et. al. 1986). Eaton et al. (1988) suggest a much larger number of IVDUs $(30,000$ to 40,000$)$. Such differences could be attributed to definition or perhaps to the collection of data. There is also a time frame difference to the studies, which may suggest an increase.
} 
IVDUs. ${ }^{42}$ While there has been a pilot needle exchange program located in Darlinghurst ${ }^{43}$ since 1986, a government approved program did not emerge until September, 1987. In January, 1988, three exchange program outlets $^{44}$ were established, and by the end of the year, over 40 more outlets were granted approval, due to the increase in support for the program (Eaton et al. 1988). By 1989, 56 outlets have been reported open and operating in New South Wales (Dolan 1989); they are able to dispense about 25,000 to 30,000 needles/syringes every month (Eaton et a1. 1988). Aside from the government needle exchange programs operating in New South Wales, there are pharmacy-based programs which distribute an estimated 850,000 sterile needles/syringes annually (Eaton et al. 1988). Despite the seemingly large number of needles dispensed to IVDUs through these government and pharmacy programs, current distribution is still considered inadequate in terms of the estimated number of injectors (Eaton et a1. 1988). There is a serious concern over the low rate of return of used needles/syringes (Eaton et al. 1988).

\footnotetext{
${ }^{42}$ Dolan (1989) makes reference to six studies which indicate that HIV-1 infection is increasing among IVDUs in Australia. Authors of these studies are: Blacker et al. 1986; Wodak and Dolan 1987; Wolk et al. 1988; Dolan accounts two personal communications with G. Vumbaca, and J. Wolk.

${ }^{43}$ Darlinghurst pilot needle exchange program began on November 13 , 1986: It was initiated to provide information and data about the operations and effectiveness of needle exchange programs (Vumbaca et al. 1987). During November 13, 1986 to September 30, 1987, there were 14,082 needles/syringes exchanged and 6,442 returned: The rate of return was approximately 46 percent (Vumbaca et al. 1987).

${ }^{44}$ Australia has approved five types of approved outlets to dispense needles/syringes: (1) already established agencies with existing staff; (2) already established agencies with extra staff as well as existing staff; (3) primary shopfront exchange centers; (4) mobile outreach services; and (5) al ready established agency operating after hours for use. For a more detailed explanation, see Eaton et al. (1988).
} 
Thail and

In Thailand, there have been 4,764 reported AIDS cases since 1984 (Newsletter 1989a). ${ }^{45}$ Moreover, data indicate that Thailand has been experiencing a rise in the number of HIV-1 infected IVDUs. The seroprevalence rate for IVDUs has increased from 15 percent in January, 1988, to 43 percent in the subsequent six months (Newsletter 1989a). The number of IVDUs in Thailand is estimated to be over 100,000, with about half living in Bangkok (Newsletter 1989b). Data indicate that most IVDUs inject heroin and are predominantly males between the age of 20 and 39 (Newsletter 1989b). There is some information that a needle exchange program has recently cormenced; however, additional information is not available at this time.

Canada

A few cities in Canada (e.g., Toronto, Vancouver, and Montreal) have recognized the need to control HIV-1/AIDS among IVDUs. In Toronto, Ontario, ${ }^{46}$ use of 111 icit drugs has been rampant. The Newsletter (1989b) reports that illicit drug use is found among the business and professional community as well as among those on the "fringe of society." Data obtained from police records show that the use of hashish and hashish oil, heroin, and hallucinogens has not increased greatly in the past several years; however, cocaine and crack usage has risen dramatically (Newsletter 1989b). The first meeting between

\footnotetext{
${ }^{45}$ Experts estimate that between 500,000 and 700,000 Thais are infected with AIDS virus, and indicate that Asia soon will lead the world in HIV-1 infections (First for Women 1992).

${ }^{46}$ Ontario is one of Canada's provinces and lies in the southeast on the Great Lakes. Toronto is the capital of Ontario.
} 
infectious disease and intravenous drug use professionals was held in January 1988, and as a result, HIV-1 testing of IVDUs was made a priority (Newsletter 1988). In Canada, three cities have established needle exchange programs: (1) Toronto, (2) Vancouver, ${ }^{47}$ and (3) Montreal ${ }^{48}$ (Newsletter 1990).

Toronto has proposed a 12-month pilot program incorporating many services which seek to facilitate changes in sexual behavior and injection practices of IVDUs. Toronto's pilot program falls under the guidance of the Department of Public Health, and will be based at two sites. One site will be an office within a community health center and the other will be a storefront setting (Youngman 1990).

Vancouver, British Columbia, adopted a trial needle exchange program in early 1989. The program was initially expected to attract approximately 200 clients, but by the end of April 1989, about 785 IVDUs visited the facility to exchange needles each day (Youngman 1990). Youngman (1990) provides other data which indicate: (1) most clients are Caucasian (60 percent to 65 percent); and (2) clients' ages range from 20 to 29 (49 percent), 30 to 39 ( 37 percent), to 40 and over (nine percent).

In Montreal, a demonstration project called "CACTUS-MONTREAL" was organized as a response to the recommendations submitted by various agencies that deal with IVDUs in order to intervene in the struggle against AIDS (Youngman 1990). Funds for the CACTUS-MONTREAL

\footnotetext{
${ }^{47}$ Vancouver is a city in British Columbia, a province of Canada and is located in the western part of the country on the Pacific coast.

${ }^{48}$ Montreal is a seaport located in the province of Quebec which lies in eastern Canada.
} 
intervention project are provided by both the Quebec Ministry of Health and the Federal Department of Health and Welfare, in an equal cost sharing arrangement (Youngman 1990). The project, which commenced on July 9, 1989, set up a fixed site setting in downtown Montreal for IVDUs. The program also involved dispensing needles and other services among the local prison population (Youngman 1990).

\section{NATIONAL NEEDLE EXCHANGE PROGRAMS}

Like Western Europe, the United States' experience of the AIDS epidemic has been, and continues to be, concerned with specific, highrisk behaviors and practices associated with sexual intimacy and/or intravenous drug use. In the United States, about one quarter of all AIDS cases diagnosed among adults and adolescents can be traced to intravenous drug use (Schuster 1988): ${ }^{49}$ Many of these cases are evident in the larger, urban centers throughout the country. Table II (on the following page) reveals the number of AIDS cases that are traced to intravenous drug use, as well as the geographic differences that exist nationaliy.

Researchers are cognizant of the variability in rates of HIV-1 seroprevalence manifested in different geographic locations. Des Jarlais and Friedman (1987) point out: "Perhaps the best single piece

\footnotetext{
${ }^{49}$ This approximation is perhaps underestimating the magnitude of the relation between AIDS and IVDUs due to the very narrow definition of the former which has been given for observational purposes (Turner et al. 1989). Various studies support this supposition of underestimating this approximation; for example, Hardy et al. (1987) report that an additional 13 percent of deaths among IVDUs were HIV-1 related yet did not meet the strict definition of AIDS set forth by the Centers for Disease Control (CDC).
} 
of information for predicting whether an individual IV drug user is likely to have been exposed to HIV is geographic location."

\section{TABLE II}

PERCENTAGE OF ALL REPORTED AIDS CASES

AMONG INTRAVENOUS DRUG USERS (IVDUS)

IN THE UNITED STATES

\begin{tabular}{|c|c|c|}
\hline State/District & Total AIDS Casesa & $\begin{array}{l}\text { Percentage of } \\
\text { AIDS Cases } \\
\text { Among IVDUs }\end{array}$ \\
\hline
\end{tabular}

\begin{tabular}{lrr}
\hline New York & 12,103 & 32.7 \\
California & 9,981 & 2.5 \\
Florida & 3,169 & 15.1 \\
Texas & 2,919 & 3.0 \\
New Jersey & 2,555 & 47.7 \\
Illinois & 1,176 & 6.0 \\
Pennsylvania & 1,084 & 9.9 \\
Georgia & 957 & 7.6 \\
Massachusetts & 915 & 13.7 \\
Washington, D.C. & 885 & 6.8 \\
United States & 44,129 & 16.6 \\
\hline
\end{tabular}

a The total includes cases reported through October 31, 1987.

- IVDUs include only heterosexual men and women with a history of intravenous drug use.

Source: Allen, J.R. and J.W. Curran. "Prevention of AIDS and HIV Infection: Needs and Priorities for Epidemiologic Research." American Journal of Public Health 78 (1988): $381-384$. 
There are several propositions, suggested by Turner et al. (1989), which contribute to the geographic variability of HIV-1 infection rates in the United States:

(1) Most IVDUs do not appear to travel extensively. In addition to limited economic resources, the need for a constant supply of drugs probably reduces their mobility, although they appear to travel some, especially to locations where friends can help them obtain drugs.

(2) A self-sustaining epidemic occurs when one infected individual produces new infection in more than one other person; the potential for the rapid transmission of HIV-1/AIDS is evident within a particular geographic locale.

(3) The frequency of ethnic differences in seroprevalence rates may indicate particular behaviors among IVDUs; therefore, questions of ethnicity rather than drug use and needle sharing may accurately measure the behaviors across minority groups who inject illicit drugs. ${ }^{50}$

Des Jarlais and Friedman (1987) provide data on HIV-1 seroprevalence among IVDUs in different geographic locations of the United States. These statistics are provided in Table III (on the following page).

New York appears to have the highest seroprevalence rate, as well as the largest number of reported AIDS cases, as shown in Table II and Table III. Des Jarlais and Friedman (1987) suggest that such variations in seroprevalence rates among geographic areas have evolved in response to the time in which human immunodeficiency type one (HIV-1) was initially introduced into the intravenous drug using population of that particular community.

${ }^{50}$ Several studies (e.g., Schoenbaum et a1. 1986) suggest that racial and ethnic variations may be due to the recruitment of subjects from different areas within a particular city, which may indicate multiple epidemics within a single city (Turner et al. 1989). 
TABLE III

HIV SEROPREVALENCE AMONG INTRAVENOUS DRUG USERS (IVDUS) IN THE UNITED STATES

\begin{tabular}{|c|c|c|}
\hline Location & of Sera Collection & Reference \\
\hline \multicolumn{2}{|c|}{$\begin{array}{l}\text { High Seroprevalence--50\% or higher } \\
\text { Manhattan, N.Y.C. } 1984\end{array}$} & $\begin{array}{l}\text { Cohen, Marmor, } \\
\text { Des Jarlais et al. } 1985\end{array}$ \\
\hline \multirow{3}{*}{ Northern New Jersey } & 1985 & $\begin{array}{l}\text { Des Jarlais, Friedman, } \\
\text { Marmor et ai. } 1986\end{array}$ \\
\hline & 1984 & $\begin{array}{l}\text { Weiss, Ginzburg, } \\
\text { Goedert et ai. } 1985\end{array}$ \\
\hline & $1985 \quad$ G & $\begin{array}{l}\text { Weiss, Ginzburg, } \\
\text { Goedert et al. } 1985\end{array}$ \\
\hline \multicolumn{2}{|c|}{$\begin{array}{l}\text { Moderate Seroprevalence -- } 25 \% \text { to } 45 \% \\
\text { Boston }\end{array}$} & Groopman 1986 \\
\hline $\begin{array}{l}\text { Bronx, New York } \\
\text { Low Seroprevalence }\end{array}$ & $\begin{array}{l}1985 \\
-5 \% \text { to } 20 \%\end{array}$ & $\begin{array}{l}\text { Schoenbaum, Selwyn, } \\
\text { Klein et a1. } 1986\end{array}$ \\
\hline Chicago & 1984 & $\begin{array}{l}\text { Spira, Des Jarlais, } \\
\text { Bokos, et al. } 1985\end{array}$ \\
\hline \multirow[t]{2}{*}{ San Francisco } & 1984 & $\begin{array}{l}\text { Spira, Des Jarlais, } \\
\text { Bokos et al. } 1985\end{array}$ \\
\hline & 1984 & $\begin{array}{l}\text { Chaisson, Onishi, } \\
\text { Moss et al. } 1986\end{array}$ \\
\hline Washington, D.C. & 1985 & Ginzburg 1986 \\
\hline \multicolumn{3}{|c|}{$\begin{array}{l}\text { Very Low Seroprevalence -- } \\
\text { less than } 5 \% \text {, but greater than } 0 \%\end{array}$} \\
\hline New Orleans & 1985 & Ginzburg 1986 \\
\hline Los Angeles & 1986 & Mascola 1986 \\
\hline Kansas City, MO & 1986 & Northrup 1986 \\
\hline
\end{tabular}

Source: Des Jarlais and Friedman (1987). 
Studies of earlier collected samples of sera from IVDUs show that HIV-1 entered this high-risk group in New York City during the middleto-late 1970 's, with the first known seropositive (i.e., showing significant levels of antibodies) serum sample collected in 1978 (Des Jarlais and Friedman 1987; Novick et al. 1985). Within the next two years (i.e., 1980), seroprevalence increased rapidly, to more than 40 percent in southern Manhattan (Novick et al. 1985). In essence, once HIV-1 has been introduced into the intravenous drug-using population, the potential exists for seroprevalence rates to increase dramatically and rapidly. Even low initial rates of seroprevalence are capable of rapid proliferation; thus, innovative intervention strategies bear consideration. In recognition of the capabilities of the disease, some locales have adopted such programs, despite drug use and possession of related paraphernalia laws that exist in the United States. Some locales have officially sanctioned needle exchange programs and others have not; some have the sponsorship of local authorities and health departments and others do not; some are experimental/pilot schemes and others are the "real" thing; and the operations of some have ended or never commenced, while others are still surviving. The United States' experience with needle exchange programs is thus not a consequence of a national policy nor a part of any federal program. The programs that have evolved are largely local, community, or grass-roots efforts responding to the manifestations of HIV-1 in the illicit drug-injecting population. At the time of this study, several locales have needle 
exchange programs in operation: Boulder, Colorado; ${ }^{51}$ New Haven, Connecticut; Honolulu; San Francisco; Portland, Oregon; Seattle, Washington; and Tacoma, Washington. Before reviewing each of these aforementioned, ongoing programs, two (in particular New York and Boston) have met serious opposition and are discussed first.

\section{New York City}

A good beginning of this overview. of needle exchange programs in the United States is a review of the New York City experience since there is a very large illicit drug-injecting population. New-York City has about 200,000 IVDUs, ${ }^{52}$ with over 50 percent al ready infected with the AIDS virus (Mahoney et a1. 1988). By September 30, 1989, there were 22,108 reported AIDS cases in New York City (New York City Department of Health 1989). Statistical projections suggest that 43,000 people will have developed AIDS in New York City by 1992 (New York City Department of Health 1989).

Cognizant of the urgency to deal with these alarmingly high numbers, the New York City Department of Health had implemented a pilot needle exchange program, called "the bridge-to-treatment", to assess the feasibility of such an intervention. In November 1988, the New York pilot needle exchange program was set up as a small, carefully monitored and controlled research study; that is, 200 IVDUs were to receive

\footnotetext{
${ }^{51}$ Little information in reference to the Boulder program was available at this time.

${ }^{52}$ As stated earlier, according to Joseph and Des Jarlais (1989), IVDUs are increasingly injecting cocaine and crack -- replacing heroin. IVDUs who inject cocaine and crack do so more frequently than those who shoot heroin; therefore, a greater risk of spreading HIV-1 exists (Joseph and Des Jarlais 1989).
} 
sterile needles/syringes along with other services such as drug .

counseling and education (Mahoney et al. 1988).

Several results and conclusions have been provided by the New York City Department of Health (1989) in an executive summary of the first ten months of the program's operation, describing the participation of the 250 clients $^{53}$ in the program. The findings follow: (1) two-thirds of the 250 clients were reported as male, and one-third female; (2) the mean age of clients was 33.4 ; (3) 27 percent were black, 53 percent were Hispanic, 18 percent were white, and two percent were unknown; (4) 54 percent had a permanent place of residence, 14 percent had temporary shelter, and 32 percent had no place of residence; (5) approximately 90 percent reported having used both heroin and cocaine; (6) 81 percent reported having shared injection equipment; (7) 63 percent reported a history of drug treatment; (8) 51 percent of the 250 clients tested positive for HIV-1 infection; and (9) 17 percent (43 clients) tested positive for syphilis.

In addition to the quantitative data provided in the executive summary (prepared by the New York City Department of Public Health, 1989), clients were asked several questions in a conversation about their perception of the pilot program. These questions and responses are reproduced below. ${ }^{54}$

\footnotetext{
${ }^{53}$ The New York City Department of Public Health states that 294 persons were recruited into the pilot needle exchange program through December 1, 1989; however, information has only been available for 250 clients. The data were not complete for the remaining 44 clients of the program; thus, statistics were computed on 250 clients.

${ }^{54}$ Questions and responses are taken directly from the executive summary of the New York City Department of Health.
} 
(1) "Why did clients enroll in the Needle Exchange Pilot Program?" Most clients responded that they wanted help with tasks they could not accomplish by themselves: Identification, entitlements, information about treatment access. Few mentioned the "free needle" as the primary reason for coming.

(2) "Why did clients return?". Most clients mentioned that they were helped by the staff on their first contact and were treated with respect. Many mentioned specific commitments they made to program staff that they wanted to. keep.

(3) "Did clients come because they wanted treatment program admission?" Many clients expressed ambivalence (sic) about drug treatment and.frustration with the difficulties and delays they had previously experienced. They accepted treatment when they learned from staff about realistic alternatives that turned out to be actually available.

(4) "What were the clients' attitudes toward HIV-1 testing?" Most clients accepted or actively requested testing. A few wanted to discuss the issue in detail. No one decided not to enroll in the program because of testing.

(5) "What did clients think of the concept of needle exchange?" Most thought the concept was good but it needed to be as close as possible to their neighborhoods. Clients stated they did not know what to expect when they first came to the program.

Overall, clients found the staff to be understanding and trustworthy, and the program to work quickly, without a lot of "red tape" (New York City Department of Health 1989). In light of the qualitative data, the pilot needle exchange program appeared to be favorable in the eyes of the clients enrolled in the program.

Much controversy, however, surrounded the New York City needle exchange program, despite its acceptance by the enrolled program clients. Adverse political reaction surfaced within the community, especially from the Police Commissioner, Benjamin Ward, and State Health Commissioner, David Axelrod, who after four years reversed his position due to political pressure (Sultan 1988; The New York Times 1990). Opponents often claim that needle exchange programs encourage illicit 
drug use; hence, evidence of an increase in the rate of injection among current IVDUs or a greater number of injectors is thought to result (Joseph and Des Jarlais 1989). To date, there is no evidence found in studies to support such claims (Joseph and Des Jarlais 1989; Sultan 1988). In fact, evidence from The Netherlands revealed that the prevalence of injecting did not increase, and that the average age of IVDUs in Amsterdam has risen from 26.4 (in 1981) to 30.1 (in 1987), while the proportion below age 22 has decreased from 14.4 percent to 4.8 percent during the same time-period (Stimson 1989).

Black and Hispanic leaders ${ }^{55}$ in New York City have also expressed their views against needle exchange programs. Minority leaders, including a New York City councilman, and Harlem Congressman, Charles Rangel, have labeled needle exchange programs "genocidal," since a disproportionate number of IVDUs are non-white (i.e., largely from the black and Hispanic population); therefore, minority leaders contend that such an intervention is considered to be racist since illicit drug use is perpetuated among minority groups rather than treated (Sultan 1988). Such widespread controversy led Mayor Dinkins to end the pilot program in the early part of 1990 (The New York Times 1990); however, by the end of 1991, the Dinkins administration started to re-examine New York's health policy in light of the AIDS epidemic.

In late October 1991, a group of New York City commissioners offered recommendations for having community-run needle exchange programs to

\footnotetext{
${ }^{55}$ There are other minority leaders such as Casey Horan of New York's ADAPT (a minority-based outreach prevention program) who favor needle exchange programs (NAN Multi-cultural NOTES on AIDS Education and Service 1989).
} 
Mayor Dinkins. Like other public officials in other locales, Dinkins has recently stated that such programs will be allowed to proceed, despite the state law which makes needle possession a crime (The New York Times 1991b). This course of action overlooks the legal prohibitions of illicit drug use and possession of related paraphernalia for the greater good of society.-- that is, the concern over the spread of HIV-1/AIDS.

\section{Boston, Massachusetts}

Several attempts have been made during the late 1980 s to establish a needle exchange program for intravenous drug users (IVDUs) in Boston, Massachusetts. In 1988, the Department of Health and Hospitals announced a proposal to establish a needle exchange program; however, the Health Care Committee voted against it in the Massachusetts State Legislature, despite the fact it was favored by city council members (News letter 1988).

A private individual named John Parker, ${ }^{56}$ however, has been unofficially dispensing needles/syringes to intravenous drug users (IVDUs) in Boston. Parker buys needles/syringes in New Hampshire, where such equipment is legally sold with a doctor's prescription, and dispenses them in several other states besides Massachusetts, including Connecticut, New Jersey, Pennsylvania, Rhode Island, and New York (The New York Times 1989; Boston Globe various articles). Since 1987, approximately 50,000 needles have been distributed by Parker (The New

\footnotetext{
${ }^{56}$ John C. Parker, age 34 , is a Yale graduate student of public health and founder of the organization "AIDS Brigade." Parker is from south Boston and is known as the "Johnny Appleseed of needles" (Boston Globe various articles).
} 
York Times 1989). Parker has been arrested for the illegal distribution of needles/syringes, but has recently been acquitted (Boston Globe various articles).

To reiterate, to date, needle exchange programs have produced much controversy and opposition. Ironically, those cities which are known to contain the larger drug-injecting population have avoided implementing a permanent needle exchange program mainly due to the controversial issues addressed earlier, and other obstacles specifically manifested in a particular community. Officials of both New York and Boston are cognizant of the growing number of IVDUs, with many of them already infected with HIV-1/AIDS; yet, in these large communities, obstacles continue to exist in implementing an intervention that holds a potential to alleviate the spread of HIV-1/AIDS among this high-risk population.

Other communities, such as those in Chicago, Los Angeles, San Francisco, and Newark, have also experienced opposition to implementing needle exchange programs. Schwartz (1987) points out that the former mayor of San Francisco, ${ }^{57}$ Diane Feinstein, has opposed the needle exchange program that has been proposed by the health commissioner (Schwartz 1987). In fact, in 1988, a group of activists in San Francisco began exchanging needles as an act of civil disobedience to mobilize public support for implementing a needle. exchange program. The group has been unsuccessful in mobilizing public support, but continues to distribute sterile injection equipment under a quasi-legal project referred to as "Prevention Point."

${ }^{57}$ There is, however, a program which is operating clandestinely; it is, of course, difficult to obtain data on this "underground" exchange. 
In New Jersey, Jack Rutledge (State Deputy Health Commissioner) proposed a plan for distributing needles, but other officials from the health department expressed fear of attracting IVDUs from other states (e.g., Pennsylvania and New York) which would add to the existing drug problem in the state (Schwartz 1987). Others contend that needle exchange programs could produce economic disincentives, such as the emergence: of a "black market" in those states where the sale of needles/syringes is illegal and where the state borders another state where a needle exchange program operates. There is no concrete evidence, to date, which supports these claims that needle exchange programs produce such negative externalities or economic disincentives.

Ostensibly, the potential for these side effects of needle exchange programs does exist. Society, however, must remain cognizant of the main objective of this particular intervention: To alleviate the spread of HIV-1/AIDS among IVDUS as well as their sexual partners and offspring. Conversely, other communities have established legitimate and workable needle exchange programs even though the numbers of IVDUs are not of such magnitude.

As mentioned earlier in this study, the number of IVDUs is of little essence, as once HIV-1 is introduced into this particular group, transmission proliferates. The needle exchange programs currently operational in the United States are discussed below.

\section{Boulder, Colorado}

The Boulder County needle exchange program was approved by the Board of Health to be coordinated by the Substance Abuse Program and the AIDS Prevention Program in conjunction with the Mental Health Center of 
Boulder, and commenced in the latter part of 1990 . There are only 300 or so intravenous drug users (IVDUs) in Boulder County, but officials deemed it necessary to control the spread of AIDS (Boulder County Health Department 1989). There are two eligibility requirements to use the Boulder needle exchange program: (1) program clients must be at least 14 years $01 \mathrm{~d}$; and (2) program clients must have at least one used needle for exchange (Boulder County Health Department 1989). On the first visit, program clients may receive up to five sterile needles for one or more dirty needles. If a program client brings more than five dirty needles to the exchange, then a one-to-one swap is provided (Boulder County Health Department 1989). After the first visit, the swap becomes a one-to-one exchange between dirty and clean injection equipment (Boulder County Health Department 1989). In addition to swapping injection equipment, program clients are taught how to clean dirty injection equipment with bleach and water, counseled on safe sex, and offered HIV-1 testing. (Boulder County Health Department 1989).

\section{New Haven, Connecticut}

New Haven is considered to be the heart of the AIDS epidemic in Connecticut. Intravenous drug users account for more than 70 percent of the diagnosed AIDS cases in New Haven (New Haven Register 1990b). Correspondingly, the Connecticut General Assembly passed a bill in the spring of 1990 to establish a pilot needle exchange program in New Haven. The New Haven needle exchange program operates from a mobile van unit that travels to areas of the city where IVDUs congregate. There are no eligibility requirements, and the service is free and anonymous. In addition, AIDS education, condoms, bleach, drug treatment and 
counseling are provided for program clients. Reports indicate that HIV1 infection rates in New Haven have declined by a third in just eight months of the program's operation (Los Angeles Times 1991).

New Haven has been conducting several studies in conjunction with the program's operation; these have provided conclusive evidence about the spread of HIV-1/AIDS via unsterile injection equipment. For example, scientists tracked number-coded syringes that were legally distributed to addicts in a special demonstration program in New Haven. These needles were returned to field workers and then given to researchers to conduct tests for HIV-1 contamination using sophisticated DNA technology (Los Angeles Times 1991). The researchers concluded that the needle exchange program reduced the time that unsterile injection equipment stayed in circulation; that is, preliminary findings indicated that the average went from two and a half weeks to six days in circulation (Los Angeles Times 1991). The percentage of needles found to be contaminated also dropped from 67.5 percent to 40 percent (Los Angeles Times 1991). Beyond that, researchers used mathematical models to project a 33 percent reduction in new AIDS cases, based on these numbers (Los Angeles Times 1991). New Haven's mayor, John C. Daniels, states:

the major significance is the fact we have evidence [that] we have really reduced tremendously the increase in the spread of AIDS in the city of New Haven through the use of dirty needles . . . it was necessary to overcome contentions that distributing sterile needles promotes the use of drugs. (Los Angeles Times 1991). 
Honolulu, Hawaii

Hawai $i$ has the eleventh highest rate of reported AIDS cases in the United States, with an estimated 3,000 to 15,000 intravenous drug users (House of Representatives, State of Hawaii 1990). The majority of new AIDS cases in Hawaii during the latter half of 1989 have occurred among intravenous drug users, their sexual partners, and offspring (House of Representatives 1990). Hawaij's HIV-1 rate of infection among IVDUs is currently more than 10 percerit; nearly all the HIV-1 pediatric AIDS cases have at least one parent who is an intravenous drug user (House of Representatives 1990).

In April 1990, the Hawai State Legislature passed a bill to allow for a two-year pilot needle exchange program to distribute sterile injection equipment to intravenous drug users (Governor's Committee on AIDS 1990). This particular needle exchange program is the first stateendorsed needle exchange program in the United States initiated by a local non-profit AIDS foundation known as "The Life Foundation." The needle exchange program, called "The Rubber Room, "159 operates solely on private funding.

Hawaij's needle exchange program opened on July 5, 1990, at a downtown site located on the second floor at 61 North Hotel Street. The fixed site operates five days per week, Monday through Friday, from two o'clock in the afternoon until six o'clock in the evening. Counseling and testing are also provided for program clients.

\footnotetext{
${ }^{58}$ The Life Foundation is Hawaij's first and largest AIDS support organization.

${ }^{59}$ Aaron Peak is an AIDS educator and activist who established the "Rubber Room."
} 
The exchange process involves the program client counting out the number of needles to be swapped, with a maximum of five needles per individual. The program client must place dirty needles in a biohazard sharp instrument container.. The number of program needles returned for a given day is recorded on a daily $\log$ sheet. From July to November 1990, 921 visits were made to the Rubber Room to exchange needles, and 2,018 needles were swapped for clean ones.

\section{Portland, Oregon}

Oregon does not prohibit the sale of needles/syringes, and they are available in pharmacies without a doctor's prescription. ${ }^{60}$ As in European pharmacies, IVDUs are not welcome customers, facing harassment and refusal by pharmacists (Maynard 1988). The needle exchange program in Portland commenced on November 1, 1989, after a few delays (i.e., particularly to obtain an insurance carrier), and is based in an al ready-established agency called "Outside-In. "61 The Outside-In needle exchange program has a strong research component, which is supported by a grant from The American Foundation for AIDS Research (AmFar). Outside-In thus conducts ongoing research on program clients. Besides research participation, program clients must be at least 18 years old and have visible signs of recent drug use (i.e., track marks). On the

${ }^{60}$ The Portland State University Magazine (1988) reports the price at forty-five cents apiece, or in bulk quantities as little as fourteen cents.

${ }^{61}$ Outside-In is a 22-year-old clinical and social service agency located in downtown Portland. It provides counseling and emergency services for the urban area's low-income folk and street youth. The staff provide education and information about the transmission of AIDS and dispense condoms and bleach as well as needles (Portland State University Magazine 1988). 
first visit, IVDUs are not expected to bring a dirty needle for the exchange; however, subsequent visits require a one-to-one swap (Newsletter 1991)

State and county health statistics indicate that Portland has between 7,000 and 10,000 IVDUs who inject heroin, cocaine, and/or crack, with an HIV-1 infection rate of approximately five percent (Stowell 1988). According to Maynard (1988), past data reveal that the HIV-1 infection rate in Portland has doubled between 1986 and 1987; continuing at this rate, 100 percent of IVDUs could be infected by the latter part of 1993 (Stowell 1988). Oliver (1989b), the Director of Outside-In, reports some statistics gathered from November 1989 to January 1990, which refer to the Outside-In program. These statistics are provided in Table IV:

TABLE IV

OUTSIDE-IN NEEDLE EXCHANGE PROGRAM REPORT NOVEMBER 1989 TO JANUARY 1990

\begin{tabular}{lrrrr}
\hline & $\begin{array}{c}\text { Nov } \\
N\end{array}$ & $\begin{array}{c}\text { Dec } \\
N\end{array}$ & $\begin{array}{l}\text { Jan } \\
N\end{array}$ & $\begin{array}{c}\text { Total } \\
N\end{array}$ \\
\hline \# of clients & $46(18)$ & $72(28)$ & $138(54)$ & $256(100)$ \\
$\begin{array}{l}\text { \# participants } \\
\text { in research }\end{array}$ & $30(13)$ & $66(29)$ & $129(57)$ & $225(100)$ \\
\# return visits & $17(7)$ & $60(25)$ & $166(70)$ & $236(100)$ \\
\# syringes dispensed & $195(9)$ & $512(23)$ & $1499(68)$ & $2206(100)$ \\
\# syringes returned & $73(5)$ & $311(22)$ & $1042(73)$ & $1426(100)$
\end{tabular}

Source: Data taken from 01iver, K. (1989b) Newsletter p.19.

Note: Totals have been changed to reflect the number per month. 
Table IV indicates that over a three month time span, the number of clients have increased from 46 to. a total of 256; the total number of participants in the research grew from 30 to 225; and the number of return visits by clients increased from 17 to 236 (01iver 1989b). Although these secondary data are not entirely clear, the numbers indicate an increase in the participation and activities of the OutsideIn needle exchange program, thus implying that the program is working favorably for IVDUs in increasing the availability and accessibility of injection equipment. In other words, because availability and accessibility are two main factors as to whether IVDUs share needles, easing these factors may indicate the program to be a success in alleviating the spread of HIV-1/AIDS.

\section{Seattle, Washington}

Seattle has established a "street corner" needle exchange program in an area where concentrated drug activity occurs. The exchange program was established in March 1989, by a local branch of "ACT-UP!"162 and in June 1989, was adopted by the Seattle-King County Department of Public Health's AIDS Prevention Project (Seattle-King County Department of Health 1989). Currently, the street-based exchange program is open six days a week for about two hours per day on a sidewalk in downtown Seattle. Staffed by one health department employee and two volunteers,

\footnotetext{
${ }^{62}$ The acronym "ACT-UP!" stands for AIDS Coalition to Unleash Power and is a grass-roots AIDS activist organization.
} 
approximately 4,000 syringes per month are exchanged, with a 70 percent rate of return of those syringes dispensed by program staff. ${ }^{63}$

Seattle-King County Department of Health (1989) reports some minimal data collected about the exchanges: ${ }^{64}$ (1) many clients are considered "regulars or repeat;" (2) more than half the exchanges are made by Caucasian clients, approximately one third of the exchanges are made by black clients, and the rest of the exchanges are made by clients who are either Latino, Native American, or Asian; and (3) approximately 80 percent of the exchanges are made by male client.s.

\section{Tacoma, Washington}

Approximately 35 miles south of Seattle, another needle exchange program has been operating since August 9, 1988, making it the oldest in the United States. The Tacoma-Pierce County Needle Exchange Program, which this study examines in detail, was initially established by a private individual, David Purchase, known as a real "mover and shaker" in needle exchange history. 65 Purchase started exchanging dirty needles for clean ones on August 9, 1988: Four months later, $\$ 3,500$ of

\footnotetext{
${ }^{63}$ Syringes dispensed by Seattle-King County Health Department are specifically marked (Seattle-King County Department of Health 1989).

${ }^{64}$ Data refer to exchanges and not individuals. Data are difficult to collect about program clients of a needle exchange. In addition, researchers who collect data from program clients are often reluctant to share information about a particular needle exchange program for various reasons.

${ }^{65}$ Much of the information provided in these next several paragraphs regarding Tacoma's experience with establishing a needle exchange program is derived from a paper by Purchase et al. 1989, "Historical Account of the Tacoma Syringe Exchange" presented at the Fifth International AIDS Conference (June 4-9, 1989) in Montreal, Quebec, Canada. Various articles of The Morning News Tribune have been used as supplemental references.
} 
his personal funds and $\$ 1,200$ of donated funds had been spent on dispensing over 10,304 needles to intravenous drug users (The Morning News Tribune 1988b).

The needle exchange program in Tacoma is truly street-based, which started on a downtown street with a "home-made sign and a borrowed table" (The Morning News Tribune 1988a). Although some changes have occurred, the program remains "street-based." Currently, there are two mobile van units that operate on streets where IVDUs congregate, such as downtown Tacoma ${ }^{66}$ and near The Hospitality Kitchen and The Food Connection at St. Leo's Parish parking lot. The Tacoma-Pierce County Health Department's pharmacy also exchanges injection equipment for IVDUs (The Morning News Tribune 1989a). In addition to exchanging needles, the mobile van units distribute condoms, bleach, AIDS information, food, and clothing (when available) (The Morning News Tribune 1989b). Referrals to drug treatment and testing for infectious diseases are also offered to program clients.

The Tacoma-Pierce County Health Department began collecting data during the early stages of Purchase's needle exchange program, and reported these preliminary statistics on injecting behaviors of program clients to determine whether the intervention had any effect on needle hygiene and frequency of injection: ${ }^{67}$ Figures 1,2 , and 3 , on the

${ }^{66}$ Pacific Avenue, downtown Tacoma, is known for attracting those individuals considered to be on the fringe of society, particularly drug dealers/users and prostitutes. A specific street name is not given, as IVDUs tend to move periodically.

${ }^{67} \mathrm{~A}$ random sample survey was conducted on eligible clients of the needle exchange program (every third person who brought a needle to exchange) and interviewed by health officials about their injection practices before and after using the exchange. Participation rate of 
following pages, indicate the findings of this preliminary study conducted by the Tacoma-Pierce County Health Department (which have been pubiished in the Newsletter by the International Working Group on AIDS and Intravenous Drug Use).

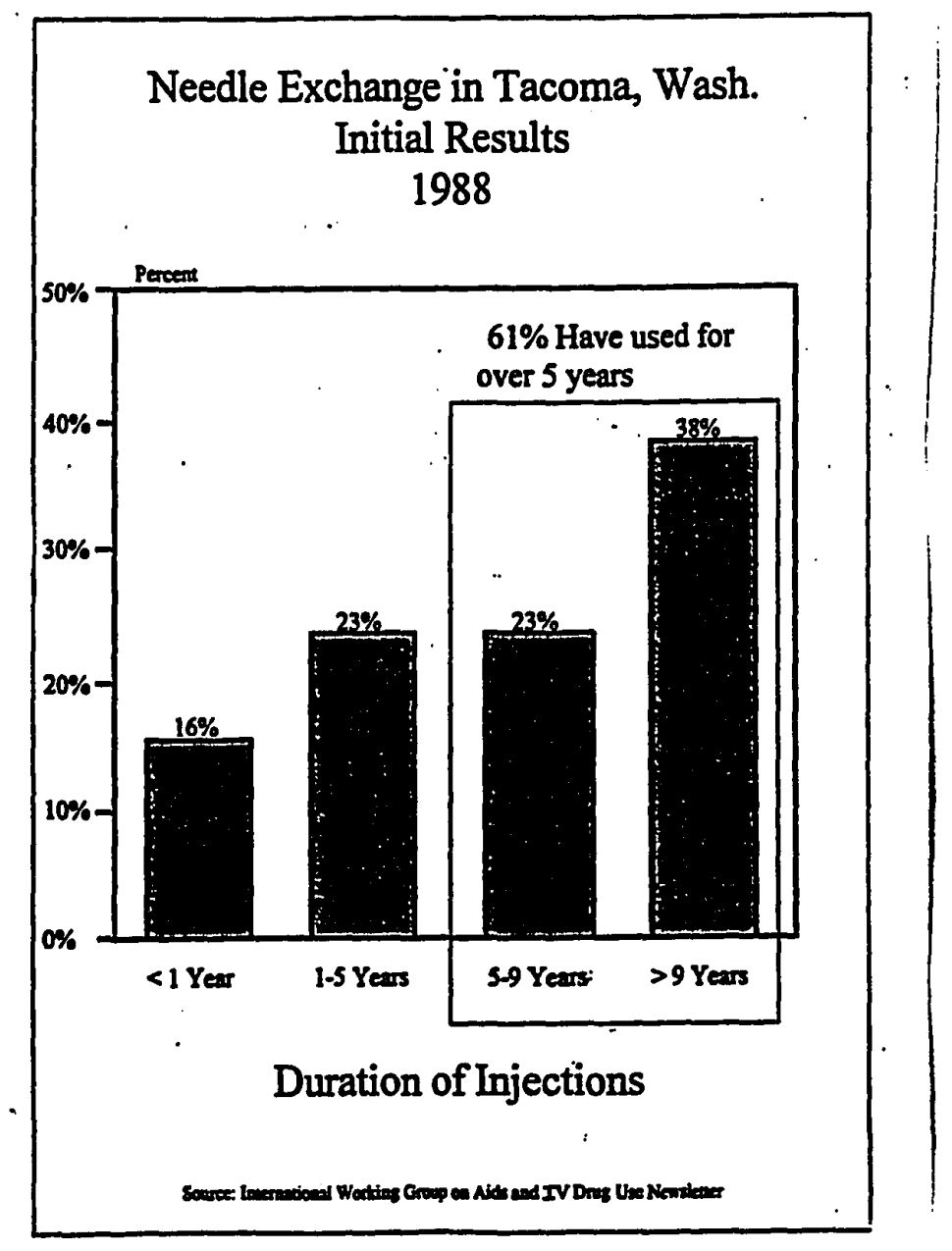

Fiqure 1. Duration of injection of needle exchange clients, Tacoma, Washington, by number of years (initial results, 1988).

the survey was 88 percent; that is, 75 clients were approached and 66 agreed to respond to the interviewer's questions (Hagan et a1. 1988). 


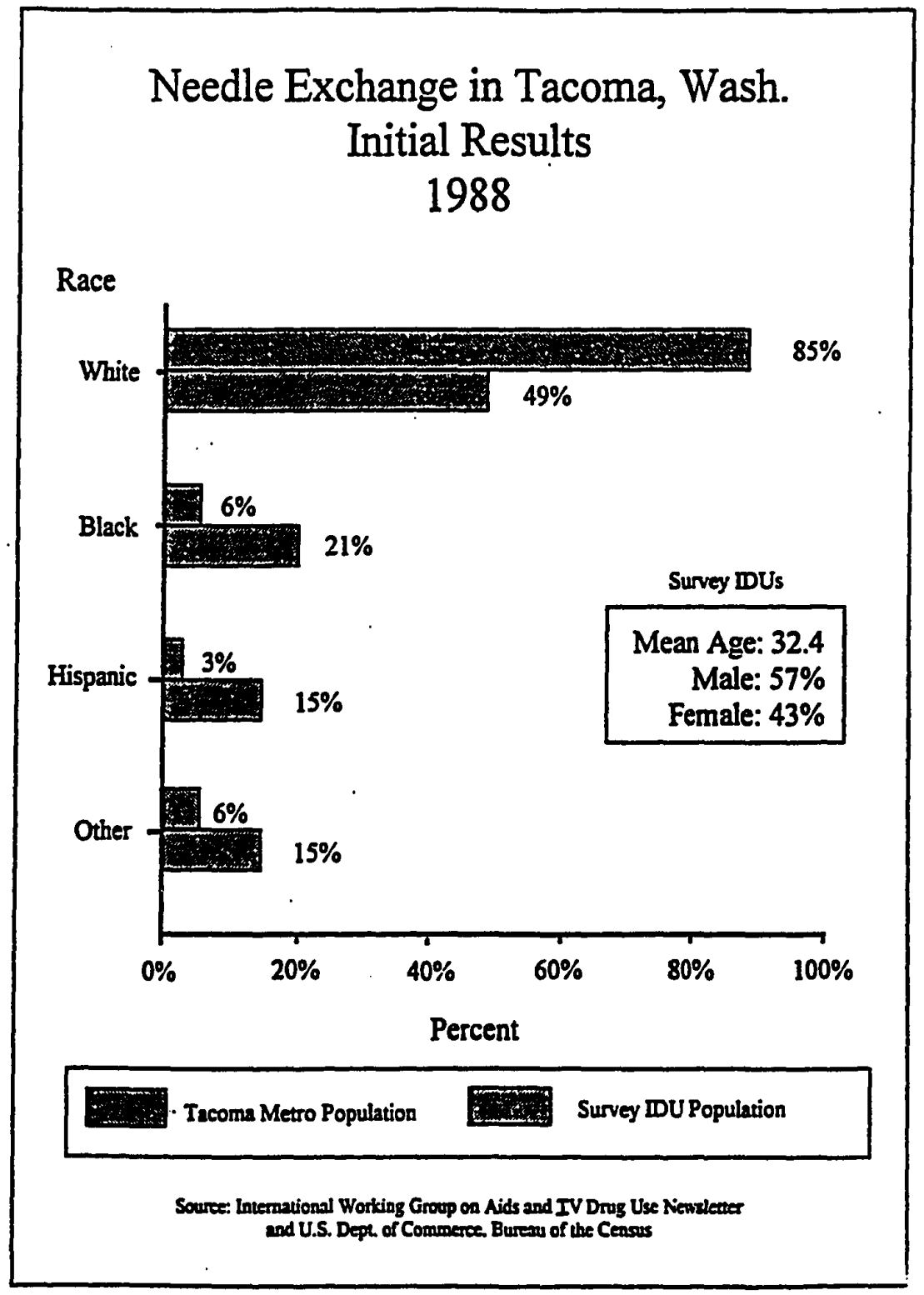

Figure 2. Needle exchange clients, Tacoma, Washington, by race and region (Tacoma metro population and the community. of intravenous drug use population under study), with general information on mean age and percent male/female (initial results, 1988). 


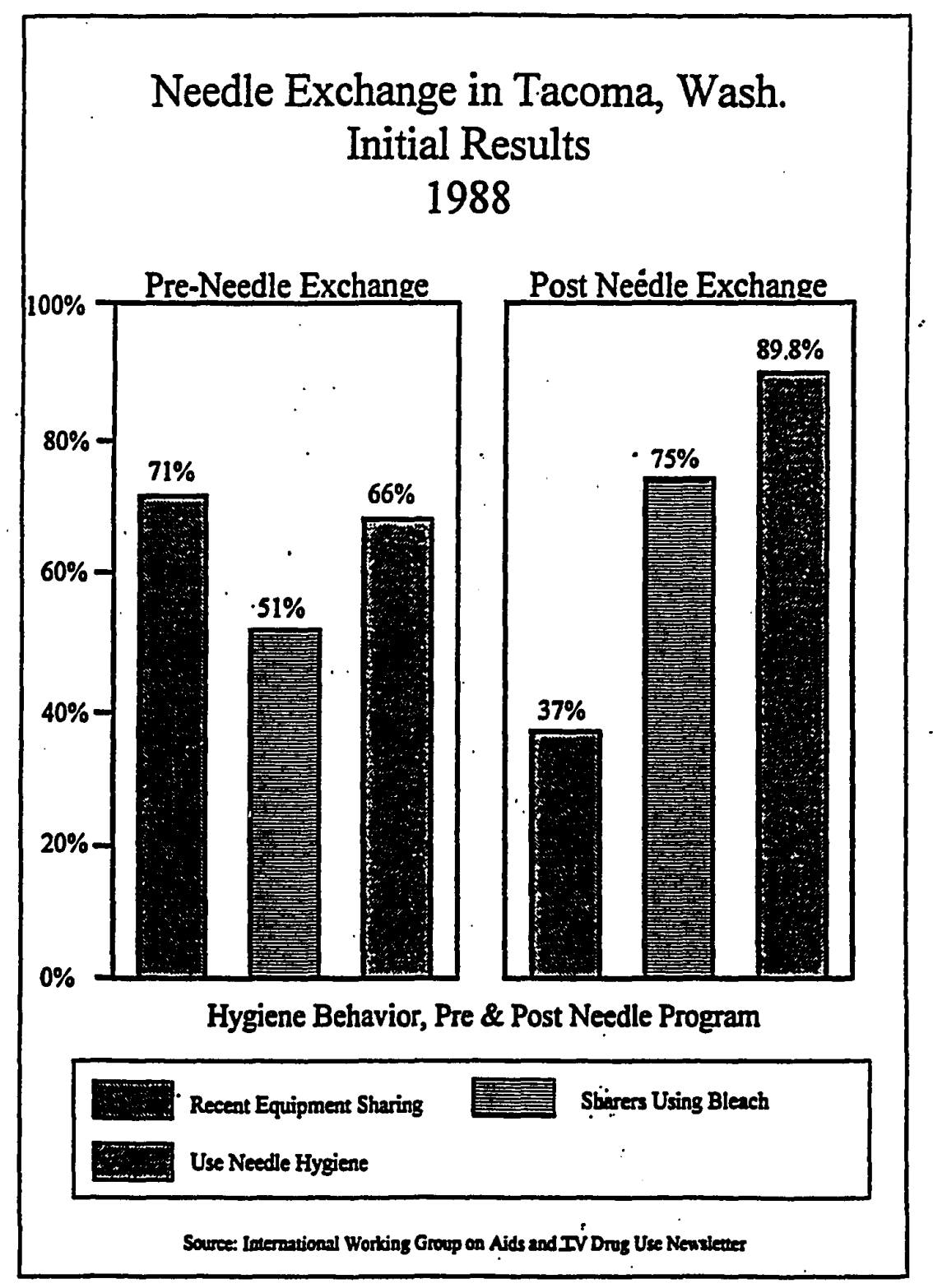

Fiqure 3. Hygiene behavior of needle exchange clients, Tacoma, Washington, pre- and post-needle exchange behavior by percent -sharing equipment, using bleach, and needle hygiene (initial results, 1988). 
Figure 1 reveals that 61 percent of the 66 clients had been injecting over five years, and that 16 percent of the $66 \mathrm{clients}$ surveyed had begun injecting within the past year. Figure 2 reveals that 57 percent of the 66 clients surveyed were male, the mean age of program clients was 32.4 , and 51 percent of the $66 \mathrm{clients}$ surveyed were non-white. Figure 3 shows positive changes in pre-needle exchange and post-needle exchange behavior in terms of needle hygiene and sharing injection equipment. ${ }^{68}$ More IVDUs reported having disinfected their injection equipment when sharing is involved, a 24 percent increase between pre-needle exchange and post-needle exchange among clients.

These findings were presented to the Board of Health in December, 1988, with citizens present to voice opinions both in favor of and opposed to the needle exchange program set forth by Purchase. In January 1989, the Board of Health voted four-to-one in favor of the needle exchange program's operations and agreed to allocate funds (costsharing between the city and the county), with $\$ 43,165$ to be spent in the first year (The Morning News Tribune 1989a).

The program, however, has escaped neither criticism nor legal obstacles. Controversy surrounded the legality of a health district's dispensing needles to IVDUs in a state where both distribution and possession of drug paraphernalia are prohibited. Subsequently, much debate and litigation have occurred over the legality issue of operating

\footnotetext{
${ }^{68}$ It is unclear what is meant by "use of needle hygiene," since "sharers using bleach" is already reported. No explanation of the legend to Figure 3 has been provided by the source.
} 
a needle exchange program for IVDUs. ${ }^{69}$ This controversy is reported in more detail in Chapter V, "The Findings."

Nonetheless, the Tacoma-Pierce County Needle Exchange Program has gained acceptance by the community as indicated by its considerable longevity and visibility (i.e., it is often mentioned in local, national, and international news), and continues to operate under the leadership of Dave Purchase. Given the distinctiveness of an accepted needle exchange program, Tacoma-Pierce County's experience provides an excellent opportunity to examine the questions raised by this Review of the Literature. This experience will be examined for an identification and understanding of the attributes that are considered to be linked to program acceptance. This research will concentrate on three main groups that continue to play a significant role in the program's acceptance: (1) law enforcement personnel, (2) health department officials, and (3) program clients. (i.e., IVDUs). An examination of their perceptions and views will provide important data on the acceptance of the program in the community and the kinds of hurdles that have been, or will be faced by the implementation and execution of needle exchange programs in other locales.

Chapter III will provide a conceptual framework for analysis of events and processes by which the Tacoma-Pierce County Needle Exchange Program was established and accepted in the community.

\footnotetext{
${ }^{69}$ The litigation on the Tacoma-Pierce County Needle Exchange Program is discussed in Chapter $V$ of this research.
} 


\section{CHAPTER III}

\section{CONCEPTUAL FRAMEWORK}

A conceptual framework is an important organizing tool that provides the researcher with a mechanism for approaching a problem and understanding how the various pieces that seem important can be linked in order to examine and explain a particular phenomenon. This chapter presents such a framework for examining the preventive health care models used to address the current AIDS epidemic among IVDUs. Given that there are neither vaccines nor cure, at the present time, for this life-threatening disease, prevention appears to be an alternative that merits the study of social and health scientists. As Russell (1986) points out, "waiting until a disease is obvious and then trying to treat it is not the only option."

Intervention programs that focus on prevention through lifestyle changes currently appear to be the best defense against the transmission of HIV-1/AIDS. Needle exchange programs are such an intervention; they seek to prevent the spread of HIV-1/AIDS among IVDUs who share injection equipment. The role that needle exchange programs occupy in the prevention of AIDS is vital not only for IVDUs, but also for the noninjecting, heterosexual population who are exposed to the virus through their sexual contacts with the drug-injecting population. 
PREVENTION OF DISEASE: REDUCING RISK FACTORS

Implicit in prevention strategies that seek to specifically guard against transmitting a particular disease are what epidemiologists refer to as "risk factors" (Mausner and Kramer 1985). Simply stated, risk factors are elements that allow for a more favorable development or contraction of a particular disease, and whose presence are associated with an increased chance that disease will occur in the future (Mausner and Kramer 1985). According to Mausner and Kramer (1985), risk factors may be "immutable" (i.e., not amenable to change) or "susceptible" (i.e., are amenable to change). Immutable risk factors of a given disease include factors such as "age," "sex," "race," and "family history." Susceptible risk factors can be altered through various strategies, including those which focus on behavioral change. IVDUs, for example, can be encouraged not to share contaminated injection equipment by making sterile injection equipment more readily available and accessible to them.

Identification and knowledge of particular risk factors are important to the prevention of life-threatening diseases, including AIDS. Traditional medical care in the United States involves massscreening or physician visits to identify an individual's risk factors for transmitting a particular disease (Imperato and Mitchell 1985). Specific medical guidelines, indicating ways in which risks could be reduced, are made available to those individuals who have routine medical examinations or regular health care services as well as those who participate in mass-screening programs. Unfortunately, not all members of society have equal access to such services as mass-screening 
or medical examinations. The social environment and how particular individuals are integrated into society may affect the level of medical and health care and the delivery of medical and health care services (Mausner and Kramer 1985).

Traditional medical care does not-appear to benefit all those individuals considered to be at risk for transmitting HIV-1/AIDS, particularly intravenous drug users (IVDUs). IVDUs, for example, are often considered to be a "hidden" subgroup of the general population who engage in acts considered to be deviant, such as prostitution, illicit drug activities, and/or theft. The subculture of IVDUs and their oftenassociated illicit activities prevent such individuals from seeking routine medical and health care services. Intravenous drug users (IVDUs) usually become visible only when they need treatment, hospital care, or are arrested (Ginzburg 1984; Selwyn et a1. 1987). Given this, IVDUs often encounter a number of barriers to access and utilization of services in a variety of ways, including client resistance and settings (Shulman 1990).

In many communities, there is a pervasive belief that IVDUs are not socially responsible, and are thus incapable of making changes to promote healthier lifestyles for themselves and increased protection for their associates. IVDUs are often stereotyped as being "selfdestructive," and uninterested in the health of other members of society (Turner et al. 1989). In turn, program staff who hold "a sense of hopelessness" attitude toward clients reinforce these resistant behaviors of IVDUs by projecting an unwelcome atmosphere that does not provide "user-friendly," or, rather, "non-judgmental" services (Shulman 
1990). Non-judgmental treatment by health care workers and easily accessible services from those workers appear to be critical to the success of prevention strategies for this population group.

Despite these stereotypical beliefs, data indicate that IVDUs are capable of making the necessary changes in drug and sexual behaviors that reduce their risk of transmitting HIV-I/AIDS, as they overcome social barriers and the physiology of addiction (Turner et al. 1989). Innovative interventions, such as needle exchange programs, apparently tend to develop a supportive environment, void of prejudice and stigma often associated with those groups outside the mainstream of society in the belief that such programs can be used to motivate the necessary behavioral changes associated with the risk of the transmission of HIV1/AIDS among IVDUs.

Subsequently, public health officials have recently turned to theories and models of the behavioral and social sciences to develop and help guide and explore possible prevention strategies that may reduce the risk of disease transmission. Such approaches have also been applied to the transmission of HIV-1/AIDS.

Efforts to reduce the risk of transmitting HIV-1/AIDS focus on the need to modify attitudes and behaviors of those individuals considered to be at high-risk. Theories which focus on changes in attitudes and behaviors are most often based on the health behavior model. Such theories provide a better understanding of the ways in which changes in attitudes and behaviors operate to reduce the risk of transmitting a certain disease. 
THE HEALTH BEHAVIOR MODEL

Changing attitudes and behaviors of those at risk is a major component in the management of many health problems (e.g., alcohol ism, obesity, hypertension, and smoking), and such an undertaking may present a difficult task for certain individuals. In regard to AIDS, changing attitudes and behaviors is considered critical to alleviating its further spread (Turner et al. 1989). Several studies suggest that groups at risk for transmitting HIV-1/AIDS are capable of changing attitudes and behaviors, despite their intimate and addictive habits (Becker and Joseph 1988; Office of Technology Assessment 1988). According to Becker and Joseph (1988):

in some populations of homosexual/bisexual men, this may be the most rapid and profound response to a health threat which has ever been documented.

Individuals at risk for AIDS, however, are most likely to make incremental changes in behavior that will allow them to continue their personal interests and goals. Male homosexuals, for example, may prefer to engage in safe sex practices rather than abstain from those activities altogether. IVDUs may be more likely to practice safer injection practices than to seek detoxification or methadone treatment (Turner et a1. 1989).

Changing the attitudes and behaviors of the community is another important component to alleviating the spread of HIV-1/AIDS among population groups outside the mainstream of society. There are two particular approaches to health behavior which help explain the complexities involved when an individual and/or community decide to 
undertake particular changes in attitudes and behaviors: (1) the "health belief theory" (which focuses on the individual) posits cognitive components as the main determinant that influence particular changes in health behaviors and health care practices; and (2) "community approaches to health" which posit social and cognitive components of change. These theories are discussed further in the following sections of this chapter.

\section{Health-Belief Theory}

The "health-belief theory" presented by Janz and Becker (1984) posits cognitive components such as "perceived susceptibility" (i.e., an individual's subjective perception of risk), "perceived severity" (i.e., feelings regarding the seriousness of transmitting a disease), "perceived benefits of the new behavior," and "perceived barriers to the adoption of the new behavior" as determinants of changes in health behaviors.

Subjective assessments of personal risk, however, do not always reflect the more objective assessments of risk (Turner et al. 1989). There is an "optimistic bias" (i.e., the attitude of "it can't happen to me") which appears to blur some individuals' perception of risk (Turner et a1. 1989). Weinstein (1987), for example, suggests that individuals tend to report themselves to be at less risk than others in light of a given health threat.

Underestimating the associated risk behavior is evident in a number of health problems, and efforts which aim to change such behaviors are thus undermined. For example, the number of unplanned, teenage 
pregnancies indicate that young adolescents appear to underestimate the associated risks of engaging in unprotected sex (Turner et al. 1989).

Although the. "cognitive health behavior" theory may be correct in suggesting that an individual's risk perception is key to influencing particular changes in behaviors, the process of subjective assessment cannot divorce itself from socio-environmental (e.g., community norms, community organizations, social values and beliefs, and physical surroundings) and demographic (e.g., age, gender, genetics, personality) conditions (0'Reilly 1988). Such conditions have profound implications for those who seek to develop prevention programs that require attitude and behavior changes among those objectively established to be at risk.

While much research concerning the prevention of chronic diseases (e.g., cardiovascular disease) has focused on the relationships between risk factors and various demographic variables, most of the major accomplishments in public health have illuminated the environment as playing a significant role in behavioral change (Puska et al. 1985). Puska et al. (1985) state:

The natural, most effective way of changing a population's risk factor levels is to work through the community: the community should be the major target rather than its individuals.

This conceptualization of health behavior theory is the main impetus for community approaches to behavioral change. 
Community Approaches to Health

"Individuals do not act in a vacuum: Rather, action occurs in a social environment" (Turner et a1. 1989). In the past few decades, social and behavioral scientists have become cognizant of the important role which the environment plays in the formation of individual attitudes and behaviors (Abrams et al. 1986; McAlister et al. 1982; Puska et a1. 1985; Thompson and Kinne 1990). According to McAlister et a). (1982):

The environment is often a determining influence on behavior and may be a direct influence on health. Thus an important goal of health promotion is the achievement of appropriate environmental changes. Community organization is an important element of such change.

In recent years, a number of major health-promotion projects have evolved in which a community approach had been employed to facilitate behavioral changes that aimed at reducing certain health risks (Abrams et a1. 1.986; Puska et a1. 1985; Thompson and Kinne 1990). According to Thompson and Kinne (1990), most of these projects emphasized multiple risk factors related to cardiovascular disease, focusing on changes in smoking and dietary behavior. As Thompson and Kinne (1990) point out:
All of them described themselves as 'community projects' and used different community institutions, organizations, groups, and individuals in the delivery of interventions. Most emphasized public education through mass media, schools, and other organizations.

In short, most of these projects were cognizant of the need to change the social context of the community in which they operated, contending that the environment plays an important role in promoting or 
inhibiting the, adoption of new behaviors (McAlister et al. 1982; Puska et a1. 1985). Advocates of community approaches to promoting health thus contend that permanent and comprehensive behavioral change is best attained by transforming the standards of acceptable behavior (i.e., the local values, norms, and behavior patterns) in a given community (Thompson and Kinne 1990).

The importance of the environment in fostering community norms to change the behaviors of individuals that engage in life-threatening health risks has been incorporated into the STOP AIDS program. The STOP AIDS program, which originated in San Francisco as a non-profit organization, worked with grass-roots gay organizations to promote social and cultural change by raising the individual awareness of peer support for safe sex practices (Turner et al. 1989). The STOP AIDS program used targeted media to create the impression of widespread community change, and support seems to have grown out of the importance of creating a supportive social environment in which those at risk can feel socially accepted in adopting a new behavior.

Thompson and Kinne (1990) note that community organization, in which the subjects of a targeted behavior change participate in planning and implementing a change program, is likely to result in changes in local values, norms, and behavior patterns that facilitate healthier lifestyles. The newly-established values, norms, and behavior patterns would lead to reductions in individuals' health-risk behavior, which, in turn, translates to lower morbidity and mortality rates associated with a particular disease (Thompson and Kinne 1990). 
Likewise, in the "theory of reasoned action" posited by Azjen and Fishbein (1980), both social and cognitive determinants are addressed in the context of changes in behaviors. This particular theory is based on the perceived and actual existence of community norms that are supportive of the new behavior (O'Reilly 1988). An individual is likely to adopt a new behavior if it is perceived to be the norm and if it is socially acceptable. Social approval thus provides a reward to the individual undergoing change (Turner et al. 1989).

\section{SUMMARY}

In sum, behavioral research suggests that the health behavior of an individual is determined by more than just knowledge of the consequences of a specific behavior (Becker 1985; Morisky et al. 1985; Kolbe 1988). In addition to cognitive determinants, the anticipated responses of others are extremely important when undertaking a new behavior.

Community programs, while promoting normative change, have typically targeted their interventions and measures to individual change (Leventhal et a1. 1980; Puska et a1. 1985). This is evident in the area of smoking in which traditional approaches have focused primarily upon individual behavioral changes, with little or no recognition of the broad social context in which one seeks to stop smoking acts (Thompson and Kinne 1990).

The theory of reasoned action has shown some value in designing and implementing a particular program that can help to create a supportive environment to influence individual change. It appears to be more difficult to create a supportive environment for changing behaviors 
among IVDUs, because unti.ke male homosexuals, few (if any) organizations exist for this particular risk group. Beyond this, much of the general public perceives IVDUs as incapable of changing injection and sexual practices; therefore, needle exchange programs may be an essential element in reducing the risk of transmitting HIV-1/AIDS. Despite the urgency of such an intervention to prevent the spread of HIV-1/AIDS, the implementation of needle exchange programs in the United States has produced much controversy and debate.

While cognizant of the controversial issues that exist, the community of Tacoma, Washington, initiated a needle exchange program in order to promote changes in injection practices among IVDUs. Unlike many other needle exchange programs, the Tacoma program has gained community acceptance (indicated by media attention, local funding, longevity, etc.). As such, the Tacoma-Pierce County Needle Exchange Program provides a good opportunity to systematically examine and analyze those factors which contribute to the acceptance of a needie exchange program. The specific research questions which guide this assessment of the Tacoma-Pierce County Needle Exchange Program are stated below.

\section{The Research Questions}

(1) "What characteristics of Tacoma-Pierce County Needle Exchange Program are linked to program acceptance by law enforcement personnel, heal th department officials, and program clients (i.e., IVDUs)?"

(2) "What characteristics of the external environment are linked to program acceptance of the Tacoma-Pierce County Needle Exchange Program by law enforcement personnel, health department officials, and program clients (i.e., IVDUs)?" 
(3) "What characteristics of the program clients are linked to program acceptance of the Tacoma-Pierce County Needle Exchange Program by law enforcement personnel, health department officials, and program clients (i.e., IVDUs)?"

The strategy regarding the exploration of these three aforementioned research questions will be presented and discussed in the following chapter, "Chapter IV: Research Strategy." 


\section{CHAPTER IV}

\section{RESEARCH STRATEGY}

This chapter discusses the design and method of the research employed, as well as data sources, and addresses each of the three research questions that guide this study, as well as how data are to be analyzed.

\section{THE CASE STUDY APPROACH}

The case study approach has a rich and varied history legitimizing its use in looking at particular phenomena. Yin (1984) posits that the case study has been a "common research strategy" that has been employed in gathering primary data in various academic fields, including psychology, sociology, political science, planning, and economics. ${ }^{70}$ This method also continues to be extensively employed in thesis and dissertation research in the aforementioned disciplines. This not only confirms that the case study approach is adaptive and flexible, but also validates its position and potential in conducting scholarly research in diverse fields.

${ }^{70}$ Yin (1984) states that the case study method has been used in various classic studies throughout the years, including Whyte's (1943) Street Corner Society; Liebow's (1967) Tally's Corner; Jacobs' (1961) The Death and Life of Great American Cities; Lipset, Trow, and Coleman's (1956) Union Democracy; and Allison's (1971) Essence of Decision Making Explaining the Cuban Missile Crisis. 
The case study approach is just one of the various methods used in social science research for the collection of "thick" (Geertz 1973), "deep" (Sieber 1973), and "holistic" (Rist 1977) primary data, and its use is considered to be advantageous under certain conditions particularly when phenomena under investigation are introductory and exploratory, and/or when the topic focuses on contemporary phenomena within real-life context but when the investigator does not have much, if any, control over behaviors and/or events (Yin 1984). Each of these conditions is explained in more detail below.

A case study which is introductory and exploratory seeks to utilize "thick," "rich," and "deep" data, thus the greatest contribution of such a case study approach may be the descriptive data which it produces. of particular importance is the idea of thick description. Unraveling the meaning behind multiple data sources requires thick analysis. This process is one in which documents and other information are analyzed and reanalyzed in a series of continuing iterations. The researcher also views each iteration critically and with "reflexive insight" (Gilchrest 1992), thereby building a description that captures all nuances of the phenomenon under study. According to Forcese and Richer (1973):

The case study offers in-depth data which often permit a researcher to follow up with more intelligent explanatory research . . l lacking any accumulated findings that might guide explanatory survey research, the case study is often a wise exploratory measure. A survey, may of course, also be exploratory. But by its nature, such an exploratory survey is apt to provide a more superficial view of the phenomena in question despite the greater number of units investigated. It would therefore serve as a less useful guide to follow up research of an explanatory intent than would a case study. 
Indeed, other research methods are capable of guiding studies that are considered to be introductory and exploratory; however, the case study approach provides for greater understanding of the phenomena under investigation from the type of data that is produced. Majchrzak (1984) points out:

Case studies allow for the identification of behaviors and other variables that were not expected to be related to the social problem. They provide for a more in depth analysis of superficial statistical portrayals of populations. They provide for a more complete understanding of a situation's complexity by examining behavior in context.

In short, the case study approach thus allows for better interpretation of data in studies that are introductory and exploratory by producing in-depth insights into the pertinent issues, and by flushing out unforeseen, yet relevant, variables of a specific study. Another condition that largely determines the type of research method employed in a particular study is the extent of control and access that an investigator has over actual behaviors and events (Yin 1984). Histories, for example, are the preferred research method when the investigator has virtually no control or access over behaviors and events, but when the topic under the investigation deals with the "dead" past (Yin 1984). The case study approach is another good research method when the investigator has virtually no control or access over behaviors or events, and is preferred when the phenomena under investigation are contemporary. By dealing with contemporary phenomena, the case study approach provides two additional sources of evidence that are not available for the historian, namely direct observation and 
systematic interviewing ( $Y$ in 1984). Moreover, the nature of this research is exploratory and introductory (i.e., seeking in-depth information), examining phenomena that are not easily manipulated in terms of behaviors or events.

The Tacoma-Pierce County Needle Exchange Program, the focus of this particular case study, is a contemporary, innovative AIDS intervention strategy that serves a "hidden" population group (i.e., IVDUs) that normally shuns authority and formal organizations (as discussed in Chapter III). It is necessary to maximize individual anonymity in order to obtain access to program clients. Informed consent forms help to protect individuals' anonymity and confidentiality, and therefore, findings are to be reported with this in mind (see "Analysis" section in Chapter III). Total anonymity or confidentiality for program clients of the Tacoma-Pierce County Needle Exchange Program cannot be granted entirely by any researcher due to the fact that IVDUs openly receive services on a street-based site; however, interviewee responses are presented as aggregated (rather than individual) findings.

DATA SOURCES

Yin (1984) states that the case study approach has a unique ability to handle multiple data sources, including documents, artifacts, interviews, and observations. A case study requires intensive and complete investigation of the phenomena under study. It allows for the use of multiple data sources essential for in-depth analysis. A strength of such a research strategy offers more confidence in the 
findings of the study through a process known as "triangulation" (i.e., drawing conclusions from several data sources).

There are several data sources available for this particular study. These include existing records, court documents of public officials, and semi-structured interviews utilizing key informants of both law enforcement personnel and program clients (i.e., IVDUs). Each of these sources is addressed below.

\section{Existing Records}

Existing records are a good source of data for secondary analysis. For this study, existing records (e.g., media coverage, litigation records/court documents, Tacoma Police Department crime statistics) provide a substantial amount of secondary data about the relationships among various members of the community in reference to the historical evolution, events, and opinions on the needle exchange program in Tacoma.

Media Coverage. Copious news articles have been published in many national newspapers on the Tacoma-Pierce County Needle Exchange Program. Numerous newspaper articles have appeared in The Morning News Tribune (the local newspaper) about the establishment of the needle exchange program, the efforts of Dave Purchase, and other related events (such as the lawsuit involving the former Director of Health of the Tacoma-Pierce County Health Department, Pierce County, and the City of Tacoma). These articles corroborate other secondary data sources which help fill in unclear or missing data from other reports and interviews. 


\section{Litigation Records/Court Documents}

Litigation records and court documents are available through many organizations for this case study. For example, the gay organization, ACTUP!, publishes a handbook for mobilizing support for needle exchange programs and contains several litigation records and court documents which detail the lawsuit that has occurred in Tacoma. These records and documents offer the actual opinions of those involved in the lawsuit (explained in detail later).

Court documents provide valid information in reference to the controversy that surrounds needle exchange programs, and provide substantially good insights into the Tacoma-Pierce County Health Department's acceptance of the program. Such information also provides a formal position of the former Director of Health of the Tacoma-Pierce County Health Department and represents the point of view of that particular public agency toward having a needle exchange program as an intervention strategy for one high-risk group, specifically, intravenous drug users (IVDUs).

\section{Semi-Structured Interviews}

Semi-structured interview schedules have been developed to use on the three groups (health department officials, law enforcement personnel, and program clients) involved in this research. The TacomaPierce County Health Department, however, refused to grant any interviews with public health officials. The reasons are explained in Chapter VI of this dissertation. The two remaining groups have been extremely cooperative and eager to participate in the study. Law enforcement personnel have expressed their interest in the study and 
await the findings of this research. "Program clients although being paid for their participation, expressed positive comments about the study's questions and intent. ${ }^{71}$ This hinted to the researcher that program clients were pleased that "outsiders" sought and valued their opinions.

Different interview schedules (see Appendix B) have been devised to elicit the information sought from each distinct group. For instance, several questions have been posed in reference to the relationship between the initiators of the needle exchange program and the Tacoma Police Department. Other questions have been posed which elicit information about departmental views of the needle exchange program. Interviews with program clients, however, are not scheduled in advance which necessitates a different type of interview schedule that requires less time to complete. In other words, a lengthy interview with a program client may prove difficult to complete since many individuals available for this particular study are approached near the needle exchange site (to ensure that they are indeed program clients), and thus do not wish to remain long in the "public eye." For this, many of the questions posed in the interview schedule for program clients (i.e., IVDUs) provided close-ended responses in order for quick recording, since a tape-recorder would deter potential interviewees from participating in this study.

71 Program clients who participated in this research were paid $\$ 5$ before the interview and $\$ 10$ upon the completion. The researcher was aware of ethical issues involved in paying cash to individuals involved in illicit drug use; however, the researcher was informed that giving cash for information was an established practice in Tacoma among this targeted population. 
The access and selection process differs for each of the two population groups (i.e., law enforcement personnel and IVDUs). The use of key informants is discussed below in terms of the access and selection of potential interviewees. Key informants, often chosen subjectively by the researcher, are trustworthy individuals within a given community who are critical to the access and selection of prospective interviewees. Such individuals are thought to provide useful and reliable information to the researcher in a case study research. A key informant is thus "one selective screen away from the investigator" (Webb et a1. 1981). This case study employs various key informants for both law enforcement personnel and program clients. The means of gaining access and selecting such key informants are reported below for each of the two groups involved in this specific study.

Law Enforcement Personnel. To start, a telephone call was made to the Office of the Chief of the Tacoma Police Department to inquire about conducting interviews with several law enforcement personnel in reference to this particular study. The secretary mentioned that appointments for interviewing law enforcement personnel are to be made directly with those individuals which a particular researcher selects for a given study. Four individuals that serve (or have served) as law enforcement officers were selected as participants in this research, and formally consented to a tape-recorded, face-to-face interview.

Selection of key informants among law enforcement personnel was based on their strategic positions within the police department, expertise of knowledge, and experience in patrolling areas where IVDUs tend to congregate. Former and current public information officers, a 
patrol officer, and a retired narcotics investigator were selected as participants in this research. Again, to maintain an optimal degree of anonymity and confidentiality, individual responses are not reported in the findings. Responses are drawn together in search for commonalities and are to be reported as findings (see "Analysis").

Program Clients. Program clients are those individuals defined as the target population who receive services from a specific program. In this particular case, program clients of the Tacoma-Pierce County Needle Exchange Program are those intravenous drug users (IVDUs) who swap dirty injection equipment for sterile equipment at one of the three designated exchange program sites. ${ }^{2}$

An exact total number of this particular target population was unknown before data allocation, since there is some difficulty in taking a "census" of such a "hidden" group. ${ }^{73}$ Yet, locating program clients did not seem to be a difficult task. A researcher only had to be familiar with Tacoma, visit areas where missions and shelters are located, and find individuals willing to talk about where a person could find the van units that operate the needle exchange program in Tacoma. In addition, media sources report from time to time the general location of where the mobile van units distribute sterile injection equipment.

\footnotetext{
${ }^{72}$ Current street-based sites in Tacoma are downtown between 15 th and Commerce, and 14th and South G Street. The Tacoma-Pierce County Health Department distributes injection equipment inside its health department pharmacy located on South 36 th and D Street.

${ }^{73}$ IVDUs are often referred to as a hidden population since many do not want their identity known. In addition, some IVDUs are homeless and/or illegal aliens.
} 
Knowledge of where to find program clients did not pose any difficulty for this research.

Although locating program clients in Tacoma posed little problem, gaining access to interview this target population could have been difficult regardless of knowing congregation sites of IVDUs. Problems could arise if program clients decided not to participate, cooperate, or speak with an interviewer, for any of several reasons. The interviewer may exhibit a judgmental attitude; clients may exhibit a paranoia toward "outsiders;" or the timing or location of requested interviews may be suspect. It seemed easier to find one individual who just swapped injection equipment at the site of where the mobile van units parked and ask him/her to participate in a study, than to indiscreetly ask on the street if he/she is an IVDU, and if so, would he/she participate in a study. In turn, obtaining the first respondent might help to "break the ice" for the researcher by quelling the skepticism and paranoia, and therefore, help in attracting other potential participants for the study. Beyond this, the researcher was ready and willing to pay these individuais for their participation. To repeat, it is common among this target group to trade money for information, especially among "street" people. The researcher exercised extreme caution in ascertaining whether an individual -- willing to participate for monetary gain -- was an actual program client and not only an opportunistic bystander. In selecting participants for this particular study, the researcher maintained a "telescopic eye" on those who approached the mobile van units and received services. This observational skill was critical in obtaining valid interviews. 
ADDRESSING THE RESEARCH QUESTIONS

To reiterate, there are three main research questions that serve as a guide for this particular case study. Each of these questions addresses: (1) various dimensions of program acceptance; and (2) possible associations which may provide the foundations for future research of AIDS intervention strategies. Specific indicators, pertinent to each particular question, are introduced, defined, and discussed in reference to the delivery of services provided by a needle exchange program. This helps to set the stage for the case study of the Tacoma-Pierce County Needle Exchange Program. The research questions are expanded below:

\section{Research Question \#1}

"What characteristics of the Tacoma-Pierce County Needle Exchange Program are linked to program acceptance?"

The characteristics of each particular needle exchange program differ in terms of "settings," "type of staff," and "method of service delivery." These are three good indicators that are considered pertinent to the characteristics of such programs, and are important to this study to explore potential barriers to the availability and accessibility of sterile injection equipment.

Settings. "Settings" refers to the type of environment in which a program is delivered, and ascertains how physically accessible a given program is to its clients; for example, a fixed-site, walk-in, sidewalk, vending machine, or mobile van unit. Each of these types of settings has advantages and disadvantages and are explained below.

A fixed-site is a setting that can be described as "institutional," and is usually established in public agencies such as health department 
clinics or pharmacies. The advantages of a fixed-site are: (1) that it is less expensive to start since the mechanisms are already in place to dispense sterile injection equipment; (2) that it is less conspicuous -"out of the public's eye" -- than a street-based setting; and (3) that it has a predictable location that provides continuity of service delivery. The disadvantages of a fixed-site are: (1) that IVDUs normally shun bureaucratic settings; (2) that clinics or pharmacies are often too busy to provide counseling, education, or referrals to IVDUs; and (3) that it is not as flexible as a street-based setting in terms of geographic mobility.

A walk-in setting can be described as a "store-front," and is usually in an area where other social services are located, such as halfway houses, shelters, plasma centers, and organizations offering free meals. The advantages of a walk-in setting are: (1) that it is less conspicuous -- "out of the public's eye" -- than a street-based setting; (2) that it has a predictable location that provides continuity of service delivery; and (3) that it easily allows for counseling, education, and referrals to IVDUs. The disadvantages of having a walkin setting are: (1) that it requires expenses for renting or leasing a building, liability insurance, and utilities; and (2) that it is not flexible in terms of geographic mobility.

Operating a needle exchange program on a sidewalk is one type of street-based setting that involves minimal equipment such as a small table, a couple of chairs, and a container to place dirty injection equipment that is exchanged for sterile injection equipment. The advantages of this type of setting are: (1) that it is relatively 
inexpensive in regard to both start-up and operating costs, compared to other street-based or a walk-in setting; (2) that it is flexible, allowing for geographic mobility; and (3) it allows for counseling, education, and drug treatment referrals to clients. The disadvantages of this type of setting are: (1) that it is too conspicuous; (2) that weather conditions may not be conducive for program operations; and (3) that daily set-up and closure procedures are inconvenient.

Vending machines which dispense sterile injection equipment are another type of setting, and have been utilized particularly in countries outside the United States. The advantages of this type of setting are: (1) that they can be placed in inconspicuous locations (such as condom machines in restrooms); (2) that they have a predictable geographic location offering continuity of service; and (3) they can offer 24-hour service delivery to IVDUs. The disadvantages of having a vending machine to dispense injection equipment are: (1) they do not offer an exchange of injection equipment, only distribution; (2) they do not allow for counseling, education, or drug treatment referrals to IVDUs; (3) they could create another supply of injection equipment for "black market" sale; (4) that opponents of needle exchange, or vandals, may seek to destroy or steal equipment; and (5) they may not maximize accessibility for IVDUs. Perhaps vending machines are best used in controlled areas such as prisons or jails.

The mobile van unit, another street-based setting, has been successfully utilized in many countries. The advantages of utilizing a mobile van unit are: (1) that it is flexible, allowing for geographic mobility; (2) that it allows for counseling, education, and drug 
treatment referrals to IVDUs; (3) that it can operate at night or in poor weather conditions; and (4) that it is less conspicuous than other street-based settings. The disadvantages of a mobile van unit are: (1) the initial cost of the van is high; and (2) the maintenance and operating costs of a van are high.

In some countries, a combination of two or more types of settings are utilized to reduce the physical barriers to services. Shulman (1990), in fact, suggests that low-barrier access to social services must be considered in order to attract and increase program clients. Strategic settings, therefore, must be considered for needle exchange programs which try to reach the "difficult-to-access" intravenous drug user who normally avoids the formal treatment of such social services. Specific queries on the interview schedules of both the law enforcement personnel and IVDUs address the appropriateness of the settings utilized by the needle exchange program in Tacoma.

Type of Staff. The staff is the human element in the provision of social services, and is comprised of those individuals responsible for carrying out the goals and objectives of a given program. They are the "street-level bureaucrats"14 who come into regular contact with the clients of the program, and who create a certain ambience which appears to be psychologically critical to a particular population group.

The type of staff can be a barrier or a benefit to a program such as a needle exchange program whose clientele engage in deviant behaviors such as illicit drug use. To elaborate, program staff may create a (1980).

${ }^{74}$ "Street-level bureaucrats" is a term coined by Michael Lipsky 
significant barrier if they perceive IVDUs as living on the fringes of society and incapable of changing their behaviors (i.e., "once an addict, always an addict") (Shulman 1990). A needle exchange program is in contrast considered to be user-friendly $y^{75}$. when the staff possesses a non-judgmental perception of IVDUs, and whereby such program ciients are perceived as wanting to make, and capable of making, changes in HIV-1 risk behaviors.

The type of staff can promote a user-friendly program by creating a relationship of trust and commitment between themselves and program clients, thus minimizing the barriers to access of receiving services. To explore whether the Tacoma-Pierce County Needle Exchange Program is user-friendly, program clients were asked specific questions about their perceptions of the accessibility and relationship with program staff.

Method of Service Delivery. "Method of service delivery" is defined in terms of the function and arrangements that are specifically designed and set forth by the sponsors of a particular program. By and large, the delivery of services is bureaucratically organized under a set of standardized rules and regulations, and functions according to formalized, systematic processes in order to maximize effectiveness and efficiency.

The diverse needs of IVDUs -- again a population group who tend to avoid the routine utilization of social welfare services -- appear to be nonconducive to the workings of a strict, formally operated program. Literature (e.g., Stimson 1989; Shulman 1990) indicates that IVDUs are

\footnotetext{
75 "User-friendly" is a term often employed in research on needle exchange programs, and appears in the literature by Don C. Des Jarlais.
} 
attracted to programs that have a low threshold for eligibility, require little or no identification, maintain an informal, non-coercive relationship between the program staff and clients, and have easy logistics.

Both law enforcement personnel and program clients were asked specific queries from the respective interview schedules about the method of service delivery set forth by the Tacoma-Pierce County Needle Exchange Program.

\section{Research Question \#2}

"What characteristics of the external environment are linked to program acceptance?"

The "characteristics of the external environment," in this particular research question, are explored through indicators such as the "nature of the geographic area," "concern over the effects of AIDS," and the "external environmental conduits" (the informal communication network and the media).

Nature of the Geographic Area. The "nature of the geographic area" is defined in terms of the social and economic characteristics of the community in which the Tacoma-Pierce County Needle Exchange Program operates. By and large, the nature of the geographic area is an important element to the accessibility of a social program, especially for "hard to reach" clients like IVDUs.

Social welfare programs that cater to "hard to reach" clients must consider the nature of the geographic area in order to minimize the barriers to access and maximize program acceptance. Selecting a specific locale for a needle exchange program can be difficult, since many of these program clients are mobile. Nonetheless, the "not in my 
backyard" (NIMBY) philosophy of the general public appears to be a large factor in selecting a particular locale for a program that serves individuals who engage in illicit drug use.

Both law enforcement personnel and. IVDUs were asked specific queries about the locales in which the needle exchange program operates. In addition, the nature of the geographic area will be observed and qualitatively analyzed in terms of accessibility.

Concern Over the Effects of AIDS. "Concern over the effects of AIDS" is another indicator that explores the characteristics of the external environment. Acknowledging the needle exchange program as an AIDS intervention strategy has led law enforcement personnel to nonenforcement of laws which refer to possession and use of illicit drugs and related paraphernalia. In other words, the legal organizations (law enforcement agencies and courts) are responsible for enforcing laws that individuals, groups, or other organizations violate. The extent to which the concern over the effects of AIDS outweighs the existing "laws on the books" which refer to the use and possession of illicit drugs and related paraphernalia is examined through court records and interviews with law enforcement personnel.

Concern over the effects of AIDS is also explored from the point of view of intravenous drug users (IVDUs). Program clients (i.e., IVDUs) were asked queries that refer to sterilizing their injection equipment and their worries of contracting AIDS. Acknowledging the terminal consequences of AIDS is an integral part of accepting a needle exchange program. 
External Environmental Conduits. The "informal communication network" and the "media" are conduits of the external environment which can have an influence on the acceptance of a needle exchange program. The informal communication network is defined as the unofficial means in which news passes among a particular subgroup of the population; it is a means by which "outsiders receive and transmit information."176 For this, the informal communication network serves a critical role in program acceptance in getting information out about the Tacoma-Pierce County Needle Exchange Program, as well as providing acceptance of the interviewer for this study.

Specific queries on the interview schedule refer to the role that the informal communication network. filled in helping the needle exchange program gain acceptance by the drug trade. Secondary data sources will supplement the data collected from interviews regarding the way in which key individuals from various agencies met informally to ease implementation of the needle exchange program in Tacoma.

The "media" is another external environmental conduit that can help or hinder the implementation of a needle exchange program, and can influence the public's acceptance of such an AIDS intervention strategy. Various news articles provided insight into the role which the media occupied before and after the Tacoma-Pierce County Needle Exchange Program.

\footnotetext{
${ }^{76}$ The term "outsiders" refers to the mainstream population or "straight" world. Outsiders in the case study refer to those members of the population who are not members of the drug community.
} 


\section{Research Question \#3}

"What characteristics of the program clients (i.e., IVDUs) are linked to acceptance of the Tacoma-Pierce County Needle Exchange Program?"

The characteristics of the program clients refer to selected features that an individual possesses. Characteristics of the program clients include "demographic information" (e.g., age, gender, ethnicity, and educational level) and "drug use habits" (e.g., type of drug injected, drug dependence, and number of times receiving drug treatment).

Demographic Information. "Demographic information" provides good data about the "typical" program client who utilizes the needle exchange program in Tacoma. Existing data published by Tacoma-Pierce County Health Department provide demographic data on program clients of the needle exchange program in Tacoma (see Chapter II). Law enforcement records, published monthly, delineate demographic data about individuals who have been arrested for drug and drug-related crimes. Interesting information can be extracted about the characteristics of program users by comparing these two sources of records.

Drug Use Habits. "Drug Use habits" such as the type of drug injected, the length of time that program clients have been injecting drugs, and the number of times that IVDUs have received drug treatment provide information which may assist in determining program acceptance. For instance, the hard-core, long term IVDU might accept a needle exchange program more readily than the recreational IVDU or a newcomer. 


\section{ANALYSIS}

Articles and publications that address research methods often neglect scholarly discussion on the analysis of qualitative data and tend to focus primarily on the collection of such data (Jones 1985). Perhaps this is because analyzing qualitative data is an extremely personal activity that has no definitive rules, such as the analysis of quantitative data has, to be followed by rote (Jones 1985). In addition, the analysis of qualitative data involves a less rigorous process than quantitative data and is, by and large, non-numerical. Hedges (1985), for instance, contends:

there are no magic tools for this. Again, one uses the same techniques as are used for analyzing conversation in ordinary life, but more intensively, more systematically and more consciously.

Similarly, Jones (1985) posits:

the analysis of qualitative data is a process of making sense, of finding and making a structure in the data and giving this meaning and significance for ourselves, and for any relevant audiences.

In this particular study, there is no formal hypothesis-testing, since the case study approach seeks to explore and describe relationships rather than test them. To this extent, the case study attempts to lay a foundation for theory-building, and perhaps produce serendipitous findings. The analysis of this particular case study is guided by three main research questions, previously discussed, each having indicators that serve as the focus for the questions posed in the interview schedules. The data will be searched for commonalities, in 
each of the groups interviewed, and findings will thus be reported, in aggregate, accordingly.

The following chapter, Chapter V, reports the findings of this

particular dissertation research, and ties the data to the conceptual

framework presented earlier in this study. 


\section{CHAPTER V}

\section{THE FINDINGS}

Opponents of needle exchange programs are quick to point out that the most effective approach to preventing the spread of HIV-1/AIDS among intravenous drug users (IVDUs) is for this high-risk group to abstain from injecting illicit drugs. Clearly, this approach is not feasible at the current time, and is not likely to occur in the very near future. Moreover, various efforts to help stop the proliferation of illegal drug use, such as the "War on Drugs," have not had a major impact on the American society. By the same token, drug treatment programs have suffered from a lack of resources and capacity to become an effective means to eradicate illicit drug use in the United States. As Des Jarlais points out:
we do not have anywhere near enough drug abuse treatment capacity for the estimated one to one-and-a-half million intravenous drug users in the country. Even if finan- cial resources were available to pay for a large scale expansion of treatment, it would be years before sufficient sites could be located and staff recruited and trained. Additionally, our present forms of drug abuse treatment are not effective for all persons who enter them. ${ }^{77}$

Currently, innovative and controversial intervention strategies, such as needle exchange programs, appear to offer the most hope in

\footnotetext{
77Turner, et a1. (1989) reference several studies conducted by Des Jarlais regarding drug treatment.
} 
helping to change those injection behaviors and practices associated with the transmission of the AIDS virus among IVDUs and their sexual partners. To this extent, the ideal and most effective approach to preventing the spread of HIV-1/AIDS among IVDUs is for this high-risk group to abstain from using non-sterile injection equipment.

As discussed in Chapter II, "Review of the Literature," several countries in Western Europe, Australia, and Canada provide legal access for intravenous drug users (IVDUs) to obtain sterile injection equipment. The United States, with an estimated one-and-one-half million IVDUs (Turner et.al. 1989), lacks a national policy regarding the implementation of needle exchange programs. Legitimate needle exchange programs, however, have emerged at the local, community, or grass roots level as an AIDS intervention strategy designed for intravenous drug users, the second largest risk group in the epidemic at this time. The Tacoma-Pierce County Needle Exchange Program is one such intervention strategy that has been officially operating since August 9, 1988, and has received national and international attention concerning its success. In Tacoma, much of this success is based upon the acceptance of the needle exchange program by three diverse groups, namely health department officials, law enforcement personnel, and program clients. The purpose of this study has been to identify various attributes that have promoted program acceptance of the needle exchange program in Tacoma, and to provide some fundamental elements for implementing similar interventions in other communities confronted by HIV-1/AIDS. 
To fulfill this purpose, Chapter V will now explore: (1) the critical relationship that helped facilitate program formation and implementation; (2) the appropriate conditions that have led to program formation and implementation; and (3) the findings as they pertain to the research questions (discussed earlier in Chapter IV) that help indicate program acceptance of the needle exchange program in Tacoma.

This chapter is divided into two main parts: Part One details the historical evolution of the Tacoma-Pierce County Needle Exchange Program based on information from secondary data sources. The historical evolution of the needle exchange program in Tacoma is truly unique, and thus becomes a vital part of program acceptance in and of itself. Part Two reports the findings from this case study!s semi-structured interviews with four law enforcement personnel and 21 program clients.

PART ONE: THE HISTORY OF THE TACOMA-PIERCE COUNTY NEEDLE EXCHANGE PROGRAM

The Tacoma-Pierce County Needle Exchange Program is the outcome of numerous formal and informal meetings and presentations, of actions between several key individuals and public agencies and organizations: It is a product of coalitions, of calculated and minimized risks, and of public entrepreneurism among various key individuals and public agencies and organizations. The majority of actions and activities discussed in this section have been traced through court documents, documented interviews conducted by Hill (1989), and numerous articles from the local newspaper, The Morning News Tribune. A triangulation of such sources has led to reliable information. 
The Role of Dave Purchase ${ }^{78}$

Dave Purchase has made a career in the field of drug treatment since 1969, and has been involved in many facets of drug treatment such as youth outreach, residential treatment, out-patient treatment, and inpatient detoxification (The Morning News Tribune 1989a; Purchase 1990). Currentiy, Purchase, the founder of the Point Defiance AIDS Projects (a non-profit organization), operates the needle exchange program under a service contract from the Tacoma-Pierce County Health Department (The Morning News Tribune 1990c).

Purchase's long-time involvement in the field of drug treatment indicates commitment in seeking ways to assist and educate individuals who have a disease of drug addiction. According to Hill (1989), when the Tacoma-Pierce County Health Department received a grant to develop an educational video on the topic of preventing AIDS for IVDUs, a friend who worked in that public agency suggested Purchase to be the narrator of the project. ${ }^{79}$ That particular video project involved Purchase and two other individuals, Terry Reid ${ }^{80}$ and Dennis Flannigan. ${ }^{81}$

\footnotetext{
${ }^{78}$ The information for this subsection has been obtained through various newspaper articles, media reports, court documents, and interviews with John Hill (1989). Purchase did grant two interviews with the researcher of this dissertation, on March 5, 1992, and March 9, 1992, but refused to sign the "informed consent form" (see Chapter VI for more details).

${ }^{79}$ Purchase has lectured extensively at seminars about the drug culture associated with the "hippie movement" of the 1960's (Hill 1989).

${ }^{80}$ Terry Reid is an employee of the Tacoma-Pierce County Health Department (formerly the Director of the Methadone Maintenance Program and currently the Manager of the Substance Abuse Section).

${ }^{81}$ Dennis Flannigan was elected to the Pierce County Council soon after the completion of the film.
} 
During that-same time, Purchase began meeting with officials at the Washington State Department of Social and Health Services seeking to establish a statewide treatment strategy that included needle exchange programs for IVDUs (Hill 1989). These endeavors, however, proved to be unsuccessful for Purchase, but he still remained committed to seeking AIDS intervention strategies, particularly for IVDUs (Hill 1989). Purchase revealed in an interview with Hill (1989):

I could see that nothing was being done [at the state level], they weren't going to start any kind of statewide program. [State officials] were ignorant of the importance of the concept; or worse.

At this point, Purchase decided to privately initiate and temporarily fund a needle exchange program in Tacoma; he subsequently contacted Reid, one of his friends in the Tacoma-Pierce County Health Department, to discuss the possibility of getting that agency to fund the program after a few months of private operation (The Morning News Tribune 1989a; Hill 1989). ${ }^{82}$ Reid, in an interview with Hill (1989), reflects on that particular meeting with Purchase:

When he [Purchase] got the idea that he could do it, he checked with me on the fact, that if he started it, was there a chance the health department might pick it up, provide the funding, and continue this service. I said yes. I thought we were in a position to do that because of our support of community outreach, the project we had underway already. Needle exchange was the logical next step in working in that arena.

\footnotetext{
${ }^{82}$ Since the latter part of 1986, several Tacoma-Pierce County Health Department officials had been exploring the likelihood of implementing a needle exchange program as a possible AIDS intervention strategy for intravenous drug users (IVDUs) (Hill 1989).
} 
Skillfully and privately, Purchase and Reid sought to mobilize support by meeting with various key individuals, especially those employed in public agencies and organizations who had the potential to ease implementation and minimize negative interferences of establishing such an innovative and controversial program. For instance, Reid met with members of the Board of Health, the Mayor of Tacoma ${ }^{83}$, and the Pierce County Executive ${ }^{84}$ (Hill 1989). Purchase met with Flannigan (who, at that time, was a member of the Pierce County Council), and together they approached Tacoma Chief Police, Ray Fjetland, about the plan to establish a needle exchange program in the city. Fjetland, concerned about public health and safety issues, agreed not to interfere with the needle exchange program (The Morning News Tribune 1988c). Fjetland added:

This isn't promoting it [drug use], it's managing it - The doper is going to do. it [drug use] anyway -he' 11 do it with a razor blade and an eyedropper (The Morning News Tribune 1988c).

Fjetland assured Purchase and Reid that the Tacoma Police Department would support the operation of a needle exchange program -- provided there were no city ordinances that prohibited the activities involved (Hill 1989). (All, however, were cognizant of the state laws against illicit drug use and possession of related paraphernalia.)

Purchase, in an interview with Hill (1989), reflects on that "support building" period:

\footnotetext{
${ }^{83}$ At that time, Doug Sutherland was the Mayor of Tacoma.

${ }^{84}$ At that time, Joe Stortini was the Pierce County Executive.
} 
In hindsight, I call the process curious confrontation: The basic presentation was, you gotta do what you gotta do, and I gotta do what I gotta do. This is what I gotta do. [Purchase said to them] I realize that once it [needle exchange] is known, people are going to be talking to you about it, so I want to let you know about it ahead of time.

Purchase comments further on the supportive relationships that were strengthened prior to opening the needle exchange program:
Without the support of the police and other officials the program may not have been possible. As things turned out: we were able to demonstrate whether it was effective or not, it was wonderful. That would not have been possible without the support provided by all the officials. They showed the courage, not me. The thing to remember is that I wasn't working at the time, so what were they going to do, fire me? On the other hand, Mayor Sutherland, County Executive Joe Stortini, councii woman Barbara Skinner, Councilman Dennis Flannigan, Chief Ray Fjetland, Health Department Director Al Allen, Terry Reid, and others were people with real jobs to lose. They are the people who made needle exchange possible in Tacoma-Pierce County (Hill 1989).

On August 9, 1988, Purchase opened a needle exchange program on the sidewalk of Pacific Avenue (in Tacoma) ${ }^{85}$ (The Morning News Tribune 1988d). The connection between Purchase and the Tacoma-Pierce County Health Department continued, and both the former and the latter were cognizant of the strategic roles which they occupied. For example, health outreach workers distributed condoms, bleach, and AIDS literature alongside Purchase on the opening day of the needle exchange program (The Morning News Tribune 1988d; Hill 1989). By the second week of the program's opening, the Tacoma-Pierce County Health Department sent its

\footnotetext{
${ }^{85}$ Pacific Avenue, downtown Tacoma, is known for attracting individuals considered to live on the fringe of society, particularly drug dealers/users, prostitutes, and so on.
} 
epidemiologist to collect data on program clients (Hill 1989). These preliminary statistics have been presented earlier, in Chapter II. By January 1989, the Tacoma-Pierce County Board of Health decided to adopt the needle exchange program as a public health measure to help retard the spread of HIV-1/AIDS among IVDUs (The Morning News Tribune 1989c and 1989 d). ${ }^{86}$

Although Purchase is credited with privately establishing the needle exchange program in Tacoma, the involvement of the Tacoma-Pierce County Health Department -- from the outset -- cannot be ignored nor minimized. Both Purchase and the Tacoma-Pierce County Health Department were cognizant of the advantages of having a private individual initiate a controversial program such as a needle exchange program. In fact, The Morning News Tribune (1988b) reports Dr. Allen ${ }^{87}$ as indicating that the "program might not have worked any other way." For this, Purchase can be viewed as a middleman for establishing a needle exchange program that would have posed many difficulties for any public agency or organization to initiate.

The Tacoma-Pierce County Needle-Exchange Program, however, has not escaped criticism or legal obstacles. Extensive debates, discussions, and correspondence were generated at the state and local levels of government, and are addressed in the following section.

\footnotetext{
${ }^{86}$ Since the adoption of the program, the Tacoma-Pierce County Heal th Department has al located $\$ 43,000$ to fund the needle exchange program to provide a van, needles, and a salary for Purchase (The Morning News Tribune 1989c). The Morning News Tribune (1990c) reported that Purchase was to seek an increase in the allocated funds to $\$ 79,000$ for expansion plans.

${ }^{87} \mathrm{Dr}$. Allen is the former Director of Board of Health of the Tacoma-Pierce County Health Department.
} 
WASHINGTON STATE LEGISLATIION

ON NEEDLE EXCHANGE PROGRAMS

Although Purchase set the stage at the local level by minimizing potential opposition by meeting with key individuals from various public agencies and organizations, legal issues surrounding the operation of a needle exchange program (i.e., funded by a public agency) were under scrutiny from the attorney for the Tacoma-Pierce County Health Department, the Pierce County Prosecutor, and the attorney for the City of Tacoma (Hill 1989). Although these attorneys did not challenge the adoption of the needle exchange program (by the Tacoma-Pierce.County Health Department), the Pierce County Prosecutor sent a cautionary letter regarding the precarious position ${ }^{88}$ which the Tacoma-Pierce County Health Department now occupied, and suggested that the Washington State Legislature address such a dilemma (Hill 1989). Subsequently, by the latter part of 1988, debates surfaced among Washington State legislators over the legality of operating needle exchange programs (Hill 1989); Washington State legislators focused on various sections of the Revised Code of Washington (RCW) 69.50 (i.e., the Uniform Controlled Substances Act) and RCW 70.24 (i.e., the Control and Treatment of Sexually Transmitted Diseases). These debates focused on whether public health officers have the power to distribute injection equipment to

\footnotetext{
${ }^{88}$ To reiterate, the possession and use of $i 1$ legal drugs and related paraphernalia is a criminal offense in the State of Washington. The Tacoma Police Department tolerated -- from the outset -- the implementation and operation of the needle exchange program in Tacoma although violations of the law are evident. This key issue is part and parcel to the acceptance of the Tacoma-Pierce County Needle Exchange Program from its inception. Indeed this is a precarious position; however, the Tacoma Police Department looked beyond the violations of the law for the greater good of society.
} 
IVDUs in order to control an epidemic (e.g., AIDS) despite the current laws against the distribution and/or possession of illicit drugs and related paraphernalia.

Various letters of correspondence (see Appendix C) surfaced between state and local public officials addressing the legal interpretations of various sections of RCW 69.50 and RCW 70.24. For instance, Braddock ${ }^{89}$ sent a letter to Flannigan acknowledging the legality of the program under RCW 70.24.400<12> (i.e., as a public health in controlling the spread of HIV-1/AIDS). The correspondence continued among other Washington state legislators discussing the specifics of terminology (e.g., "materials" and "officer") used in both RCW 69.50 and RCW 70.24. Opponents of needle exchange programs, for instance, argued that "materials" did not encompass the distribution of injection equipment for illicit purposes, particularly for IVDUs (Wolfe 1990). Consequently, Dr. Wolf $\mathrm{e}^{90}$ sought an opinion from the Washington State Attorney Generai' 's Office ${ }^{91}$ regarding the issue of legality of needle exchange programs in a state where there are prohibitions against the possession and use of illicit drugs and related paraphernalia ( $\mathrm{Hill}$ 1989). Wolfe posed the question of whether a needle exchange program --

${ }^{89}$ Dennis Braddock is a Washington State Representative for the 42nd Legislative District, and Health Care Committee Chair.

${ }^{90}$ Charles Wolfe, M.D., specializes in preventive medicine and holds a Master's Degree in Public Health. Wolfe is also a Washington State Representative for the 4th Legislative District in Spokane Valley, and has participated in the legislative debate over the legality of needle exchange programs in the 1989 Legislature as an opponent.

${ }^{91}$ At that time, Ken Eikenberry was Washington State Attorney General. The Assistant Washington State Attorney General was Jerry A. Ackerman. 
as an AIDS intervention strategy designed for IVDUs -- violated RCW

69.50.412<2>7, the law which prohibits the distribution and/or possession of illicit drugs and related paraphernalia (Hill 1989). On

March 28, 1989, Washington State Assistant Attorney General, Jerry A.

Ackerman, sent a reply to Wolfe's query:

As just noted, no exceptions to the applicability of $\mathrm{RCW}$ 69.50.412<2> are contained in the Uniform Controlled Substances Act. Moreover, one of the fundamental principles of statutory construction is that where the language of a statute is plain, free from ambiguity, and devoid of uncertainty, there is no room for construction and the statute's meaning must be discovered from its wording .. However, since it has been suggested that the enactment of chapter 206, Laws of 1988, has somehow affected the continued applicability of RCW $69.50 .412<2>$ to needle exchange programs, I will examine that construction requiring that multiple statutory enactments should, if possible, be construed to give meaning and effect each . . Chapter 206, Laws of 1988, (the AIDS Act) subsequentily expanded and amended Washington's statutory provisions relating to sexually transmitted diseases. The AIDS Act, as enacted and subsequently codified at RCW 70.24 et seq., contains no provision that, either expressly or by clear implication, purports to amend or repeal RCW 69.50.412<2> or any other statutory provisions relating to "drug paraphernalia." To the contrary, the legislative history of the AIDS Act shows that the legislature specifically considered and rejected a proposed provision that would have provided exactly the exemption now being suggested.

Subsequentiy, Wolfe and other legislative opponents of needle exchange programs took immediate action to try to outlaw such interventions; legislative opponents made an attempt to push through an amendment to the 1989 Omnibus Drug bil1,92 which was being considered

\footnotetext{
${ }^{92}$ The Omnibus Drug Act (Second Substitute House Bill No. 1793, Chapter 271, Laws of 1989) passed the Senate by strong majorities; 89-8 in the House; 37-10 in the Senate. The provisions clearly prohibited needle exchange programs statewide. Section 107 was vetoed by Governor Booth Gardner (Hill 1989; see Appendix C).
} 
by the Washington State Senate (The Morning News Tribune 1989e; Hill 1989). The amendment would have prohibited the operation of needle exchange programs statewide, and bring an end to the debate over the legality of such interventions (The Morning News Tribune 1989g; Hill 1989). On April 23, 1989, the House and Senate overwhelmingly passed the 97 page Omnibus Drug Bill -- with the amendment still intact: May 7, 1989, Governor Gardner signed the bill, however, only after having vetoed Section 107 which would have outlawed needle exchange programs in Washington State ${ }^{93}$ (The Morning News Tribune 1989h; Hill 1989; see Appendix ().

Gardner's veto strongly states that needle exchange programs do not promote illicit drug use but rather offer a means to help control the spread of a deadly disease, AIDS. For example, Gardner's veto message of Section 107, Second Substitute House Bill No. 1793 points out:

Section 107 of the bill would prohibit and force closure of needle exchange programs, currently operating in Tacoma and Seattle which are a means to reduce HIV/AIDS transmission and encourage treatment referral. These model programs have received national attention for their innovative and credible management of the needle exchange. Both programs are operated and strictly controlled by local public health authorities and are structured to accommodate maximum research benefit. I do not condone use of illegal drugs or their taking by intravenous means. The reality is that these programs have very little potential for encouraging more illegal drug use but a very high potential for limiting the spread of serious and deadly diseases which impact not only the persons involved but others. For both humane and economic reasons, we must do everything we can to halt the spread of AIDS.

\footnotetext{
${ }^{93} \mathrm{Dr}$. Allen wrote a letter to Governor Booth Gardner to formally request a veto of the Section 107 -- the amendment that would have banned needle exchange programs statewide (Hill 1989; see Appendix C).
} 
Debates concerning. the aforementioned legal issues subsided among legislators, but continued to be a concern of the Washington State Attorney General (Ken Eikenberry), who issued an opinion stating that any needle exchange program operating in Washington was in violation of RCW 69.50 (The Morning News Tribune 1989f; Rohan 1990). In turn, Dr. Allen filed a lawsuit in the Pierce County Superior Court to test the legality of the Tacoma-Pierce County Needle Exchange Program on October 20, 1989. On November 1, 1989, city funds ${ }^{94}$ for operating the needle exchange program in Tacoma were cut pending the court ruling. The next section discusses the lawsuit by extracting data mainly from court documents and litigation sumaries from various key individuals.

\section{The Lawsuit}

The capacity of courts to establish and implement public policy in the United States has been on display in a broad array of social issues, for instance, education, housing, labor, and welfare rights. In many ways, there is an American mindset to view social problems in legal terms (Scheingold 1974), allowing the judicial branch of American government to participate in establishing and implementing public policy that can effect the general citizenry or perhaps specific groups in society. Horowitz (1977) states that there is an "attractiveness" of passing social issues to judges in that there are benefits to be gained. In other words, judges are less burdened by commitments than other lawmakers (e.g., legislators) to "pet programs" and more distant from

\footnotetext{
${ }^{94}$ Funding for the Tacoma-Pierce County Needle Exchange Program is shared -- 50 percent by the City of Tacoma and 50 percent by Pierce County (The Morning News Tribune 1990b).
} 
stakeholders who are in a position to block action in other arenas (Horowitz 1977).

The legality issue of establishing and operating a needle exchange program in Tacoma has been resolved and clarified by a court decision. Dr. Allen's motion for summary judgment sought a court ruling that would legally sanction the needle exchange program as an AIDS intervention strategy; the City of Tacoma's motion for summary judgment asked the court to rule against sanctioning the program; and Pierce County filed a brief that coincided with Dr. Allen's request (The Morning News Tribune 1990a). Other organizations supported the motion filed by Dr. Allen and joined the lawsuit as amici curiae (i.e., friends of the court), namely the Washington State.Medical Association, the Pierce County AIDS Foundation, the Martin Luther King, Jr. Ecumenical Center, the Northwest AIDS Foundation, and the Tacoma Chapter of the National Council of Jewish Women (The Morning News Tribune 1990a). On Friday, February 16, 1990, legal arguments were presented to the Pierce County Superior Court and are summarized below.

The Plaintiff: Dr. Allen's Motion For Summary Judgment. Dr. Allen (plaintiff) brought motion for summary judgment to establish that a needle exchange program does not violate criminal law, and contends that an AIDS intervention program is a response to concerns of public health -- and not in violation of RCW 69.50.102. Rohan ${ }^{95}$ (1990) states that Dr. Allen's authority to operate the needle exchange program should be confirmed based on three main points:

${ }^{95}$ Robert $\mathrm{J}$. Rohan is an attorney who interpreted the laws in Dr. Allen's brief in support of motion for summary judgment. 
1. Under RCW 70.05, for 98 years, local health officers such as Dr. Allen and local health boards have had the power to take steps to prevent and control infectious diseases such as AIDS. This statutory authority is undisputed.

2. The 1988 AIDS Act authorized Dr. Allen as the regional director of the Pierce-Kitsap Regional AIDS Network to establish a needle exchange program.

3. The 1971 Drug Paraphernalia Act contains an exemption for actions of public officials, such as undercover police officers and public health workers, and was never intended to limit public health officials fighting an epidemic like AIDS.

Rohan (1990) addresses the first point in reference to Dr. Allen's broad power to control and prevent contagious and infectious diseases as indicated in RCW 70.05.060<4> and $\mathrm{RCW} 70.08 .070$. In being consistent in the ways in which public health officials deal with contagious and infectious diseases, a needle exchange program is considered as an AIDS prevention strategy for one high-risk group (Rohan 1990).

The second point -- entirely separate from the statutory authority given to public officials to control the spread of contagious and infectious diseases -- is that the 1988 AIDS Act also considers AIDS prevention strategies such as a needle exchange program for intravenous drug users (IVDUs) by granting exception to RCW 69.50. In other words, the AIDS Act of 1988 (i.e., RCW 70.24) set forth a strong statement of purpose, and granted public health officials the capacity to use alternative strategies to combat contagious and infectious diseases such as AIDS -- consistent with prior public health legislation and court rulings (Rohan 1990). Rohan (1990) cites a portion of RCW 70.24:

The legislature finds that the incidence of sexually transmitted diseases is rising at an alarming rate, and that these diseases result in significant social, health, and economic costs including infant and maternal 
mortality, temporary and lifelong disability; and premature death ... The legislature also finds that medical knowledge and information about sexually transmitted diseases are rapidly changing. It is therefore the intent of the legislature to provide a program that is sufficiently flexible to meet the emerging needs, [and] deals efficiently and effectively with reducing the incidence of sexually transmitted diseases [Emphasis supplied.] RCW 70.24.015.

Rohan (1990) contends that the language in the AIDS Act

is a plain legislative mandate that as prevention strategies are developed, they are available for use by the regional directors of the regional AIDS service networks such as Dr. Allen. This interpretation is consistent with the Washington Supreme Court holding that public health officials must be able to use the latest scientific knowledge to prevent infectious and contagious diseases and endorsing the use of the 'best scientific thought of the age. ${ }^{196}$

Rohan (1990) addresses the third point regarding the intended use of the definition of "public officers." · For instance, RCW 69.50.506<c> (i.e., the exemption section) states:

No liability is imposed by this chapter upon any authorized state, county or municipal officer, engaged in the lawful performance of his duties.

The Washington State Attorney General's Office acknowledges that RCW 69.50 indicates an exemption for the actions of "public officers," but states that the operations of a needle exchange program do not apply under such provisions. Moreover, the Washington State Attorney General's Office contends that Dr. Allen and the individuals who carry out the daily operations of the needle exchange program are not

${ }^{96}$ State ex rel. McBride v Superior Court (see Rohan 1990). 
"officers" and thus not exempt under RCW 69.50. They justified this claim by defining the term "officers" from a civil case (regarding a compensation issue) $)^{97}$ which conveyed an interpretation of the state constitution (Rohan 1990).

Rohan (1990) argues that the Washington State Attorney General's Office inappropriately defined "officer" (since RCW 69.50 is a criminal statute), and neglected to use the intended meaning of the term under the criminat code (i.e., RCW 9A.04.110<13>) as follows:
"Officer" and "public officer" means a person holding office under a city, county, or state government, or the federal government who performs a public function and in so doing is vested with the exercise of some sovereign power of government, and includes all assistants, deputies, clerks, and employees of any public officer and all persons lawfully exercising or assuming to exercise any powers or functions of a public officer.

Rohan (1990) suggests that the term "public officer" includes Dr. Allen, outreach workers, program staff, and assistants as they are "exercising . . . the powers or functions of a public officer."

The Defendants: Pierce County and The City of Tacoma's Memorandum in Support of Summary Judgment.

Pierce County. Pierce County (defendant) supports the request brought forth by $\mathrm{Dr}$. Allen, and agrees that the needle exchange program in Tacoma should be legally sanctioned (Vanscoy 1989)..$^{98}$ To elaborate, Pierce County agrees with the assertions made by Dr. Allen regarding the deficiencies in the formal opinion of the Washington State Attorney

${ }^{97}$ State ex rel. Brown V Blew (See Rohan 1990). County.

${ }^{98}$ Douglas W. Vanscoy was the Deputy Prosecuting Attorney for Pierce 
General's Office (which led to the suspension of funds from the City of

Tacoma for the needle exchange program), and therefore, suggests:

The Court should not lightly construe a criminal statute which predated the existence of that disease so as to remove one of the few effective means for controlling its spread. The Court should find the power of health officials to be commensurate with the danger presented to the public and hold that RCW 69.50.412<2> does not reach needle exchange programs implemented by local health officers (Vanscoy 1989).

The other defendant in this lawsuit, the City of Tacoma, has not viewed the needle exchange program as favorably as Pierce County. The City of Tacoma's memorandum in support of motion for summary judgment is presented below.

The City of Tacoma. The cjty's major points of contention center around (1) violations of RCW 69.50, which prohibits the sale/possession of illicit drugs and related paraphernalia, and (2) that a needle exchange is not legitimized by the 1988 AIDS Act. The City of Tacoma supports granting public health officers discretion to combat the AIDS epidemic, but argues that such authority should be limited -- not unlimited (Smith 1990). ${ }^{99}$ Smith contends:

The authority of Dr. Allen is limited, at the very least, by the criminal law of the State of Washington. Dr. Allen is not vested with the discretion to ignore the criminal statutes of this State. If, as Dr. Allen suggests, because of his position and his responsibilities, he is not bound by the prohibition against delivery of drug paraphernalia. (RCW 69.50.412<2>), then what other statutes might the Health Officer disregard to protect the public health? Why could he not provide the drugs to be injected, perhaps for a small price? All sorts of mischief could be avoided if addicts --

${ }^{99} \mathrm{Smith}$ is one of the attorneys for the City of Tacoma. 
some of whom are also AIDS victims -- did not have to elude the law in order to acquire the drugs they inject. Could not the Health officer himself administer the illegal injection in the interest of protecting the public health? Might the injection thereupon become legal -- no further formality necessary? It hardly needs saying that public officials -- even health officials -- are not above the law.

Smith (1990) further states that Dr. Allen insists that the operation of the needle exchange program is a "proper and necessary extension of his authority as a Public Health Officer." The City of Tacoma contends, however, that there are other means to conduct needle "sterilization":00 without distributing injection equipment for the use of illicit drugs. Smith (1990) points out that Dr. Allen has chosen a means of needle sterilization which violates the law. ${ }^{101}$

Both the plaintiff and defendants presented arguments which centered around RCW 69.50 and RCW 70.24 (the statutes that hold the capacity to legally sanction or ban a needle exchange program in the State of Washington) interpreting and defining terms to their own advantage. Arguments of the plaintiff and defendants, however, differed in the directions taken to convince the judge of the positions taken regarding the operations of the needle exchange program in Tacoma. The Superior Court for the State of Washington, County of Pierce, issued a ruling

${ }^{100}$ The word "sterilization" is used because Dr. Allen and Pierce County attorneys have interpreted needle exchange as "sterilization."

${ }^{101}$ The 1988 AIDS Act provides that a regional AIDS service network plan shall include components, such as: "Intervention strategies to reduce the incidence of HIV infection among high-risk groups, possibly including needle sterilization and methadone maintenance" (RCW $70.24 .400<3>$ ). 
which favored the legal arguments presented by the plaintiff, Dr. Allen.

Judge Robert Peterson: The Ruling From The Bench. Judge Robert Peterson embraced the arguments brought forth in Dr. Allen's motion for summary judgment. In short, Judge Peterson's ruling emphasized that $\mathrm{Dr}$. Allen is acting in a lawful manner under the duties of a health officer, and the individuals who carry out the daily operations of the needle exchange program are under that jurisdiction. Immunity is provided to Dr. Allen under the exemption stated in RCW 69.50. Judge Peterson confirmed the broad powers of Dr. Allen as a health officer to reduce the spread of AIDS. Moreover, the court ruled that the RCW 69.50 is a general statute which refers to a wide array of drug paraphernalia, whereas the 1988 AIDS Act directly relates to the issue of sterile needles as an AIDS intervention strategy. Judge Peterson states that public health officers may execute intervention strategies which are considered effective means to control the spread of contagious and infectious diseases (The Morning News Tribune 1990a). The City of Tacoma did not appeal the court's ruling (The Morning News Tribune 1990b). Clearly this was a victory for needle exchange as one means to reduce the spread of HIV-1/AIDS, and the court's ruling sets a precedence in support of such programs throughout the United States.

Despite former Governor Gardner's support for needle exchange programs, and even though the court's ruling legally sanctioned needle exchange programs, program acceptance is not unconditionally guaranteed. In other words, the law enforcement personnel and IVDUs might have rejected such a needle exchange program which aims to change behaviors 
and practices associated with injecting illicit drugs. The attributes of program acceptance have been examined in this particular research through various face-to-face interviews with key law enforcement personnel and program clients (i.e., IVDUs) of the needle exchange program and are presented below. ${ }^{102}$

\section{PART TWO: INTERVIEWEES' PERSPECTIVES ON PROGRAM ACCEPTANCE}

As discussed in Chapter IV, "Research Strategy, " original data have been collected for this research through semi-structured interviews seeking the viewpoints of law enforcement officers and program clients regarding factors relating to what contributes to the needle exchange program in Tacoma. Data collected from these interviews have provided insights into each of the three diverse population groups directly involved in various aspects of the needle exchange program in Tacoma. Four law enforcement personnel and 21 program clients were asked specific questions during face-to-face interviews about the needle exchange program and its operations. The findings are presented in the remaining pages of this chapter.

\section{Research Question \#1}

"What characteristics of the needle exchange program in Tacoma are linked to program acceptance?"

${ }^{102}$ This study did not obtain any specific information about the Tacoma-Pierce County Health Department's fixed-site, pharmacy-based needle exchange program, and did not interview at that site location to gather data. Any information about the pharmacy as an exchange site has been obtained through interviewed program clients at the South 14 th and $G$ Street "street-based" site as well as through the interviews with law enforcement personnel. 
Settings. Both program clients and law enforcement personnel were asked several questions regarding the importance and effectiveness of settings in delivering services to a paranoid population group such as IVDUS.

The Point Defiance AIDS Projects, under contract from the TacomaPierce County Health Department, operates two mobile van units which distribute sterile injection equipment to IVDUs. ${ }^{103}$ Mobile van units park on the streets of Tacoma where IVDUs congregate, and are able to relocate the vehicles when the drug trade ${ }^{104}$ decides to move to another locale to congregate (i.e., to meet with others for various purposes such as buying and selling drugs, and socializing). In other words, mobile van units follow the movement of the drug trade. For example, the drug trade's location of congregation changed at least once during this particular study (i.e., from the parking lot of St. Leo's Parish to South 14th and G Street just one street over and behind St. Leo's Parish parking lot), and mobile van units moved along with them to swap the IVDUs' injection equipment.

Perhaps the two most important elements in having mobile van units deliver services to program clients who periodically change location, and who have a dislike for government settings are: (1) flexibility, and (2) accessibility. For law enforcement personnel, flexibility is a very important element of an appropriate setting for both their agency and program clients (i.e., IVDUs); thus mobile van units help the needle

\footnotetext{
${ }^{103}$ In some cases, the mobile van units deliver sterile injection equipment to IVDUs.

${ }^{104 " D r u g ~ t r a d e " ~ r e f e r s ~ t o ~ a ~ g r o u p ~ o f ~ i n d i v i d u a l s ~ w h o ~ u s e ~ a n d / o r ~ s e l l ~}$ illicit drugs.
} 
exchange program achieve that element. Data obtained through interviews with various law enforcement personnel indicate that mobile van units essentially need to follow the drug trade to be effective. The mobile van units go directly to the environment of the program clients -- and that is an important part of program acceptance, especially for IVDUs. TABLE $V$ reveals the number of miles IVDUs traveled, one way, to receive services, and indicates the importance of accessibility to program clients that were interviewed in this study.

\section{TABLE V}

DISTANCE TRAVELED BY INTERVIEWED PROGRAM CLIENTS

TO RECEIVE SERVICES OF THE TACOMA-PIERCE

COUNTY NEEDLE EXCHANGE PROGRAM

$N=21$

Total $=100$ percent

As Table $V$ shows, the majority (67 percent) of the interviewed program clients traveled one mile or less to receive their injection equipment. Not one of the 21 respondents indicated traveling a distance 
of five miles or more to swap injection equipment at the needle exchange program. ${ }^{105}$

Table VI further indicates the importance of accessibility to interviewed program clients.

\section{TABLE VI}

RETURN VISITS AS AN INDICATOR OF

ACCESSIBILITY: FREQUENCY OF USE

NUMBER OF VISITS BY

INTERVIEWED PROGRAM CLIENTS

N

$(\%)$

\begin{tabular}{rrr}
\hline$>10$ & 15 & $(71.4)$ \\
$6-10$ & 3 & $(14.3)$ \\
$2-5$ & 3 & $(14.3)$ \\
$<2$ & 0 & $(0.0)$ \\
\hline
\end{tabular}

$N=21$

Total $=100$ percent

Periodic return visits to the needle exchange program also suggest satisfaction among the program clients with this type of setting. As seen in Table VI, 15 out of the 21 (71.4 percent) respondents have reported using the needle exchange program over 10 times, and none of the respondents indicated that it was their first time for using the needle exchange program. In essence, return visits are a good indicator of satisfaction among the program clients (i.e., IVDUs) with this type of setting, and, thus indicate that mobile van units provide a low barrier to physical accessibility.

${ }^{105}$ The 21 respondents refer to the interviewed program clients who participated in this research. 
The Tacoma-Pierce County Health Department also operates a fixedsite out of its pharmacy window. Although 16 of the 21 program clients (76 percent) who have been interviewed state that they have never utilized the pharmacy to exchange injection equipment, it still serves a valuable function by being located close to the methadone maintenance program. By observation, the pharmacy is considered to have a convenient location and seems to provide good access to those individuals who are most likely to fall back into injecting illicit drugs. Furthermore, having one fixed-site setting can provide an element of certainty for IVDUs, and eliminates guesswork in finding the mobile van units.

Comparatively, mobile van units allow for quicker and easier relocation than fixed-site settings. Mobile van units can avoid the rental or lease agreement required for fixed-sites; licensing fees; and physical moving of furniture, supplies, and equipment. In other words, the relocation of a fixed-site is much more problematic and complex than a mobile van unit which can simply turn on the ignition and follow the drug trade. The importance of having mobile van units to deliver services to program clients cannot be overstated. The Tacoma-Pierce County Needle Exchange Program characterizes an ideal setting, like The Netherlands', by having a combination of the two types of settings. These settings thus allow for greater acceptance in terms of accessibility and flexibility by all those involved with the needle exchange program, particularly law enforcement personnel and IVDUs.

Iype of Staff. The type of staff that operates the mobile van units is critical to IVDUs' accessibility, to services, and therefore, the 
relationships that are formed between the program clients and staff are extremely important to program acceptance. Purchase privately started the needle exchange program in Tacoma without bureaucratic formalities, and this has attracted the type of staff that distributes sterile injection equipment to IVDUs. ${ }^{106}$ Program clients, however, have basically expressed that a user-friendly relationship is maintained between themselves and the program staff. Table VII summarizes characteristics of program staff and interviewed clients' perception of those characteristics.

TABLE VII

INTERVIEWED CLIENTS' PERCEPTIONS

OF PROGRAM STAFF

\begin{tabular}{lrrrrr}
\hline \multicolumn{5}{c}{ RESPONSES N(\%) } \\
$\begin{array}{lrrrr}\text { CHARACTERISTICS } \\
\text { OF PROGRAM STAFF }\end{array}$ & $\begin{array}{l}\text { VERY } \\
\text { HIGH }\end{array}$ & HIGH & MEDIUM & LOW & \multicolumn{1}{c}{$\begin{array}{l}\text { VERY } \\
\text { LOW }\end{array}$} \\
\hline Closeness & $7(33)$ & $9(43)$ & $4(19)$ & $0(0)$ & $1(5)$ \\
Friendliness & $11(52)$ & $8(38)$ & $2(10)$ & $0(0)$ & $0(0)$ \\
Informality & $2(9)$ & $5(24)$ & $4(19)$ & $5(24)$ & $5(24)$ \\
Non-Judgmental & $7(33)$ & $13(62)$ & $1(5)$ & $0(0)$ & $0(0)$ \\
Trustworthy & $4(19)$ & $14(67)$ & $3(14)$ & $0(0)$ & $0(0)$ \\
Committed & $7(33)$ & $13(62)$ & $1(5)$ & $0(0)$ & $0(0)$ \\
& & & & & \\
\hline
\end{tabular}

$N=21$

Total $=100$ percent

Overwhelmingly, the interviewed program clients perceived the staff to be very appropriate. The program staff were described by the respondents as being close, friendly, non-judgmental, trustworthy, and

${ }^{106}$ The researcher was not given the opportunity to interview the staff who operate the mobile van units for reasons stated in Chapter VI. 
committed. The respondents were less likely to think program staff were formal.

A11 21 respondents' indicate that they were able to communicate comfortably with the program staff. Several interviewees commented that many individuals would not use the needle exchange program if the staff "preached" about the consequences of illicit drug use. To this extent, the findings suggest that a "user-friendly" relationship between program clients and program staff exists, and thus implies that the TacomaPierce County Needle Exchange Program is accessible and flexible in delivering services to the program clients.

From the perspective of the law enforcement personnel, the staff who operate the mobile van units are able to serve a variety of individuals known to be IVDUs. For law enforcement personnel, "user-friendly" means speaking with carefully picked vocabulary, ${ }^{107}$ displaying non-coercive mannerisms, having a "dressed-down" appearance, and having a nonjudgmental attitude toward program clients. In their opinion, IVDUs are not as likely to utilize the needle exchange program, if in fact, the staff appears in any way connected with a bureaucratic environment (i.e., in appearance, use of language, mannerisms, or attitude).

Aside from the staff who operate the needle exchange program, Tacoma Police Chief Ray Fjetland has been instrumental in gaining acceptance of such a controversial program. Personal opinions about the needle exchange program varied among individual law enforcement officers in

\footnotetext{
${ }^{107}$ Staff who operate the mobile van units have come up with "oreliners" on condom use, bleach used to clean injection equipment, and so on. Most program clients do not want a "sermon" on illicit drug use, or any lengthy explanations concerning safe sex and so on.
} 
Tacoma. As a matter of fact, there was a split decision within the Tacoma Police Department in reference to supporting a needle exchange program in Tacoma. Much of the split tended to center around the lack of enforcement of the illicit drug use and related paraphernalia laws, and the message that might be conveyed to the young people resulting therefrom. In essence, the main reasons that caused a split in the departmental decision was that. a needle exchange program "contradicted the current law on the books., "and that young people may be led to believe that it is "okay. to do drugs because there is now an available forum for getting clean needles" to use illicit drugs. Nonetheless, when Fjetland gave his support for establishing a needle exchange program in Tacoma, law enforcement personnel accepted the controversial program as a matter of policy. Beyond that, program acceptance became easier for law enforcement officers once the needle exchange program became legitimized by the court. Currently, law enforcement officers maintain a professional, "hands-off" relationship with the staff and program clients of the needle exchange program; however, they continue to patrol the area (i.e., as part of their normal routine) where the drug trade occurs. Perhaps without the support and cooperation of Fjetland, from the very beginning, a workable relationship might not have transpired among all the groups involved. Indeed, the survival of the Tacoma-Pierce County Needle Exchange Program is highly attributed to the cooperation of the Tacoma Police Department.

Method of Service Delivery. The needle exchange program in Tacoma offers a service to its clients in a non-bureaucratic style. Nineteen of 21 respondents are satisfied in the way in which the Tacoma-Pierce 
County Needle Exchange Program operates. There is no "red-tape" for clients to go through in order to receive services; that is, there are no eligibility requirements (e.g., confess use, waiting period, plead poverty, identification) to receive services of the needle exchange program. Furthermore, the needle exchange program in Tacoma does not request any identification -- in any form -- from a prospective client, in order to receive services. Interviewed program clients are skeptical about offering identification to receive services. Seventeen of the 21 respondents ( 80 percent) stated that they would not utilize the needle exchange program if they had to give their name, address, social security number, and/or other types of identification. Correspondingly, law enforcement personnel agree that program clients would reject the services provided by the needle exchange program if eligibility requirements to use the program were put into effect. Eligibility requirements, especially the request for identification, would pose a non-penetrable barrier to program clients -- ultimately defeating its purpose.

Requesting a piece of identification from an individual who utilizes the needle exchange program is not particularly valuable to law enforcement personnel. Law enforcement personnel claim they are familiar with most IVDUs in Tacoma, and recognize the areas in which the drug trade occurs. Interview data reveal that:

We (law enforcement officers) are aware of who some of the drug users are but that's because some are involved in criminal activities and have an arrest record ... there's no secret .. . We know them usually by first name basis . . their addiction has progressed to such a level that the issue of anonymity is not an issue. 
What is of value is that interviewed program clients believe that their freedom and safety are protected under the current method of service delivery.

Unlike the Portland needle exchange, which requires its clients to be at least 18 years old and have visible signs of illicit drug use, Tacoma's program does not require a program client to be a particular age or show proof of recent drug use. ${ }^{108}$ Unlike Hawaij's program, which limits the number of exchanges to five per day, Tacoma's program allows program clients to swap an unlimited number of needles, provided they bring one dirty needle for each sterile one received. Absolutely no injection equipment is given to IVDUs without their bringing in used works -- in essence, on a one-to-one swap. First-time program clients thus need to find a dirty needle/syringe (i.e., on the streets, in parks, greenbelts, and trash) to bring to the needle exchange program.

Law enforcement personnel have supported the ways in which injection equipment is distributed and collected at the needle exchange program. For instance, prior to the implementation of the needle exchange program, the Tacoma Police Department would receive frequent telephone calls about IVDUs discarding used, uncapped injection equipment in gutters, parks, mini-greenbelts, streets, and other areas throughout the city. According to Tacoma Police Chief, Ray Fjetland (1989):

Black tar heroin use increased dramatically; and with it new social and public safety issues . . . the community became increasingly aware of discarded needles and their potential for accidental infection. Children were finding them in the restroom tissue dispensers of the

\footnotetext{
marks."

${ }^{108}$ One indicator of "recent drug use" would be to show "track
} 
finest restaurants and hotels; and public health officials. became increasingly alarmed about the number of IV drug users who tested HIV positive.

In fact, law enforcement personnel point out that having a method of service delivery that involves a one-to-one exchange is more beneficial than simply handing out injection equipment via vending machines, or even other needle exchange programs which do not require a one-to-one swap.

Court documents reveal that both Fjetland and Glen Tharp ${ }^{109}$ recognize the additional benefit of having a one-to-one swap of injection equipment, rather than simply handing out works. Tharp (1989) confirms Fjetland's statement and points out that a reduction has occurred in the number of haphazardly discarded, used needles/syringes found around Tacoma. Tharp (1989) further points out:

there has been a significant reduction over the past six to eight months in the number of used syringes found in the areas of the city which I am responsible for maintaining .. . Previously, my crew and I observed syringes in shrubbery, buried or semi-buried in flowerbeds and tree tub containers, thrown into trash containers, and laying out in the open park areas downtown. often, the syringes had been plunged into the dirt of flowerbeds or tree tub containers and were not visible. My crews would discover the concealed syringes unexpectedly when they picked out trash or weeded. Two of my crew members were stuck with needles . . . Now, very few syringes are being found in the areas in which my crews and I formerly saw syringes on a regular basis. The locations in which my crew and I have observed the greatest reduction in the number of syringes are: South 9th and Commerce Streets going east on 9th to Pacific

${ }^{109} \mathrm{Glen}$ Tharp is the Grounds Maintenance Supervisor, Street Maintenance Division, Department of Public Works of the City of Tacoma, Washington. Tharp and his crew of 10 people maintain lawns, greenbelts, and parks in the City of Tacoma. 
Avenue .. South 12th Street and Pacific Avenue ... South 10th Street and Pacific Avenue.

Both law enforcement personnel and ground maintenance personnel thus claim there are less complaints from citizens in regard to discarded injection equipment. Indeed, this indicates satisfaction in the method of service delivery for both law enforcement personnel and program clients which ultimately promotes program acceptance of the TacomaPierce County. Needle Exchange Program.

Positive Externalities/Spillover Effects. Positive externalities, or spillover effects, are the additional benefits (often unintentional or unforeseen during the program formation or implementation stages) resulting from the operations of a particular program. The TacomaPierce County Needle Exchange Program offers some positive externalities for each of the three groups.

For program clients, the needle exchange program offers other valuable items in addition to sterile injection equipment, such as bleach, condoms, AIDS literature, sterile water, personal hygiene products, clothing, free testing (e.g., AIDS, various sexually transmitted diseases, tuberculosis, and hepatitis B), and informal legal advice. According to one program client who participated in this study, the needle exchange staff told him "legal things . . like anyone caught dealing drugs within 1,000 yards of a day care would get an automatic 15 years (in jail)."

Another positive externality -- that is, beyond all the extra items and services already provided by the needle exchange program -- is that 
it provides an opportunity for IVDUs to come in contact with others who understand -.. but are not victimized -- by drug addiction.

Law enforcement personnel have also experienced additional benefits since the establishment of the needle exchange program. Prior to the needle exchange program, many law enforcement officers who patrolled high-crime areas have experienced a needle stick injury from searching or frisking a suspect. As one law enforcement officer points out:

pretty much any officer that has worked a high-crime area or area of high drug addiction use -- abuse -- has come out of somebody's pocket with a needle stuck in their palm with a depressed syringe... having capped, clean needles is pretty important to us

Fjetland (1989) also acknowledges the potential for infection via accidental needle stick injuries, and confirms in a court document that "police officers found more and more syringes on suspects" prior to the establishment of the needle exchange program in Tacoma. Reducing the chances of accidental infection becomes a vital factor in the acceptance of the needle exchange program in Tacoma, since the staff who operate the mobile van units strive to educate IVDUs about capping injection equipment.

\section{Research Question \#2}

"What characteristics of the external environment are linked to program acceptance?"

Nature of the Geographic Area. Two current geographic locations where the mobile van units locate to exchange injection equipment are somewhat different in physical and psychological landscape. The locale of South 14th and G Street, for example, is considered to be urbanized, 
semi-residential, and a high-crime area (according to law enforcement personnel). There are several other social services offered in this particular neighborhood such as The Hospitality Kitchen and The Food Connection located inside the former Catholic grade school now known as St. Leo's Parish. Both injectors and non-injectors utilize The Hospitality Kitchen and The Food Connection, which provide free meals for a variety of folk. The Martin Luther King Ecumenical Center is also located within a block of St. Leo's Parish. The hours of operation seem to correspond to the activities which occur at the locale where intravenous drug users (IVDUs) congregate; for instance, one mobile van unit parks at this particular locale from 11:30 a.m. to 2:30 p.m.

The downtown locale, South 15th and Commerce Street, is urbanized and non-residential. The intersection of these two streets reveals the epitome of urban blight, where even the plasma center has relocated to a more desirable area. Within this locale is the Rescue Mission, a shelter which offers free meals and other activities to a variety of individuals, and the Last Chance shelter. These streets border areas that are considered relatively "safe" in the daytime, as there are several major banks and many retail establishments and restaurants which attract numerous patrons during the typical " 9 to 5 " working hours. In the evening (i.e., after 5:00 in the afternoon), however, this area is transposed into the turf of "street" people and drug trade. The hours of operation tend to coincide with the nature of the geographic area in terms of safety; for instance, one mobile van unit parks at this locale from $3: 00$ to $5: 00$ p.m. 
The nature of the geographic area can be problematic for program acceptance; thus the needle exchange program needs to be strategically located near familiar places which are tolerant of the drug trade. As presented earlier (in Part One of this chapter), opposition toward the needle exchange program in Tacoma occurred among various politicians regarding program acceptance. Other individuals, however, have expressed their concerns about having a program which caters to IVDUs. For example, the downtown business community opposed the needle exchange program on grounds that it increased drug trafficking and activities. Denzil Rowley ${ }^{110}$ (1990), expressing his opposition to the needle exchange program (i.e., referring particularly to the early stages when the exchange was located on the sidewalk of Pacific Avenue), claimed in a court document:

drug dealers were providing and receiving curb service from automobiles .. This drive-up drug trafficking became so large a business and of such concern that the City of Tacoma police finally put a line of concrete road barriers down the curb side, between 14th and 15th and Pacific, in order to make it more difficult for cars to stop for drug trafficking purposes . . . Since late 1988, or early 1989, the needle exchange program has moved up to about 14 th and Cormerce Street in Tacoma. Since then, streets in front of our store have remarkably improved, there being far fewer drug users or drugrelated activities on the street. I attribute this change generally to the movement of the [needle exchange] program, which largely took its patrons with it.

The use of mobile van units has helped to reduce opposition by allowing for more circumspect collection and distribution of injection

\footnotetext{
${ }^{110}$ Denzil Rowley is the general manager and vice-president of a downtown furniture company.
} 
equipment. The number of complaints have decreased after mobile van units relocated up the street, out of sight of retail establishments, to a more accessible environment -- an environment that is referred to as "user-friendly."

Other characteristics of the external environment are considered important to program acceptance. Law enforcement personnel state "convenience" as an important characteristic of the external environment in order for IVDUs to take advantage of the needle exchange program. Table VIII shows the importance of the geographic area as perceived by interviewed program clients.

TABLE VIII

INTERVIEWED IVDUS' PERCEPTION

OF THE EXTERNAL ENVIRONMENT

\begin{tabular}{llll} 
NATURE OF & \multicolumn{2}{c}{ RESPONSES } \\
GEOGRAPHIC & VERY & N(\%) & \\
AREA & IMPORTANT & IMPORTANT NEUTRAL UNIMPORTANT & VERY UNIMPORTANT
\end{tabular}

\begin{tabular}{lrllll}
\hline Proximity & $10(48)$ & $6(28)$ & $2(10)$ & $0(0)$ & $3(14)$ \\
Privacy & $9(43)$ & $6(28)$ & $4(19)$ & $1(5)$ & $1(5)$ \\
Urban Setting & $8(38)$ & $6(28)$ & $4(19)$ & $2(10)$ & $1(5)$ \\
Familiarity & $8(38)$ & $7(33)$ & $4(19)$ & $1(5)$ & $1(5)$ \\
\hline
\end{tabular}

$N=21$

Total $=100$ percent

For program clients (i.e., IVDUs) "proximity," "privacy,"

"familiarity of an area," and "urban" are considered important 
characteristics of the external envïronment in reference to program acceptance; for example, most respondents' claim that having the needle exchange program operate near other social services, shelters, and so on is an important characteristic of the external environment; many also state that "privacy" is an important characteristic of the external environment; 15 of the 21 respondents (71 percent) claim that "familiarity of an area" is an important characteristic of the external environment; and 14 of the 21 respondents (66 percent) claim that "urban" is an important characteristic of the external environment. Concern Over the Effects of AIDS. These two locales (mentioned in the above section) are well known to law enforcement personnel as well as the clients of the Tacoma-Pierce County Needle Exchange Program. Although mobile van units which distribute needles to program clients at these two locales are quite ordinary, having no particular markings, both IVDUs and law enforcement personnel seem cognizant of illicit activities that occur at the sites. Law enforcement personnel are willing to "close an eye" to illegal drug use for a greater good to society. ${ }^{111}$ In other words, the "concern over the effects of AIDS" has led to the non-enforcement of existing laws regarding illicit drug use and possession of related paraphernalia for a more noble cause (i.e., to control the spread of HIV-1/AIDS).

Inasmuch as a needle exchange program has evolved and survived in a state where the possession of illicit drugs and related paraphernalia is

\footnotetext{
${ }^{111}$ To reiterate, there was a departmental split in the support of the Tacoma-Pierce County Needle Exchange Program in the beginning until the lawsuit clarified the legality of the Program. Subsequently, "closing an eye" to illegal drug use has been part and parcel to the acceptance of the Tacoma-Pierce County Needle Exchange Program.
} 
against the law, in itself, displays widespread concern over the effects of AIDS by many agencies and organizations. Many of these agencies and organizations have adopted specific policies and guidelines in reducing the risk of accidental infection of HIV-1/AIDS. For example, law enforcement agencies in many states have integrated AIDS awareness in their mandatory training programs. This is a brief explanation of the training of Tacoma law enforcement officers: ${ }^{112}$

police officers have to go through basic training for thirteen weeks at the. Washington State Criminal Justice Training Commissions Academy in Burien (Washington). They go through a field training officer program in our department (Tacoma Police Department) for anywhere from about six to 12 weeks depending on how they excel through the program -- where they work one on one with another officer, a field training officer, and they're evaluated daily. There's in-service training, there's roll call training with publications that are put out to them -- legal publications, health publications, and some of the in-service training covers some of the concerns with regard to AIDS ... That becomes a real concern . . especially for officers that come into contact with people who are bleeding or people who spit on us . . people who like to spit in your face and then say ' $\mathrm{Ha} \mathrm{Ha}^{\mathrm{I}}$ I got AIDS' ... those types of concerns ... So they're aware of this and they've been educated for the likelihood of somebody spitting on their face ... I don't think it's not impossible... but just so minuscule ... It's unimaginable but they're aware that when you're dealing with people and particularly high-risk groups that you deal with it. It's all part of training. They read and know what's going on . . O Officers are able to use masks and gloves for CPR, etc., ... Again it's not just for the AIDS virus but for hepatitis that's been around.

Like law enforcement personnel, intravenous drug users (IVDUs) are cognizant and concerned about the effects of AIDS. Table IX shows the

\footnotetext{
${ }^{112}$ Information about the training programs has been obtained through face-to-face interviews with law enforcement personnel.
} 
concern over the effects of AIDS of interviewed program clients in terms of pointing out the most important reasons as to why they use the needle exchange program.

TABLE IX

INTERVIEWED IVDUS' CONCERN

OVER THE EFFECTS OF AIDS

\begin{tabular}{|c|c|c|c|c|c|}
\hline \multirow{2}{*}{$\begin{array}{l}\text { REASONS WHY IVDUS } \\
\text { USE THE NEEDLE } \\
\text { EXCHANGE }\end{array}$} & \multirow{2}{*}{$\begin{array}{l}\text { VERY } \\
\text { IMPORTANT }\end{array}$} & \multicolumn{2}{|c|}{$\begin{array}{l}\text { RESPONSES } \\
N(\%)\end{array}$} & \multirow[b]{2}{*}{ UNIMPORTANT } & \multirow{2}{*}{$\begin{array}{l}\text { VERY } \\
\text { UNIMPORTANT }\end{array}$} \\
\hline & & IMPORTANT & NEUTRAL & & \\
\hline To not get AIDS & $15(71)$ & $4(19)$ & $2(10)$ & $O(0)$ & $0(0)$ \\
\hline $\begin{array}{l}\text { To not get Other } \\
\text { Diseases }\end{array}$ & $15(71)$ & $4(19)$ & $2(10)$ & $0(0)$ & $0(0)$ \\
\hline $\begin{array}{l}\text { To not Spread AIDS } \\
\text { to Others }\end{array}$ & $15(71)$ & $4(19)$ & $1(5)$ & $1(5)$ & $0(0)$ \\
\hline $\begin{array}{l}\text { Because Friends use } \\
\text { the Program }\end{array}$ & $9(43)$ & $10(48)$ & $0(0)$ & $2(10)$ & $0(0)$ \\
\hline $\begin{array}{l}\text { To get Free } \\
\text { Syringes }\end{array}$ & $15(71)$ & $5(24)$ & $1(5)$ & $0(0)$ & $0(0)$ \\
\hline $\begin{array}{l}\text { Because "Not Sharing } \\
\text { Works" is the Right } \\
\text { Thing to do }\end{array}$ & $14(67)$ & $6(28)$ & $0(0)$ & $0(0)$ & $1(5)$ \\
\hline
\end{tabular}

$N=21$

Total $=100$ percent

Although 20 of the 21 respondents claim that it is important to use the Tacoma-Pierce County Needle Exchange Program for the obvious reason (i.e., to get free needles), other concerns have been expressed as to why they want to use the program. Among these concerns are: (1) not 
wanting to contract or spread AIDS or other blood-borne diseases (e.g., hepatitis B) through the use of dirty needles; (2) the importance of using the needle exchange program because their friends do; and (3) the importance of using the needle exchange program because "it is the right thing to do." Other comments concerning the use of the program included: (1) "it saves lives;" (2) "it allows us to get tested for AIDS and just communicate with people who. understand our problems and needs;" (3) "used needles get hard and dul1;" and 4) "getting to know the people who are friends helping you."

Although IVDUs engage in a risk-taking behavior (i.e., injecting illegal drugs), they still express concern about contracting a disease which involves pain, suffering, devastation, and ultimately, death. This concern among program clients is clearly indicated in their expressed fear and worry about contracting AIDS and is depicted by their knowledge of this debilitating disease. Some of the comments, expressed by interviewed program clients, are cited below which indicate their concern over the effects of AIDS:

AIDS shortens your life, causes a lot of hardship, pain, and misery... nobody wants to get AIDS because no one can help you . - AIDS means getting very sick, losing weight, death ... needle exchange helps you keep healthy 'cause if it wasn't there you have to go to alternative routes that wouldn't be 100 percent no risk - . needle exchange reduces your fear of getting AIDS because you know your works are clean. . . needle exchange reduces my worries about getting AIDS 105 percent. 
Sharing works was a cormon practice prior to the establishment of the needle exchange program in Tacoma. ${ }^{113}$ Interview data revealed that 15 of the 21 respondents (71 percent) claim that they would not resort to sharing injection equipment again -- even if the needle exchange program was terminated. Only four of the 21 respondents (19 percent) indicate that they would move to another community, or city, that had a needle exchange program in operation, just because of the availability of sterile, free works. To this extent, the common argument presented by opponents of needle exchange programs -- that needle exchange programs attract IVDUs from other locales and hence increase the population of this group -- does not apply for the case of Tacoma. (Note: Although only eight of the 21 respondents are aware of the needle exchange program in Seattle, they are basically unaware of similar programs outside the State of Washington.)

Correspondingly, if the Tacoma-Pierce County Needle Exchange Program was terminated tomorrow, interviewed program clients claim that they would resort to the "black market"114 to buy works, sterilize their injection equipment with bleach, find a pharmacy that would agree to

${ }^{113}$ See Chapter II, Figure 3, P. 69.

${ }^{114}$ In fact, both law enforcement personnel and program clients claim that a "black market" exists for buying injection equipment. This black market has been created out of the demand for works and made available through various sources such as individuals who are diabetics, willing to sel1 their excess injection equipment for a premium (i.e., minimum \$1 and as high as $\$ 2$ per needle/syringe), or from hospitals, nursing homes, clinics, and pharmacies where needies/syringes have been stolen and hence sold on the black market. This black market still exists today to a smaller extent, even though free needles are offered through the needle exchange program. 
sell needies/syringes to IVDUs, ${ }^{115}$. look for used injection equipment discarded in parks, gutters, alleys, or streets (i.e., as many didprior to the advent of the needle exchange program in Tacoma) and/or resort to stealing them from hospitals or nursing homes. ${ }^{116}$

Nineteen of the, 21 respondents (90 percent) claimed that they knew how to clean their injection equipment, and eight of the 21 respondents (38 percent) indicate that they had to help teach other IVDUs how to sterilize works. Not only does this convey the concern over the effects of AIDS among this high-risk population group, but also suggests the capacity for change to occur in the behavior and attitude of IVDUs. To this extent, the argument that IVDUs are incapable of changing behavior and attitude is not an accurate portrayal for program clients of the Tacoma-Pierce County Needle Exchange Program.

External Environmental Conduits. External environmental conduits (informal communication network and the media) have played an important role in helping Purchase and Reid obtain support from other public agencies and organizations. These conduits, discussed in the following sections, have also helped to establish program acceptance among intravenous drug users (IVDUs).

\footnotetext{
${ }^{115}$ Three of the 21 interviewed program clients (14 percent) had knowledge of certain pharmacies willing to sell needles/syringes to IVDUs.

${ }^{116}$ Seven of the 21 interviewed program clients stated that they would most likely buy needles/syringes on the black market; three of the 21 interviewed program clients claimed that they would buy needles/ syringes at various pharmacies; one of the 21 interviewed program clients interviewed stated that he would use bleach; and two of the 21 interviewed program clients revealed that they would try to find used needles/syringes on the streets, parks, greenbelts, and/or gutters. The remainder had no comment.
} 
1. The Informal Communication Network. The informal communication network is an important, dependable means by which information is disseminated, and which helps to provide an environment conducive for program acceptance. This phenomenon is manifested by the actions among key individuals employed in various public agencies and organizations. As such, the informal communication network among key individuals (e.g., Reid, Flannigan, Fjetland, and Allen) employed in various public agencies and organizations has helped strengthen relationships and build coalitions to establish a needle exchange program in Tacoma.

Intravenous drug users (IVDUs) also have an informal communication network $^{117}$ which has had a sizeable impact on program acceptance of the needle exchange program. Perhaps one good indicator of the existence of an informal communication network, among IVDUs, is the way in which program clients have heard about the needle exchange program in Tacoma. Table $X$ (on the following page) shows how respondents heard about the needle exchange program in Tacoma.

The majority heard about the needle exchange program through a friend. Correspondingly, 15 of the 21 respondents (71 percent) have brought other IVDUs to take advantage of the needle exchange program. These program clients stated that they brought other IVDUs to utilize the program because ". . they needed clean rigs,"118 "... to get

\footnotetext{
${ }^{117}$ Purchase refers to this informal communication network as the "street telegraph" (Purchase 1990).

118"Rigs" is often used synonymously with slang terms for injection equipment such as "works," "outfits," or "instruments."
} 
TABLE $X$

HOW RESPONDENTS (IVDUS) HEARD ABOUT

THE NEEDLE EXCHANGE PROGRAM

IN TACOMA

\begin{tabular}{lcc}
\hline HOW HEARD & N & $(\%)$ \\
\hline Through a Friend & 14 & $(67)$ \\
Through Some Form of the Media & 5 & $(24)$ \\
Just Wal ked Up on It & 2 & $(10)$ \\
\hline$N=21$ & & \\
Total $=100$ percent
\end{tabular}

tested for diseases," ". . to prevent them from spreading AIDS," ". . to teach them about clean works," ". . . I didn't want to share my works," and/or ". . . to help them get educated." Purchase (1990), in a court document, declares:

They [IVDUs] have taught each other in a sense in the 'street telegraph' to wipe off the needle point too. It had not occurred to them [IVDUs] to do that . . . One of my tests for effectiveness in getting the message through is how often I hear the information come back. How often I hear our clients standing around telling each other the same stuff we told them; and we hear that a lot. The slogan is 'stay alive.' We see them give each other condoms. We see them talk about reports of testing to each other. We see one person encouraging another to do that when it comes up.

The informal communication network is a dependable means by which messages are transmitted among IVDUs in Tacoma; it also transmits information quickly and accurately. Moreover, the informal communication network is a vehicle in which individuals outside the drug trade 
can gain the trust of IVDUs. The information that is disseminated via this network can effect the access to IVDUs by outsiders. One interviewee admitted that the drug trade participants do not generally trust outsiders, and as a result, they avoid contact with them as much as possible. For instance, IVDUs refused to speak or cooperate with two journalists who recentiy visited the site of South 14th and G Street. Word spread quickly and accurately via the informal communication network that speaking with these outsiders (i.e., journalists) would not provide any direct benefits (e.g., cash or clothing), to those of the drug trade. ${ }^{119}$

During the course of this study's interview process, information spread quickly and accurately among intravenous drug users (IVDUs) about the amount of payment offered to program clients for their participation. For this, the researcher had to make sure that IVDUs were genuine program clients through personal observation and through the reliance on the insight and judgment of trusted informants.

Such an effective means of disseminating information -- exemplified by the messages transmitted via the informal communication network -among a "hidden" population becomes an integral part of the external environment associated with program acceptance among IVDUs. For this, the informal communication network plays a significant role in "advertising" the needle exchange program in Tacoma.

2. The Media. The media also occupies an important role in creating a conducive environment for gaining program acceptance. For

${ }^{119}$ This example was provided by information obtained through semistructured interviews with program clients who participated in this case study. 
instance, The Morning News Tribune has published (and continues to publish) articles regarding the dangers of accidental needle stick injuries from picking up carelessly discarded, used injection equipment by IVDUs. Reid (The Morning News Tribune 1988c) was quoted in one article:

Syringes -- by-products of the city's increasing drug addict population -- pose a serious threat to public health.. Obviously it's a public health problem right now . . . If you get jabbed by a contaminated needle, it's something to be concerned about.

Essentially, the media helps to "prime" the public by publishing such articles. In particular, the local newspaper published articles about the needle exchange program in the context of the AIDS epidemic and not necessarily illicit drug use. Beyond this, the media could assist in spreading information -- correctly or incorrectly -- about a particular event, individual, issue, policy, or program. For example, The Morning News Tribune conducted an opinion poll among Pierce County residents just one month after the adoption of the needle exchange program by the Tacoma-Pierce County Health Department. An article in The Morning News Tribune (1989b) provided favorable information about the needle exchange program in Tacoma:

About two-thirds of Pierce County residents agree with the Board of Health decision to spend $\$ 43,000$ to fund a hypodermic-needle-exchange program designed to reduce the spread of AIDS, a morning News Tribune poll indicates . . Some 67.2 percent of the 411 people sampled said they agreed with the program, while 18.4 percent disagreed, and 14.4 percent either were undecided, didn't know enough about the issue to respond or refused to respond . - The poll, conducted by Tacoma Market Research on Jan. 11, 18, 19, 30, and 31, has a margin of error of plus or minus 4.8 percent. 
A11 of these environmental conduits (the informal communication network and media) help pave the way for program acceptance; these have helped reduce the risks and uncertainties which might have hindered the program's initial support, and ultimately, its success.

Research Question \#3

"What characteristics of program clients (i.e., IVDUs) are linked to program acceptance of the needle exchange program in Tacoma?"

Table XI shows the interviewed program clients' demographic characteristics of the participants of this study.

TABLE XI

CHARACTERISTICS OF INTERVIEWED

PROGRAM CLIENTS: DEMOGRAPHICS

\begin{tabular}{lrr}
\hline CHARACTERISTIC & N & $(\%)$ \\
\hline $\begin{array}{l}\text { Gender - } \\
\text { Male } \\
\text { Female }\end{array}$ & 17 & $(81)$ \\
$\begin{array}{l}\text { Race - } \\
\text { Non-white } \\
\text { White }\end{array}$ & 4 & $(19)$ \\
$\begin{array}{l}\text { Education - } \\
\text { Less than High School }\end{array}$ & 18 & $(86)$ \\
High School or More & 3 & $(14)$ \\
$\begin{array}{l}\text { Employment - } \\
\text { Unemployed } \\
\text { Employed }\end{array}$ & 16 & $(24)$ \\
& & $(76)$ \\
\hline
\end{tabular}

$N=21$

Total $=100$ percent 
The data collected in this study reveal findings similar to the Tacoma-Pierce County Health Department's preliminary statistics (see Chapter II), even though participants of the former were not randomly sampled. The findings reveal that: (1) more of this group were male than reported in the preliminary statistics of the 1988 study conducted by the Tacoma-Pierce County Health Department (see Chapter II); ${ }^{120}$ (2) the majority of the 21 respondents were at least high school graduates; ${ }^{121}$ and (3) only one had a legal means of employment. ${ }^{122}$

In terms of drug use characteristics, most claimed to be drug dependent; ${ }^{123}$ and 76 percent indicated that they have been IVDUs for at least five years. This is slightly higher than the 61 percent reported by the Tacoma-Pierce County Health Department's preliminary statistics (see Chapter II). Most survey respondents stated that they inject drugs daily, ${ }^{124}$ and a mix of heroin and cocaine (i.e., "speedballing") was

${ }^{120}$ There were 14 black males, two Hispanic males, one white male, two black females, and two white females interviewed in this particular study, and four females.

${ }^{121}$ Three of the 16 respondents claimed to have an Associate's Degree, and one stated having a Bachelor's Degree.

${ }^{122}$ Nine of the 21 respondents (43 percent) admitted to illicit means of income (e.g., prostitution, "work the streets," "hustling," and "odd street jobs").

${ }^{123}$ These reasons were offered by the respondents when asked why they claimed to be drug dependent: (1) "because I use drugs every day;" (2) "because I use it every day of my life for 21 years;" (3) "because I got to have it;" (4) "because of addiction; " and (5) "because of longterm use."

${ }^{124}$ One of the respondents, claiming daily drug use, stated that he/she injects $\$ 350$ worth of drugs per day -- about three-and-a-half grams per day. 
reported to be the substance most injected by interviewed program clients. ${ }^{125}$

Table XII reports the drug use habits of those IVDUs who participated in this study.

TABLE XII

CHARACTERISTICS OF INTERVIEWED PROGRAM

CLIENTS: DRUG USE HABITS

\begin{tabular}{|c|c|c|}
\hline CHARACTERISTIC & N & $(\%)$ \\
\hline Claimed Drug Dependency & 18 & (86) \\
\hline $\begin{array}{l}\geq \text { Five Years } \\
\text { of IV Drug Use }\end{array}$ & 16 & $(76)$ \\
\hline $\begin{array}{l}\text { Frequency of Drug Use } \\
\text { Daily } \\
\text { Almost Daily } \\
\text { Once Per Week } \\
\text { Every Two Weeks }\end{array}$ & $\begin{array}{r}15 \\
4 \\
1 \\
1\end{array}$ & $\left.\begin{array}{r}(71) \\
(19) \\
(5) \\
5\end{array}\right)$ \\
\hline
\end{tabular}

Crime statistics published monthly by the Tacoma Police Department show the following data regarding the race and age of adults (i.e., males and females over the age of 18) arrested for drug abuse. ${ }^{126}$ These numbers are reported in Tables XIII and XIV on the following pages.

${ }^{125}$ Heroin was the most injected drug used by IVDUs, followed by cocaine, barbiturates, and amphetamines (i.e., speed).

${ }^{126}$ Drug abuse arrests include the possession, sale, or use of an illicit drug. 
Table XIII shows that the largest percentage of those arrested for drug abuse in Tacoma are white. In fact, more than half of the total number of arrests for drug abuse in Tacoma, are comprised of whites. Whites, however, comprise 85 percent of the Tacoma Metropolitan population which indicates that the statistics for whites are lower in proportion to the population. There is a disproportionate number of non-whites arrested for drug abuse; that is, although the arrests of non-whites total less than 50 percent, only 15 percent of the Tacoma Metropolitan population are comprised of non-whites.

\section{TABLE XIII}

MALE/FEMALE, ADULT DRUG ABUSE ARRESTS BY RACE: TACOMA, WASHINGTON, FROM 1988 - 1991

\begin{tabular}{|c|c|c|c|c|}
\hline & & & EAR & \\
\hline & $\#^{1988}(\%)$ & $\#^{1989}(\%)$ & $\#^{1990}(\%)$ & $\#^{1991}(\%)$ \\
\hline $\begin{array}{l}\text { WHITE } \\
\text { BLACK } \\
\text { INDIAN } \\
\text { ASIAN } \\
\text { HISPANIC }\end{array}$ & $\begin{array}{r}612(62.3) \\
347(35.3) \\
20(2.0) \\
4(0.4) \\
0\end{array}$ & $\begin{array}{l}577(60.0) \\
356(37.1) \\
21(2.2) \\
5(0.5) \\
0\end{array}$ & $\begin{array}{c}675(54.7) \\
522(42.3) \\
30(2.5) \\
6(0.5) \\
0\end{array}$ & $\begin{array}{c}542(53.45) \\
449(44.28) \\
14(1.38) \\
9(0.89) \\
0\end{array}$ \\
\hline $\begin{array}{l}\text { ANNUAL TO } \\
\text { OF ARREST } \\
\text { FOR DRUG } \\
\text { ABUSE: }\end{array}$ & 983 & 959 & 1233 & 1014 \\
\hline
\end{tabular}

Source: Tacoma Police Department. Monthly Summary of Crime Statistics. (Numbers 261-308), January 1992.

The findings of the pilot study conducted by the Tacoma-Pierce County Health Department during the latter part of 1988 indicate that 51 percent of the program clients were non-white. Moreover, interview 
data of this particular research reveal that 18 of the 21 respondents (86 percent) were non-white. This suggests that the Tacoma-Pierce County Needle Exchange Program might be serving a particular group of IVDUs differing from those being arrested (as indicated in Table XIII), which may have an impact on program acceptance for both law enforcement personnel and program clients. Beyond this, data show that law enforcement personnel are continuing to arrest individuals for illicit drug use, but perhaps not program clients of the Tacoma-Pierce County Needle Exchange Program. Again, this suggests that law enforcement personnel have a "hands-off" policy regarding the arrest of program clients (i.e., IVDUs), and this suggests program acceptance for both groups (i.e., IVDUs and law enforcement personnel).

Table XIV reveals that the greatest percentage of those arrested for drug abuse, in Tacoma, fall between the ages of 18 to 29 . The data presented in XIV (like the data in Table XIII) do not correspond to the preliminary statistics provided by the pilot study conducted by the Tacoma-Pierce County Health Department. ${ }^{127}$ The information that the needle exchange program serves an older population than is being arrested for drug abuse in Tacoma might attribute to greater program acceptance.

${ }^{127}$ The Tacoma-Pierce County Health Department preliminary statistics (presented in Chapter II) concluded that the mean age of program clients was 34. As seen in Table XIV, the range of 18 to 29 was the age group most arrested for drug abuse in 1988, 1989, 1990, and 1991. 
TABLE XIV

MALE/FEMALE, ADULT DRUG ABUSE ARREST

STATISTICS BY AGE GROUPS:

TACOMA, WASHINGTON, 1988 - 1991

\begin{tabular}{|c|c|c|c|c|}
\hline & & YEAR & & \\
\hline & $\begin{array}{l}1988 \\
\# \quad(\%)\end{array}$ & $\begin{array}{r}1989 \\
\text { \# }(\%)\end{array}$ & $\begin{array}{l}1990 \\
\#(\%)\end{array}$ & $\#^{1991}(\%)$ \\
\hline 60 and over & 0 & 0 & $2(0.2)$ & $9(0.9)$ \\
\hline $50-59$ & $20(2.04)$ & $17(1.77)$ & $25(2.0)$ & $23(2.3)$ \\
\hline $40-49$ & $72(7.32)$ & $88(9.18)$ & $117(9.5)$ & $120(11.8)$ \\
\hline $30-39$ & $337(34.28)$ & $332(34.62)$ & $403(32.7)$ & $352(34.7)$ \\
\hline $18-29$ & $554(56.36)$ & $522(54.43)$ & $686(55.6)$ & $510(50.3)$ \\
\hline $\begin{array}{l}\text { ANNUAL TOTAL } \\
\text { OF ARRESTS } \\
\text { FOR DRUG } \\
\text { ABUSE: }\end{array}$ & 983 & 959 & 1233 & 1014 \\
\hline
\end{tabular}

Source: Tacoma Police Department. Monthly Summary of Crime Statistics. (Numbers 261-308). January 1992.

The concluding remarks, including the key implications and limitations of this study, are reported in the next and final chapter. 


\section{CHAPTER VI}

THE CONCLUSION: SUMMARY OF FINDINGS, IMPLICATIONS, AND LIMITATIONS

In examining the case study of the Tacoma-Pierce County Needle Exchange Program, the community approach to the prevention of an iliness or disease was used as a framework to help explain the acceptance of the innovative AIDS intervention strategy to help change the risk behavior associated with the transmission of HIV-1/AIDS among IVDUs. The community approach to prevention has been discussed in Chapter III in terms of the importance of the environment in fostering community norms to change the behaviors of individuals who engage in life threatening health risks, such as in smoking cessation programs, the STOP AIDS program of the gay community, and so forth. In reference to this approach, the Tacoma-Pierce County Needle Exchange Program promotes changes in injection practices among intravenous drug users (IVDUs) by eliminating the need to share needles/syringes by making sterile injection equipment more readily available and accessible.

For the most part, data were sought and obtained (as revealed in Chapter IV) through semi-structured interviews involving 21 program clients and four law enforcement personnel. (Note: A large sample size for each of the population groups was never intended for this particular case study.) A number of percentages have been calculated to enhance the data that have been gathered. The data were reported in aggregate rather than miniature biographies due to the nature of the topic, and 
the effort to minimize the risk of breaking the informed consent form agreement between the researcher and the respondents. Again, the purpose of this particular case study is introductory and exploratory, seeking to motivate further research which might employ larger sample sizes which might in turn allow for various testing techniques. The focus of this research has been to gain insights about the attributes of program acceptance of the Tacoma-Pierce County Needle Exchange Program. It was never the intention of the researcher to report on individuals' experiences and encounters in receiving services provided by the TacomaPierce County Needle Exchange Program; nor. was it the researcher's intention to examine whether the Tacoma-Pierce County Needle Exchange Program reduced the spread of HIV-1/AIDS. Every effort has been made on the part of the researcher to minimize the risks to those who have participated in this dissertation endeavor.

In addition, existing records such as court documents, media articles, and crime statistics have provided good data for secondary analysis. Both original and secondary data, reported in Chapter $V$, provided good support to identify various attributes of program acceptance of the Tacoma-Pierce County Needle Exchange Program. The identification of these attributes may prove valuable to other cities contemplating the implementation of a needle exchange program, as an AIDS intervention strategy, for IVDUs. The aim of this study has been to look beyond the use of illicit drugs and focus on the attributes of a successful needle exchange program.

This case study has attempted to identify various attributes of the acceptance of the Tacoma-Pierce County Needle Exchange Program by three 
main groups, namely the health department officiais, law enforcement personnel, and program clients (i.e., IVDUs). To reiterate, the TacomaPierce County Needle Exchange Program is the first legitimate program of its kind in the United States, and has been acknowledged as a success, both nationally and internationally. This controversial program's high visibility in the media and its longevity have encouraged other communities to seriously consider a needle exchange program as a valuable and successful prevention strategy that has been said to help slow the spread of HIV-1/AIDS among one particular high-risk group, intravenous drug users (IVDUs) (The Morning News Tribune 1993).

Needle exchange programs have attracted much criticism in many other cities in the United States, for example, New York. Aside from the obvious differences (e.g., geographic size of the city, ethnic composition, population, and revenue base) that comprise urban areas in the United States, certain attributes of the needle exchange program, its clientele, and external environment have been identified in order to minimize the opposition which might interfere with the success of the implementation and survival of such an innovative intervention strategy. The attributes identified in this case study may be pertinent to other communities planning such interventions. At the very least, these are program characteristics that should be discussed prior to planning a needle exchange program. The more important and critical attributes of program acceptance, as discussed in this case study of the Tacoma-Pierce County Needle Exchange Program, are explained below. 
SUMMARY OF FINDINGS

1. The setting is linked to program acceptance. The two most important characteristics for a successful setting are physical accessibility and geographical flexibility, which are achieved mainly by being mobile in order to accommodate the changes in location of the drug trade and upon the requests made by law enforcement personnel. An effective needle exchange program should include at least one mobile van unit to optimize its physical accessibility and geographical flexibility.

2. The type of staff is linked with program acceptance. The most important characteristic for those who come into contact with intravenous drug users (IVDUs) is accessibility, which is achieved by having a staff that is considered by program clients as being "userfriendly" (i.e., described by both program clients and law enforcement personnel as maintaining a relationship that is considered to be close, friendly, non-judgmental, trustworthy, committed, and non-coercive). An effective needle exchange program should employ a user-friendly staff to optimize its accessibility for a "hidden" population group like IVDUs.

3. The method of service delivery is linked to program acceptance. The most important characteristic of a successful delivery of services to an apprehensive population group such as IVDUs is "no-to-low barrier," which is achieved by having a method that entails zero to little restrictions in terms of cost, number of exchanges allowed, eligibility requirements (e.g., waiting period, confession of use, minimum age, proof of residency, and poverty), identification, or formal paperwork from program clients. An effective needle exchange program 
should have a no-to-low barrier method of service delivery to optimize its client base in the delivery of services. The requirement of a oneto-one exchange (i.e., one used needle/syringe swapped for each sterile one), however, is beneficial for the entire community -- particularly in terms of reducing the number of accidental infections from carelessly discarded, used needles/syringes.

4. The nature of the geographic area is linked to program acceptance. One of the most important characteristics of the external environment is the nature of the geographic area, which is conducive to the familiarity of the area. Even though the "not-in-my-back-yard" (NIMBY) philosophy is important to both residential and commercial areas, the "art" of remaining inconspicuous (i.e., somewhat hidden) from the mainstream population is beneficial for all three groups (health department officials, law enforcement personnel, and program clients). An effective needle exchange program should investigate the external environment when considering implementation in order to optimize its accessibility of the geographic area.

5. The concern over the effects of AIDS is linked to program acceptance. Another important characteristic of the external environment is the concern over the effects of AIDS by all three groups (health department officials, law enforcement personnel, and program clients). Knowledge and fear of contracting HIV-1/AIDS have helped the needle exchange program in Tacoma gain acceptance. To this extent, increasing individual and community awareness about the transmission, consequences, and prevention of HIV-1/AIDS is critical to program acceptance. 
As one reaction to the increase in awareness to the threat of this lethal epidemic, the Tacoma-Pierce County Health Department embraced the efforts of Dave Purchase and cautiously took the necessary steps to legalize the AIDS intervention program through the judicial system. Program acceptance might have had difficulties from the outset if the concern over the effects of AIDS, among health department officials and law enforcement personnel, had not been foremost and sincere. The emphasis on a public health issue -- rather than one of drug abuse -was key to clarifying the legality issues, which ultimately paved the way for program acceptance among the various public agencies in Tacoma. In addition, the non-enforcement of laws which restrict possession and use of illicit drugs and related paraphernalia became a policy which reflected the more urgent public health concern among the law enforcement personnel. The Tacoma Police Department should be heralded not only for supporting the formulation and implementation of the TacomaPierce County Needle Exchange Program, but also for contributing to the success and longevity of this particular AIDS intervention strategy.

For program clients, the concern over the effects of AIDS is equated with painful, long-term sickness, and -- ultimately -- death. The knowledge and fear of the consequences of contracting HIV-1/AIDS through unsterile injection equipment were conveyed by program clients; therefore, increased awareness has become an integral part of the acceptance of the Tacoma-Pierce County Needle Exchange Program.

6. The informal communication network is linked with program acceptance. The way in which information is spread among this "hidden" population is critical to the success and longevity of the 
Tacoma-Pierce County Needle Exchange Program. Dave Purchase pointed out in a court document, the valuable role in which the "street telegraph" plays in the everyday lives of IVDUs. The "street telegraph" has been instrumental in bringing new IVDUs to the Tacoma-Pierce County Needle Exchange Program. Programs which serve a "hidden" population need to depend on unconventional means of "marketing" skills to attract clients, as formal means may not be applicable nor appropriate. For this reason, an effective informal communication network (e.g., "street telegraph"), considered to be trustworthy and dependable, is important to program acceptance.

7. The media is linked to program acceptance. The role which the media occupies can generate support or opposition for a controversial program such as a needle exchange program. To reiterate, the local newspaper, The Morning News Tribune, published several articles regarding carelessiy discarded, used injection equipment and the dangers of accidental needle stick injuries. For this, the media plays a valuable role in rendering support for such a program -- which appears to reduce the number of contaminated needles/syringes carelessiy discarded -- by informing the public of such dangers. The possible benefits to society may not be known in absence of such information.

The local media sources did not focus on illicit drug use nor the early opposition of the downtown business community. In addition, the local newspaper referred to the court clarification regarding the legality of the Tacoma-Pierce County Needle Exchange Program as a "friendly" lawsuit. To this extent, the media has influenced program acceptance. 
8. Length of time of injecting drugs (of interviewed program clients) is linked to program acceptance. Program acceptance might be greater among long-term IVDUs (i.e., those individuals who have been injecting illicit drugs for at least five years), as well as those who consider themselves to be drug dependent.

9. The differences between the "typical" program client and those individuals who have been arrested by the Tacoma Police Department for drug abuse in terms of racial/ethnic background and age might be linked to program acceptance. The idea that the Tacoma-Pierce County Needle Exchange Program seems to be serving a different group of IVDUs than are being arrested by the Tacoma Police Department might contribute to acceptance.

10. Characteristics of program clients are linked to program acceptance. For instance, the number of years of formal education, employment status, gender, and age of the "typical" interviewed program client appear to be linked to program acceptance. The typical interviewed program client of the Tacoma-Pierce County Needle Exchange Program has a high school diploma and no legally obtained, reported income, is a male, and is approximately 32 years of age. ${ }^{128}$

\section{IMPLICATIONS}

The focus of this dissertation has been on the contributions toward the acceptance Tacoma-Pierce County Needle Exchange Program by three diverse groups: health department officials, law enforcement personnel,

${ }^{128}$ The mean age was taken from the Tacoma-Pierce County Health Department's preliminary statistics (see Chapter II: Figure 2). 
and intravenous drug users (IVDUs). The aforementioned ten attributes of the Tacoma-Pierce County Needle Exchange Program, its clientele, and external environment have produced a successful AIDS intervention strategy.

\section{Relationship to Public Policy}

The needle exchange program emerged because of the possibilities of IVDUS' spreading HIV-1/AIDS among other injectors, their sexual partners, and ultimately to the greater population. In reference to public policy, this activity has been the impetus for examining needle exchange programs in light of an urgent public health issue rather than a drug abuse issue. Such urgency has awakened some public policy makers and street-level bureaucrats to re-examine various codes and laws in a new context.

In a similar fashion, various practices and behaviors that have long been considered "socially deviant" have been overlooked for the sake of preventing the further spread of HIV-1/AIDS. Many scholars and practitioners alike have long regarded those who engage in risk-taking behaviors (such as intravenous drug use) as being incapable of making rational choices and changes in attitude and behavior. In the light of this deadly epidemic and intravenous drug use, the possibility that some of those individuals who engage in risk-taking behaviors may change their injecting practices is worth providing free, sterile "works" to this "hidden" population that is regarded as one high-risk group for spreading HIV-1/AIDS.

Nonetheless, not one approach by itself -- whether education, public health measures, vaccination, therapies -- is likely to be entirely 
successful in fighting the problems instilled by HIV-1/AIDS epidemic. Moreover, all such approaches, including needle exchange programs, must be organized and integrated into the workings of national AIDS prevention efforts, so that common goals can be attained and that all levels of government are aware of the activities provided. Such coordination does not imply that a centralized agency or organization is necessary for success or acceptance, but rather for funding, monitoring, and research purposes. To this extent, a comprehensive, national policy is not likely to occur until the number of deaths from AIDS increases dramatically among the non-injecting, heterosexual population.

\section{Relationship to Urban Studies}

Initially, the AIDS epidemic in the United States surfaced in the larger, more populated urban centers (e.g., San Francisco, New York, and Los Angeles), and even though this deadly disease has permeated suburban and rural areas, the epidemic continues to be discussed and dealt with, by and large, in an urban context. The impersonality of city life is thought to be conducive for those individuals or groups (e.g., IVDUs) choosing to live on the fringes of society, and hence becomes key to any urban theme or phenomenon under examination. Perhaps this is a remnant of the historical perception of the "ills" of city life (Wirth 1938), or the special conduciveness to unconventionality of urban centers, and/or the reflection of the "not in my back yard" philosophy. For whatever reasons, however, the focus of this study cannot divorce itself from an urban context. 
Health Care Costs

In a time of rising medical costs and extensive debate regarding cost containment in the present health care delivery system, the realities of the AIDS epidemic can neither be ignored nor overstated. Much concern continues to center around the economic impact of HIV1/AIDS on the health care system, and deserves some attention in discussing an intervention which holds the potential to slow the spread of such a costly disease. Although the economic impact of HIV-1/AIDS on the health care system is another topic, and is beyond the scope of this particular research to provide in-depth coverage, it is worth providing a brief discussion to illustrate the monetary savings of preventing at least one person from not contracting HIV-1/AIDS.

Even though reports are based on estimates and projections, there are several studies that have been conducted on the direct health care costs that occur from complete personal medical care services ${ }^{129}$ (Scitovsky and Rice 1987; Kizer et al. 1987). Researchers estimate that the average total medical costs for each AIDS case, from diagnosis until death, range between $\$ 55,000$ and $\$ 77,000 .^{130}$ (Cooper et al. 1988).

In addition to such direct health care costs for HIV-1/AIDS cases, there are other indirect costs associated with HIV-I/AIDS. Indirect

\footnotetext{
${ }^{129}$ Complete personal medical care expenditures entail hospital services, physician inpatient and outpatient services, outpatient ancillary services, and nursing home, home care, and hospice services. Nonpersonal expenditures include biomedical research, health education campaigns, blood screening and testing, and support services (Scitovsky and Rice 1987).

${ }^{130}$ These figures are in "1986" dollars. In addition, these figures may not be representative of all AIDS cases, geographic areas, or hospital fees.
} 
costs entail the loss of wages when absent from work or from early medical retirement, the loss of future earnings for individuals who are permanently $i 11$, and the cost to infectious disease control in the wake of other health services that are passed on to all consumers (e.g., autoclaving machinery to sterilize dental equipment between patients, additional equipment used by paramedics, law enforcement officers, or fire fighters).

There are potential savings that accrue as a result of less haphazardly discarded, used needles by having IVDUs exchanging used injection equipment for sterile ones through a needle exchange program like Tacoma's. The potential savings which prevention holds is astronomical in terms of the treatment not only for the HIV-1/AIDS, but also for other diseases, such as tuberculosis, hepatitis $B$, and other sexually transmitted diseases (STDS) associated with risk behaviors and practices of IVDUs and their sexual partners.

The Tacoma-Pierce County Needle Exchange Program is said to have an impact on the reduction in the number of carelessly discarded, used injection equipment, and thus, reduces the risk of infection from accidental needle stick injuries to others. Preventing these injuries from occurring in just one law enforcement officer would produce savings in terms of not only health costs associated with a particular infectious disease, but also in terms of additional training and employment costs involved in replacing that particular person in the event of premature death. Indirect costs reflecting the event of a premature death involve supporting the officer's family for a greater number of years than anticipated. 
In addition, there is always the potential for lawsuits to occur which bear not only costs to those directly involved, but also to society. Governmental maintenance employees, also at higher risk for accidental needle stick injuries, can share similar positive externalities from a needle exchange program. Beyond this, and again, the wellness of the general public is at stake. The indirect and direct health care costs of the AIDS epidemic place the burden of these expenses on urban areas where there are large numbers of AIDS cases. For instance, intravenous drug users (IVDUs) are often dependent on the public health care system for medical treatment; hence, the large number of IVDUs in particular cities such as New York, Miami, Los Angeles, and Newark will experience the realities and costs of the AIDS epidemic, especially in the municipal hospitals (Cooper et al. 1988). According to Cooper et al. (1988), the increasing numbers of IVDUs with AIDS have significantly taken a toll on health care resources since many individuals of this group are impoverished and often homeless.

To this extent, prevention is more cost efficient than incurring the costs associated with people who have HIV-1/AIDS. To reiterate, the eradication of illicit drugs is not promising; the so-called "War on Drugs" is considered -- especially by many law enforcement personnel -to be a mere farce. The supply and demand which encourage drug sales in the United States is a "well-oiled" economic machine, making any attempt to combat the "War on Drugs" a feeble exercise. Beyond this, the availability of treatment for intravenous drug use is less than the demand even before the AIDS epidemic (Cooper et a1. 1988). 
Although expanding the drug treatment system ${ }^{131}$ in the United

States holds some potential as a means to reduce the spread of AIDS among non-infected individuals, more non-traditional interventions need to be implemented: ${ }^{132}$ Needle exchange programs are key to not only combating the AIDS epidemic, but also in reducing the burden of costs to the individual and society.

\section{Civil Disobedience}

Throughout history, various individuals, groups, and/or organizations have participated in social movements, demonstrations, and other acts of non-violence -- often illegal -- to seek changes in the status quo. The action against civil authority undertaken in a nonviolent way is referred to as "civil disobedience" (Bolland and Hunter 1990).

Civil disobedience is just one tactic based on personal beliefs and emotions that is used to change a particular law which is considered unjust by those seeking change. Rawls (1969) states:

Being completely open about one's acts and being willing to accept the legal consequences of one's conduct is a bond given to make good one's sincerity, for that one's deeds are conscientious is not easy to demonstrate to another or even before oneself.

The Tacoma-Pierce County Needle Exchange Program evolved under the rubrics of civil disobedience insofar as several key actors recognized

\footnotetext{
${ }^{131}$ Cooper et a1. (1988) state that treating AIDS ranges between $\$ 55,000$ and $\$ 70.000$, but drug treatment is approximately $\$ 3,000$ per person in a non-residential program.

${ }^{132}$ Cooper et al. (1988) state that persuading IVDUs to abandon drugs or enter drug treatment may be a difficult task.
} 
the need for such an AIDS intervention strategy which could ultimately slow the potential for penetration of this deadly disease into the heterosexual, non-injecting population. For this, each of these key actors participated in the formulation and implementation of the TacomaPierce County Needle Exchange Program with sincere conviction based on principles which refer to the "common good" of society.

To reiterate, Purchase (the initiator of the needle exchange program in Tacoma) skillfully and non-violently carried out his agenda within a context of civil disobedience where arrest and punishment were.expected and accepted as a possible end. Purchase executed his plans under the appeal for social cooperation. Tacoma Police Chief, Ray Fjetland, supported the efforts of Purchase from the beginning. He based his actions upon the grounds of the "common good" of society from the outset of the formulation stages, and maintained this principle during the implementation stages of the Tacoma-Pierce County Needle Exchange Program.

The Tacoma Police Department maintained an attitude similar to outreach workers in supporting a program which contradicts the current "laws on the books." The longevity and success of the Tacoma-Pierce County Needle Exchange Program may not have occurred without such favorable support of the Tacoma Police Department led by such an entrepreneurial public servant, Chief Fjetland.

\section{LIMITATIONS}

There are several limitations to this dissertation research: These are: (1) the inability to interview health department officials; (2) 
sources of bias (in regard to semi-structured interviews and existing data sources); and (3) disadvantages of the case study approach. These are discussed in terms of the methodological challenges concerning this study.

\section{The Inability to Interview Health Department Officials}

During the beginning stages of this dissertation (Sumer, 1990), the researcher met with the epidemiologist for the Tacoma-Pierce County Health Department to discuss the feasibility of conducting a case study on certain aspects of the needle exchange program. Representing the health department, the epidemiologist exemplified a cooperative attitude toward the researcher and the intended study. The epidemiologist did not express any concerns or anticipate problems in allowing the researcher to conduct a dissertation research about the Tacoma-Pierce County Needle Exchange Program, nor did she recommend other individuals within the agency to contact for arranging the requested interviews with health department officials.

Several months later (Fall, 1990), the researcher was sent an application to attend the "North American Syringe Exchange Convention" to be held in October, 1990, and sponsored by the Point Defiance AIDS Projects and the Tacoma-Pierce County Health Department. The convention allowed the researcher to obtain up-to-date information about various efforts to establish national needle exchange programs and to meet key individuals -- from around the world -- involved in innovative AIDS intervention strategies.

Approximately 18 months later (March, 1992), telephone contact was made with Purchase to set up an interview date, and meeting place was 
set at a local restaurant that same week (i.e., March 5, 1992).

Although Purchase responded to every question asked by the researcher, he wanted the epidemiologist at the health department to sign his "informed consent form" (introduced and read prior to the interview) since his organization (Point Defiance AIDS Projects) maintains a service contract with that public agency to dispense injection equipment to intravenous drug users (IVDUs). Furthermore, Purchase recommended that the researcher meet again with the epidemiologist to obtain the interviews with health department officials, emphasizing that he was not an employee of that public agency. ${ }^{133}$

The researcher contacted the epidemiologist at the Tacoma-Pierce County Health Department, and reminded her of our meeting several months previously. Again, the researcher met with the epidemiologist to discuss the purpose of the study and semi-structured interviews. The epidemiologist indicated that a memo would be sent to those health department officials which the researcher requested to interview about the study, and that the researcher should contact them after a week to

${ }^{133}$ When questioned about the informed consent form that needed to be signed for the use of interview data obtained from Purchase, the epidemiologist stated that he (Purchase) is not an employee of the Tacoma-Pierce County Health Department, and that permission was not necessary from the agency. In fact, the interagency memo (see Appendix D) sent unintentionally by the Tacoma-Pierce County Health Department to the researcher) confirmed that Purchase did not need agency approval, but chose to defer to the epidemiologist. In other words, the decision to sign the informed consent form was entirely up to Purchase. Subsequentiy, Purchase was sent informed consent forms to sign, on two separate occasions; however, these were not returned. In fact, Purchase never returned any of the researcher's telephone calls after the two interview sessions. Therefore, no data obtained through Purchase's interviews have been used in this dissertation. Information about Purchase and his involvement with the needle exchange program has been collected through various secondary sources explained in Chapter IV. 
set an interview date (see Appendix D). Numerous telephone calls, meetings, and correspondence occurred over the following several weeks to try to make appointments to interview public health officials. Only one public health official responded to the researcher's telephone calls and proceeded to set a date for May 16, 1992; however, this was automatically canceled by another public health official who stated that an executive committee meeting would be necessary to analyze whether the time spent during the interviews could be justified. (Note: The researcher offered to pay for lunch and conduct interviews during that time.) Public health officials of the Tacoma-Pierce County Health Department spent more time discussing whether the interviews could be justified than if they would have agreed at the beginning to participate in the study.

After several more weeks, the researcher received a telephone call stating that the Tacoma-Pierce County Health Department declines to participate in this study for various reasons such as: (1) the inability to justify the time spent for interviews; (2) that costs exceed the benefits of this particular research; and (3) unwillingness to support outside research regarding the needle exchange program. Ironically, the epidemiologist wrote in the intra-agency memo that this particular study "appears to be a worthwhile study" (see Appendix D).$^{134}$

\footnotetext{
${ }^{134}$ The researcher requested that the Tacoma-Pierce County Health Department return all materials (e.g., informed consent forms, questionnaires, and proposals) following the denial to interview public health officials. Within a few days, the researcher received two separate envelopes -- one from Patty Rankensmeyer and another from Terry Reid. The envelope sent by Terry Reid contained the researcher's informed consent form on top, the origirial intra-agency memo and cover
} 
The lack of cooperation from the Tacoma-Pierce County Health Department has had some impact on this dissertation research. For one, the procrastination of the Tacoma-Pierce County Health Department officials delayed the data collection procedure by at least three months. A second impact occurred during the interview process with program clients (i.e., IVDUs). The epidemiologist personally drove several miles, during regular daytime office hours, to discourage program clients from participating in this study. ${ }^{135}$ Program clients, however, ignored the epidemiologist's comments, but nonetheless, her (the epidemiologist's) efforts to interfere in this particular research may have had some impact on their responses to some of the questions. Another impact is that the researcher was unable to collect original data regarding the viewpoints of health department officials. Nonetheless, the secondary sources of data are likely to be credible in gathering adequate and reliable information about health department officials' acceptance of the needle exchange program.

Various communities perceive the Tacoma-Pierce County Health Department as being innovative by its adoption of such a controversial program which seeks to change the injection practices of associated with the transmission of HIV-1/AIDS among IVDUs; therefore, researchers get the impression that such an agency would be cooperative in participating

letter (sent to Terry Reid from Holly Hagen, epidemiologist) sandwiched between a copy of the interview schedule. It remains unknown as to whether the original intra-agency memo and cover letter have been sent intentionally or unintentionally.

${ }^{135}$ The "justification" of time spent to discourage IVDUs from participating in this dissertation research was obviously not an issue, as this certainly was a waste of the epidemiologist's work hours. 
in such social science research. Acquiring data directly from the Tacoma-Pierce County Health Department was clearly problematic for the researcher of this study. The Tacoma-Pierce County Health Department behaved in a threatened manner, nearly claiming ownership of the TacomaPierce County Needle Exchange Program and its clientele for purposes of research and in regard to already published findings. Other organizations possessed findings from the Tacoma-Pierce County Health Department, including the International Working Group on AIDS and Intravenous Drug Use (now defunct) and ACT-UP!. To this extent, the Tacoma-Pierce County Health Department subjectively offers and supplies data to those organizations that clearly support needle exchange programs. Ostensibly, this demonstrates the workings of a restrictive bureaucracy in which such an agency subjectively controls information to individuals, groups, and/or organizations in which the utilization of data is unknown. The Tacoma-Pierce County Health Department clearly exercised control over the agency's previous studies, and declined to share any preliminary findings. To reiterate, secondary sources (e.g., court documents, media reports, articles supplied from the International Working Group on AIDS and Intravenous Drug Use and ACT-UP!), had to be utilized to uncover pertinent data.

Hill's (1989) Master's thesis corroborates this unwillingness to support any researcher outside the Tacoma-Pierce County Heaith Department and reveals:

it is worthy to note that it can be difficult to acquire data from the health department. They put up subtle, yet effective barriers to providing information to persons outside their agency. Officials are very busy and time is a premium they can not provide often. 
Still, they make access to department personnel for data gathering difficult. The release of information is tightly controlled by top administration. Though officials were most candid in their response to questions for this report, there was some obvious friction if the line of questioning did not follow their expectations . . One official in particular, refused to return calls or make timely an appointment, even weeks in advance, until intervention by a board member made the interview possible. There is an undeniable air of autocracy within the agency from the top administration to the lowest level of authority.

In hindsight, the issue was not of justifying time spent on participating in this particular research nor that the costs to the Tacoma-Pierce County Health Department exceeded the benefits, but rather that public health officials sought to protect the needle exchange program. From the outset, the researcher clearly stated the purpose of this dissertation research and upon request of the Tacoma-Pierce County Health Department, shared the interview schedules of both program clients and health department officials with that agency. The researcher accommodated every request made by the Tacoma-Pierce County Health Department. The Tacoma-Pierce County Health Department, however, chose not to participate in the researcher's study, and threatened to notify Portiand State University regarding the interviewing of program clients (i.e., IVDUs). ${ }^{136}$ The researcher considers the way in which the Tacoma-Pierce County Health Department exerted this form of "protec-

\footnotetext{
${ }^{136}$ In fact, the Tacoma-Pierce County Health Department was trying to claim "exclusive rights" to interview program clients of the TacomaPierce County Needle Exchange Program. The researcher responded to this claim by stating to the agency that program clients are not objects of ownership, but people who are indeed free and capable of making their own decisions. The participation of program clients is not the decision of the Tacoma-Pierce County Health Department. Indeed, this was just a ploy to discourage the researcher from carrying out the interviews with program clients.
} 
tionism" -- of the needle exchange program and its clients -- to be unprofessional, discriminatory, and frustrating.

Ironically, the Tacoma Police Department shared information freely and cooperatively. Law enforcement personnel extended their time and serious perspectives for this case study. The Tacoma-Pierce County Health Department may well be advised to practice the common courtesies offered by the Tacoma Police Department for individuals who are conducting research which might produce findings that may be beneficial in decision-making and various policy actions for other needle exchange programs.

\section{Sources of Bias}

There are potential sources of bias that may be part of any study and most data collection techniques, especially when conducting research involving self-reported information. Although this particular study employs multiple data sources to try to achieve reliable findings, there is no guarantee that any research is free of biases. The potential sources of biases are discussed below according to each of the data gathering techniques that have been used in this particular study.

Semi-structured Interviews. An interview is basically a conversation between two people (i.e., an interviewer and respondent) with the purpose to gain pertinent information. Although the interview procedure seems to be rather simplistic, the interviewer must be aware of potential sources of bias which might affect the quality of data utilized for analysis. Cannell and Kahn (1968), for example, point out three basic elements for a good interview: (1) accessibility, (2) 
cognition, and (3) motivation. These elements are discussed in reference to this study.

1. Accessibility. The first element, accessibility, refers to whether the respondent has adequate information to answer a particular question. A respondent may not have adequate information due to loss or lapses in memory or may lack the knowledge about certain issues (Cannell and Kahn 1968). In this particular research, the use of key informants has reduced the chances of this type of bias to occur. Again, a key informant is an individual that has unusually good access to pertinent information.

A few of the program clients that participated in this research were intoxicated by a particular substance to a degree which might have distorted some of the responses elicited. For example, one program client (respondent) began to drift in and out of consciousness, and therefore, many of the questions had to be repeated. Nonetheless, most of the program $c l i e n t s$ that were interviewed were attentive, literate, and possessed comprehensive knowledge of the needle exchange program and offered good insights into the topic of this dissertation.

Law enforcement personnel selected for this research held key positions in the Tacoma Police Department. These individuals had unusually good access to information and possessed a wealth of knowledge about the Tacoma-Pierce County Needle Exchange Program and its clientele.

2. Cognition. The second element, cognition, refers to the respondent's understanding and expectations of the role in which he/she is to occupy during the interview. Cannell and Kahn (1968) point out 
that the respondent needs to establish, from the beginning, what is relevant information to give, how much information to give, and in what frame of reference he/she should offer the answers. The interviewer, however, should explain the role of the respondent during the initial contact, and probe for more detail when considered appropriate. For this particular research, each respondent that participated in the study was read, verbatim, the informed consent form. The informed consent form explained the purpose of the research, and that information obtained through these interviews would not be used against them (respondents) in a harmful manner. This clarified, from the beginning, the expectations and relevance of the study to the respondents in both groups (law enforcement personnel and IVDUs).

In particular, law enforcement personnel were cognizant of departmental policy toward this innovative program, and when deemed appropriate, provided responses accordingly. Yet, in some cases, personal opinions were offered for some responses, even if these were not congruent with departmental policy. This implied that law enforcement personnel understood the expectations and relevance of the information sought, and the appropriate role of being a respondent in this particular research. To this extent, the information obtained through the interviews with law enforcement personnel is considered extremely valuable, and underlines the need for anonymity and confidentiality of the respondents.

3. Motivation. The third element, motivation, refers to the respondent's initial decision to cooperate and complete the interview. There may be many reasons as to why individuals choose to participate in 
a study. To reiterate, program clients were paid $\$ 15$ each to participate in this study -- that is, $\$ 5$ at the beginning and $\$ 10$ upon completion. Indeed, money is a motivator in obtaining respondents from this target population to participate in this study. Once the interview proceeds, however, then other motivators begin to influence the respondent's choice to complete the interview. For example, many program clients enjoyed talking about themselves, once trust was gained between the interviewer and respondent. Respondents, in fact, showed the interviewer knifing scars, gunshot wounds, back ailments, knee and foot injuries, and tattoos. Typically, respondents began to feel more comfortable with the researcher, and the conversation strayed at times from the original interview questions.

Law enforcement personnel were not paid for an interview, but were motivated by reasons different from those of the clients. The Tacoma Police Department viewed this as a valuable and worthwhile study and officers were eager to cooperate. Law enforcement personnel granted prompt and timely interviews and have expressed interest in reading the findings of this study.

Existing Data Sources. The use of existing data sources such as court documents, crime statistics, journal articles, and other publications provides several advantages and disadvantages. Perhaps the greatest advantage of using existing data sources is its nonreactivity. As Walizer and Wiener (1978) point out:

the general idea is that unobtrusive measurement does not interfere with the ongoing activity of subjects. Therefore, a more 'natural' flow of events might be observed. In other words, there is little chance that 
content analysis itself may be 'causing' what is being observed.

Other advantages to using existing records inciude factors of economy, particularly time and expense. Essentially, the use of existing records for analysis involves minimal costs compared to other data collection techniques. Several important documents and reports were readily available.

Nonetheless, existing sources of data have constraints or disadvantages. For example, Webb et al. (1981) discuss two major sources of bias that may occur in recorded data. These are called "selective deposit" and "selected survival." Selective deposit implies that a potential bias may exist in various records and publications that are to be analyzed. In other words, the researcher must be cognizant that these records have been compiled for specific purposes and have already been screened, selected, and edited by at least one individual, one who may have ulterior motives in choosing certain data to preserve, or to highlight, or to delete. Selective survival refers to the problem of missing or destroyed data. This raises skepticism to the researcher as to what data have been intentionally retained or destroyed for some unknown purpose.

For the purposes of this particular study, court documents have been recorded by a credible procedure, thus leaving little chance for particular data to be omitted or destroyed purposely. The credibility of self-reported declarations, however, remains unknown. Other materials, provided by various public agencies, offer quantifiable data that have been collected for a specific purpose. Public agencies and 
their employees often sort out (and exclude) information which may not be favorable for sustaining particular programs or job positions. In addition, raw data are rarely provided to indicate how a given statistic is derived. By using multiple data sources, however, credibility can be established through corroborative efforts. Insofar as the credibility of media sources remains largely undetermined, they are perhaps best used in support of other data sources, including materials from other agencies.

\section{Disadvantages of the Case Study Approach}

The main disadvantage of the case study approach is its inability to generalize to a larger population in terms of the specific findings of this research. Since this is an introductory and exploratory research, the findings are not ends in themselves to be used to make broad, sweeping generalizations, but rather to identify various attributes to be recommended to other communities who are considering such innovative interventions.

The other problem which a researcher may encounter in using this research strategy is that of data analysis. A search for commonalities in the responses may allow for some bias creep to occur in terms of researcher subjectivity, but every effort has been made to comb the data, several times, with a critical eye.

\section{A CALL FOR MORE RESEARCH}

This case study has been introductory and exploratory in nature, which is in itself a call for more research on the topic of needle exchange programs. Certainly, there is a need for social science 
research in the area of policies on AIDS in order to implement the best possible intervention programs seeking to reduce the spread of such a deadly disease. This particular case study attempts to provide some insights into an AIDS intervention program that appears to be successful in the eyes of three diverse groups: law enforcement personnel, heaith department officials, and program clients (i.e., IVDUs).

The purpose of conducting a case study is to generate questions that can be examined in future research. The ten attributes are found to be important in this case study in influencing the acceptance (and ultimately the success) of the Tacoma-Pierce County Needle Exchange Program; however, it is not possible to generalize these findings beyond the Tacoma experience. Similar hypotheses need to be tested in other communities to see if these same ten attributes remain important.

This research is not exhaustive, but seeks to stimulate other social scientists to conduct more case studies on needle exchange programs. In addition, the costs of such programs relative to their benefits must be examined to determine whether the funds for such interventions save a number of lives or treatment costs. This study suggests that needle exchange programs have complex characteristics attached to them, and that they deserve to be studied in more depth in order to better understand those complexities.

Again, although impossible to know whether a needle exchange program reduces the spread of HIV-1/AIDS, such innovative interventions are considered beneficial. Health educators argue that numerous lives can be saved. For instance, Purchase indicates that the Tacoma-Pierce County Needle Exchange Program has "exchanged over 400,000 syringes and 
has saved 500 lives" from the deadly AIDS virus (The Morning. News Tribune 1993). Regardless, there are positive spillovers or externalities of this AIDS intervention. Of importance are that program clients become educated in terms of the risks associated with sharing works, and the ways in which to avoid spreading HIV-1/AIDS and other infectious diseases. For law enforcement personnel, maintenance employees, and ground keepers, the risk of infection through accidental needle stick injuries is greatly reduced.

Finally, a plea for quick action is needed in the wake of this deadly epidemic. The needs for innovative measures and interventions are extremely critical to this urgent public health threat. The AIDS epidemic can no longer be hidden under the guise of illicit behavior; rather, it is a disease that. effects us all, and its spread must be rapidly reversed. 
REFERENCES

Abrams, D.B., J.P. Elder, R.A. Carleton, T.M. Lasater, and L.M. Artz. "Social Learning Principles for Organizational Health Promotion: An Integrated Approach." In Health and Industry: A Behavioral

Medicine Perspective, ed. M.F. Cataldo, and T.J. Coates. New York: Wiley-Interscience Publications, 1986.

Agar, M.H. Ripping and Running: Formal Ethnography of Urban Heroin Addicts. New York: Seminar Press, 1973.

Allen, Jack, and John L. Betts. History: USA. New York: American Book Company, 1967.

Allen, J.R., and J.W. Curran. "Prevention of AIDS and HIV Infection: Needs and Priorities for Epidemiologic Research." American Journal of Public Health 78 (1988): 381-384.

Allison, G.T. Essence of Decision-Making: Explaining the Cuban Missile Crisis. Boston: Little, Brown, 1971.

Anderson, Roy M., and Robert M. May. "Understanding the AIDS Pandemic." Scientific American Medicine Special Issue (1993): 86-92.

Andersson, B., B. Ljungberg, and K. Tunving. "HIV Prevention Program Among Drug Addicts -- A Teamwork Between a Clinic for Infectious Diseases and a Center for Psychosocial Treatment of Drug Addicts in Lund, Sweden." Report from the University of Lund, Lund, Sweden: 1988 .

Azjen, L., and M. Fishbein. Understanding Attitudes and Predicting Social Behavior. New Jersey: Englewood Cliffs, 1980.

Becker, M.H. "Patient Adherence to Prescribed Therapies." Medical Care 23 (1985): 539-555.

Becker, M.H., and J.G. Joseph. "AIDS and Behavioral Change to Reduce Risk: A Review." American Journal of Public Health 78 (1988): 394-410.

Benison, S. "Poliomyelitis and the Rockefeller Institute: Social Effects and Institutional Response." Journal of the History of Medicare 29 (1974): 74-92. 
Black, J.L., M.P. Dolan, H.A. De Ford, J.A. Rubenstein, W.E. Penk, R. Robinowitz, and J.R. Skinner. "Sharing Needles Among Users of IV Drugs (Letter)." New England Journal of Medicine 314 (1986): 446447.

Blacker, P., et al. "Exposure of IVDU to AIDS Retroviruses." Austral ian New Zealand Journal of Medicine 16: (1986): 686-690. In K. Dolan (Cross Ref.), "HIV/AIDS and IVDU in New South Wales, Australia." Paper from the Monitoring Research Group, University of London Goldsmiths' College, London, England: (February 1989).

Blattner, W., et al. "Epidemiology of Human T-Lymphotropic Virus Type III and the Risk of Acquired Immunodeficiency Syndrome. "Annals of Internal Medicine 103 (1985): 665-670.

Bolland, Kate, and Allyson Hunter. Seattle Needle Exchange Resource Manual. Seattle: Needle Exchange and IOU Committee (ACT-UP!), 1990.

Booth, W. "AIDS and Drug Abuse: No Quick Fix." Science 239 (12 February 1988): 717-719.

Boston Globe (newspaper). Document 25542: 2 May 1989.

- Document 30214: 25 May 1989.

- Document 10113: 10 January 1990.

- Document 11098: 11 January 1990.

Boulder County Health Department. The Works. A Community AIDS Prevention Program, 4 May 1989.

Brown, L.S.; D.L. Murphy, and B.J. Primm. "Needle Sharing and AIDS in Minorities." Journal of the American Medical Association 258:

(1987): $1474-1475$.

Buning, E.C., et al. "Amsterdam's Drug Policy and Its Implications for Controlling Needle Sharing." In Needle Sharing Among Intravenous Drug Abusers: National and International Perspectives. ed. R.J. Battjes et al. Research Monograph Series 80 Rockville, Maryland: United States Department of Health and Human Services, Public Health Services, Alcohol, Drug Abuse, and Mental Health Administration, National Institute on Drug Abuse (NIDA), 1988a.

. "Needle and Syringe Exchange in Amsterdam." Papers presented at the Fourth International Conference on AIDS, June 12-16, Stockholm, Sweden: 1988b.

Cannell and Kahn. In The Handbook of Social Psychology Volume 2: Research Methods, ed. G. Lindzey and E. Aronson. Reading, Massachusetts: Addison-Wesley, 1968. 
Carr, Janette and Steve Dalton. "Syringe Exchange: The Liverpool Experience." Druglink (May/June 1988).

Castro, K.G., A.M. Hardy, J.W. Curran. "The Acquired Immunodeficiency Syndrome: Epidemiology and Risk Factors for Transmission." In AIDS and IV Drug Abusers: Current Perspectives, ed. Robert Galea, et aT. Owings Mills, Maryland: National Health Publishing, 1988.

Centers for Disease Control (CDC). "Pneumocystis Pneumonia -- Los Angeles." Morbidity and Mortality Weekly Report 30 (1981): 250-25.

- "Prevention of Acquired Immunodeficiency Syndrome (AIDS): Report of Inter-Agency Recommendations." Morbidity and Mortality Weekly Report 32 (1983a): 101-103.

- "Acquired Immunodeficiency Syndrome (AIDS) -- United States." Morbidity and Mortality Weekly Report 33 (1983): 661-664.

- "Revision of the Case Definition of Acquired Immunodeficiency Syndrome (AIDS) for National Reporting -- United States." Morbidity and Mortality Weekly 34 (1985): 373-375.

- "Acquired Immunodeficiency Syndrome (AIDS) Among Blacks and Hispanics -- United States," Morbidity and Mortality Weekly Report 35 (1986a): 655-766.

- "Acquired Immunodeficiency Syndrome (AIDS) in Western Palm Beach County, Florida," Morbidity and Mortal ity Weekly Report 35 (1986b): 609-612.

- "Antibody to Human Immunodeficiency Virus in Female Prostitutes," Morbidity and Mortality Weekly Report 36 (1987a): 157-161.

- "AIDS Weekly Surveillance Report -- United States." AIDS Program (28 December 1987b).

Chaisson, R.E., A.R. Moss, R. Onishi, D. Osmond, and J.R. Carlson. "Human Immunodeficiency Virus Infection in Heterosexual Intravenous Drug Users in San Franscisco." American Journal of Public Health 77 (1987): 169-172.

Chaisson, R.E., D. Osmond, P. Bacchetti, B. Brodiek, M.A. Sande, and A.R. Moss. "Cocaine, Race, and HIV Infection in IV Drug Users." Paper presented at the Fourth International AIDS Conference, June 12-16, 1988, Stockholm, Sweden.

Chmiel, J.S., R. Detels, R.A. Kaslow, M. Van Raden, L.A. Kingsley, and R. Brookmeyer. "Factors Associated with Prevalent Human Immunodeficiency Virus (HIV) Infection in the Muiticenter AIDS Cohort Study." American Journal of Epidemiology 126 (1987): 568577. 
Cooper, Theodore, et al. Confronting AIDS: Update 1988. Washington, D.C.: National Academy-Press, 1988.

Craven, Donald E. "AIDS in Intravenous Drug Users." In AIDS 1988: American Association for the Advancement of Science (AAAS) Symposia Papers, ed. Ruth Kulstad. Washington, D.C.: American Advancement of Science, (1988).

Curran, J.W., et al. "The Epidemiology of AIDS: Current Status and Future Prospects." Science 229 (1985): 1352-1357.

- "Epidemiology of HIV Infection and AIDS in the

United States." Science 239 (February 1988): 610-616.

Darrow, William W., et al. "Behaviors Associated With HIV-1

Infection and the Development of AIDS." In AIDS: Papers From

Science, 1982-1985, ed. R. Kulstad, Washington, D.C.: American Association for the Advancement of Science. 1988.

Department of Health and Social Security (DHSS) (press release 1986/418). "New Measures to Fight the Spread of AIDS." (cited in) G.V. Stimson (Author), "Injecting Equipment Exchange Schemes in England and Scotland." In Needle Sharing Among Intravenous Drug Abusers: National and International Perspectives. ed. R.J. Battjes and R.W. Pickens. Research Monograph 80, Rockvi11e, Maryland: United States Department of Heaith and Human Services, Public Health Services, Alcohol, Drug Abuse, and Mental Health Administration, National Institute on Drug Abuse (NIDA), 1988.

Des Jarlais, D.C. "Effectiveness of AIDS Educational Programs for Intravenous Drug Users." Background Paper prepared for the Health Program, Office of Technology Assessment, United States Congress. Washington, D.C., 1987a.

- "Research on HIV Infection Among Intravenous Drug Users: State of the Art and State of the Epidemic." Paper presented at the Third International AIDS Conference, June 1-5, 1987b, Washington, D.C.

- "HIV Infection Among Persons Who Inject Illicit Drugs: Probiems and Progress." Paper presented at the Fourth International AIDS Conference, June 12-16, 1988, Stockholm, Sweden.

Des Jarlais, D.C. and S.R. Friedman. "AIDS and the Sharing of Equipment for Illicit Drug Injection: A Review of Current Data." Paper prepared for the National Institute on Drug Abuse (consultants' report), New York Division of Substance Abuse, New York City, New York, 12 January 1987. 
Des Jarlais, D.C. and J.S. Woods. "Needle Exchanges." In Newsletter 3 (1), International Working Group on AIDS and IVDUs. (May 1988): 5-6.

Des Jarlais, D.C., M.E. Chamberland, S.R. Yancovitz, P. Weinberg, and S.R. Friedman. "Heterosexual Partners: A Large Risk Group for AIDS." Lancet 2 (1984): 1346-1347.

Des Jarlais, D.C., S.R. Friedman, and D. Strug. "Acquired Immunodeficiency Syndrome Among Intravenous Drug Users: A Sociocultural Perspective." In The Social Dimension of AIDS: Method and Theory, ed. D.A. Feldman and T.M. Johnson. New York: Praeger, 1986a.

Des Jarlais, D.C., S.R. Friedman, T.J. Spira, et al. "A Stage Model of HTLV-III-LAV Infection in Intravenous Drug Users." Problems of Drug Dependence (Proceedings of the 47th Annual Scientific Meeting, Committee on Problems of Drug Dependence). Research Monograph 67, Rockville, Maryland: United States Department of Health and Human Services, Alcohol, Drug Abuse, and Mental Health Administration, National Institute on Drug Abuse (NIDA), (1986b): 328-334.

Des Jarlais, D.C., E. Wish, S.R. Friedman, R.L. Stoneburner, F. Yancovitz, D. Mildban, W. El-Sadr, E. Brady, and M. Cuadrado. "Intravenous Drug Users and the Heterosexual Transmission of the Acquired Immunodeficiency Syndrome." New York State Journal of Medicine 87 (1987a): 283-286.

Des Jarlais, D.C., S. Tross, and S.R. Friedman. "Acquired Immunodeficiency Syndrome and Other Manifestations of HIV Infection: Epidemiology, Etiology, Immunology, Clinical Manifestations, Pathology, Control, Treatment, and Prevention." In AIDS (Acquired Immunodeficiency Syndrome) and Other Manifestations of HIV InfeCtion, ed. Wormser et a1. Parkridge, New Jersey: Noyes Publications, (1987b): 1053-1070.

Dolan, K. "HIV in New South Wales, Australia" Paper from Monitoring Research Group, London, England: University of London Goldsmiths ' College, February 1989.

Drucker, E. "AIDS and Addiction in New York City." American Journal of Drug and Alcohol Abuse 12, (1986): 165-181.

Eaton, C., D. Lenaway, K. Oliver, and G. Vumbaca. "Needle Exchange III: The Australian System Plus England's Second Year Report and Update on the USA." In Newsletter $3(3 / 4)$ International Working Group on AIDS and Drug Use, 1988.

Essex, M. and P.J. Kanki. "The Origins of AIDS Virus." In The Science of Aids: Readings from Scientific American Magazine. New York: W.H. Freeman and Company, 1989. 
Fauci, A.S. "The Human Immunodeficiency Virus:- Infectivity and Mechanisms of Pathogenesis." Science 239 (5 February 1988): 617122.

Fineberg, Harvey V. "Education to Prevent AIDS: Prospects and Obstacles." Science 239 (February 1988): 593-596.

"The Social Dimensions of AIDS." In The Science of AIDS: Readings from Scientific American Magazine. New York: W.H. Freeman and Company. 1989.

First for Women. "AIDS: What Can Be Done?" 28 September 1992, (Volume 4, Issue 39): $39-49$.

Fischl, M.A., et al. "Evaluation of Heterosexual Partners, Children, and Household Contacts of Adults with AIDS. "Journal of American Medical Association 257 (1987): 640-644.

Fisher, Peter. "A Report From the Underground: The. Status of the Unauthorized Needle Exchange in New Haven, Connecticut, by AIDS Community Educators." In Newsletter 5 (1), International Working Group on AIDS and IVDUS, March 1990.

Fjetland, Raymond A. Affidavit of Raymond A. Fjetland in Support of Plaintiff's Motion for Summary Judgment. Superior Court for the State of Washington, County of Pierce, Alfred M. Allen, M.D. (Plaintiff) $v$ The City of Tacoma (Defendant). No. 89-2-09067-3, 6 December 1989.

Forcese, Dennis P., and Stephan Richer. Social Research Methods. Englewood Cliffs, New Jersey: Prentice-Ha11, Inc., 1973.

Friedland, G.H., and R.S. Klein. "Transmission of the Human Immunodeficiency Virus. "New England Journal of Medicine 317 (1987): 1125-1135.

Friedland, G.H., C. Harris, C. Butkus-Small, D. Shine, B. Moll, W. Darrow, and R.S. Klein. "Intravenous Drug Users and the Acquired Immunodeficiency Syndrome: Demographic, Drug Use, and Needle Sharing Patterns." Archives of Internal Medicine 145 (1985): 14131417.

Friedman, S.R., D.C. Des Jarlais, and J. Sotheran. "AIDS Health Education for Intravenous Drug Users." Health Education Quarterly 13 (1986): 383-393.

Friedman, S.R., C. Dozier, C. Sterk, T. Williams, J.L. Sotheran, D.C. Des Jarlais, et al. "Crack Use Puts Women at Risk for Heterosexual Transmission of HIV from IVDUs." Paper presented at the Fourth International AIDS Conference, June 12-16, 1988, Stockholm, Sweden. 
Gal10, Robert C., and Luc Montagnier. "The AIDS Epidemic." 'In The Science of AIDS: Readings from Scientific American Magazine. New York: W.H. Freeman and Company, 1989.

Geertz, Clifford. The Interpretations of Culture. New York: Basic Books, 1973.

Gilchrest, Valerie J. "Key Informant Interviews." In Doing Qualitative Research, ed. Benjamin F. Crabtree and William L. Miller. Newberry Park, California: Sage Publication, 1992.

Ginzburg, H.M. "Acquired Immune Deficiency Syndrome (AIDS) and Drug Abuse." Public Health Reports 99 (1984): 206-212.

Ginzburg, H.M., et al. "The Epidemiology of Human T-Cell Lymphotrophic Virus, Type III (HTLV-III Disease)." Psychiatric Annals 16 (1986): 153-157.

Goedert, J.J., M.G. Sarngadharan, R.J. Biggar, S.H. Weiss, D.M. Winn, R.J. Grossman, M.H. Greene, A.J. Bodner, D.L. Mann, D.M. Strong, R.C. Gallo, and W.A. Blattner. "Determinants of Retrovirus (HTLVIII) Antibody and Immunodeficiency Conditions in Homosexual-Men." Lancet 2 (1984): 711-715.

Goedert, J.J., et al. "Heterosexual Transmission of Human Immunodeficiency Virus: Association With Severe Depletion of T-helper Lymphocytes in Men With Hemophilia." AIDS Res. Hum. Retrovirus 3 (1987): 355-361.

Gold, M.S., et al. "Cocaine Update: From Bench to Bedside." Advances in Alcohol and Substance Abuse 5 (1986): 35-60.

Gottlieb, M.S., R. Schroff, H.M. Schanker, J.D. Weisman, P. Thim Fan, R.A. Wolf, and A. Saxon. "Pneumocystis Carinij Pneumonia and Mucosal Candidiasis in Previousiy Healthy Homosexual Men." New England Journal of Medicine 305 (1981): 1425-1431.

Governor's Committee on AIDS. "Description of: Hawaij's Sterile Needle Exchange Program." October 1990.

Hagan, H., et al. "Needle Exchange in Tacoma, Washington -- Initial Results." In Newsletter 3 (1988): 4-6.

Hardy, A.M., E.T. Starcher, J.W. Morgan, J. Drucker, A. Kristal, J.M. Day, C. Kelly, E. Ewing, and W. Curran. "Review of Death Certificates to Assess Completeness of AIDS Case Reporting." Public Health Reports 102 (1987): 386-390. 
Hartgers, C., E.C. Buning, G.W. Van Santen, A.D. Verster, and R.A. Coutinho, "The Impact of Needle and Syringe-Exchange Prograrme in Amsterdam on Injecting Risk Behavior" (from Municipal Heaith Service, Department of Public Health and Environment, and the Municipal Health Service, Drugs Department, Amsterdam, The Netherlands). In AIDS 19893 (9) (1989): 571-576.

Haseltine, W.A., and F. Wong-Staal. "The Molecular Biology of the AIDS Virus." In The Science of AIDS: Readings from Scientific American Magazine. New York: W.H. Freeman and Company, 1989.

Hedges, Alan. "Group Interviewing." In Applied Qualitative Research. ed. R. Walker Brookfield, Vermont: Gower, 1985.

Heyward, W.L., and J.W. Curran. "The Epidemiology of AIDS in the U.S." In The Science of AIDS: Readings from Scientific American Magazine. New York: W.H. Freeman and Company, 1989.

Hill, John. "The Anatomy of a Public Policy: The Developmental Stages of a Needle Exchange for IV Drug Users in Tacoma, Washington." Master's Thesis, The Evergreen State College, 1989.

Ho, D.D., R. Schooley, and T. Rota. "HTLV-III in the Semen and Blood of a Heal thy Homosexual Man." Science. 226 (1984): 451-453.

Horowitz, Donald L. The Courts and Social Policy. Washington, D.C., The Brookings Institute, 1977.

House of Representatives. State of Hawaij, Fifteenth Legislature, 1990. House Bill Number 2044 (H.D. 2; S.D.2), ACT 280.

Imperato, P.J., and G. Mitche11. Acceptable Risks. New York: Viking Penguin Inc., 1985.

Jacobs, Jane. The Death and Life of Great American Cities. New York: Random House, 1961.

Janz, N.K. and M.H. Becker. "The Health Belief Model: A Decade Later." Health Education Quarterly 11 (1984): 1-47.

Jones, Sue. "The Analysis of Depth Interviews." In Applied Qualitative Research. ed. R. Walker. Brookfield, Vermont: Gower, 1985.

Joseph, S.C., and D.C. Des Jarlais. "Needle and Syringe Exchange as a Method of AIDS Epidemic Control." In AIDS Update 2 (5) (September/October 1989): 1-8.

Kingsley, L.A., R. Kaslow, C.R. Rinaldo, Jr., K. Detre, N. Odaka, M. Van Raden, R. Detels, B.F. Polk, J. Chmiel, S.F. Kelsey, D. Ostrow, and B. Visscher. "Risk Factors for Sero-Conversion to HIV Virus Among Male Homosexuals." Lancet 1 (1987): 345-349. 
Kizer, K.J., et a1. An Updated Quantitative Analysis of AIDS in Cal ifornia. Sacramento: California Department of Health Services, 1987.

Kolbe, L. "Behavioral Epidemiology of AIDS: An Organizing Model." In AIDS 1988: American Association for the Advancement of Science. ed. R. Kulstad. Washington, D.C.: American Association for the Advancement of Science, 1988.

Kools and Buurman. "MDHG Spuitenomruilsysteem!" (1986: cited in) C. Buning, et al. "Amsterdam's Drug Policy and Its Implications for Controlling Needle Sharing." In Needle Sharing Among Intravenous Drug Users: National and International Perspectives, ed. R.J. Battjes, et al. Research Monograph Series 80, Rockville, Maryland: United States Department of Health and Human Services, Public Health Services, Alcohol, Drug Abuse, and Mental Health Administration, National Institute on Drug Abuse (NIDA), 1988.

Leventhal, H., P.D. Cleary, M.A. Safer, and M. Gutmann. "Cardiovascular Risk Modification by Community-Based Programs for Programs for Life-Style Change: Comments on the Stanford Study." Journal of Consulting and Clinical Psychology 48 (1980): 150-158.

Levy, J.A., et a1. "Infection by the Retrovirus Associated with the Acquired Immunodeficiency Syndrome: Clinical, Biological, and Molecular Features." Annals of Internal Medicine 103 (1985): 604609.

Lewis, Eugene. Public Entrepreneurship: Toward a Theory of Bureaucratic Political Power. Bloomington, Indiana: Indiana University Press, 1980.

Liebow, E. Talley's Corner. Boston: Little, Brown, 1967.

Lipset, S.M., M. Trow, and J. Coleman. Union Democracy: The Inside Politics of the International. Typographical Union. New York: Free Press, 1956.

Lipsky, Michael. Street-Level Bureaucracy. New York: Russell Sage Foundation, 1980.

Los Angeles Times. "Study Indicates Clean Syringe Program Cuts Spread of AIDS." John J. Goldman, 15 August 1991.

Louria, D., et al. "The Major Medical Complications of Heroin Addiction:" Annals of Internal Medicine 67 (1967): 1-22.

Lundborg, Hans. "Sweden." In the Third Annual Meeting of the International Working Group on AIDS and IV Drug Use -- Minutes From the Meeting, 1988. 
Mahoney, K., C. Eaton, M. Zweig, D.C. Des Jarlais, S. Schultz, and S. Joseph. "The Needle and Syringe Exchange Pilot Program in New York City." New York City Department of Public Health: Beth Israel Medical Center, November 1988.

Majchrzak, Ann. Methods for Policy Research. Beverly Hills, California: Sage Publications, 1984.

Mann, J.M., J. Chin, P. Piot, and T. Quinn. "The International Epidemiology of AIDS." In The Science of AIDS: Readings From Scientific American. New York: W.H. Freeman and Company, 1989.

Marx, Jean. "More About the HTLVs and How They Act." In AIDS: Papers from Science, 1982-1985, ed. R. Kulstad. Washington, D.C.: American Association for the Advancement of Science, 1985.

Mausner, J., and S. Kramer. Epidemiology. Philadelphia, Pennsylvania: W.B. Saunders Company, 1985.

Maynard, H. (cited in) C.D. Stowell. (Author), "Eye on the Needle." Portland State University Magazine. (Fall 1988): 17-20.

McAlister, A., P. Puska, J.T. Salonen, J. Toumilehto, and K. Koskela. "Theory and Action for Health Promotion: Illustrations from the North Karelia Project." American Journal of Public Health 72 (1982): 43-50.

Morisky, D.E., et al. "Evaluation of Family Health Education to Build Social Support for Long-Term Control of High Blood Pressure." Health Education Quarterly 12 (1985): 35-50.

The Morning News Tribune (newspaper, Tacoma, Washington). "Bleach No Longer Thought to be Good way to Kill HIV on Needles." By Cataherine Woodard. 3 June 1993.

"New York Official Praises Local Needle Exchange Program." 12 October 1988a. $1988 \mathrm{~b}$.

- "Health Board May Ok Needles For Drug-Users." 20 December . "Dispose of Used Syringes Properly, Officials Say." 14 April 1988c.

- "On Own Initiative, Tacoman Starts Needle Exchange." Kim Severson, 10 August 1988d.

- "NE Organizer: 'It's About Saving Lives:' Saturday Interview--Dave Purchase." 07 January 1989a.

- "Poll Gives Support To Needle Exchange." 03 February 1989b. 
- "Health Board OKs Needle Exchange." 10 February 1989c.

- "Senăte Outlaws Needle Exchange: New Drug Bill Pulls a Few

Switches." Peter Callaghan, 30 March 1989d.

. "Attorney General: Needle Exchange Provides Vital Service."

08 April 1989e.

- "Exchange of Needles Endorsed." 13 April $1989 \mathrm{f}$.

- "Lawmakers Outlaw Needle Program: Veto Looms." Scott

WiTson, 20 April 1989g.

- "Gardner will Use Veto to Back Needle Exchanges" Scott

WiTson/Kim Severson, 28 April 1989h.

- "Needle Exchange Ruled Legal" Debby Abe, 17 February 1990a.

- "Tacoma Won't Challenge Needle-Program Ruling."

21 February $1990 \mathrm{~b}$.

- "Needle Exchange Project May Expand." 06 June 1990c.

11 July "Drug Chief Says Needle Exchanges Don't Help." Sonya Ross

NAN Multi-Cultural NOTES on AIDS Education and Service 2 (5) "Needle Exchange Programs Controversy: Are They Effective in Slowing the Spread of HIV?" (June/July 1989): 1-3.

Newcombe, R. "Syringes: The Liverpool Syringe Exchange Scheme for Drug Injectors." Mersey Drugs Journal 1 (1) (1987): 8-10.

New Haven Health Department. "Demonstration Needle Exchange Program Protocol: Executive Sumary." 17 September 1990.

New Haven Register (newspaper). "Needle Exchange Plan Approved by House." 4 May 1990a.

- "O'Neill Signs Needle-Swap Bill Into Law." 16 June 1990b.

Newmeyer, J.A. "The IV Drug User and Secondary Spread of AIDS." Paper prepared for the CBASSE Committee on AIDS Research and the Behavioral, Social, and Statistical Sciences, 1988.

Newsletter 3 (4-6). "Special Issue: IV International Conference on AIDS: 1988 June 12-16, Stockholm, Sweden." New York: International Working Group on AIDS and IV Drug Use. September 1988.

Newsletter 4 (12). "In this Issue: Policy and IV Drug Use." New York: International Working Group on AIDS and IV Drug Use, March 1989a. 
Newsletter 4 (3). "Fifth International Conference on AIDS: Montreal, 4-9 June 1989, With A Special Supplement." New York: International Working Group on AIDS and IV Drug Use; September 1989b.

Newsletter 5 (1). "A Report From Poland and Canada's Needle Exchange Programmes." New York: International Working Group on AIDS and IV Drug Use, March 1990.

Newsletter $5(2-4)$. "Sixth International Conference On AIDS: 22 June 1990, San Francisco, California, USA." New York: International Working Group on AIDS and IV Drug Use, May 1991.

New York City Department of Health. (27 December 1989) "The Pilot Needle Exchange Study of New York City: A Bridge to Treatment, the First Ten Months of Operations." (executive summary presented to the New York State Department of Health Commissioner, D. Axel rod), New York: Library for AIDS Resource, January 1990.

New York Times. "Needle Swapper Makes a Point." Warren King--section A-8. 10 August 1988.

"AIDS Battler Gives Needles Illicitly to Addicts." 20 November 1989. 1990.

- "Dinkins to End Needle Plan for Drug Users." 14 February

"Needle Exchange Is Being Revived." Mireya Navarro, 29 October 1991a. 30 October 1991a.

"Needle Swap Programs Gaining Favor." Mireya Navarro,

Novick, D.M., et al. "Antibody to LAV, the Putative Agent of AIDS, in Parenteral Drug Abusers and Methadone Maintenance Patients:

Therapeutic, Historical, and Ethical Aspects." In Problems of Drug Dependence, ed. L. Harris. Bethesda, Maryland: National Institute on Drug Abuse (NIDA), 1985.

Office of Technology Assessment. "Do Insects Transmit AIDS?" US Congress, Washington, D.C.: Government Printing Office, 1987, p.iii.

"How Effective is AIDS Education?" US Congress, Washington, D.C.: Government Printing Office, 1988.

Oliver, K. (cited in) C.D. Stowell. (Author), "Eye on the Needle." Portland State University Magazine Fall 1988: 17-20.

"Outside-In Needle Exchange Program Report." In Newsletter $4(3)$, New York: International Working Group on AIDS and IV Drug Use, $1989 \mathrm{~b}$. 
O'Reilly, K.R. "Risk Behaviors and Their Determinants." In AIDS 1988: American Association for the Advancement of Science, ed. R. Kulstad. Washington, D.C., American Association for the Advancement of Science, 1988.

Pape, J.W., B. Liautaud, and F. Thomas. "Characteristics of the Acquired Immunodeficiency Sydnrome in (AIDS) in Haiti." New England Journal of Medicine 309 (1983): 945-950.

Parker, H., et al. "The New Heroin Users: Prevalence and Characteristics in Wirral, Merseyside." British Journal of Addiction 82 (1987): 147-157.

Peterman, T.A., H. Jaffe, and P. Feorino. "Transfusion Associated Acquired Immunodeficiency Syndrome in the United States." Journal of American Medical Association 254 (1985): 29132917.

Piot, P., H. Taelman, and K. Minlangy. "Acquired Immunodeficiency Syndrome in a Heterosexual Population in Zaire." Lancet 2 (1984): 65-69.

Piot, P., F.A. Plummer, F.S. Mhalu, J.L. Lamboray, J. Chin, and J.M. Mann. "AIDS: An International Perspective." Science 239 (5 February 1988): 573-579.

Polk, B.F., et al. "Predictions of the Acquired Immuno-deficiency Syndrome Developing a Cohort of Seropositive Homosexual Men." New England Journal of Medicine 316 (1987): 63-66.

The Portland State University Magazine. "Eye on the Needle." See Stowe11, 1988.

Price, Richard W., et al. "The Brain in AIDS: Central Nervous System HIV-1 Infection and AIDS Dementia Complex." In AIDS 1988: American Association for the Advancement of Science, ed. R. Kulstad. Washington, D.C.: American Association for the Advancement of Science, 1988.

Public Health Service (PHS). "The 1990 Health Objectives for the Nation: A Midcourse Review." United States Department of Health and Human Services. November 1986: 177-192.

Purchase, D. Declaration of David Purchase in Support of Dr. Allen's Motion for Summary Judgment. Superior Court for the State of Washington, County of Pierce, Alfred M. Allen, M.D. (Plaintiff) v. The City of Tacoma (Defendant). No. 89-2-09067-3, 10 January 1990.

Purchase, D., et al. "Historical Account of the Tacoma Syringe Exchange." Paper presented at the Fifth International AIDS Conference, June 5-9, 1989: Montreal, Quebec, Canada. Abstact \#7184. 
Puska, P., A. Nissinen, J. Toumilehto, J.T. Salonen, K. Koskela, A. McAlister, T.E. Kottke, N. Maccoby, and J.W. Farquhar. "The Community-Based Strategy to Prevent Coronary Heart Disease: Conclusions from the Ten Years of the North Karelia Project." Annual Review of Public Health 6 (1985): 147-193.

The Random House Dictionary. (Second edition) New York, Random House, Inc., 1987.

Rawls, John. "The Justification of Civil Disobedience." In Civil Disobedience: Theory and Practice, ed. Hugo Adam Bedau. New York: Pegasus, 1969.

Redfield, R.R., and D.S. Burke. "HIV Infection: The Clinical Picture." In The Science of AIDS: Readings from Scientific American Magazine. New York: W.H. Freeman, 1989.

Redfield, R.R., P. Markham, and S. Salahuddin. "Frequent Transmission of HTLV-III Among Spouses of Patients with AIDS-Related Complex (ARC) and the Acquired Immunodeficiency Syndrome (AIDS): A Family Study." Journal of American Medical Association 253 (1985): 15711573.

Revised Code of Washington. The Statute Law Committee (volume 6), 1989.

Rist, Ray. "On the Relations Among Educational Research Paradigms From Disdain to Detente." Anthropology and Education 8 (1977): 42-49.

Robertson, J.R., et al. "Epidemic of AIDS-Related Virus (HTLV-III/LAV) Infection Among Intravenous Drug Abusers." British Medical Journal 292 (1986): 527.

Rosenberg, Charles E. The Cholera Years. Chicago: University of Chicago Press, 1962.

. "Disease and Social Order in America: Perceptions and Expectations." Milbank Quarterly 64 (1986).

Rohan, Robert J. (Attorney for Dr. Allen). Plaintiff's Reply In Brief for Summary Judgment. Superior Court for the State of Washington, County of Pierce, ATfred M. Allen, M.D. (Plaintiff) v. The City of Tacoma (Defendant). No. 89-2-09067-3, 13 February 1990.

Rowley, Denzil. Affidavit of Denzil Rowley. Superior Court for the State of Washington, County of Pierce, Alfred M. Allen, M.D. (Plaintiff) v. The City of Tacoma (Defendant). No. 89-2-09067-3, 25 February 1990.

Russe11, Louise B. Is Prevention Better Than Cure?. Washington, D.C.: The Brookings Institute, 1986. 
Safer, Morley. "Needle Park" (transcript) CBS NEWS 60 Minutes. Journal Graphics XXII 18 (14 January 1990): 7-11.

Salahuddin, S.Z., P.D. Markham, M. Popovic, et al. "Isolation Infections Human T-Cel1 Leukemia/Lymphotropic with Acquired Immunodeficiency Syndrome (AIDS) or AIDS-Related Complex (ARC) and. From Healthy Carriers: A Case Study of Risk Groups and Tissue Sources." Proceedings from National Academy of Science, USA, 82, 5530 (1985).

Sandland, R., et al. "Estimation of the Number of Heroin Users in New South Wales Using Police Arrest Data: Development of a Statistical Mode1." New South Wales Drug and Alcohol Report 86 (1) (April 1986).

Scheingold, Stuart A. The Politics of Rights. New Haven: Yale University Press, 1974.

Schoenbaum, E.E., P.A. Selwyn, R.S. Klein, M.F. Rogers, K. Freeman, and G.H. Friedland. "Prevalence of and Risk Factors Associated with HTLV-III/LAV Antibodies among Intravenous. Drug Abusers in Methadone Programs in New York City." Paper presented at the Second International Conference on AIDS, June 23;, 1986, Paris, France.

Schultz H. "Gutachten zur rechtlichen Zulassiakeit von 'Fixerraument.'" Bern, Switzerland, Bundesamt fur Gesundheitswesen. Translated and Summary prepared by P. Tscherning. ADAPT, New York, 1989.

Schuster, C.R. "Intravenous Drug Users and AIDS Prevention." Public Health Report 103 (1988): 261-266.

Schwartz, W.A. "Drug Addicts with Dirty Needles." The Nation 244 (24) (20 June 1987).

Scitovsky, A.A., and D.P. Rice. "Estimates of Direct and Indirect costs of Acquired Immunodeficiency Syndrome in the United States: 1985, 1986, 1991." Public Health Report 102 (1987): 5-17.

Scottish Home and Health Department (SHHD). "HIV Infection in Scotland." Report from the Scottish Comittee on HIV Infection and Intravenous Drug Misuse (1986) (cited in) G.V. Stimson (Author) "Injecting Equipment Exchange Schemes in England and Scotland." In Needle Sharing Among Intravenous Drug Abusers: National and International Perspectives, eds. R.J. Battjes and R.W. Pickens, Research Monograph 80 Rockville, Maryland: United States Department of Health and Human Services, Public Health Services, Alcohol, Drug Abuse, and Mental Health Administration, National Institute on Drug Abuse (NIDA), 1988.

Seattle-King County Department of Health (AIDS Prevention Project). "Needle Exchange." 31 September 1989. 
Seattle Post-Intelligencer. "Tacoma Supports Needle Exchange to Combat AIDS." Tom Paulson, 5 January 1989.

Selwyn, P.A., C. Cox, C. Feiner, C. Lipshutz, and R. Cohen. "Knowledge about AIDS and High-Risk Behavior Among Intravenous Drug Abusers in New York City." AIDS International Journal 1 (4) (1987): 247-254.

Shilts, Randy. And the Band Played On. New York: St. Martin's Press, 1987.

Short, R. "Health Summary." Times Health Supplement (March 1986): 9.

Shulman, L.C. In Needle Sharing Among Intravenous Drug Abusers: National and International Perspectives, ed. R.J. Battjes and R.W. Pickens. Research Monograph 93 Rockville, Maryl and: United States Department of Health and Human Services, Public Health Services, Alcohol, Drug Abuse, and Mental Health Administration, National Institute on Drug and Alcohol Abuse (NIDAO), 1990.

Sieber, Sam. "The Integration of Field Work and Survey Methods." American Journal of Sociology 78 (1973): 1335-1359.

Simpson, D.D., J. Savage, and S. Sells. Data Book on Drug Treatment Outcomes. Fort Worth: Texas Institute of Behavioral Research. 1978

Slaff, J.I. and J.K. Brubaker. The AIDS Epidemic. New York: Warner Books, Inc., 1985.

Smith, Michael D. (Assistant City Attorney). City of Tacoma's Motion for Summary Judgment. Superior Court for the State of Washington, County of Pierce, Alfred M. Allen, M.D. (Plaintiff) v. The City of Tacoma (Defendant). No. 89-2-09067-3, 12 January 1990.

Sodroski, J. and W.A. Haseltine. "The Molecular Biology of HIV-1 Replication and Pathogenesis." In AIDS 1988: Amercian Association for the Advancement of Science Symposia Papers, ed. R. Kulstad Washington, D.C.: American Advancement for the Advancement of Science, 1988.

Stimson, G.V. "Injecting Equipment Exchange Schemes in England and Scotland." In Needle Sharing Among Intravenous Drug Abusers: National and International Perspectives, ed. R.J. Battjes, and R.W. Pickens, Research Monograph 80 Rockville, Maryland: United States Department of Health and Human Services, Public Health Services, Alcohol, Drug Abuse, and Mental Health Administration, National Institute on Drug and Alcohol Abuse (NIDA), 1988.

Stimson, G.V. "Syringe-Exchange Programmes for Injecting Drug Users" (editorial review). Monitoring Research Group, London: Goldsmiths' College, (30 March 1989): 253-260. 
Stover, Heino. "Needle Exchange VI: Slot Machines and Exchange Programmes: an Important HIV-Prevention Measure (A View from West Germany." In News letter 4 (3) International Working Group on AIDS and Drug Use (September 1989): 12.

Stowel1, C.D. "Eye on the Needle." Portland State University Magazine (Fail 1988): 17-20.

Sultan, Olivier. "A Case for the City's Needle Exchange Program." The New York Observer (19 December 1988).

Swenson, R.M. "Plagues, History, and AIDS." American Scholar 57 (Spring 1988): 1-4. Sydney Morning Herald. (newspaper, Australian) 12 January 1988.

Tacoma Police Department. "Monthly Summary of Crime Statistics." Numbers 261-300: 28 January 1992.

Tharp, Glen. Affidavit in Support of Plaintiff's Motion for Sumary Judgment. Superior Court for the State of Washington, County of Pierce, Alfred M. Allen, M.D. (Plaintiff) v. The City of Tacoma (Defendant). No. 89-2-09067-3, 29 November 1989.

Thompson, B., and S. Kinne. "Social Change Theory: Application to Community Health." In Health Promotion at the Community Level. ed. N. Bracht: Newbury Park, California: Sage, 1990.

Time. "SWITZERLAND Closed Needle Park." 17 February 1992, page 53.

Trauner, J.J. "The Chinese as Medical Scapegoats." California History 57 (1978): 70-84.

Tuchman, B.W. A Distant Mirror: The Calamitous 14th Century. New York: Knopf, 1978.

Tunving, K., et a1. "A HIV-Prevention Syringe Exchange Program in Lund, Sweden. Two Years of Observations of the Attenders." Paper presented at the Fifth International Conference on AIDS. June 5-8, 1989, Montreal, Quebec, Canada.

Turner, Charles F., et al. eds. AIDS, Sexual Behavior, and Intravenous Drug Use. Washington, D.C.: National Academy Press, 1989.

Van de Perre, P., et al. "Acquired Immunodeficiency Syndrome in Rwanda." Lancet 2 (1984): 62-65.

Vanscoy, Douglas W. (Deputy Prosecuting Attorney). Defendant Pierce County's Memorandum in Support of Summary Judgment. Superior Court for the State of Washington, County of Pierce, Alfred $M$. Allen, M.D. (Plaintiff) v. The City of Tacoma (Defendant). No. 892-09067-3, 23 January 1989. 
Vumbaca, G., et al. "Darlinghurst Pilot Needle and Syringe Exchange Programme." Report 1987.

Walizer, Michael H. and Paul L. Wienir. Research Methods and Analysis: Searching for Relationships. New York: Harper and Row Publishers, 1978.

Webb, E.T., et al. Nonreactive Measures in the Social Sciences. Boston: Houghton Mifflin Company, 1981.

Weinstein, N.D. "Unrealistic Optimism About Susceptibility to Health Problems: Conclusions from a Community-Wide Sample." Journal of Behavioral Medicine 10 (1987): 481-500.

Whyte, William F. Street Corner Society: The Social Structure of an Italian Slum. Chicago: University of Chicago Press, 1943.

Wirth, L. "Urbanism as a Way of Life." American Journal of Sociology 44 (1938): 3-24.

Wolk, J.S., et al. "HIV Seroprevalence in Syringes of Intravenous Drug Users Using Syringe Exchanges in Sydney, Australia, 1987." Paper presented at the Fourth International Conference on AIDS, June 1216, Stockholm, Sweden, 1988.

Wodak, A., and K. Dolan. "Antibodies to the Human Immunodeficiency Virus in Needles and Syringes Used by Intravenous Drug Abusers." Medical Journal of Australia 147 (1987): 275-276.

Wolfe, Charles R., M.D. Affidavit of Charles Wolfe. Superior Court for the State of Washington, County of Pierce, Alfred M. Allen, M.D. (Plaintiff) v. The City of Tacoma (Defendant). No. 89-2-09067-3, 25 February 1990.

Worth, D. Self-Help Interventions with Women at High Risk of HIV Infection. New York City: Montefiore Medical Center, 1988.

Yin, Robert K. Case Study Research: Design and Methods. Beverly Hills, California: Sage Publications, 1984.

Youngman, G. "Needle Exchange VII: Canadian Needle Echange Programmes." In Newsletter 5 (1), International Working Group on AIDS and IV Drug Use, March 1990. 


\section{APPENDIX A}

INJECTION EQUIPMENT AND DRUG PARAPHERNALIA ("WORKS ") OF IVDUS:

THE POTENTIAL SOURCES OF CONTAMINATION 
APPENDIX A

INJECTION EQUIPMENT AND DRUG PARAPHERNALIA ("WORKS ") OF IVDUS: THE POTENTIAL SOURCES OF CONTAMINATION

\section{The Syringe:}

Mode of Contamination: Infected blood may remain in the syringe between uses. This often occurs when injectors "boot" (i.e., to draw blood back and forth into a syringe multiple times during injection into a vein in order to obtain the last trace of the drug from the syringe).

Method of Decontamination: Bleach, alcohol, detergent, or hydrogen peroxide is highly effective in cleansing the syringe from contaminants.

\section{The Needle:}

Mode of Contamination: Infected blood may remain inside or outside the needle.

Method of Decontamination: Flush a cleansing agent through the needle and dip the needle into a cleansing agent.

\section{The Cooker:}

A cooker is the small container that is used to dissolve the drug that is to be injected: Usually the drug is in powder form.

Mode of Contamination: Infected blood can be transferred from needle/syringe during the process of drawing up a new shot. 
Method of Decontamination: Sterilize needle/syringe with cleansing agents between shots. Use clean cotton between shots. Heat the cooker between shots. At times, a small piece of cotton is used to strain undissolved impurities from the substance in the cooker as it is drawn up into the syringe. Generally, IVDUs will "beat" the cotton; that is, add a small amount of water to squeeze out the last drops of the drug.

\section{The Rinse Water}

Rinsing out syringes/needles with water between uses to prevent clotting and thus unusable works is a common procedure.

Mode of Contamination: Rinse water can become a source of contamination if syringes/needles are not properly sterilized.

Method of Decontamination: Multiple rinses with a bleach solution.

Source: Newmeyer (1988). 
APPENDIX B

INTERVIEW SCHEDULE: HEALTH DEPARTMENT OFFICIALS, LAW ENFORCEMENT PERSONNEL, AND INTRAVENOUS DRUG USERS (IVDUS) 


\section{APPENDIX B}

\section{INTERVIEW SCHEDULE: HEALTH DEPARTMENT OFFICIALS, LAW ENFORCEMENT PERSONNEL, AND INTRAVENOUS DRUG USERS (IVDUS)}

Research Question \#1: "What characteristics of the Tacoma-Pierce County Needle Exchange Program are linked to program acceptance?"

NOTE: Throughout the questionnaire, where boxes appear, please circle or "X" out the appropriate box.

(1) How did the health department determine the appropriate settings for the needle exchange program? (settings)

(2) How important is it to have walk-in agencies to distribute needles for a needle exchange program? (settings)

\begin{tabular}{|l|l|l|l|l|}
\hline $\begin{array}{l}\text { Very } \\
\text { Important }\end{array}$ & Important & $\begin{array}{l}\text { In the } \\
\text { Middle }\end{array}$ & Unimportant & $\begin{array}{l}\text { Very Un- } \\
\text { important }\end{array}$ \\
\hline
\end{tabular}

(2a) Could you elaborate on your response?

(3) How important is it to have mobile van units distribute needles for a needle exchange program? (settings) Circle below the appropriate box.

\begin{tabular}{|l|l|l|l|l|}
\hline $\begin{array}{l}\text { Very } \\
\text { Important }\end{array}$ & Important & $\begin{array}{l}\text { In the } \\
\text { Middle }\end{array}$ & Unimportant & $\begin{array}{l}\text { Very Un- } \\
\text { important }\end{array}$ \\
\hline
\end{tabular}

(3a) Could you elaborate on your response?

(4) How would the degree of acceptance of the needle exchange program be affected by relying on different settings (please respond to each sub-question "a" thru "e"):

(4a) Would the degree of acceptance be stronger or weaker if no mobile van units were utilized in the program?

\begin{tabular}{|l|l|l|}
\hline Stronger & Weaker & Don't Know \\
\hline
\end{tabular}

(4b) Would the degree of acceptance of the needle exchange program be stronger or weaker if needles were distributed only through pharmacies? 


\begin{tabular}{|l|l|l|}
\hline Stronger & Weaker & Don't know \\
\hline
\end{tabular}

(4c) Would the degree of acceptance be stronger or weaker if only fixed-site agencies within the health department distributed needles?

\begin{tabular}{|l|l|l|}
\hline Stronger & Weaker & Don't Know \\
\hline
\end{tabular}

(4d) Would the degree of acceptance be stronger or weaker if store-front locations were used throughout various parts of the city/community?

\begin{tabular}{|l|l|l|}
\hline Stronger & Weaker & Don't know \\
\hline
\end{tabular}

(4e) Would the degree of acceptance be stronger or weaker if vending machines were used in health department agencies or pharmacies to distribute needles? (settings)

\begin{tabular}{|l|l|l|}
\hline Stronger & Weaker & Don't Know \\
\hline
\end{tabular}

(5) Would the health department like to have the following different settings? (settings)

\begin{tabular}{|l|l|l|l||}
\cline { 2 - 4 } \multicolumn{1}{c|}{} & YES & NO & DON 'T KNOW \\
\hline Private Places & & & \\
\hline Store-Front & & & \\
\hline Vending Machines & & & \\
\hline In Hospitals & & & \\
\hline In Pharmacies & & & \\
\hline Other & & & \\
\hline
\end{tabular}

(If other, what type of setting?)

(6) Is access for program clients of the needle exchange program in Tacoma considered to be low barrier (i.e., easy to receive services and accessible)?

\begin{tabular}{|l|l|l|}
\hline YES & NO & DON'T KNOW \\
\hline
\end{tabular}


(6a) In what ways is/is not the access considered to be low barrier? (type of staff)

(7) Do you think the staff dispensing the injection equipment is "user-friendly" (i.e., non-judgmental, non-coercive?) (type of staff)

\begin{tabular}{|l|l|l|l|l|}
\hline $\begin{array}{l}\text { Strongly } \\
\text { Agree }\end{array}$ & Agree & $\begin{array}{l}\text { Strongly } \\
\text { Disagree }\end{array}$ & Di sagree & $\begin{array}{l}\text { Strongly } \\
\text { Disagree }\end{array}$ \\
\hline
\end{tabular}

(8) Are the barriers to access minimized by a staff that is userfriendly? (type of staff)

\begin{tabular}{|l|l|l|}
\hline YES & NO & DON'T KNOW \\
\hline
\end{tabular}

(If don't know, skip to Q-9)

(8a) Why or why not?

(9) How important is it to have a "user-friendly" staff in that it is necessary to create a relationship of trust and commitment between staff and program clients? (type of staff)

\begin{tabular}{|l|l|l|l|l|}
\hline $\begin{array}{l}\text { Very } \\
\text { Important }\end{array}$ & Important & $\begin{array}{l}\text { In The } \\
\text { Middle }\end{array}$ & Unimportant & $\begin{array}{l}\text { Very } \\
\text { Unimportant }\end{array}$ \\
\hline
\end{tabular}

(9a) If so, why is it important? 
(10) How essential is a relationship of trust and commitment to the success of the Tacoma-Pierce County Needle Exchange Program? (type of staff)

\begin{tabular}{|l|l|l|l|l|}
\hline $\begin{array}{l}\text { Very } \\
\text { Important }\end{array}$ & Important & $\begin{array}{l}\text { In The } \\
\text { Middle }\end{array}$ & Unimportant & $\begin{array}{l}\text { Very } \\
\text { Unimportant }\end{array}$ \\
\hline
\end{tabular}

(10a) If so, why?

(11) How do you develop and promote a relationship of trust and commitment between staff and program clients? (type of staff)

(12) Do you think IVDUs are capable of making changes in risk-taking behaviors such as sharing needles? (type of staff)

\begin{tabular}{|l|l|l|}
\hline YES & NO & DON'T KNOW \\
\hline
\end{tabular}

(If no or don't know, skip to Q-13)

(12a) How does a needle exchange program encourage drug users to change risk-taking behaviors?

(13) Do you think program clients of the needle exchange program can be educated to avoid sharing injection equipment if a formal program of needle exchange must be abandoned? (type of staff)

\begin{tabular}{|l|l|l|}
\hline YES & NO & DON'T KNOW \\
\hline
\end{tabular}

(14) Describe the staff in relationship to the program clients of the needle exchange program in Tacoma: (type of staff) 


\begin{tabular}{|l|l|l|l|l|}
\hline $\begin{array}{l}\text { Very } \\
\text { Distant }\end{array}$ & Distant & $\begin{array}{l}\text { Neither } \\
\text { Distant } \\
\text { nor Close }\end{array}$ & Close & $\begin{array}{l}\text { Very } \\
\text { Distant }\end{array}$ \\
\hline
\end{tabular}

\begin{tabular}{|l|l|l|l|l|}
\hline $\begin{array}{l}\text { Very } \\
\text { Friendly }\end{array}$ & Friendly & $\begin{array}{l}\text { Neither Un- } \\
\text { frieridly nor } \\
\text { Eriendly }\end{array}$ & Unfriendly & $\begin{array}{l}\text { Very } \\
\text { Unfriendly }\end{array}$ \\
\hline
\end{tabular}

\begin{tabular}{|l|l|l|l|l|}
\hline $\begin{array}{l}\text { Very } \\
\text { Formal }\end{array}$ & Formal & $\begin{array}{l}\text { Neither } \\
\text { Formal Nor } \\
\text { Informal }\end{array}$ & Informal & $\begin{array}{l}\text { Very } \\
\text { Informal }\end{array}$ \\
\hline
\end{tabular}

\begin{tabular}{|c|c|c|c|c|}
\hline $\begin{array}{l}\text { Very } \\
\text { Judgmental }\end{array}$ & $\begin{array}{l}\text { Judg- } \\
\text { mental }\end{array}$ & $\begin{array}{l}\text { Neither } \\
\text { Judgmental } \\
\text { nor Non- } \\
\text { judgmental }\end{array}$ & $\begin{array}{l}\text { Non-Judg- } \\
\text { mental }\end{array}$ & $\begin{array}{l}\text { Very Non- } \\
\text { judgmental }\end{array}$ \\
\hline
\end{tabular}

\begin{tabular}{||l|l|l|l|l|}
\hline $\begin{array}{l}\text { Very } \\
\text { Untrust- } \\
\text { worthy }\end{array}$ & $\begin{array}{l}\text { Neither Un- } \\
\text { trustworthy } \\
\text { nor Trust- } \\
\text { worthy }\end{array}$ & $\begin{array}{l}\text { Untrust- } \\
\text { worthy }\end{array}$ & $\begin{array}{l}\text { Very } \\
\text { Trust- } \\
\text { worthy }\end{array}$ & \begin{tabular}{l} 
worthy \\
\hline
\end{tabular} \\
\hline
\end{tabular}

\begin{tabular}{|l|l|l|l|l|}
\hline $\begin{array}{l}\text { Very Un- } \\
\text { committed }\end{array}$ & $\begin{array}{l}\text { Un- } \\
\text { committed }\end{array}$ & $\begin{array}{l}\text { Neither Un- } \\
\text { committed nor } \\
\text { Committed }\end{array}$ & $\begin{array}{l}\text { Com- } \\
\text { mitted }\end{array}$ & $\begin{array}{l}\text { Very } \\
\text { Committed }\end{array}$ \\
\hline
\end{tabular}

(15) How were formal regulations for the needle exchange program in Tacoma developed? (method of service delivery)

\begin{tabular}{|l|l|l|}
\hline YES & NO & DON'T KNOW \\
\hline
\end{tabular}

(15a) Who developed these formal regulations?

(15b) How were these approved and with whose approval?

(16) Are there any eligibility requirements (i.e., criteria to use the program) for IVDUs to use the program? (method of service delivery)

\begin{tabular}{|l|l|l|}
\hline YES & NO & DON'T KNOW \\
\hline
\end{tabular}


(If no or don't know, skip to Q-20)

(17) Are the following items a requirement for eligibility?

\begin{tabular}{||l|l|l|l||}
\cline { 2 - 4 } \multicolumn{1}{c|}{} & YES & NO & DON'T KNOW \\
\hline \hline Name & & & \\
\hline Address & & & \\
\hline Age & & & \\
\hline Identification & & & \\
\hline $\begin{array}{l}\text { Previous Source } \\
\text { of Needles }\end{array}$ & & & \\
\hline $\begin{array}{l}\text { Passport } \\
\text { Green Card }\end{array}$ & & & \\
\hline Proof of Residency & & & \\
\hline Other & & & \\
\hline
\end{tabular}

(If other, what?)

(18) Has there been any resistance by IVDUs in giving any of the above information to obtain eligibility to utilize the needle exchange?

\begin{tabular}{|l|l|l|}
\hline YES & NO & DON'T KNOW \\
\hline
\end{tabular}

(19) Are eligibility requirements the same for both the fixed-site agency and mobile van units?

\begin{tabular}{|c|c|c|}
\hline YES & NO & DON'T KNOW \\
\hline
\end{tabular}

(If yes or don't know, skip to Q-21)

(19a) What are the differences in eligibility requirements for the fixed-site agency and the mobile van units? 
(20) Were there any eligibility requirements that have been attempted or suggested by the health department?

\begin{tabular}{|c|c|c|}
\hline YES & NO & DON'T KNOW \\
\hline
\end{tabular}

(21) Has the health department ever disqualified (i.e., barred) any individual IVDU from receiving clean needles from the TacomaPierce County Needle Exchange Program? (method of service del ivery)

\begin{tabular}{|l|l|l|}
\hline YES & NO & DON'T KNOW \\
\hline
\end{tabular}

(If no or don't know, skip to Q-23)

(22) For what reason(s) did the health department disqualify such individual (s) from receiving sterile needles from the needle exchange? (method of service delivery)

\begin{tabular}{||l|l|l|}
\cline { 2 - 3 } \multicolumn{1}{c|}{} & YES & NO \\
\hline \hline $\begin{array}{l}\text { Caught selling county } \\
\text { needles obtained to other } \\
\text { IVDUs for a profit }\end{array}$ & & \\
\hline "Fell off the wagon" & & \\
\hline $\begin{array}{l}\text { Falsifying eligibility } \\
\text { requirements }\end{array}$ & & \\
\hline $\begin{array}{l}\text { Attitude/Behavior problems } \\
\text { between IVDUs and staff }\end{array}$ & & \\
\hline Other & & \\
\hline
\end{tabular}

(If other, what?)

(23) In terms of day-to-day operations, how are sterile needles dispensed from the mobile van sites? (method of service delivery) 
(24) Do operations differ at the fixed-site location than those of the mobile van units? (method of service delivery)

\begin{tabular}{|l|l|l|}
\hline YES & NO & DON'T KNOW \\
\hline
\end{tabular}

(If no or don't know, skip to Q-25)

(24a) What are the differences in operations?

(25) How are contaminated needles returned?

(26) Are program clients (i.e., IVDU) limited in the number of needles in which they can receive during the day? (method of service delivery)

\begin{tabular}{||l|l|l|}
\cline { 2 - 3 } \multicolumn{1}{c|}{} & YES & NO \\
\hline Limited & & \\
\hline Unlimited & & \\
\hline
\end{tabular}

(If unlimited, skip to Q-27)

(26a) If limited, what is the maximum number of needles per day in which a program client may receive?

(27) Do clients have to return a dirty needle for every clean one? (method of service delivery)

\begin{tabular}{|l|l|l|}
\hline YES & NO & DON'T KNOW \\
\hline
\end{tabular}

(If yes or don't know, skip to Q-28)

(27a) If no, why not? 
(28) Are there any specific procedures for returning used needles? (method of service delivery)

\begin{tabular}{|l|l|l|}
\hline YES & NO & DON'T KNOW \\
\hline
\end{tabular}

(If no or don't know, skip to Q-29)

(28a) What is the procedure for returning used needles?

(29) Are any other services and/or items offered to program clients? (method of service delivery)

\begin{tabular}{|l|l|l|}
\hline YES & NO & DON'T KNOW \\
\hline
\end{tabular}

(If no or don't know, skip to Q-31)

(30) Are any of the following items offered to program clients?

\begin{tabular}{|l|l|l|}
\cline { 2 - 3 } \multicolumn{1}{c|}{} & YES & NO \\
\hline \hline Bleach & & \\
\hline Sterile Water & & \\
\hline Condoms & & \\
\hline Cotton Swabs & & \\
\hline Literature & & \\
\hline Other & & \\
\hline
\end{tabular}

(If other, what?) 
(31) What are the hours of operation? (method of service delivery)

\begin{tabular}{||l|l|l|l|l||}
\hline \hline PLACE & FROM & TO & $\begin{array}{l}\text { HOURS } \\
\text { PER DAY }\end{array}$ & $\begin{array}{l}\text { HOURS } \\
\text { PER WEEK }\end{array}$ \\
\hline \hline St. Leo's & & & & \\
\hline $\begin{array}{l}\text { Downtown } \\
\text { Tacoma }\end{array}$ & & & & \\
\hline Pharmacy & & & & \\
\hline
\end{tabular}

(32) Did any informal procedures or rules develop by "street level bureaucrats" (i.e., law enforcement officers or program staff) and/or program clients? (method of service delivery)

\begin{tabular}{|l|l|l|}
\hline YES & NO & DON'T KNOW \\
\hline
\end{tabular}

(If no or don't know, skip to Q-33)

(32a) What informal procedures or rules developed, and whom initiated them?

Research Question \#2: "What characteristics of the external environment are linked to program acceptance?"

(Note: the following questions refer to the "nature of the geographic area" which refers to the external environment.)

(33) Describe the physical location and ambience in which the needle exchange operates.

(33a) St. Leo's:

(33b) Downtown Tacoma: 
(33c) Pharmacy

(34) Would other locations work as well in terms of enhancing community acceptance?

\begin{tabular}{|l|l|l|}
\hline YES & NO & DON'T KNOW \\
\hline
\end{tabular}

(If no, skip to Q-34b)

(If don't know, skip to Q-35)

(34a) Where? (Go to Q-35)

(34b) Why not?

(35) Would other locations work as well in terms of maximizing accessibility for IVDUs?

\begin{tabular}{|c|c|c|}
\hline YES & NO & DON'T KNOW \\
\hline
\end{tabular}

(If no, skip to Q-35b)

(If don't know, skip to Q-36)

(35a) Where?

(35b) Why not? 
(36) What criteria are used to select the locations of the mobile van units?

\begin{tabular}{||l|l|l|l|}
\cline { 2 - 4 } \multicolumn{1}{c|}{} & YES & NO & DON'T KNOW \\
\hline Citizen Tolerance & & & \\
\hline $\begin{array}{l}\text { Near to Other } \\
\text { Social Services }\end{array}$ & & & \\
\hline Non-residential & & & \\
\hline Don't Know & & & \\
\hline Other & & & \\
\hline
\end{tabular}

(If other, what?)

(37) What criteria are used to select the locations for the fixed-site agency?

\begin{tabular}{|l|l|l|}
\cline { 2 - 3 } \multicolumn{1}{c|}{} & YES & NO \\
\hline $\begin{array}{l}\text { Concealed From } \\
\text { the Street }\end{array}$ & & \\
\hline $\begin{array}{l}\text { Near Other } \\
\text { Social Services }\end{array}$ & & \\
\hline Don't Know & & \\
\hline Other & & \\
\hline
\end{tabular}

(If other, what?)

(38) In selecting locations for a needle exchange, how important is it to prevent a "not in my back yard" philosophy from interfering with making wise choices?

\begin{tabular}{|l|l|l|l|l|}
\hline $\begin{array}{l}\text { Very } \\
\text { Important }\end{array}$ & Important & $\begin{array}{l}\text { In The } \\
\text { Middle }\end{array}$ & Unimportant & $\begin{array}{l}\text { Very Un- } \\
\text { important }\end{array}$ \\
\hline
\end{tabular}

(38a) If so, why is it important? 
(39) Has the "not in my back yard" philosophy created any problems for the Tacoma-Pierce County Needle Exchange Program?

(Note: the following questions refer to the socio-political climate which refers to the external environment)

(40) Did any particular groups/organizations oppose having a needle exchange program in Tacoma?

\begin{tabular}{|l|l|l|}
\hline YES & NO & DON'T KNOW \\
\hline
\end{tabular}

(If no or don't know, skip to Q-44)

(41) Which groups/organizations stated opposition?

\begin{tabular}{||l|l|l|}
\cline { 2 - 3 } \multicolumn{1}{c|}{} & YES & NO \\
\hline Black Groups/Organizations & & \\
\hline Church Groups/Organizations & & \\
\hline Business Groups/Organizations & & \\
\hline Other groups/Organizations & & \\
\hline
\end{tabular}

(If other, state name(s):

(42) For those groups/organizations with "yes" responses: For what reasons did those groups/organizations oppose the needle exchange program in Tacoma? 
(42a) Black groups/organizations:

\begin{tabular}{||l|l|l|}
\cline { 2 - 3 } \multicolumn{1}{l|}{} & YES & NO \\
\hline \hline $\begin{array}{l}\text { Opposition related to } \\
\text { needle exchange program } \\
\text { itself }\end{array}$ & & \\
\hline $\begin{array}{l}\text { Opposition related to the } \\
\text { external environment }\end{array}$ & & \\
\hline Other & & \\
\hline
\end{tabular}

(If other, what?)

(42b) Church groups/organizations:

\begin{tabular}{||l|l|l|}
\cline { 2 - 3 } \multicolumn{1}{l|}{} & YES & NO \\
\hline $\begin{array}{l}\text { Opposition related to } \\
\text { needle exchange program } \\
\text { itself }\end{array}$ & & \\
\hline $\begin{array}{l}\text { Opposition related to the } \\
\text { external environment }\end{array}$ & & \\
\hline Other & & \\
\hline
\end{tabular}

(If other, what?)

(42c) Business groups/organizations:

\begin{tabular}{|l|l|l|}
\cline { 2 - 3 } \multicolumn{1}{c|}{} & YES & NO \\
\hline \hline $\begin{array}{l}\text { Opposition related to } \\
\text { needle exchange program } \\
\text { itself }\end{array}$ & & \\
\hline $\begin{array}{l}\text { Opposition related to } \\
\text { the external environment }\end{array}$ & & \\
\hline Other & & \\
\hline
\end{tabular}

(If other, what?) 
(42d) Other groups/organizations (name):

\begin{tabular}{|l|l|l|}
\hline \multicolumn{1}{l|}{$\begin{array}{l}\text { Opposition related to } \\
\text { needle exchange program } \\
\text { itself }\end{array}$} & & YES \\
\hline $\begin{array}{l}\text { Opposition related to } \\
\text { the externaal environment }\end{array}$ & & \\
\hline Other & & \\
\hline
\end{tabular}

(If other, what?)

(43) For those groups/organizations with "yes" responses: Was the opposition(s) resolved?

\begin{tabular}{||l|l|r||}
\cline { 2 - 3 } \multicolumn{1}{c|}{} & YES & NO \\
\hline Black Groups/Organizations & & \\
\hline Church Groups/Organizations & & \\
\hline Business Groups/Organizations & & \\
\hline Other & & \\
\hline
\end{tabular}

(Note: the following are questions regarding the "concern over the effects of AIDS" which refers to the external environment).

(44) Is AIDS education and awareness department-wide or the job of a few?

\begin{tabular}{||l|l|l|l|}
\cline { 2 - 4 } \multicolumn{1}{c|}{} & YES & NO & DON'T KNOW \\
\hline \hline Department-Wide & & & \\
\hline Job of a Few & & & \\
\hline Don't Know & & & \\
\hline
\end{tabular}

(45) Have you ever participated in any fundraisers in reference to AIDS, such as walkathons, auctions, etc?

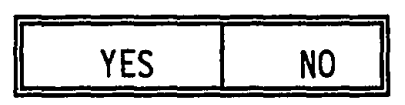

(If no, skip to Q-46)

(45a) If yes, which ones? 
(46) Do you know anyone that has AIDS, or has died from AIDS?

\begin{tabular}{|l|l|}
\hline YES & NO \\
\hline
\end{tabular}

(47) How aware are you of the effects of AIDS?

\begin{tabular}{|l|l|l|l|l|}
\hline $\begin{array}{l}\text { Very } \\
\text { Aware }\end{array}$ & Aware & $\begin{array}{l}\text { In the } \\
\text { Middle }\end{array}$ & Unaware & $\begin{array}{l}\text { Very } \\
\text { Unaware }\end{array}$ \\
\hline
\end{tabular}

(47a) What are the effects of AIDS?

(48) Are there particular employees at the health department considered responsible for program acceptance?

\begin{tabular}{|l|l|l|}
\hline YES & NO & DON'T KNOW \\
\hline
\end{tabular}

(If no or don't know, skip to Q-49)

(48a) If yes, what is their name and title (if any)?

(49) How much of program acceptance is due to general department policies?

(Note: the following are questions regarding the informal comunication network.)

(50) Did any other social service organization want to sponsor the needle exchange program in Tacoma?

\begin{tabular}{|l|l|l|}
\hline YES & NO & DON'T KNOW \\
\hline
\end{tabular}


(If no or don't know, skip to Q-52)

(51) Which of the following wanted to sponsor a needle exchange?

\begin{tabular}{|l|l|l|}
\cline { 2 - 3 } \multicolumn{1}{c|}{} & YES & NO \\
\hline Hal fway Houses & & \\
\hline Private Foundations & & \\
\hline Other & & \\
\hline
\end{tabular}

(If other, name?)

(52) Did any social service organization hurt or help with the needle exchange program's acceptance in Tacoma?

\begin{tabular}{|c|c|c|}
\hline YES & NO & DON'T KNOW \\
\hline
\end{tabular}

(If no or don't know, skip to Q-53)

(52a) If yes, which ones helped or hurt?

(52b) What role, if any, have other social service agencies played in terms of helping or hurting the needle exchange gain acceptance?

\begin{tabular}{||l|l|l|l||}
\cline { 2 - 4 } \multicolumn{1}{c|}{} & HELPED & HURT & ROLE \\
\hline \hline Hal fway Houses & & & \\
\hline Missions & & & \\
\hline Plasma Centers & & & \\
\hline Shelters & & & \\
\hline
\end{tabular}

Research Question \#3: "What characteristics of the program clients are linked to program acceptance of the Tacoma/Pierce County Needle Exchange Program?"

(53) Are you aware of differential acceptance of the Needle Exchange Program among ethnic groups?

$$
\begin{array}{|l|l|}
\hline \text { YES } & \text { NO } \\
\hline
\end{array}
$$


(If no, skip to Q-54)

(53a) If yes, could you elaborate on this element?

(53b) Could you supply any statistical data or information on this element?

(54) Are you aware of the race/ethnic background of the users in reference of those being arrested for drug use?

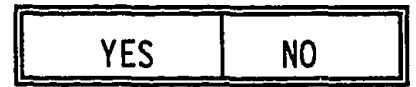

(If no, skip to Q-55)

(54a) If yes, could you supply any statistical data or information on this element?

The following are some questions to ask in order to check responses.

(55) What are your feelings of having a needle exchange program as one intervention in controlling the spread of HIV-1/AIDS.

\begin{tabular}{|l|l|l|l||}
\hline Positive & & Negative & \\
\hline Actively Supportive & & Non-Supportive & \\
\hline Necessary & & Unnessary & \\
\hline Effective & & Ineffective & \\
\hline
\end{tabular}

(56) Do you think the needle exchange program contradicts anti-drug policies? 


\begin{tabular}{|l|l|l|l|l|}
\hline $\begin{array}{l}\text { Strongly } \\
\text { Agree }\end{array}$ & Agree & $\begin{array}{l}\text { in the } \\
\text { Middle }\end{array}$ & Disagree & $\begin{array}{l}\text { Strongly } \\
\text { Disagree }\end{array}$ \\
\hline
\end{tabular}

(57a) If so, why?

(57) Do you think needle exchange programs make drug-treatment programs less-attractive?

\begin{tabular}{|l|l|l|l|l|}
\hline \hline $\begin{array}{l}\text { Strongly } \\
\text { Agree }\end{array}$ & Agree & $\begin{array}{l}\text { In the } \\
\text { Middle }\end{array}$ & Disagree & $\begin{array}{l}\text { Strongly } \\
\text { Disagree }\end{array}$ \\
\hline
\end{tabular}

(57a) If so, why?

(58) What are your feelings about needle exchange programs in communities in which illicit drug use is against the law?

(59) Describe the relationship that the health department maintains with the police department.

(60) Do you foresee any future obstacles or problems to the needle exchange program in Tacoma? 
INTERVIEW SCHEDULE: LAW ENFORCEMENT PERSONNEL

Research Question \#1: "What characteristics of the Tacoma-Pierce County Needle Exchange Program are linked to program acceptance?"

(1) Describe your feelings about having a needle exchange in communities where illicit drug use is against the law.

(2) Do you think having a needle exchange contradicts anti-drug use laws?

\begin{tabular}{|l|l|l|}
\hline YES & NO & DON'T KNOW \\
\hline
\end{tabular}

(If don't know, skip to Q-3)

(2a) If yes or no, why?

(3) Initially, did the Tacoma Police Department (TPD) have any concerns about "closing an eye" to the drug scene for a "greater good"?

\begin{tabular}{|c|c|c|}
\hline YES & NO & DON'T KNOW \\
\hline
\end{tabular}

(If no or don't know, skip to Q-4) 
(3a) If yes, what were these initial concerns?

\begin{tabular}{|l|l|}
\hline TPD Acknowledging Illegal Activities & \\
\hline Increasing Drug Traffic & \\
\hline Increasing Crime & \\
\hline Increasing Drug Sales & \\
\hline Increasing Prostitution & \\
\hline Condoning the use of Illegal Drugs & \\
\hline Other & \\
\hline
\end{tabular}

(If other, what?)

(3b) If yes, how were these concerns dealt with?

(4) Did the TPD have any input in determining the appropriate settings for the needle exchange program?

\begin{tabular}{|c|c|c|}
\hline YES & NO & DON'T KNOW \\
\hline
\end{tabular}

(If no or don't know, skip to Q-5)

(4a) If yes, what were the concerns and considerations of the TPD in determining the settings? 
(4b) Would the TPD like to see different settings? (settings)

\begin{tabular}{||l|l|}
\hline In Pharmacies & \\
\hline In Clinics & \\
\hline In Hospitals & \\
\hline Vending Machines & \\
\hline No Mobile Van Units & \\
\hline No Fixed-Site Agency & \\
\hline Other & \\
\hline
\end{tabular}

(If other, what?)

(5) How important is it to have walk-in agencies for the needle exchange program?

\begin{tabular}{|l|l|l|l|l|}
\hline $\begin{array}{l}\text { Very } \\
\text { Important }\end{array}$ & Important & $\begin{array}{l}\text { In The } \\
\text { Middle }\end{array}$ & $\begin{array}{l}\text { Un- } \\
\text { important }\end{array}$ & $\begin{array}{l}\text { Very Un- } \\
\text { important }\end{array}$ \\
\hline
\end{tabular}

(6) How important is it to have mobile van units for the needle exchange program?

\begin{tabular}{||l|l|l|l|l||}
\hline $\begin{array}{l}\text { Very } \\
\text { Important }\end{array}$ & Important & $\begin{array}{l}\text { In The } \\
\text { Middle }\end{array}$ & $\begin{array}{l}\text { Un- } \\
\text { important }\end{array}$ & $\begin{array}{l}\text { Very Un- } \\
\text { important }\end{array}$ \\
\hline
\end{tabular}

(7) Which setting provides better access in terms of acceptance? (settings) Check the better setting:

\begin{tabular}{||l|l|}
\hline \hline Acceptance by the TPD & \\
\hline Mobile Van Units & \\
\hline Pharmacy & \\
\hline
\end{tabular}

\begin{tabular}{|l|l||}
\hline Acceptance by the IVDUs & \\
\hline Mobile Van Units & \\
\hline Pharmacy & \\
\hline
\end{tabular}




\begin{tabular}{|l|l|}
\hline Acceptance by the Health Department & \\
\hline Mobile Van Units & \\
\hline Pharmacy & \\
\hline
\end{tabular}

(8) Have any unusual problems developed in terms of the use of mobile van units? (settings)

\begin{tabular}{|l|l|}
\hline Congregation of IVDUs & \\
\hline Increased Drug Traffic in that Area & \\
\hline Increased Prostitution in that Area & \\
\hline Crime in that Area & \\
\hline Other & \\
\hline
\end{tabular}

(If other, what?)

(9) Is access for program clients considered to be low barrier? (settings)

\begin{tabular}{|c|c|c|}
\hline YES & NO & DON'T KNOW \\
\hline
\end{tabular}

(If no, skip to Q-9b)

(If don't know, skip to Q-10) 
(9a) If yes, in what ways is access considered to be low barrier?

\begin{tabular}{|l|l|l||}
\hline Location & & \\
\hline Staff & & \\
\hline Minimal Police Patrol & & \\
\hline Police Cooperation & & \\
\hline Near Other Social Services & & \\
\hline $\begin{array}{l}\text { Type of Cormercial Activities/ } \\
\text { Operations }\end{array}$ & & \\
\hline Citizen Tolerance & & \\
\hline Other & & \\
\hline
\end{tabular}

(If other, what?)

(Go to Q-10)

(9b) If no, why is access not considered to be low barrier?

\begin{tabular}{|l|l|l||}
\hline Location & & \\
\hline Staff & & \\
\hline Police Patrolling the Area & & \\
\hline Police Harassment & & \\
\hline Citizen Harassment & & \\
\hline $\begin{array}{l}\text { Type of Commercial Activities/ } \\
\text { Operations }\end{array}$ & & \\
\hline Far From Other Social Services & & \\
\hline Other & & \\
\hline
\end{tabular}

(If other, what?) 
(9c) Would any other setting provide better access for program clients (IVDUs)? (settings)

\begin{tabular}{||l|l|l|}
\cline { 2 - 3 } \multicolumn{1}{c|}{} & YES & NO \\
\hline In Pharmacies & & \\
\hline In Hospitals & & \\
\hline In Clinics & & \\
\hline Vending Machines & & \\
\hline Store-front Distribution & & \\
\hline Vending Machines & & \\
\hline Other & & \\
\hline
\end{tabular}

(If other, what?)

(10) Do you know any of the staff involved directly with the needle exchange program? (type of staff)

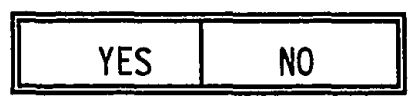

(If no, skip to Q-11)

(10a) Is that person an asset to the needlle exchange program in terms of creating a "user-friendly" (i.e., non-judgmental, non-coercive) atmosphere for IVDUs?

\begin{tabular}{|l|l|l|}
\hline YES & NO & DON'T KNOW \\
\hline
\end{tabular}

(10b) Do you think the staff is "user-friendly" (type of staff)

\begin{tabular}{|l|l|l|}
\hline YES & NO & DON'T KNOW \\
\hline
\end{tabular}


(10c) In what ways is the staff "user-friendly"?

(11) Do you think that a "user-friendly" staff helps to maximize accessibility for IVDUs? (type of staff)

\begin{tabular}{|c|c|c|}
\hline YES & NO & DON'T KNOW \\
\hline
\end{tabular}

(If don't know, skip to Q-12)

(11a) If yes or no, why?

(12) What kind of relationship does the TPD have with the program staff?

\begin{tabular}{|l|l|l|l|l|}
\hline \hline $\begin{array}{l}\text { Very } \\
\text { Friendly }\end{array}$ & Friendly & $\begin{array}{l}\text { In the } \\
\text { Middle }\end{array}$ & $\begin{array}{l}\text { Un- } \\
\text { friendly }\end{array}$ & $\begin{array}{l}\text { Very Un- } \\
\text { friendly }\end{array}$ \\
\hline
\end{tabular}

\begin{tabular}{|l|l|l|l|l|}
\hline $\begin{array}{l}\text { Very } \\
\text { Trusting }\end{array}$ & Trusting & $\begin{array}{l}\text { In the } \\
\text { Middle }\end{array}$ & $\begin{array}{l}\text { Not Very } \\
\text { Trusting }\end{array}$ & $\begin{array}{l}\text { Not } \\
\text { Trusting }\end{array}$ \\
\hline
\end{tabular}

\begin{tabular}{|l|l|l|l|l|}
\hline $\begin{array}{l}\text { Very } \\
\text { Cordial }\end{array}$ & Cordial & $\begin{array}{l}\text { In the } \\
\text { Middle }\end{array}$ & $\begin{array}{l}\text { Not Very } \\
\text { Cordial }\end{array}$ & $\begin{array}{l}\text { Not } \\
\text { Cordial }\end{array}$ \\
\hline
\end{tabular}

\begin{tabular}{|l|l|l|l|l|}
\hline $\begin{array}{l}\text { Very } \\
\text { Committed }\end{array}$ & Committed & $\begin{array}{l}\text { In the } \\
\text { Middle }\end{array}$ & $\begin{array}{l}\text { Not Very } \\
\text { Cormitted }\end{array}$ & $\begin{array}{l}\text { Not } \\
\text { Committed }\end{array}$ \\
\hline
\end{tabular}

\begin{tabular}{|l|l|l|l|l|}
\hline $\begin{array}{l}\text { Very } \\
\text { Distant }\end{array}$ & Distant & $\begin{array}{l}\text { In the } \\
\text { Middle }\end{array}$ & Close & $\begin{array}{l}\text { Very } \\
\text { Close }\end{array}$ \\
\hline
\end{tabular}

\begin{tabular}{|l|l|l|l|l|}
\hline $\begin{array}{l}\text { Not } \\
\text { Helpful }\end{array}$ & $\begin{array}{l}\text { Not Very } \\
\text { Helpful }\end{array}$ & $\begin{array}{l}\text { In the } \\
\text { Middle }\end{array}$ & Helpful & $\begin{array}{l}\text { Very } \\
\text { Helpful }\end{array}$ \\
\hline
\end{tabular}




\begin{tabular}{|l|l|l|l|l|}
\hline $\begin{array}{l}\text { Very Un- } \\
\text { friendly }\end{array}$ & $\begin{array}{l}\text { Un- } \\
\text { friendly }\end{array}$ & $\begin{array}{l}\text { In the } \\
\text { Middle }\end{array}$ & Friendly & $\begin{array}{l}\text { Very } \\
\text { Friendly }\end{array}$ \\
\hline
\end{tabular}

\begin{tabular}{|l|l|l|l|l|}
\hline $\begin{array}{l}\text { Very } \\
\text { Formal }\end{array}$ & Formal & $\begin{array}{l}\text { In the } \\
\text { Middle }\end{array}$ & Informal & $\begin{array}{l}\text { Very } \\
\text { Informal }\end{array}$ \\
\hline
\end{tabular}

\begin{tabular}{|l|l|l|l|l|}
\hline $\begin{array}{l}\text { Very bureau- } \\
\text { cratic }\end{array}$ & $\begin{array}{l}\text { Bureau- } \\
\text { cratic }\end{array}$ & $\begin{array}{l}\text { In the } \\
\text { Middle }\end{array}$ & $\begin{array}{l}\text { Not Very } \\
\text { Bureau- } \\
\text { cratuc }\end{array}$ & $\begin{array}{l}\text { Not } \\
\text { Bureau- } \\
\text { cratic }\end{array}$ \\
\hline
\end{tabular}

\begin{tabular}{|l|l|l|l|l|}
\hline $\begin{array}{l}\text { Very } \\
\text { Judgmental }\end{array}$ & $\begin{array}{l}\text { Judg- } \\
\text { mental }\end{array}$ & $\begin{array}{l}\text { In the } \\
\text { Middle }\end{array}$ & $\begin{array}{l}\text { Non-Judg- } \\
\text { mental }\end{array}$ & $\begin{array}{l}\text { Very Non- } \\
\text { Judgmental }\end{array}$ \\
\hline
\end{tabular}

(Other?)

(13) If responses to items presented in Question 12 indicate a more distant, not helpful, unfriendly, formal, bureaucratic, judgmental relationships, then do/does ... (If relationship is otherwise, skip to Q-14)

(13a) - . the program itself inherently keep informal, close, trusting, helpful, and friendly relationships from developing between the health department and the TPD?

\begin{tabular}{|l|l|l|}
\hline YES & NO & DON'T KNOW \\
\hline
\end{tabular}

(13b) . . the personalities of the staff keep informal, close, trusting, helpful, and friendly relationships from develop between the health department and TPD?

\begin{tabular}{|l|l|l|}
\hline YES & NO & DON'T KNOW \\
\hline
\end{tabular}

(13c) ... the program clients (IVDUs) who engage in illegal activities keep informal, close, trusting, helpful, and friendly relationships from developing between the health department and the TPD?

\begin{tabular}{|c|c|c|}
\hline YES & NO & DON'T KNOW \\
\hline
\end{tabular}


(13d) If no or don't know, then what accounts for the distant, unfriendly, formal, bureaucratic, judgmental relationship that exists between the health department and the TPD?

(Go to Q-15)

(14) If responses to items presented in Question 12 indicate a more close, helpful, friendly, informal, non-bureaucratic, nonjudgmental relationships, then do/does ...

(14a) . . the program itself account for the close, helpful, friendly, informal, non-bureaucratic, non-judgmental relationship that exists between the health department and TPD?

\begin{tabular}{|c|c|c|}
\hline YES & NO & DON'T KNOW \\
\hline
\end{tabular}

(14b) . . do the personalities in both groups lead to trust?

\begin{tabular}{|c|c|c|}
\hline YES & NO & DON'T KNOW \\
\hline
\end{tabular}

(14c) . . . the way in which Dave Purchase initiated the program account for the close, helpful, friendly, informal, nonbureaucratic, non-judgmental relationship that exists between the health department and the TPD?

\begin{tabular}{|l|l|l|}
\hline YES & NO & DON'T KNOW \\
\hline
\end{tabular}

(14d) . . . the fact that a "friendly lawsuit" between the health department and TPD account for the close, helpful, friendly, informal, non-bureaucratic, non-judgmental relationship that exists between the health department and the TPD?

\begin{tabular}{|c|c|c|}
\hline YES & NO & DON'T KNOW \\
\hline
\end{tabular}

(14e) If no or don't know, then what accounts for the more close, helpful, friendly, informal, non-bureaucratic, nonjudgmental relationship that exists between the health department and the TPD? (type of staff)

(15) Is the TPD satisfied with the ways in which needles are dispensed and returned? (method of service delivery)

\begin{tabular}{|l|l|l|}
\hline YES & NO & DON'T KNOW \\
\hline
\end{tabular}


(If yes or don't know, skip to Q-16)

(15a) If no, is the health department aware of the TPD's dissatisfaction with the ways in which needles dispensed and returned? (method of service delivery)

\begin{tabular}{|c|c|c|}
\hline YES & NO & DON'T KNOW \\
\hline
\end{tabular}

(15b) How would the TPD rather have needles dispensed and returned? (method of service delivery)

(16) Is the police department satisfied with having no eligibility requirements for IVDUs to use the program (e.g., name, address, age, identification restrictions)? (method of service delivery)

\begin{tabular}{|l|l|l|}
\hline YES & NO & DON'T KNOW \\
\hline
\end{tabular}

(16a) If no, why?

(17) Do any of the operations of the needle exchange program interfere with any activities of the police department? (method of service delivery)

\begin{tabular}{|l|l|l|}
\hline YES & NO & DON'T KNOW \\
\hline
\end{tabular}

(If no or don't know, skip to Q-18) 
(17a) If yes, which ones?

\begin{tabular}{||l|l|l|}
\cline { 2 - 3 } \multicolumn{1}{l|}{} & YES & NO \\
\hline \hline Settings & & \\
\hline Hours & & \\
\hline Days & & \\
\hline Locations & & \\
\hline Collection Procedures & & \\
\hline Other & & \\
\hline
\end{tabular}

(If other, what?)

(18) Does the TPD even feel compelled to interfere with needle exchange operations? (method of service delivery)

\begin{tabular}{|c|c|c|}
\hline YES & NO & DON'T KNOW \\
\hline
\end{tabular}

(If no or don't know, skip to Q-19)

(18a) If yes, why and in what ways?

(18b) Under what circumstances or hypothetical situations would the TPD interfere with needle exchange operations? (method of service delivery)

(19) Are you aware of any informal procedures or rules that have been developed by "street level bureaucrats" (i.e., law enforcement officers or program staff) to meet the needs of the program clients (i.e., IVDUs)? (method of service delivery) 
(If no or don't know, skip to Q-20)

(19a) If yes, please provide examples:

(20) Has Tacoma, as a result of having a needle exchange program, experienced an influx of drug users from nearby communities which do not have a needle exchange?

\begin{tabular}{|c|c|c|}
\hline YES & NO & DON'T KNOW \\
\hline
\end{tabular}

(If no or don't know, skip to Q-21)

(20a) Is this influx seen as a threat to the program or as an example of the program's success -- or other events or examples?

\begin{tabular}{||l|l|l||}
\cline { 2 - 3 } \multicolumn{1}{c|}{} & YES & NO \\
\hline Threat to the Program & & \\
\hline Success of the Program & & \\
\hline Don't Know & & \\
\hline Other Events & & \\
\hline Other Examples & & \\
\hline
\end{tabular}

Other Events (what?)

Other Examples (what?)

(21) Does the TPD officially track drug users? (method of service delivery)

\begin{tabular}{|c|c|c|}
\hline YES & NO & DON'T KNOW \\
\hline
\end{tabular}

(If no or don't know, skip to Q-22) 
(21a) If yes, how does the TPD track them?

(21b) If yes, have the IVDUs been informed officially that TPD is tracking them?

\begin{tabular}{|c|c|c|}
\hline YES & NO & DON'T KNOW \\
\hline
\end{tabular}

(21c) Is the health department aware of the tracking of IVDUs by TPD?

\begin{tabular}{|c|c|c|}
\hline YES & NO & DON'T KNOW \\
\hline
\end{tabular}

(21d) Are street-level staff aware of the TPD tracking IVDUs?

\begin{tabular}{|c|c|c|}
\hline YES & NO & DON'T KNOW \\
\hline
\end{tabular}

(Go to Q-23)

(22) Does the TPD unofficially track IVDUs?

\begin{tabular}{|l|l|l|}
\hline YES & NO & DON'T KNOW \\
\hline
\end{tabular}

(If no or don't know, skip to Q-23)

(22a) If yes, is the health department aware of the unofficial tracking of IVDUs by the TPD?

\begin{tabular}{|c|c|c|}
\hline YES & NO & DON'T KNOW \\
\hline
\end{tabular}

Research Question \#2: "What characteristics of the external environment are linked to program acceptance?"

(23) How important is it to the operation of the program to have localized places/sites to distribute injection equipment to IVDUs? (nature of geographic area)

\begin{tabular}{|l|l|l|l|l||}
\hline \hline $\begin{array}{l}\text { Very } \\
\text { Important }\end{array}$ & Important & $\begin{array}{l}\text { In The } \\
\text { Middle }\end{array}$ & $\begin{array}{l}\text { Un- } \\
\text { important }\end{array}$ & $\begin{array}{l}\text { Very Un- } \\
\text { important }\end{array}$ \\
\hline
\end{tabular}


(23a) If so, why?

(24) Has there been much opposition from the business community?

\begin{tabular}{|c|c|c|}
\hline YES & NO & DON'T KNOW \\
\hline
\end{tabular}

(If no or don't know, skip to Q-25)

(24a) If yes, by what groups/organizations?

(24b) If yes, what was the issue or concern?

(24c) If yes, is this opposition ongoing or was it just in the beginning?

(25) Has there been much opposition from minority groups/organizations?

\begin{tabular}{|l|l|l|}
\hline YES & NO & DON'T KNOW \\
\hline
\end{tabular}

(If no or don't know, skip to Q-26)

(25a) If yes, by what groups/organizations? 
(25b) If yes, what was the issue or concern?

(25c) If yes, is this opposition ongoing or was it just in the beginning?

(26) Has there been much opposition from other law enforcement agencies? (nature of geographic area)

\begin{tabular}{|l|l|l|}
\hline YES & NO & DON'T KNOW \\
\hline
\end{tabular}

(If no or don't know, skip to Q-27)

(26a) If yes, is this opposition ongoing or was it just in the beginning?

(26b) If yes, what was the issue or concern?

(27) Do the locations enhance acceptability by law enforcement agencies (nature of geographic area)

\begin{tabular}{|c|c|c|}
\hline YES & NO & DON'T KNOW \\
\hline
\end{tabular}

(If don't know, skip to Q-28)

(27a) Why or why not? 
(28) Has the TPD participated in the selection of the locations for the mobile van units?

\begin{tabular}{|c|c|c|}
\hline YES & NO & DON'T KNOW \\
\hline
\end{tabular}

(If no, skip to Q-30)

(If don't know, skip to Q-31)

(29) What criteria were used in selecting the locations?

\begin{tabular}{|l|l|}
\hline Blighted areas & \\
\hline Near Other Social Services & \\
\hline Non-Residential & \\
\hline Citizen Tolerance & \\
\hline Other & \\
\hline
\end{tabular}

(If other, what?)

(Go to Q-31)

(30) Would the department have selected different locations? (nature of geographic area)

\begin{tabular}{|l|l|l|}
\hline YES & NO & DON'T KNOW \\
\hline
\end{tabular}

(If no or don't know, skip to Q-31)

(30a) If yes, why?

(30b) If yes, where?

(31) Does the TPD have education programs for patrol officers regarding AIDS? (concern over the effects of AIDS)

\begin{tabular}{|c|c|c|}
\hline YES & NO & DON'T KNOW \\
\hline
\end{tabular}


(If no or don't know, skip to Q-32)

(31a) Are police officers required to participate in these programs or do they voluntarily participate in such programs? (concern over the effects of AIDS)

\begin{tabular}{||l|l|l|}
\cline { 2 - 3 } \multicolumn{1}{c|}{} & YES & NO \\
\hline Required & & \\
\hline Voluntary & & \\
\hline
\end{tabular}

(32) Have you ever participated in any fundraisers/rallies in reference to "fighting" AIDS, such as walkathons? (concern over the effects of AIDS)

\begin{tabular}{|c|c|c|}
\hline YES & NO & DON'T KNOW \\
\hline
\end{tabular}

(33) Do you know anyone that has AIDS, or has died from AIDS? (concern over the effects of AIDS)

\begin{tabular}{|c|c|c|}
\hline YES & NO & DON'T KNOW \\
\hline
\end{tabular}

(34) How aware are you of the effects of AIDS? (concern over the effects of AIDS)

\begin{tabular}{|l|l|l|l|l|}
\hline $\begin{array}{l}\text { Very } \\
\text { Aware }\end{array}$ & Aware & $\begin{array}{l}\text { In the } \\
\text { Middle }\end{array}$ & Unaware & $\begin{array}{l}\text { Very } \\
\text { Unaware }\end{array}$ \\
\hline
\end{tabular}

(34a) What are the effects of AIDS?

(35) Have other social service agencies played a role in promoting the success of the needle exchange program?

\begin{tabular}{|c|c|c|}
\hline YES & NO & DON'T KNOW \\
\hline
\end{tabular}

(If no or don't know, skip to Q-37) 
(36) What role have the following social service agencies played in promoting the success of the needle exchange program? (informal communication network)

Halfway Houses:

\begin{tabular}{||l|l|l|l|l|}
\hline $\begin{array}{l}\text { Very } \\
\text { Strong } \\
\text { Strong Role }\end{array}$ & $\begin{array}{l}\text { Neither } \\
\text { Strong } \\
\text { Role }\end{array}$ & $\begin{array}{l}\text { Wery nor } \\
\text { Weak }\end{array}$ & $\begin{array}{l}\text { Weak } \\
\text { Role }\end{array}$ & $\begin{array}{l}\text { Weak } \\
\text { Role }\end{array}$ \\
\hline
\end{tabular}

Missions:

\begin{tabular}{||l|l|l|l|l|}
\hline $\begin{array}{l}\text { Very } \\
\text { Strong } \\
\text { Role }\end{array}$ & $\begin{array}{l}\text { Strong } \\
\text { Role }\end{array}$ & $\begin{array}{l}\text { Neither } \\
\text { Strong nor } \\
\text { Weak }\end{array}$ & $\begin{array}{l}\text { Weak } \\
\text { Role }\end{array}$ & $\begin{array}{l}\text { Very } \\
\text { Weak } \\
\text { Role }\end{array}$ \\
\hline
\end{tabular}

Plasma Centers:

\begin{tabular}{|l|l|l|l|l|}
\hline $\begin{array}{l}\text { Very } \\
\text { Strong } \\
\text { Role }\end{array}$ & $\begin{array}{l}\text { Strong } \\
\text { Role }\end{array}$ & $\begin{array}{l}\text { Neither } \\
\text { Strong nor } \\
\text { Weak }\end{array}$ & $\begin{array}{l}\text { Weak } \\
\text { Role }\end{array}$ & $\begin{array}{l}\text { Very } \\
\text { Weak } \\
\text { Role }\end{array}$ \\
\hline
\end{tabular}

Shelter:

\begin{tabular}{|l|l|l|l|l|}
\hline \hline $\begin{array}{l}\text { Very } \\
\text { Strong } \\
\text { Role }\end{array}$ & $\begin{array}{l}\text { Strong } \\
\text { Role }\end{array}$ & $\begin{array}{l}\text { Neither } \\
\text { Strong } \\
\text { nor Weak }\end{array}$ & $\begin{array}{l}\text { Weak } \\
\text { Role }\end{array}$ & $\begin{array}{l}\text { Very } \\
\text { Weak } \\
\text { Role }\end{array}$ \\
\hline
\end{tabular}

Other Agency:

\begin{tabular}{|l|l|l|l|l|}
\hline $\begin{array}{l}\text { Very } \\
\text { Strong } \\
\text { Role }\end{array}$ & $\begin{array}{l}\text { Strong } \\
\text { Role }\end{array}$ & $\begin{array}{l}\text { Neither } \\
\text { Strong nor } \\
\text { Weak }\end{array}$ & $\begin{array}{l}\text { Weak } \\
\text { Role }\end{array}$ & $\begin{array}{l}\text { Weak } \\
\text { Weak } \\
\text { Role }\end{array}$ \\
\hline
\end{tabular}

(37) What role has the TPD itself played in regard to helping the needle exchange program gain acceptance? (informal communication network)

\begin{tabular}{|l|l|l|l|l|}
\hline $\begin{array}{l}\text { Very } \\
\text { Strong } \\
\text { Role }\end{array}$ & $\begin{array}{l}\text { Strong } \\
\text { Role }\end{array}$ & $\begin{array}{l}\text { Neither } \\
\text { Strong nor } \\
\text { Weak }\end{array}$ & $\begin{array}{l}\text { Wery } \\
\text { Weak } \\
\text { Role }\end{array}$ & $\begin{array}{l}\text { Weak } \\
\text { Role }\end{array}$ \\
\hline
\end{tabular}

(38) Are you familiar with the lawsuit that occurred between the health department and the City of Tacoma during the early days of the needle exchange program?

\begin{tabular}{|l|l|l|}
\hline YES & NO & DON'T KNOW \\
\hline
\end{tabular}

(If no or don't know, skip to Q-39) 
(38a) In what ways did the lawsuit between the health department and City of Tacoma strengthen program acceptance? (informal communication network)

Research Question \#3: "What characteristics of the program clients are linked to the acceptance of the Tacoma-Pierce County Needle Exchange Program?"

(39) Has there been much opposition from minority leaders in the community over the needle exchange program?

\begin{tabular}{|l|l|l|}
\hline YES & NO & DON'T KNOW \\
\hline
\end{tabular}

(If no or don't know, skip to Q-40)

(39a) If yes, why?

(40) Do you know if the ratio of minority users reflect the ratio of those being arrested for drug use?

\begin{tabular}{|c|c|c|}
\hline YES & NO & DON'T KNOW \\
\hline
\end{tabular}

(40a) Could you give me any information about these statistics?

(41) Are you aware of the race/ethnic background of the program users in reference to those being arrested for illicit drug use?

\begin{tabular}{|l|l|l|}
\hline YES & NO & DON'T KNOW \\
\hline
\end{tabular}


(41a) Could you give me any information about these statistics?

Other Miscellaneous Questions:

(42) Describe the relationship that the TPD generally maintains with the health department.

(43) Do you think needle exchange programs make drug treatment programs less-attractive?

\begin{tabular}{|l|l|l|}
\hline YES & NO & DON'T KNOW \\
\hline
\end{tabular}

(If don't know, skip to Q-44)

(43a) Why or why not?

(44) Do you foresee any obstacles to continuation of the needle exchange program in Tacoma?

\begin{tabular}{|c|c|c|}
\hline YES & NO & DON'T KNOW \\
\hline
\end{tabular}

(If no or don't know, end)

(44a) If yes, what kinds of obstacles? 
INTERVIEW SCHEDULE: PROGRAM CLIENTS (IVDUS).

Research Question \#1: "What characteristics of the Tacoma-Pierce County Needle Exchange Program are linked to program acceptance?"

(1) How many times have you used the needle exchange in Tacoma? (settings)

\begin{tabular}{|l|l|}
\hline First Time & \\
\hline Two to Five Times & \\
\hline Six to Ten Times & \\
\hline Over Ten Times & \\
\hline
\end{tabular}

(2) What needle exchange sites have you used? (settings)

\begin{tabular}{|l|l|}
\hline $\begin{array}{l}\text { St. Leo's } \\
\text { (Location of the mobile van unit) }\end{array}$ & \\
\hline $\begin{array}{l}\text { Downtown Tacoma } \\
\text { (Location of the mobile van unit) }\end{array}$ & \\
\hline $\begin{array}{l}\text { Health Department Pharmacy } \\
\text { (Fixed-site agency) }\end{array}$ & \\
\hline
\end{tabular}

(3) Ordinarily, how far do you have to travel to use the needle exchange program in Tacoma? (settings)

\begin{tabular}{|l|l|}
\hline 0 to 0.5 mile & \\
\hline 0.6 to 1.0 mile & \\
\hline 1.1 to 3.0 miles & \\
\hline 3.1 to 5.0 miles & \\
\hline 5.1 miles or more & \\
\hline
\end{tabular}

(4) Do you know of any other needle exchange programs in other cities, communities, counties, or countries? (settings)

\begin{tabular}{|l|l|l|}
\hline YES & NO & DON'T KNOW \\
\hline
\end{tabular}

(If no, skip to Q-5) 
(4a) If yes, which program?

(4b) If yes, have you ever used a needle exchange program in another city, county, community, or country?

\begin{tabular}{|c|c|c|}
\hline YES & NO & DON'T KNOW \\
\hline
\end{tabular}

(If no, skip to Q-5)

(4c) If yes, where were these programs located (e.g., city), and which of these were most able to meet your particular needs?

(5) For the most part, do you think that the relationship between IVDUs and the staff of the needle exchange program is: (type of staff)

\begin{tabular}{|l|l|l|l|l|}
\hline $\begin{array}{l}\text { Very } \\
\text { Distant }\end{array}$ & Distant & $\begin{array}{l}\text { In the } \\
\text { Middle }\end{array}$ & Close & $\begin{array}{l}\text { Very } \\
\text { Close }\end{array}$ \\
\hline
\end{tabular}

\begin{tabular}{|l|l|l|l|l|}
\hline $\begin{array}{l}\text { Very Un- } \\
\text { friendly }\end{array}$ & $\begin{array}{l}\text { Un- } \\
\text { friendly }\end{array}$ & $\begin{array}{l}\text { In the } \\
\text { Middle }\end{array}$ & Friendly & $\begin{array}{l}\text { Very } \\
\text { Friendly }\end{array}$ \\
\hline
\end{tabular}

\begin{tabular}{||l|l|l|l|l|}
\hline $\begin{array}{l}\text { Very } \\
\text { Formal }\end{array}$ & Formal & $\begin{array}{l}\text { In the } \\
\text { Middle }\end{array}$ & Informal & $\begin{array}{l}\text { Very In- } \\
\text { formal }\end{array}$ \\
\hline
\end{tabular}

\begin{tabular}{||l|l|l|l|l|}
\hline $\begin{array}{l}\text { Very Judg- } \\
\text { mental }\end{array}$ & $\begin{array}{l}\text { Judg- } \\
\text { mental }\end{array}$ & $\begin{array}{l}\text { In the } \\
\text { Middle }\end{array}$ & $\begin{array}{l}\text { Non Judg- } \\
\text { mental }\end{array}$ & $\begin{array}{l}\text { Very In- } \\
\text { formal }\end{array}$ \\
\hline
\end{tabular}

\begin{tabular}{||l|l|l|l|l|}
\hline $\begin{array}{l}\text { Very Un- } \\
\text { trustworthy }\end{array}$ & $\begin{array}{l}\text { Trust- } \\
\text { worthy }\end{array}$ & $\begin{array}{l}\text { In the } \\
\text { Middle }\end{array}$ & $\begin{array}{l}\text { Trust- } \\
\text { worthy }\end{array}$ & $\begin{array}{l}\text { Very In- } \\
\text { formal }\end{array}$ \\
\hline
\end{tabular}

\begin{tabular}{|l|l|l|l|l|}
\hline $\begin{array}{l}\text { Very Un- } \\
\text { committed }\end{array}$ & $\begin{array}{l}\text { Un- } \\
\text { committed }\end{array}$ & $\begin{array}{l}\text { In the } \\
\text { Middle }\end{array}$ & Committed & $\begin{array}{l}\text { Very Com- } \\
\text { mitted }\end{array}$ \\
\hline
\end{tabular}

(6) Are you committed to using the needle exchange program to serve your own personal needs? (type of staff)

\begin{tabular}{|l|l|l|}
\hline YES & NO & DON'T KNOW \\
\hline
\end{tabular}


(7) Are you committed to the staff currently operating the needle exchange? (type of staff)

\begin{tabular}{|c|c|c|}
\hline YES & NO & DON'T KNOW \\
\hline
\end{tabular}

(8) Are there individuals who you consider important to program operations? (type of staff)

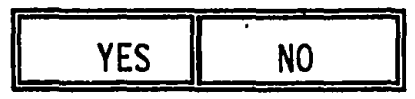

(If no, skip to Q-9)

(8a) If yes, who are they?

(9) Are you able to communicate comfortably with any particular individuals working at the Needle Exchange Program? (type of staff)

\begin{tabular}{|l|l|}
\hline YES & NO \\
\hline
\end{tabular}

(If no, skip to Q-10)

(9a) If yes, who are they?

(10) Did you have to go through any "red-tape" to receive services of the needle exchange program? (method of service delivery)

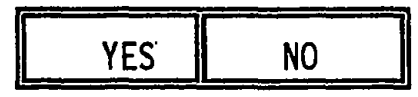

(If no, skip to Q-11)

(10a) If yes, what did you have to go through to receive services? 
(10b) Was this embarrassing for you?

\begin{tabular}{|l|l|}
\hline YES & NO \\
\hline
\end{tabular}

(10c) Did you feel as if you were being harassed?

\begin{tabular}{|l|l|}
\hline YES & NO \\
\hline
\end{tabular}

(11) The needle exchange staff is not thinking of asking for any identification, but I am just wondering if you have ever been asked to provide any type of identification to receive clean works from the needle exchange? (method of service delivery)

\begin{tabular}{|c|c|c|}
\hline YES & NO & DON'T KNOW \\
\hline
\end{tabular}

(If no or don't know, skip to Q-13)

(12) Which of the following items did you have to show to receive clean works? (method of service delivery)

\begin{tabular}{||l|l|l|l||}
\cline { 2 - 4 } \multicolumn{1}{c|}{} & YES & NO & DON'T KNOW \\
\hline \hline Driver's License & & & \\
\hline Social Security Card & & & \\
\hline Green Card & & & \\
\hline Passport & & & \\
\hline Proof of Age & & & \\
\hline Proof of Address & & & \\
\hline Other & & & \\
\hline
\end{tabular}

(If other, what?)

(Go to Q-15)

(13) Again, the needle exchange staff is not planning to ask you to provide identification, but if you were, would you provide identification to receive clean works? This is for research only and not part of any plans of the health department nor the needle exchange program. 


\begin{tabular}{|c|c|c|}
\hline YES & NO & DON'T KNOW \\
\hline
\end{tabular}

(If no or don't know, skip to Q-15)

(14) What kind of identification would you feel comfortable in providing?

\begin{tabular}{|l|l|l|l|}
\cline { 2 - 4 } \multicolumn{1}{c|}{} & YES & NO & DON'T KNOW \\
\hline Driver's License & & & \\
\hline Social Security Card & & & \\
\hline Green Card & & & \\
\hline Passport & & & \\
\hline Proof of Age & & & \\
\hline Proof of Address & & & \\
\hline Other & & & \\
\hline
\end{tabular}

(If other, what?)

(15) Again, this is just a question and not part of any plans of the health department nor the needle exchange -- for this study only -. If identification is required, do you think that some IVDUs would be skeptical to use the needle exchange program?

\begin{tabular}{|c|c|c|}
\hline YES & NO & DON'T KNOW \\
\hline
\end{tabular}

(16) Do you feel that your anonymity is protected by present needle exchange procedures in Tacoma? (method of service delivery)

(If yes or don't know, skip to Q-17)

(16a) If no, what do you suggest be done to assure anonymity? 
(17) Do you have any difficulty in the way the needle exchange program in the City of Tacoma operates? (method of service delivery)

\begin{tabular}{|c|c|c|}
\hline YES & NO & DON'T KNOW \\
\hline
\end{tabular}

(If no or don't know, skip to Q-18)

(17a) What are these difficulties?

(17b) Do these difficulties present a problem to you when you use the needle exchange in Tacoma?

\begin{tabular}{|l|l|l|}
\hline YES & NO & DON'T KNOW \\
\hline
\end{tabular}

If yes, why? (method of service delivery)

(18) Do the current hours of operations of each distribution site meet your needs to exchange needles? (method of service delivery)

\begin{tabular}{||l|l|l|l||}
\cline { 2 - 4 } \multicolumn{1}{c|}{} & YES & NO & DON'T KNOW \\
\hline \hline St. Leo's Site & & & \\
\hline Downtown Tacoma Site & & & \\
\hline Health Department Pharmacy & & & \\
\hline
\end{tabular}

(If yes or don't know, skip to Q-19)

(18a) If no, what time do you need sites to be open for you?

(18b) Do others you know need similar times to be open?

\begin{tabular}{|c|c|c|}
\hline YES & NO & DON'T KNOW \\
\hline
\end{tabular}


(19) Do you get any of the following items from the needle exchange program? (method of service delivery)

\begin{tabular}{||l|l|l|}
\cline { 2 - 3 } \multicolumn{1}{c|}{} & YES & NO \\
\hline Bleach & & \\
\hline Condoms & & \\
\hline AIDS Literature & & \\
\hline Sterile Water & & \\
\hline Other & & \\
\hline
\end{tabular}

(If other, what?)

Research Question \#2: "What characteristics of the external environment are linked to program acceptance?"

(20) How important is the nature of the geographic area (i.e., in providing for proximity, privacy, urban/commercial, familiarity) in terms of attracting individuals who want to exchange works: that is, how important are the following items in terms of you utilizing the needle exchange program? (nature of the geographic area)

(20a) Proximity (i.e., how important is it to have the needle exchange program nearby):

\begin{tabular}{|l|l|l|l|l|}
\hline $\begin{array}{l}\text { Very } \\
\text { Important }\end{array}$ & Important & $\begin{array}{l}\text { In The } \\
\text { Middle }\end{array}$ & $\begin{array}{l}\text { Un- } \\
\text { important }\end{array}$ & $\begin{array}{l}\text { Very Un- } \\
\text { important }\end{array}$ \\
\hline
\end{tabular}

(20b) Privacy (i.e., how important is the type of location in helping you to remain anonymous (unknown) as a program client/IVDU):

\begin{tabular}{||c|c|c|c|c|}
\hline $\begin{array}{c}\text { Very } \\
\text { Important }\end{array}$ & Important & $\begin{array}{l}\text { In The } \\
\text { Middle }\end{array}$ & $\begin{array}{l}\text { Un- } \\
\text { important }\end{array}$ & $\begin{array}{l}\text { Very Un- } \\
\text { important }\end{array}$ \\
\hline
\end{tabular}

(20c) Urban/Commercial (i..e., downtown, non-residential)

\begin{tabular}{||l|l|l|l|l|}
\hline $\begin{array}{l}\text { Very } \\
\text { Important }\end{array}$ & Important & $\begin{array}{l}\text { In The } \\
\text { Middle }\end{array}$ & $\begin{array}{l}\text { Un- } \\
\text { important }\end{array}$ & $\begin{array}{l}\text { Very Un- } \\
\text { important }\end{array}$ \\
\hline
\end{tabular}


(20d) Familiarity (i.e., an area that is physically and psychologically-known by substance users to offer other services such as missions, shelters, plasma centers.)

\begin{tabular}{|l|l|l|l|l|}
\hline $\begin{array}{l}\text { Very } \\
\text { Important }\end{array}$ & Important & $\begin{array}{l}\text { In The } \\
\text { Middle }\end{array}$ & $\begin{array}{l}\text { Un- } \\
\text { important }\end{array}$ & $\begin{array}{l}\text { Very Un- } \\
\text { important }\end{array}$ \\
\hline
\end{tabular}

(21) What value does a needle exchange program personally hold for you in terms of utilizing such a program: for instance, how important is using a needle exchange program in terms of the following reasons: (concern over the effects of AIDS)

(21a) To get free needles:

\begin{tabular}{|l|l|l|l|l|}
\hline $\begin{array}{l}\text { Very } \\
\text { Important }\end{array}$ & Important & $\begin{array}{l}\text { In The } \\
\text { Middle }\end{array}$ & $\begin{array}{l}\text { Un- } \\
\text { important }\end{array}$ & $\begin{array}{l}\text { Very Un- } \\
\text { important }\end{array}$ \\
\hline
\end{tabular}

(21b) To not get AIDS yourse1f:

\begin{tabular}{|l|l|l|l|l|}
\hline $\begin{array}{l}\text { Very } \\
\text { Important }\end{array}$ & Important & $\begin{array}{l}\text { In The } \\
\text { Middle }\end{array}$ & $\begin{array}{l}\text { Un- } \\
\text { important }\end{array}$ & $\begin{array}{l}\text { Very Un- } \\
\text { important }\end{array}$ \\
\hline
\end{tabular}

(21c) To not get other diseases (e.g., hepatitis B, etc.):

\begin{tabular}{|l|l|l|l|l|}
\hline $\begin{array}{l}\text { Very } \\
\text { Important }\end{array}$ & Important & $\begin{array}{l}\text { In The } \\
\text { Middle }\end{array}$ & $\begin{array}{l}\text { Un- } \\
\text { important }\end{array}$ & $\begin{array}{l}\text { Very Un- } \\
\text { important }\end{array}$ \\
\hline
\end{tabular}

(21d) To not spread AIDS to others:

\begin{tabular}{|l|l|l|l|l|}
\hline $\begin{array}{l}\text { Very } \\
\text { Important }\end{array}$ & Important & $\begin{array}{l}\text { In The } \\
\text { Middle }\end{array}$ & $\begin{array}{l}\text { Un- } \\
\text { important }\end{array}$ & $\begin{array}{l}\text { Very Un- } \\
\text { important }\end{array}$ \\
\hline
\end{tabular}

(21e) To not spread other diseases to others:

\begin{tabular}{|l|l|l|l|l|}
\hline $\begin{array}{l}\text { Very } \\
\text { Important }\end{array}$ & Important & $\begin{array}{l}\text { In The } \\
\text { Middle }\end{array}$ & $\begin{array}{l}\text { Un- } \\
\text { important }\end{array}$ & $\begin{array}{l}\text { Very Un- } \\
\text { important }\end{array}$ \\
\hline
\end{tabular}

(21f) Because your friends utilize the program:

\begin{tabular}{|l|l|l|l|l|}
\hline $\begin{array}{l}\text { Very } \\
\text { Important }\end{array}$ & Important & $\begin{array}{l}\text { In The } \\
\text { Middle }\end{array}$ & $\begin{array}{l}\text { Un- } \\
\text { important }\end{array}$ & $\begin{array}{l}\text { Very Un- } \\
\text { important }\end{array}$ \\
\hline
\end{tabular}

(21g) Because not sharing works is the "right thing to do":

\begin{tabular}{|l|l|l|l|l|}
\hline $\begin{array}{l}\text { Very } \\
\text { Important }\end{array}$ & Important & $\begin{array}{l}\text { In The } \\
\text { Middle }\end{array}$ & $\begin{array}{l}\text { Un- } \\
\text { important }\end{array}$ & $\begin{array}{l}\text { Very Un- } \\
\text { important }\end{array}$ \\
\hline
\end{tabular}


(22) Is there another reason for you to use the needle exchange program other than those stated above? (concern over the effects of AIDS)

\begin{tabular}{|l|l|l|}
\hline YES & NO & DON'T KNOW \\
\hline
\end{tabular}

(If no or don't know, skip to Q-23)

(22a) What is the reason?

(23) To what extent does the needle exchange program reduce your worry about your chances of getting AIDS? (concern over the effects of AIDS)

Why worry about getting AIDS?

What are the effects of AIDS?

(24) If Tacoma had no needle exchange program and another city or community did would you consider moving to that new place? (concern over the effects of AIDS)

\begin{tabular}{|l|l|l|}
\hline YES & NO & DON'T KNOW \\
\hline
\end{tabular}

(25) Do you know anyone who is HIV-1 positive or that has AIDS (or has died from AIDS)? (concern over the effects of AIDS)

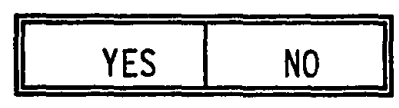

(If no, go to Q-26)

(25a) If yes, was that inividual using intravenous drugs?

\begin{tabular}{|l|l|l|}
\hline YES & NO & DON'T KNOW \\
\hline
\end{tabular}


(26) How did you hear about the needle exchange program in Tacoma? (informal communication network)

\begin{tabular}{||l|l|l|}
\cline { 2 - 3 } \multicolumn{1}{c|}{} & YES & NO \\
\hline Medical Referral & & \\
\hline Friend & & \\
\hline Media & & \\
\hline In a Hal fway House & & \\
\hline In a Shelter & & \\
\hline In the Rescue Mission & & \\
\hline In a Plasma Center & & \\
\hline Jail & & \\
\hline Other & & \\
\hline
\end{tabular}

(If other, what?)

(27) Are you aware of any other needle exchange programs in operation in the State of Washington? (informal comunication network)

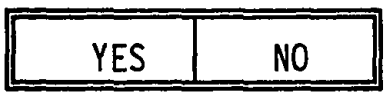

(If no, skip to Q-28)

(27a) If yes, which ones?

(27b) How did you hear about them? 
(28) Are you aware of any other needle exchange programs in outside the State of Washington? (informal communication network)

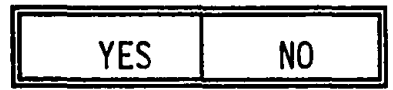

(If no, skip to Q-29)

(28a) If yes, which ones?

(28b) How did you hear about them?

Research Question \#3: "What characteristics of program clients (i.e., IVDUs) are linked to the acceptance of the Tacoma-Pierce County Needle Exchange Program?"

\begin{tabular}{|c|c|}
\hline GENDER: & MARITAL STA \\
\hline Male & Married \\
\hline \multirow[t]{4}{*}{ Female } & Divorced \\
\hline & Separated \\
\hline & Widowed \\
\hline & Single \\
\hline
\end{tabular}

(31) Are you currently employed?

\begin{tabular}{|l|l|}
\hline YES & NO \\
\hline
\end{tabular}

(If no, skip to $Q-32 b$ )

(31a) If yes, what is your occupation? 
(31b) If no, what is your source of income?

(32) What is the state of your own health:

\begin{tabular}{|l|l|}
\hline Excellent & \\
\hline Very Good & \\
\hline Good & \\
\hline Fairly Good & \\
\hline Poor & \\
\hline Don't Know & \\
\hline
\end{tabular}

(Al1 are questions referring to demographics of the IVDU)

(33) What type of drug or drugs do you inject?

\begin{tabular}{|c|c|c|c|c|c|}
\hline \multicolumn{6}{|l|}{ Heroin } \\
\hline \multicolumn{6}{|l|}{ Cocaine } \\
\hline \multicolumn{6}{|l|}{ Speed } \\
\hline \multicolumn{6}{|l|}{ Barbiturates } \\
\hline Mix of the above, & WHAT? & $\mathrm{H}$ & C & $S$ & B \\
\hline Other & & & & & \\
\hline
\end{tabular}

(34) How often do you inject drugs?

\begin{tabular}{|l|l|}
\hline Daily & \\
\hline Almost Everyday & \\
\hline If so, How Many Days Per Week? & \\
\hline Once Per Week & \\
\hline About Every Two Weeks & \\
\hline About Once Per Month & \\
\hline Other & \\
\hline How Often? & \\
\hline
\end{tabular}


(35) Do you know how to sterilize your works?

\begin{tabular}{|l|l|}
\hline YES & NO \\
\hline
\end{tabular}

(36) Have you ever personally had to sterilize your works?

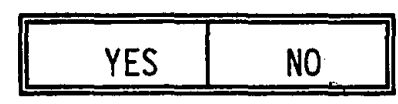

(37) Did you ever have to sterilize other people's works?

\begin{tabular}{|l|l|}
\hline YES & NO \\
\hline
\end{tabular}

(38) Do you occasionally share works?

\begin{tabular}{|l|l|}
\hline YES & NO \\
\hline
\end{tabular}

(If no, skip to Q-39)

(38a) For what reason(s) do you sometimes share works?

\begin{tabular}{|l|l|l|}
\cline { 2 - 3 } \multicolumn{1}{c|}{} & YES & NO \\
\hline No Clean Works Available & & \\
\hline No Bleach to Sterilize Works & & \\
\hline For the Joy of Sharing Works & & \\
\hline To be Intimate With Drug Partner & & \\
\hline Carelessness & & \\
\hline Ignorance & & \\
\hline Purchased Drug From Seller in This Way & & \\
\hline Other & & \\
\hline Don't Know & & \\
\hline
\end{tabular}

(What?) 
(39) If you had problems in getting clean works, would you share works? \begin{tabular}{|l|l|}
\hline YES & NO \\
\hline
\end{tabular}

(40) In the past week, have you loaned your works to another individual?

\begin{tabular}{|c|c|}
\hline YES & NO \\
\hline
\end{tabular}

(41) Have you ever engaged in prostitution?

\begin{tabular}{|l|l|}
\hline YES & NO \\
\hline
\end{tabular}

(42) Have you brought others to use the needle exchange program?

\begin{tabular}{|l|l|}
\hline YES & NO \\
\hline
\end{tabular}

(If no, skip to Q-43)

(42a) How many?

\begin{tabular}{||l|l|}
\hline One Person & \\
\hline Two to Five Persons & \\
\hline Over Five Persons & \\
\hline
\end{tabular}

(42b) Why did you bring others to the needle exchange program?

(43) Do you think that having clean works available decreases your chances of getting HIV-1/AIDS?

\begin{tabular}{|l|l|l|}
\hline YES & NO & DON'T KNOW \\
\hline
\end{tabular}

(44) Do you think that having clean works available decreases your chances of getting other infections?

\begin{tabular}{|c|c|c|}
\hline YES & NO & DON'T KNOW \\
\hline
\end{tabular}


(45) Do you consider yourself to be drug dependent?

\begin{tabular}{|c|c|c|}
\hline YES & NO & DON'T KNOW \\
\hline
\end{tabular}

(If no, skip to Q-45b)

(45a) If yes, would you consider going through a drug treatment program?

\begin{tabular}{|c|c|c|c|}
\hline YES & NO & DON'T KNOW & ALREADY HAVE \\
\hline
\end{tabular}

(45b) Do you consider yourself as a recreational user?

\begin{tabular}{|c|c|c|}
\hline YES & NO & DON'T KNOW \\
\hline
\end{tabular}

(46) Level of Education:

\begin{tabular}{||l|l|l|}
\cline { 2 - 3 } \multicolumn{1}{c|}{} & YES & NO \\
\hline High-School Graduate* & & \\
\hline Associate's Degree & & \\
\hline Bachelor's Degree & & \\
\hline Master's Degree & & \\
\hline Doctorate's Degree & & \\
\hline
\end{tabular}

* (If no, what is the last grade that you completed?)

(47) In general, tell me how you feel about having a needle exchange program in the Tacoma. 


\section{APPENDIX C}

COPIES OF LETTERS FROM VARIOUS STATE OFFICIALS, HOUSE BILL' NO. 1793, AND SECTION 107 THAT WAS VETOED BY FORMER GOVERNOR BOOTH GARDNER 


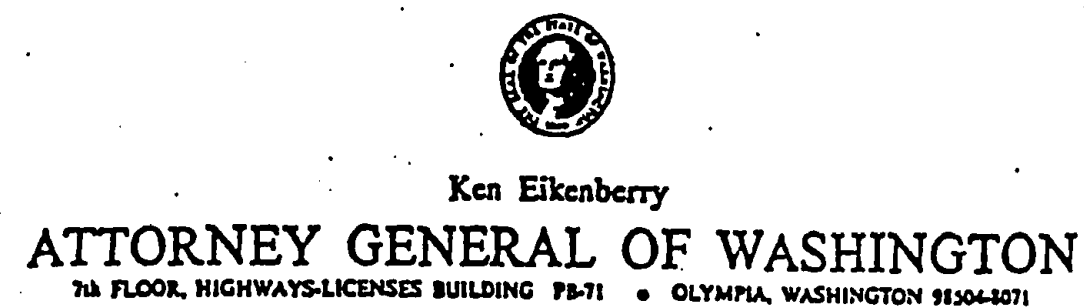

March 28, 2989

The Bonorable Charlie Holfe

State Representative

Fourth District

424 Bouse Office Bullaing

Olympia, HA 98504

Re: Eypodermic Needle Exchange Program, opinton Request 89-2-106

Dear Representative Holfe:

By letter previously acknowledged, you requested an opinion from the Attorney General's office regarding hypodermic needle exchange prograns. I have paraphrased your question as follows:

Does a hypodermic needle exchange program intended to combat the opread of AIDS by intravenous drug users violate state law prohibiting the distribution and/or possession of drug paraphermal1a (RCH 69.50.412(2))?

As you are aware, I must, of course, caution that this letter should not and cannot be regarded as an official opinion of the office of the Attorney General. To the extent that opinions are expressed herein, they are my informal opinions only and not those of the Attorney General.

I answer your question in the wanner set forth in the Eollowing analysis.

\section{ANALTSTS}

In your letter posing the question paraphrased above, you cited, apparently as an alternative to providing us with a hypothetical factual situation, the example of the needle exchange program participated in by the Tacoma-Pierce County Eealth Department. Accordingly, in an effort to provide a responsive answer to your question, I have informally inguired as to the general nature of that program. 


\section{ÖFF̈CE OF̈ THE ATTORNEY GENERAL}

\section{Eonorable Charlle Holfe}

Harch 28, 1989

Page 2

The information supplied in response to my inquiry indicates, in pertinent part, that the racoma-Pierce county Bealth Department apparently participates in a program which supplies and dispenses sterile hypodermic needles in exchange for used or "dirty" hypodermic needles. The needle exchange program is adolttedly directed at intravenous drug users and $1 \mathrm{~s}$ a part of the health department's overall AIDS prevention program which aloo offers information on drug dependency assistance and AIDS counseling. Sterile needies are evidently provided only to Individuals surrendering used needles. The health department is aware of the "drug paraphernalia" statute, RCH 69.50.412(2), and has; nonetheless, elected to continue its participation in the needle exchange program. It has been suggested that the enactment of chapter 206, Iavs of 1988 (RCH 70.24 et seg.), has somehow made RCH $69.50 .412(2)$ inapplicable to the just-described program.

With the foregoing in mind, it next becomes necessary to examine the possibly relevant statutory provisions. Clearly, one - of those provisions is RCH 69.50.412(2) which provides:

69.50.412 Probibited acts: Z-Penalties. - •

(2) It is unlawful for any person to deliver, possess with intent to deliver, or manufacture with intent to dellver drug paraphernalla, knowing, or under circumstances where one reasonably should know, that it will be used to plant, propagate, cultivate, grow, harvest, manufacture, compound, convert, produce, process prepare, test, analyze, pack, repack, store, contain, conceal, inject, ingest, inhale, or otherwise introduce into the human body a controlled substance. Any person who violates this subsection is guilty of a misdemeanor.

Mso necessary to an analysis of your question is RCW 69.50.102, which defines drug paraphernalla as:

69.50.102 Drug paraphernalia - Definitions. (a) As used in this chapter, "drug paraphernalia" means all equipment, products, and materials of any kind which are used, Intended for use, or designed for use in planting, propagating, cultivating, growing, 
OFFICE OF THE ATTORNEY GENERAL:

Eonorable Charlie Nolfe

Harch 28, 1989

Page 3

harvesting, manufacturing, compounding, converting, producing, processing, preparing, testing, analyzing, packaging, repackaging, storing, contalning, concealing, injecting, Ingesting, inhaling, or otherwise introducing Into the human body a controlled substance. It includes, but is not limited to:

\section{$\because \bullet \bullet$}

(11) Eypodermic syringes, needles, and other objects used, intended for use, or designed for use in parenterally injecting controlled substances into the human body:

- •

An examination of the above-quoted statutes reveals, with regard to the question under consideration, that the offense defined in RCF 69.50.412(2) consists of the following general elements:

(1) Delivery (or possession with intent to deliver), of

(2) drug paraphernalia, with

(3) knowledae (actual or constructive) that the drug paraphernalla will be used to perform an act prohiblted by the statute.

Bypodermic needies are included in the definition of drug paraphernalia at RCH 69.50.102(11), and injection or other introduction of controlled substances into the human body are acts speciflcally prohibited by RCA 69.50.412(2).

Then the three elements of an RCh 69.50.412(2) violation 1.e.. delivery, drug paraphernalia, and knowledge - are applied to a program such as that described at the outset of this analysis, it becomes clear that, barring a legally cognizable exception or defense to application of the statute, a health department agent or employee distributing needles to Intravenous drug users could, given sufficient proof, be convicted of violating that statute. Further, while some of the provisions of the Oniform Controlled Substances Act, RCH 69.50 et seg.: contain limited exemptions to their applicability, RCH $69.50 .412(2)$ is 
OFFICE OF THE ATTORNEY GENERAL

$\cdot$

Bonorable Charlie volfe

Karch 28, 1989

Page 4

not such a provision. RCH 69.50.412(2) clearly, unamblguously, and withqut qualification states that it applies to "any person."

As just noted, no exceptlons to the appllcability of RCH $69.50 .412(2)$ are contained in the Oniform Controlled Substances Act. Horeover, one of the fundamental principles of statutory construction is that where the language of a statute is plain, free from ambiguity, and devoid of uncertainty, there is no room for construction and the statute's meaning must be discovered

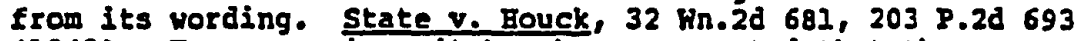
(1949). Bowever, since it has been suggested that the enactment of chapter 206, Iaws of 1988, has somehow affected the continued applicability of RCW $69.50 .412(2)$ to needle exchange programs, I will examine that contention, mindful of another principle of statutory construction reguiring that multiple statutory enactments should, if possible, be construed to glve meaning and effect to each. Hiller y. King County, 59 wn.2d 601, 360 P.2d 304 (1962).

Chapter 206, Iaws of 1988, (the AIDS Act) substantially expanded and amended Washington's statutory provisions relating to sexually transmitted diseases. The AIDS Act, as enacted and subsequently codified at RCH 70.21 et seq.. contains no provision that, either expressly or by clear Implication, purports to amend or repeal RCH 69.50.112(2) or any other atatutory provision relating to "drug paraphernalia." To the contrary, the legislative history of the AIDS Act shows that the legislature speciflcally considered and rejected a proposed provision that would have provlded exactly the exemption now being suggested.

The members of the iegislature were expressly aware of $\dot{R} C H$ 69.50.412 at the time they were considering and enacting the AIDS Act. The penultimate draft of the legislation which ultimately became the AIDS Act, Engrossed Second Substitute Senate Bill (E2SSB) 6221, provided in section 801(12) that:

\section{1 "Person" is defined at RCH 69.50.201(5) as:}

(r) "Person" means Individual; corporation, government or governmental uubdivision or agency, business trust, estate, trust, partnership or association, or any other legal entity. 


\section{OFFICE OF THE ATTORNEY GENERNL}

Bonorable Chairle Nolfe Harch 28, 1989

Page 5

(12) The use of appropriate materlals as authorized by reglonal AIDS service networks in the prevention or control of EIV infection shall not be deemed a violation of RCH 69.50.412. (Emphasis added).

("Regional AIDS service networks" are the statutory mechanlsms created by the AIDS Act to ensure the delivery of treatrentrelated services by local health departments. $R C H 70.24 .400$. In an amendment just prior to final passage of E2SSB 6221, however, a full vote of the Bouse of Representatives, later conicurred in by a full vote of the Senate, stripped from the bill the proposed exemption from RCH 69.50.412. Fiftleth Leglslature, Journal of the Bouse, Karch 9, 1988, Page 1406. E2SSB 6221 $5801(12)$, now codified as RCH 70.24.400(12), was instead amended to read:

(12) The use of appropriate materlals may be authorized by regional AIDS service networks in the prevention or control of BIV infection.

The signiflcance of the legislature's specific rejection of the proposed exemption to the applicabillty of RCH 69.50 .412 cannot be overlooked. Consideration of the legislative history of an enactment has long been held to be a legitimate method of ascertaining legislative intent. Bellevue Fire Fighters 0 . Bellevue, 100 Wn.2d 748, 675 P.2d 592 (1984). Further, the value and appropriateness of considering sequentlal drafts of a bill is likewise acknowledged. Id. Horeover, while the legislature expressly demonstrated its awareness of $\mathrm{RCH} 69.50 .412$ and the prior drafts of E2SSB 6221 in the course of enacting the AIDS Act, such an awareness is presumed in any event as a fundamental precept of statutory construction. Id. Accordingly, I must conclude that the enactment of chapter 206, Laws of 1988, was not intended to and did not effect an amendment, repeal, or other IImitation upon the applicability of RCW 69.50 .412 .

The foregoing conclusion is also consistent with the wellrecognized reguirement that statutes be given a harmonizing construction where possible. Migterek $v$. Wash. Mineral Prods., 85 pin. 2d $166,531 \mathrm{P} .2 \mathrm{~d} 805$ (1975). The above-stated conclusion allows each of the enactments In question to stand as drafted. To hold otherwise would require a determination that the AIDS Act had impliedly repealed or amended RCH 69.50.412. Constructions resulting in repeal or amendment by implication are not favored at 1aw. Id. 
OFFICE OF. THE ATTORNEY GENERAL

Fonorable Charl1e Holfe

March 28,1989

Page 6

thile I belleve that the foregoing analysis answers the question posed, I must caution that it does not necessarily follow that a prosecuting attorney's office would seek to file charges in the situation degcribed above. The decision regarding whether or not to flle criminal charges in connection with a specific set of facts 18 one that is ordinarily entrusted to the sound discretion of the prosecuting attorney involved. - In the exercise of that discretion, prosecutors routinely weigh many factors, both legal and practical, before deciding whether or not to allocate scarce resources to a particular potential prosecution. There is no reason to believe that that same weighing process would not occur in the evaluation of a potentlal RCW $69.50 .412(2)$ vlolation of the sort analyzed above.

I trust the foregoing information will be of assistance to you.

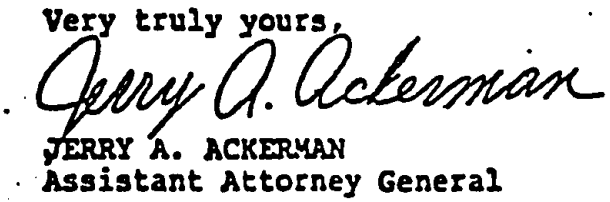

JAA/bW 

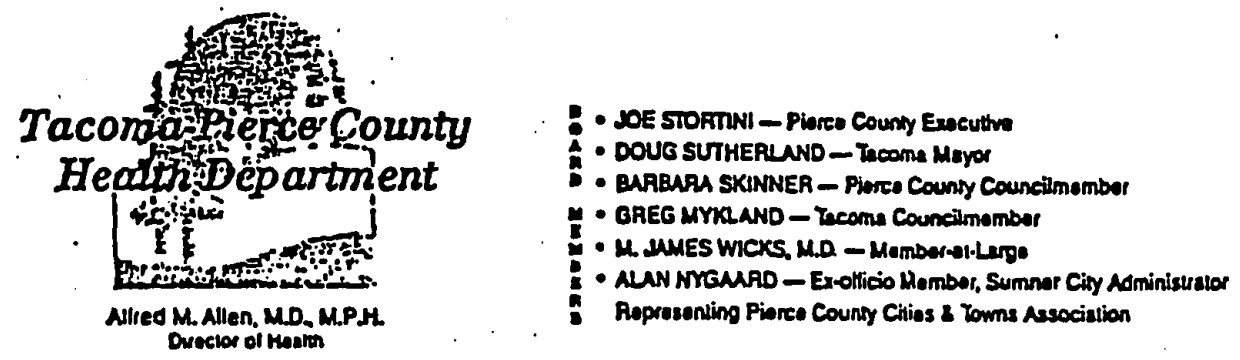

Apri1 25, 1989

The Bonorable Booth Gardner

Governor of the State of Hashington

Capital Campus

Olympia, WA 98504

Dear Governor Gardner:

I am writing to underacore the importance of eterile needle exchange programs to stop the epread of AIDS. To protect the public health, I urge you to use your authority to veto section 107 of ESSB 1793. I believe this amendment conflicts with my Iesponsibility as a health offleer under RCW 70.05.070.

Drug abue is a serious crisis in our commuity and we certainly support the passage of measures such as the Omnibus Drug Bill. Bowever, it would be a grave mintake to enact this bill with an amendment which prohibits needle exchange. Doing wo will not curb drug abuse but will surely doom the lives of hundreds of men, women and infants.

The needle exchange program in Tacoma was funded by thic Department only after preliminary atudy indicated the program could reduce transmision of the RIDS virun: Needle exchange participants were sharing needles less often, their level of drug use had not increased and many were following through with drug treatment referrals. Continued evaluation of this program will yield important information for professionals concerned about both drug abuse and AIDS.

Given the seriousness of the AIDS epidemic and the encouraging findings from our local program, I believe it is critical that we continue our efforts. We have greatly appreclated your supportive comments on needle exchange in the part.

sincerely,
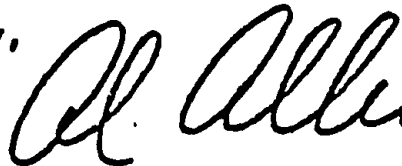

Alfred H. Allen

Director of Bealth

AMA:JB:CAW . 


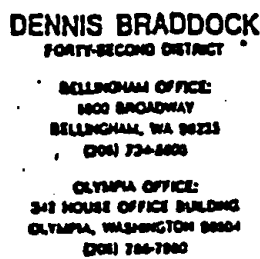

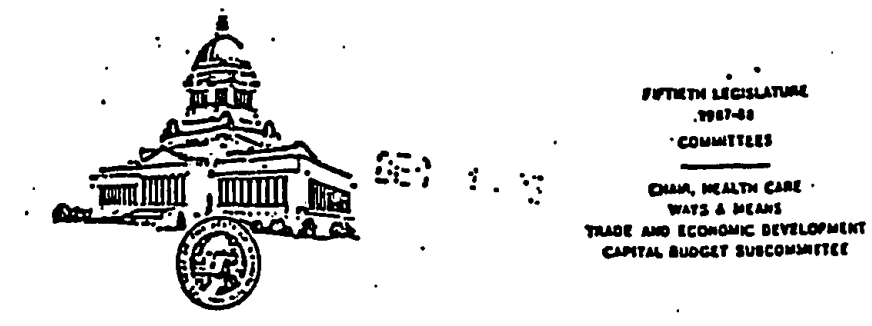

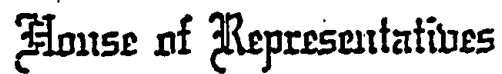

December 13, 1958

\section{STATE OF WASHINGTON} OLYMPLA

Dennis Flannigan

County Council Member, Room 1046.

930 Tacoms Avenue South

Tacoma, Washington 98402

Dear Mr. Flanaigan:

I have been asked to offer my interpretation of the legislative intent of RCW 7024.400 (12): "The use of approprizte materials may be authorized by Iegional AIDS service networks in the prevention or control of HIV infection." The question posed here is whether or not this section of the law would permit public health agencies to implement a needle exchange program to prevent the spread of HiV infection. I believe it would. $\cdot$

As Chair of the House Health Care Committee, I fecl qualified to present the following argument, although there may be other opinions among fellow legislators. I would like to point out, however, that my comments should be considered advisory at best, since constitutionally the courts have the only official prerogative of jaterpreting legislative intent onee the bill is passed into law.

I answer in the affirmative regarding the posed question for three reasons:

(1) When the Legislature was deliberating the Omnibus AIDS Legislation [SB 6221] it secognized that the future "at risk" population was not only the gay and bisexual males, but, increasingly, the intravenous [IY] drug user. Further, Commiltee was informed that the availability of clean acedles for drug users through efforts such as needle exchange programs had great potenitial for controlling the disease.

(2) In diseussions with committee members, we considered cnumerating the types of "materials" in the law, but decided against such drafting because by mentioning some "materials" the Legislature might be construed as 
exeluding others. This would have been extremely problematic because AIDS is such a relatively new discase and the best intervention methods may be yet to come.

(3) The members realized that being somewhat non-specific regarding which "materials" to be jneluded has the consequence of providing extraordinary broad authority. On the other hand, the members wanted to provide some flexibility to the service providers. Further, the members were more willing to do so because the authority is given exelusively to the AlDS serviecs networks. There are only six networks and they are run by local health officers. Currently, there are 31 LHOs in the state and all hold M.D. degrees with specialized training in public health. Collectively, they enjoy a great deal of respeet and trust from the Legislature. Our final decision, to grant a certain degree of diseretion to these diatinguished individuals, was less troublesome than if it were granted to a unknown number of less qualified persons.

1 hope this discussion is helpful. If I can be of any further assistance, please feel free to contact me or the committee lead stafr, Bill Hagens [206] 786-7131.

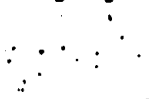

Sincerely,

QLer 2 redole

DENNIS BRADDOCK

State Representative

42nd Legislative Distriet

Health Care Committee Chair

.DBikd 


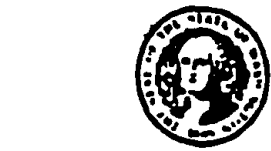

\section{STATE OF WASHINGTON \\ orore or wa continco}

OLYMPIA

BOOTH GARONLE

cominnon

May 7. 1989

To the Monorable, the House

of Ropresentatives of the

State of Washington

Ladies and Gentleaen:

I an returning herowith, without oy approval as to seetion 107, Engrossed Second Substitute House dill No. I7fs entitied:

maH ACT Ralating to alcohol and controlled substanices abuse."

This anibus bill reprasents a eajor sceoplishent by the Legislature in working to address the soricus and pressing issue of substance abuse in our state and secioty. The Leglstature is to be comanded for its afforts to address this lssw in a comprehensive fashion. 1t. also contains tha essence of flve Covernor-request blilis which sddress this issue.

Sectien 107 of the bill would prohibit and fores closure of medle exehange prograns, currently oparating in Tecous and Sattle which are a wans to reduce Mivialos transaission and encourege treatment raforral. These model prograws have reecived atienal attention for their innovetive and credible anageaent of the meedle exehange. Loth prograns are oporated and strictly controlled by leeal public malth wthorities and are structured to accomodate axime resaarch banfit. I do not condons use of Ill logal drugs or their taking by intravenous eacens. Tm raflity is that these prograns have very little potentlat for encouraging core lllegal drug use but a very high potential for lisiting the spread of saplews and dadly diseases which iepact not enly the parsons involved but others. For both henem and econonie reasens, w eust do overything we ean to halt the spread of AlOS.

Wth the exeoption of section 107, Engressed Second substitute House dill Mo. 1793 is approved.

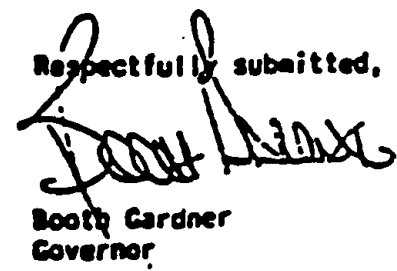

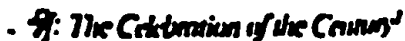

an. 


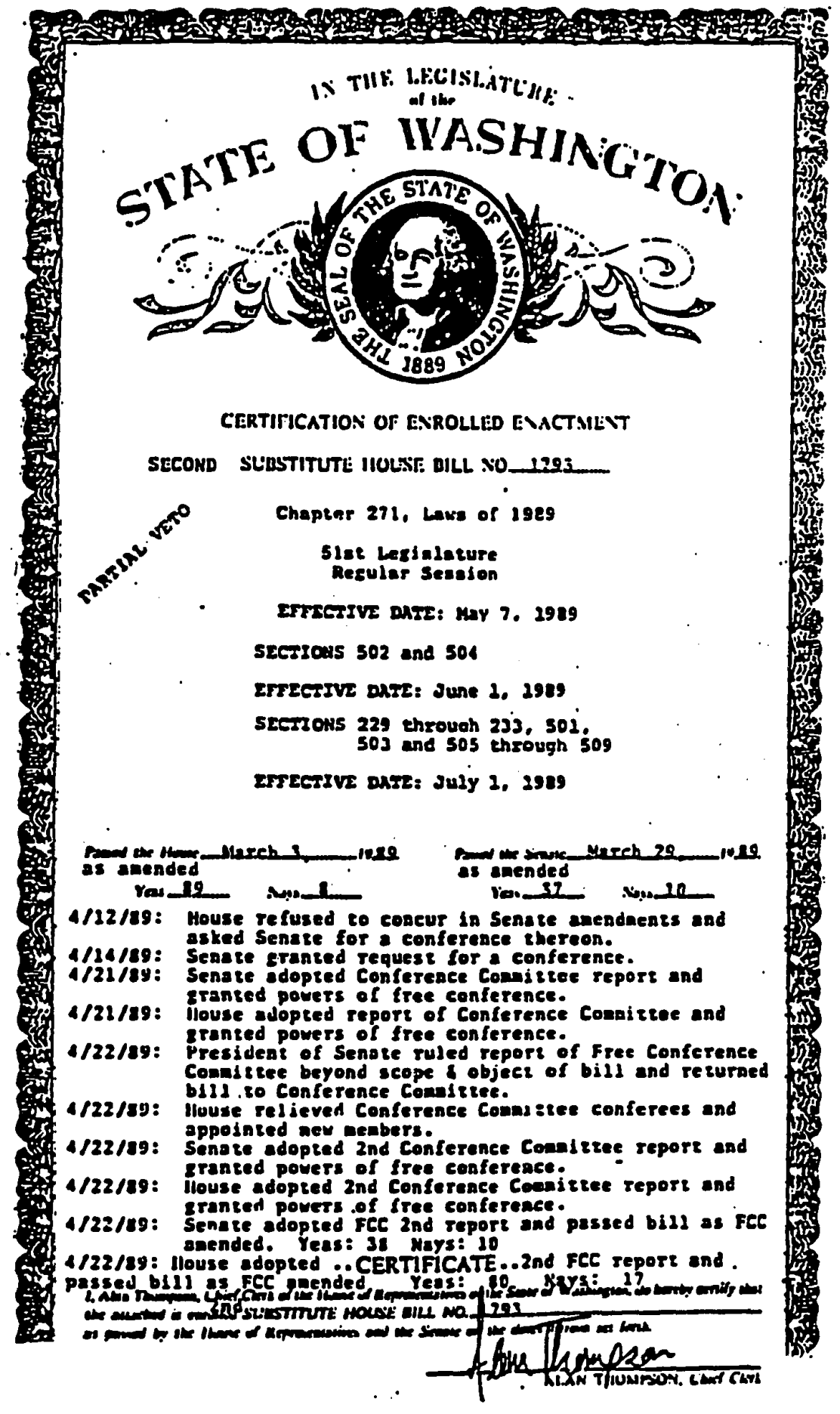




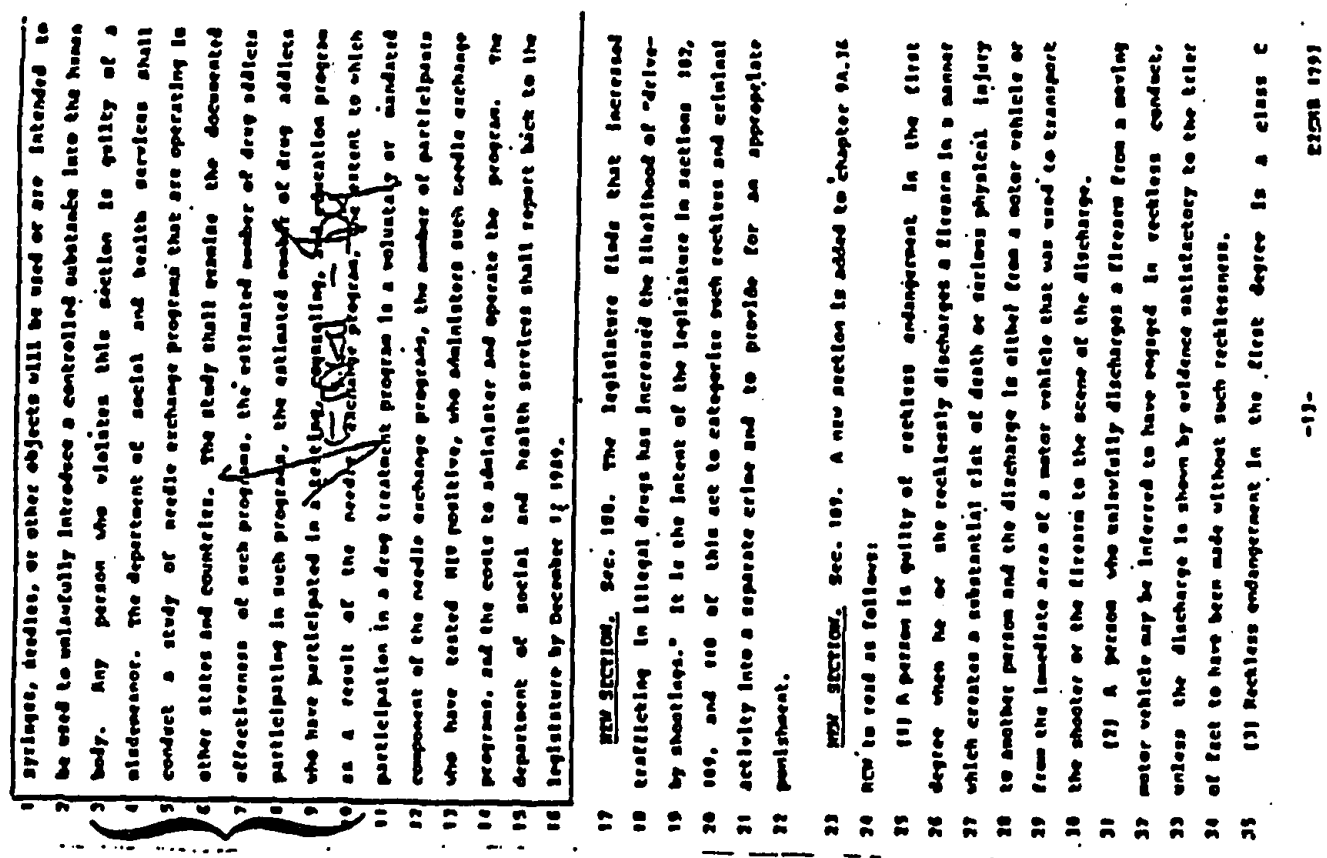

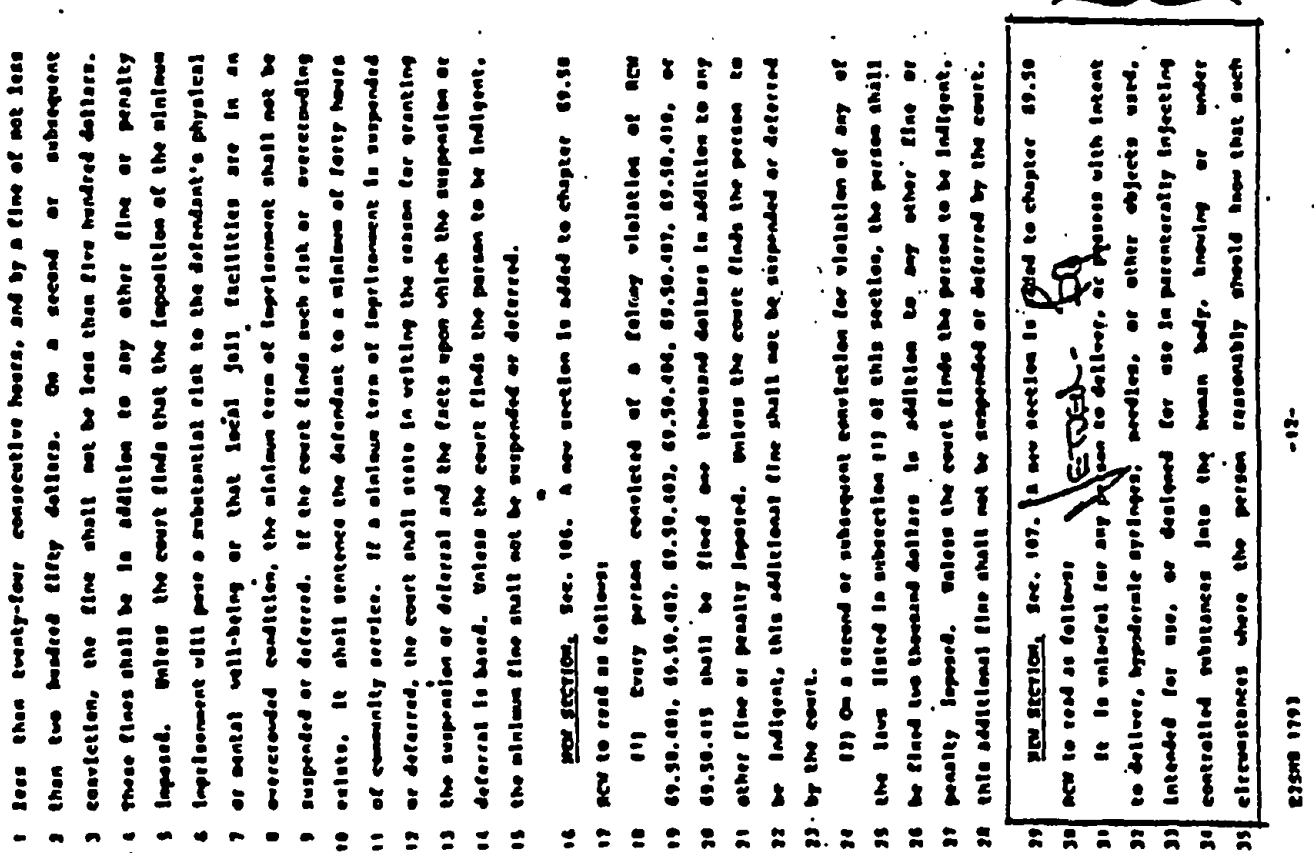


APPENDIX D

COPY OF MEMORANDUM (COVER LETTER) AND INTRA-AGENCY

ROUTING SLIP SENT BY HOLLY HAGEN, TACOMA-PIERCE

COUNTY HEALTH DEPARTMENT'S EPIDEMIOLOGIST

IN REFERENCE TO HER INITIAL SUPPORT

AND COOPERATION WITH

THE RESEARCHER 


\section{TACOMA-PIERCE COUNTY HEALTH DEPARTMENT \\ OFFICE OF COMMUNITY ASSESSMENT \\ MEMORANDUM}

DATE: $\quad$ April 13,1992

TO: Christiane B. Hale, Chief, Office of Community Assessment Patty Reinkensmeyer, Director, Community Health Division Jerry Reid, Section Manager, Substance Abuse

FROM: Holly Hagan, Epidemiologist tw $x \sigma$ tht

SUBJECT: Case Study of Community Acceptance of the Tacoma syringe Exchange

Lauren Ibraham, a doctoral student in the Urban studies Department at Portland State University, has asked my approval for carrying out a case-study of the Tacoma exchange. (Actually, Dave Purchase is the person empowered to grant approval, but he has deferred to me).

I have reviewed her proposal (Attachment 1) and it appears a worthwhile study. She has obtained human use approval through the PSU IRB (Attachment 2). She would like to interview Patty, Terry and myself about our views on the community's acceptance of the program. I would like to recommend that we agree to support this study if there are no unforeseen objections. 


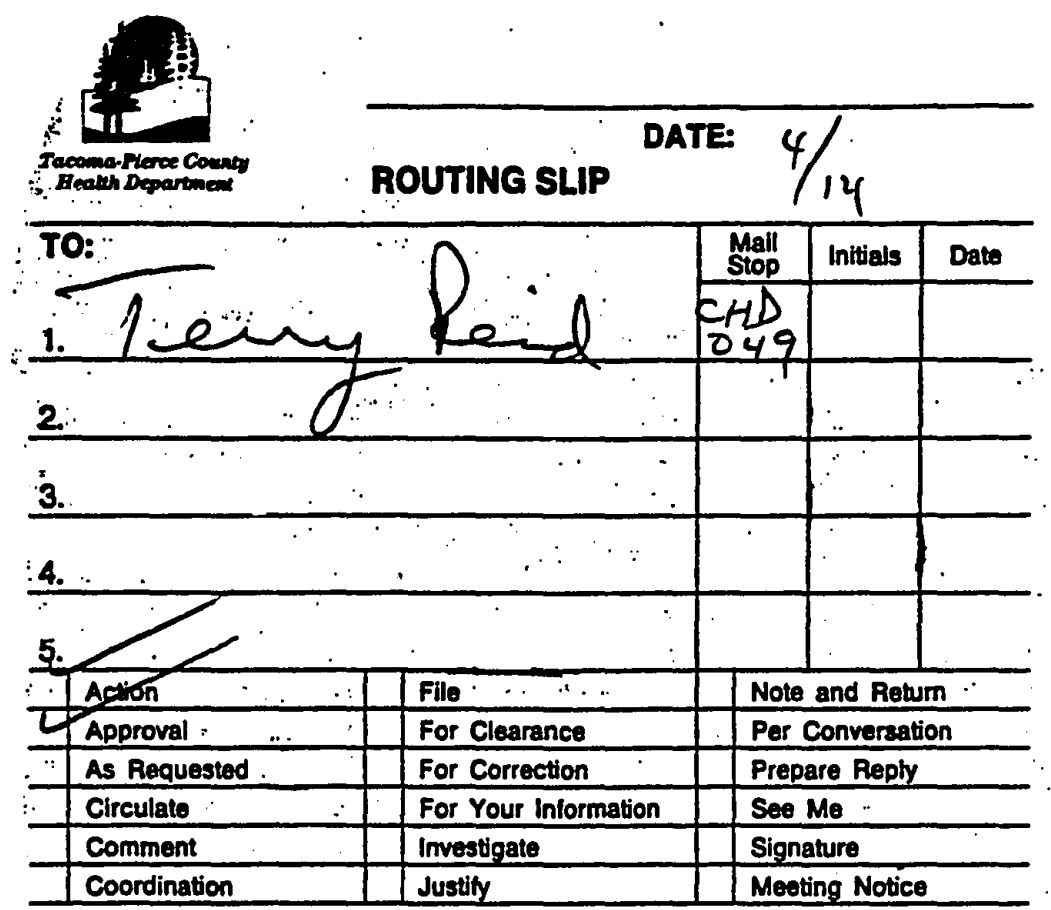

REMARKS

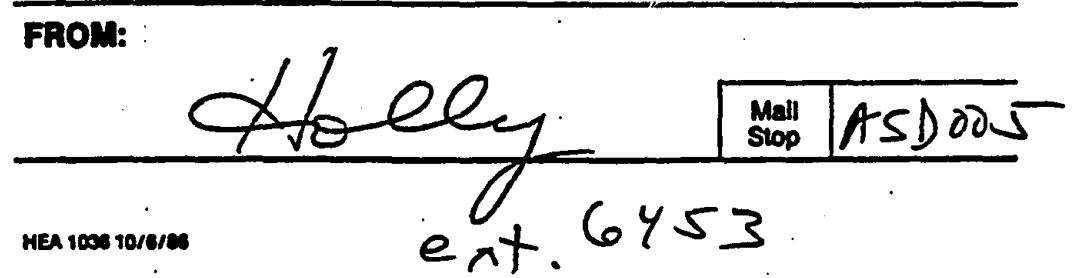

